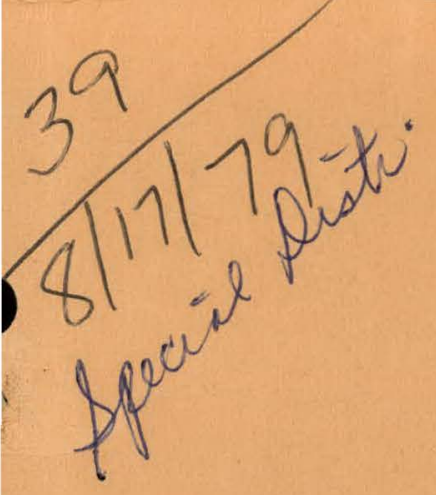

WAPD-TM-1371

DOE RESEARCH AND DEVELOPMENT REPORT

FUEL UTILIZATION POTENTIAL IN

LIGHT WATER REACTORS WITH

ONCE-THROUGH FUEL IRRADIATION

(AWBA DEVELOPMENT PROGRAM)

JULY 1979

CONTRACT DE-AC11-76PNO0014 


\section{DISCLAIMER}

This report was prepared as an account of work sponsored by an agency of the United States Government. Neither the United States Government nor any agency Thereof, nor any of their employees, makes any warranty, express or implied, or assumes any legal liability or responsibility for the accuracy, completeness, or usefulness of any information, apparatus, product, or process disclosed, or represents that its use would not infringe privately owned rights. Reference herein to any specific commercial product, process, or service by trade name, trademark, manufacturer, or otherwise does not necessarily constitute or imply its endorsement, recommendation, or favoring by the United States Government or any agency thereof. The views and opinions of authors expressed herein do not necessarily state or reflect those of the United States Government or any agency thereof. 


\section{DISCLAIMER}

Portions of this document may be illegible in electronic image products. Images are produced from the best available original document. 


\title{
FUEL UTILIZATION POTENTIAL IN LIGHT WATER REACTORS WITH ONCE-THROUGH FUEL IRRADIATION (AWBA Development Program)
}

\author{
D. S. Rampolla \\ G. H. Conley \\ N. R. Candelore \\ G. K. Cowell \\ G. P. Estes \\ B. K. Flanery \\ E. Duncombe \\ J. Dunyak \\ D. G. Satterwhite \\ Contract DE-AC11-76PNO0014 \\ JULY 1979 \\ Printed in the United States of America \\ Available from the \\ National Technical Information Service \\ U. S. Department of Commerce \\ 5285 Port Royal Road \\ Springfield, Virginia 22151
}

\section{NOTE}

This document is an interim memorandum prepared primarily for internal reference and does not represent a final expression of the opinion of Westinghouse. When this memorandum is distributed externally, it is with the express understanding that Westinghouse makes no representation as to completeness, accuracy, or usability of information contained therein.

\section{BETTIS ATOMIC POWER LABOAATORY WEST MIFFLIN, PENNSYLVANIA}

Operated for the U. S. Department of Energy by WESTINGHOUSE ELECTRIC CORPORATION 


\section{NOTICE}

This report was prepared as an account of work sponsored by the United States Government. Neither the United States, nor the United States Department of Energy, nor any of their employees, nor any of their contractors, subcontractors, or their employees, makes any warranty, express or implied, or assumes any legal liability or responsibility for the accuracy, completeness or usefulness of any information, apparatus, product or process disclosed, or represents that its use would not infringe privately owned rights. 


\section{FOREWORD}

The Shippingport Atomic Power Station located in Shippingport. Pennsylvania was the first large-scale, central-station nuclear power plant in the United States and the first plant of such size in the world operated solely to produce electric power. This program was started in 1953 to confirm the practical application of nuclear power for large-scale electric power generation. It has provided much of the technology being used for design and operation of the commercial, central-station nuclear power plants now in use.

Subsequent to development and successful operation of the Pressurized Water Reactor in the DOE-owned reactor plant at the Shippingport Atomic Power Station, the Atomic Energy Commission in 1965 undertook a research and development program to design and build a Light Water Breeder Reactor core for operation in the Shippingport Station.

The objective of the Light Water Breeder Reactor (LWBR) program has been to develop a technology that would significantly improve the utilization of the nation's nuclear fuel resources employing the well-established water reactor technology. To achieve this objective. work has been directed toward analysis. design, component tests, and fabrication of a water-cooled, thorium oxide fuel cycle breeder reactor for installation and operation at the Shippingport Station. The LWBR core started operation in the Shippingport Station in the Fall of 1977 and is expected to be operated for about 3 to 4 years. At the end of this period. the core will be removed and the spent fuel shipped to the Naval Reactors Expended Core Facility for a detailed examination to verify core performance including an evaluation of breeding characteristics.

In 1976, with fabrication of the Shippingport LWBR core nearing completion, the Energy Research and Development Administration established the Advanced Water Breeder Applications (AWBA) program to develop and disseminate technical information which would assist U.S. industry in evaluating the LWBR concept for commercial-scale applications. The program will explore some of the problems that would be faced by industry in adapting technology confirmed in the LWBR program. Information to be developed includes concepts for commercial-scale prebreeder cores which would produce uranium-233 for light water breeder cores while producing electric power. improvements for breeder cores based on the technology developed to fabricate and operate the Shippingport LWBR core, and other information and technology to aid in evaluating commercial-scale application of the LWBR concept.

All three development programs (Pressurized Water Reactor, Light Water Breeder Reactor, and Advanced Water Breeder Applications) have been administered by the Division of Naval Reactors with the goal of developing practical improvements in the utilization of nuclear fuel resources for generation of electrical energy using water-cooled nuclear reactors.

Technical information developed under the Shippingport, LWBR, and AWBA programs has been and will continue to be published in technical memoranda. one of which is this present report. 


\section{TABLE OF CONTENTS}

I. INTRODUCTION

A. Purpose and Scope

B. Summary

C. Report Organization

II. BACKGROUND

A. Neutron Conservation Methods

B. Fuel Utilization of Operational, Planned, and Conceptual Reactors

C. Abstracts of Previous Seed-Blanket Reactor Studies

III. FACTORS AFFECTING FUEL UTILIZATION

A. Neutron Losses

1. Background

2. Sensitivity of Fuel Utilization to Neutron Losses

B. Reduction of Neutron Losses

1. Reflecting Blankets

2. Seed-Blanket Geometry and Movable Fuel Reactivity Control

3. Fuel Management

4. Core Structure and Materials

5. Power Density

C. Fuel Materials and Uranium Enrichment

D. Fuel Burnup

E. Summary

IV. DESIGN CONSIDERATIONS

A. Fuel System Design

1. Plate-Type Fuel Elements Versus Fuel Rods

2. Fuel Types

3. Summary:

B. Thermal and Hydraulic Design

1. Background

2. Current Methods for Flow Apportionment

3. Other Methods for Flow Apportionment

4. Conclusion

C. Mechanical Design

1. Background

2. Mechanical Requirements for Movable Fuel Control

3. Conclusion

2

3

3

3

4

6

V. FUEL UTILIZATION OF PRIOR DESIGNS WHEN EVALUATED AS ONCE-THROUGH CONVERTER-BURNERS 


\section{TABLE OF CONTENTS (Cont)}

REFERENCES

GLOSSARY

APPENDIX A-Fuel Utilization Calculations

A-1

APPENDIX B-Fuel Utilization Principles and Methods of Analysis

B-1

APPENDIX C-Description of Previous Seed-Blanket Reactors and Reactor Conceptual

C-1 Design Studies

\section{IST OF FIGURES}

Figure

Title

Page

1 Sensitivity of Once-Through Fuel Utilization to Neutron Losses

10

\section{LIST OF TABLES}

Table

Title

Page

1 Examples of Fuel Utilization in Operating Reactors With Once-Through Fuel Irradiation

Examples of Fuel Utilization in Conceptual Design Reactors With OnceThrough Fuel Irradiation 
Current commercial light water reactor cores operate without recycle of fuel, on a "once-through" fuel cycle. To help conserve the limited nucle. ar fuel resources, there is interest in increasing the energy yield and, hence, fuel utilization from once-through fuel irradiation. This report evaluates the potential increase in fuel utilization of light water reactor cores operating on a once-through cycle assuming 0.2 percent enrichment plant tails assay. This evaluation is based on a large number of survey calculations using techniques which were verified by more detailed calculations of several core concepts. It is concluded that the maximum fuel utilization which could be achieved by practical oncethrough pressurized light water reactor cores with either uranium or thorium is about $17 \mathrm{MWYth} / \mathrm{ST} \mathrm{U}_{3} \mathrm{O}_{8}$ (Megawatt Years Thermal per Short Ton of $\mathrm{U}_{3} \mathrm{O}_{8}$ ). This is about 50 percent higher than that of current commercial light water reactor cores. Achievement of this increased fuel utilization would require average fuel burnup beyond $50,000 \mathrm{MWD} / \mathrm{MT}$ and incorporation of the following design features to reduce parasitic losses of neutrons: reflector blankets to utilize neutrons that would otherwise leak out of the core; fuel management practices in which a smaller fraction of the core is replaced at each refueling; and neutron economic reactivity control, such as movable fuel control rather than soluble boron control. For a hypothetical situation in which all neutron leakage and parasitic losses are eliminated and fuel depletion is not limited by design considerations, a maximum fuel utilization of about $20 \mathrm{MWYth} / \mathrm{ST} \mathrm{U}_{3} \mathrm{O}_{8}$ is calculated for either uranium or thorium. It is concluded that fuel utilization for comparable reactor designs is better with uranium fuel than with thorium fuel for average fuel depletions of 30,000-35,000 MWD/MT which are characteristic of present light water reactor cores.

\section{FUEL UTILIZATION POTENTIAL IN LIGHT WATER REACTORS WITH ONCE-THROUGH FUEL IRRADIATION (AWBA Development Program)}

\section{INTRODUCTION}

\section{A. Purpose and Scope}

The purpose of this report is to evaluate the potential fuel utilization which could be achieved with "once-through" irradiation of fuel (no recycle of fuel) in pressurized light water reactors.

Fuel utilization of a once-through reactor core is defined as the thermal energy produced by the reactor core (in megawatt-years) per short ton (ST) of $\mathrm{U}_{3} \mathrm{O}_{8}$ required from the mill to supply fuel for the reactor core, assuming the expended core is discarded without recovery of residual fuel. The definition of fuel utilization in terms of $\mathrm{U}_{3} \mathrm{O}_{8}$ required from the mill avoids the need to assume or assign a value to uranium losses in milling. These losses are expected to rise as lower grade ores are mined. Such losses must of course be accounted for, but they are independent of the design details of the reactor which ultimately uses the fuel. Fuel utilization of current commercial pressurized light water reactor cores on the once-through fuel cycle is about $11.7 \mathrm{MWYth} / \mathrm{ST} \mathrm{U}_{3} \mathrm{O}_{8}$, based on data in Reference 1 for the case of 0.2 percent enrichment plant tails assay.

Starting with development work on the Pressurized Water Reactor (PWR Core 1) in 1953, the Division of Naval Reactors has conducted an ongoing program to develop the technology for improving utilization of nuclear fuel resources in water-cooled nuclear reactors. This led to the development of two reactors which operated successfully in the Shippingport Atomic Power Station, PWR Core 1 and PWR Core 2. A third reactor, the Light Water Breeder Reactor (LWBR), is currently operating in 
the Shippingport plant. The LWBR core is a seed-blanket design as were the earlier PWR cores. The LWBR, however, has additional features including a peripheral reflector region and movable fuel control, which lead to more efficient utilization of neutrons.

While the LWBR core was not designed to have application to once-through fuel cycles, the principles used to achieve breeding in the LWBR core are applicable to improving fuel utilization in once-through light water reactors. Based on the experience gained in the LWBR program and its predecessors, a study has been made of the fuel utilization achievable in light water reactor cores using the once-through fuel cycle. In addition, an examination has been made of the features which would be required in the areas of fuel element design, thermal hydraulic design, and mechnical design to support the changes in nuclear design which would achieve improved fuel utilization.

\section{B. Summary}

The principal conclusions of this investigation into the fuel utilization of once-through light water reactors assuming 0.2 percent enrichment plant tails assay are:

1. On a practical basis, a fuel utilization of about $17 \mathrm{MWYth} / \mathrm{ST} \mathrm{U}_{3} \mathrm{O}_{8}$. an increase of less than 50 percent relative to current light water reactors, could be attained with either uranium or thorium by increasing average fuel burnup beyond 50,000 MWD/MT and by inconrnorating the following design features to reduce parasitic loss of neutrons:

a. Reflector blankets to utilize neutrons that would otherwise leak out of the core

b. Neutron economic control, such as movable fuel rather than soluble boron control

c. Fuel and structural materials containing minimum amounts of neutron poisons.

2. For a hypotheticalideal situation in which all neutron leakage and losses to control poisons and core structure, including fuel rod cladding, are eliminated and fuel depletion is not limited by design considerations, a maximum fuel utilization of about $20 \mathrm{MWYth} / \mathrm{ST} \mathrm{U}_{3} \mathrm{O}_{8}$ is calculated for either uranium or thorium. This represents a hypothetical increase by a factor of less than 1.75 compared to current commercial reactors.

3. Fuel utilization of about $15 \mathrm{MWYth} / \mathrm{ST} \mathrm{U}_{3} \mathrm{O}_{8}$ is judged to be achievable with uranium in a conventionally controlled (soluble boron) pressurized light water reactor with average fuel burnup of about 50,000 MWD/MT.

4. For average fuel depletions of 30,000-35,000 MWD/MT which are characteristic of present light water reactor cores, uranium fuel yields higher fuel utilization than thorium fuel in comparable reactor designs. For thorium fuels to provide equivalent fuel utilization, average depletions in excess of $50,000 \mathrm{MWD} / \mathrm{MT}$ would be required.

5. The theoretically achievable fuel utilization in a once-through seed-blanket reactor is nearly independent of the seed enrichment over the range of 5 to 93 weight percent uranium-235 in uranium. However, the design features necessary to achieve high fuel utilization at low enrichment have not been developed and may not be practical. 
6. The development of practical, once-through seed-blanket reactors with optimized, oncethrough fuel utilization would require extension of current technology in the areas of movable fuel control, peripheral reflector blankets, minimization of neutron losses to structure, and improvements in fuel elements. Although the Naval Reactors Division of the Department of Energy is not working directly to design once-through light water reactors with improved fuel utilization, the technology being developed through the Department of Energy Water Cooled Breeder Program would have application to such once-through light water reactors.

\section{Report Organization}

The present report reviews and updates previous seed-blanket reactor studies. Section II presents background information on fuel utilization, as well as abstracts of previous seed-blanket reactor studies. Section III presents an overview of the factors affecting fuel utilization and the relationship of these factors to the fuel utilization of the reactors presented in Section II.B. These factors include fuel management, neutron losses, fuel type, and fuel burnup. Section IV presents an overview of the principal design considerations for seed-blanket reactors, including fuel element, thermal-hydraulic and mechanical design considerations necessary to the implementation of movable fuel reactivity control. Section $V$ discusses the fuel utilization of prior seed-blanket reactor concepts when evaluated with once-through fuel irradiation. Conclusions are presented in Section VI.

A glossary and three appendices follow the main text. The glossary defines the terms used throughout the report. Appendix A presents fuel utilization calculations for a variety of fuel types for both uniformly enriched cores and seed-blanket cores. The fuel types include uranium, thorium, mixtures of uranium and thorium, and a range of enrichments in uranium-235. Calculations of the sensitivity of fuel utilization to enrichment, burnup, neutron losses, power density, and fuel-to-coolant ratio are also presented. Appendix $B$ presents the theoretical basis for the method used to perform the calculations of Appendix A. This includes the development of an analytical method for using point depletion calculations to estimate fuel utilization for both seed-blanket cores and fuel-managed conventional cores; the validation of the method by comparison with two-dimensional spatial seedblanket cell calculations; and a description of the methods used to perform the neutron flux and fuel depletion calculations. Appendix $C$ presents a more detailed description of operational and conceptual seed-blanket cores which have been developed under the direction of the Division of Naval Reactors.

\section{BACKGROUND}

\section{A. Neutron Conservation Methods}

The chief requirement for obtaining high fuel utilization is minimizing losses of neutrons to capture in control poisons or in non-fuel materials inside and outside of the reactor. This requirement, referred to as neutron conservation, is important because each neutron conserved is available for converting a fertile atom such as uranium-238 or thorium-232 to a fissile atom such as plutonium239 or uranium-233. Neutron conservation extends the time for which a fission chain reaction can be sustained and, therefore, increases the once-through energy yield. 
There are two unique neutron-conserving design features in the LWBR core. The first is the use of movable fuel assemblies to control core reactivity during power operation. This is in lieu of soluble boron or poison control rods. The movable fuel system provides for the capture of excess neutrons in fertile thorium-232 rather than in control poison. The second feature is the use of reflector assemblies around the core periphery to prevent neutron loss through leakage. These reflector assemblies either capture leakage neutrons in fertile thorium-232 or scatter them back into the core. Both of these design features could be used in a once-through light water reactor core, with either uranium238 or thorium-232 fertile material, to achieve a fuel utilization higher than that currently achieved by conventional pressurized light water reactors. For once-through application, these features would be designed to enhance the depletion of bred fissile fuel to produce energy. For breeder application, these features would be designed as in the LWBR core to maximize the fissile fuel inventory at end of core life. Typically, the use of these features would increase reactor size, complexity, and cost.

\section{B. Fuel Utiliżation of Operational, Planned, and Conceptual Reactors}

Table 1 gives examples of fuel utilization achieved with operating nuclear reactors since the Shippingport Atomic Power Station was started up in 1957 with PWR (Pressurized Water Reactor) Core 1. Table 2 gives the calculated value of fuel utilization for one planned reactor and one conceptual reactor.

The fuel utilization values presented are without recycle of the spent fuel. The fuel utilization is given in terms of the megawatt years of thermal energy which are obtained from each short ton (2000 pounds) of uranium oxide (in the form $\mathrm{U}_{3} \mathrm{O}_{8}$ ) obtained from the mill. This unit is written as $\mathrm{MWY}$ th/ST $\mathrm{U}_{3} \mathrm{O}_{8}$. Fuel utilization values throughout this report are based on an assumed uranium enrichment plant tails assay of 0.2 percent uranium-235 in uranium. Higher tails assay would reduce fuel utilization and lower tails assay would improve fuel utilization.

A brief description of the significant core features follows.

PWR-1

Yankee-Rowe

Indian Point

PWR-2
Light water cooled and moderated. Seed-blanket core. Seed fuel-93 percent uranium alloyed with zirconium. Blanket fuel-natural uranium in oxide form. Control by poison rods plus fixed burnable boron. Blanket irradiated for four seed lives.

Light water cooled and moderated. Fuel-slightly enriched uranium in oxide form. Control by poison rods. Entire core removed at first refueling.

Light water cooled and moderated. Fuel-highly enriched uranium, in oxide form, mixed with thorium oxide. Control by poison rods plus burnable boron in fuel rod cladding. Entire core removed at first refueling.

Similar to PWR 1. Seed fuel-93 percent enriched uranium in oxide form diluted with zirconium oxide. Blanket irradiated for two seed lives. 
Reactor

PWR Core 1

Yankee-Rowe (First Core)

Indian Point (First Core)

PWR Core 2

Generic Current PWR (1000 MWe)

Generic Current BWR (1000 MWe)

CANDU (Bruce)
Fuel Utilization

$\left(\text { MWYth/ST } \mathrm{U}_{3} \mathrm{O}_{8}\right)^{(1)}$

7.0

$3.2^{(2)}$

$2.9^{(2)}$

7.3

11.7

1

11.8

1

$17.2^{(3)}$

(1) Megawatt years of thermal energy per short ton of $\mathrm{U}_{3} \mathrm{O}_{8}$ from the mill; assumes uranium enrichment plant tails assay is 0.2 percent uranium-235 in uranium.

(2) Based on total energy production at time of first refueling

(3) The benefit of CANDU is actually lower than implied here because thermal efficiency of CANDU is 29 percent as compared with 33-34 percent for current PWR and BWR plants. Equivalent fuel utilization of a CANDU plant would be about $15 \mathrm{MWYth} / \mathrm{ST} \mathrm{U}_{3} \mathrm{O}_{8}$.

\section{TABLE 2. EXAMPLES OF FUEL UTILIZATION IN CONCEPTUAL DESIGN REACTORS WITH ONCE-THROUGH FUEL IRRADIATION}

Reactor

PWR CE System 80

Thorium Seed Blanket Converter-Burner
Fuel Utilization

$\left(\text { MWYth/ST } \mathrm{U}_{3} \mathrm{O}_{8}\right)^{(1)}$

11.4

13.8
8

Reference

9

(1) Megawatt years of thermal energy per short ton of $\mathrm{U}_{3} \mathrm{O}_{8}$ from the mill; assumes uranium enrlchment plant tails assay is 0.2 percent uranium -235 in uranlum. 
Generic PWR*

Generic BWR*

CANDU

PWH-C̈t

System 80

(Design)

Thorium Seed-

Blanket

Converter-Burner

(Concept)
Light water cooled and moderated. Fuel-slightly enriched uranium in oxide form. Control by soluble boron in coolant. Approximately one-third of core refueled at each refueling, with remaining spent modules reshuffled (fuel management).

Light water cooled and moderated. Fuel-slightly enriched uranium in oxide form. Control rods used to compensate for reactivity changes during depletion. Approximately one-fourth of core refueled at each refueling.

Heavy water cooled and moderated. Fuel-natural uranium in oxide form. Control by poison rods. Refueling on-line, and performed almost continuously.

Light water cooled and moderated. Fuel-slightly enriched uranium in oxide form. Control by soluble boron in coolant. Aporoximately one-third nf r.nre rofucled at cach refueling, with remaininy spenl mudules reshuffled (fuei management). This type of reactor expected to be operational in the 1980's.

Light water cooled and moderated. Seed-blanket core. Seed fuel-assumed to be 93 percent enriched uranium (in oxide form) diluted with zirconium oxide. Blanket fuel-assumed to be natural thorium oxide. Control assumed to be by movable fuel. Entire core assumed to be replaced at each refueling.

It is evident from Tables 1 and 2 that PWR Core 1, a seed-blanket reactor, achieved good fuel utilization when compared with the initial Yankee-Rowe and Indian Point cores of about the same era. It is also evident that the fuel utilization of current operational or near operational commercial cores in Table 1 has improved greatly. The Canadian CANDU plants, which are now operational, achieve higher fuel utilization than current light water reactors with a once-through fuel cycle.

The thorlum converter-burner study was made in 1964 as part of the AEC LSBR program. This study indicated the possibility of achieving a fuel utilization without recycle which is 18 percent higher than that of present (1979) commercial light water reactors.

\section{Abstracts of Previous Seed-Blanket Reactor Studies}

The seed-blanket reactors that were actually built and operated are PWR Core 1, PWR Core 2, and LWBR. Over 2000 technical reports on the technology developed for these reactors have been published. "The Shippingport Pressurized Water Reactor Project Catalog of Document Abstracts" (References 10 through 12) contains a listing of reports relating to PWR Core 1 and PWR Core 2. Reference 13 provides a description of the LWBR core and lists reports on the technology developed for LWBR. Abstracts of some of these reports follow.

\footnotetext{
"These generic reactors are representative of reactors which are currently operating and have ratings of
} 800 to 1100 MWe (Reference 1). 
1. "The Shippingport Pressurized Water Reactor," Addison-Wesley Publishing Co., Inc., September 1958 (Reference 14).

On December 18,1957, the Shippingport Atomic Power Station began supplying electricity to the Duquesne Light Company, serving the Greater Pittsburgh, Pennsylvania area. That date marked the successful culmination of more than 4 years of planning, development, and construction to build the first large-scale, central-station nuclear power plant in the United States, and the world's first plant of such size operated solely to produce electric power. Reactor design, fuel element development, core construction, and the seed-blanket concept are detailed in this book.

2. "PWR Core 2 Reactor Design Description Report," WAPD-296, March 1968 (Reference 15).

This report describes the significant design features of PWR Core 2, the second core installed at the Shippingport Atomic Power Station. The core mechanical and fuel element characteristics are also discussed. A brief description of the Shippingport reactor plant is provided, with emphasis on those plant changes required to permit reactor operation at $505 \mathrm{MW}$ (thermal).

3. "Large Power Reactor Program," WAPD-LPR-141, Interim Report, July 1963 (Reference 16).

The objective of the Large Power Reactor (LPR) program was to determine the potential of a seed-blanket reactor for application in a large, central-station power plant (about $500 \mathrm{MW}$ (electrical)). This interim report describes initial research, engineering, and design work on seed-blanket concepts using both uranium and thorium systems.

4. "Large Power Reactor Program (Interim Report Supplement, The Design of Seed-Blanket Cores)," WAPD-LPR-154, July 1963 (Reference 17).

This supplement to WAPD-LPR-141 provides a thorough exposition of the principles of seedblanket reactor design and analysis of uranium-235/uranium-238 and uranium-235/thorium232 systems. It also discusses the feasibility of breeding in a thorium cycle using uranium233/thorium and reports results of an experimental program to verify nuclear design models.

5. "Report on Large Power Reactor (LPR) Program," WAPD-LPR-181, December 1963 (Reference 18).

This report summarizes reactor design work on a thorium converter-burner core, on a thorium converter-recycle core, and on a converter-burner reactor with a central-breeding region. Both reactor and plant design studies are included.

6. "Feport on Large Power Reactor (LPR) Program (Supplementing WAPD-LPR-181 dated December 1963)," WAPD-LPR-256, September 1964 (Reference 9).

Further design work on a thorium converter-burner and thorium converter-recycle cores and reactor plant development work are described. Additional experimental results, fuel element design, and thermal and hydraulic test results are reported. 


\section{FACTORS AFFECTING FUEL UTILIZATION}

This section discusses briefly the considerations that govern fuel utilization in a once-through reactor. Appendices $\mathrm{A}$ and $\mathrm{B}$ present a more detailed and quantitative discussion, including calculations of fuel utilization for a variety of fuel and core types, and the technical basis for the calculations. Fuel utilization is strongly influenced by neutron utilization, that is, by the relative rates at which neutrons born in fission events are captured in various reactor materials.

\section{A. Neutron Losses}

\section{Background}

Fuel utilization in any core is very sensitive to neutron losses. To discuss neutron losses it will be necessary to consider the neutron economy in a reactor which is operated to produce power. During operation at power, criticality must be maintained (or reactivity must be controlled): that is, the neutron economy must be such that for each $\mathrm{N}$ neutrons captured in core materials or leaking from the core, $\mathrm{N}$ neutrons must be produced by fission of fissile nuclides. In conventional light water reactors the condition of criticality at power is maintained by the use of neutron absorbers called control poisons. In conventional pressurized water reactors this poison is primarily a boron compound dissolved in the coolant. Poison rods, containing any of several neutron absorbing materials, can also be used for this purpose. In the absence of such control poisons the core would produce an excess number of neutrons; that is, for every $\mathrm{N}$ neutrons captured in core materials or leaking from the core, more than $\mathrm{N}$ neutrons would be produced. The neutrons captured by control poisons are among a group of neutrons which will be referred to as excess neutrons. The rest of this group consists primarily of neutrons which leak from the boundaries of the core and are captured in moderator and structure outside the core. An obvious way to increase once-through fuel utilization above the values currently achieved by conventional light water reactors is to make use of these excess neutrons to produce energy or additional fissile nuclides from fuel materials which do not require further mining of uranium. One such material is natural thorium. Another is depleted uranium, that is, enrichment plant tails with an assay of 0.2 to 0.25 percent uranium-235 in uranium. Still another material is natural uranium; although this requires uranium mining it turns out that capture of excess neutrons in natural uranium can improve fuel utilization. All three of the foregoing materials are referred to as blanket fuel. Finally, fuel utilization can be increased by improved fuel management. This technique, which is discussed in more detail in a later subsection, consists in arranging partially spent fuel modules, which would otherwise be removed from the reactor, with fresh fuel modules. This is done so that some neutrons, which would otherwise be captured in control poisons, are captured instead in the fuel remaining in partially spent fuel modules.

\section{Sensitivity of Fuel Utllization to Neutron Losses}

Typically, in a commercial pressurized light water reactor about 4 percent of the neutrons produced by fission are captured in removable poison, and another 4 percent are lost to leakage. If all of these excess neutrons could be captured in fuel (either spent seed fuel or blanket fuel), the fuel utilization could be increased by about $7 \mathrm{MWYth} / \mathrm{ST} \mathrm{U}_{3} \mathrm{O}_{8}$ to a value of about $19 \mathrm{MWYth} / \mathrm{ST} \mathrm{U}_{3} \mathrm{O}_{8}$. The reason for this sensitivity is that on the average each neutron captured in spent seed fuel or in 
blanket fuel would produce 2 to 3 fissions. The process, would proceed as follows. The blanket or spent seed would contain fissile atoms (either uranium-235 atoms normally present in natural uranium, or uranium-233 atoms or plutonium-239 atoms produced by previous capture of neutrons by fertile atoms). An excess neutron entering the blanket or spent seed could cause a fission which produces additional neutrons which in turn could cause additional fissions, and so on. Eventually, the chain of events caused by the initial fission would terminate because each neutron captured in the blanket or spent seed would produce on the average less than one successor. Thus, the blanket or spent seed would act as a net absorber of excess neutrons, but unlike a poison would add significantly to the energy output of the core.

The sensitivity of fuel utilization to neutron losses is displayed in Figure 1. At any value for the neutron losses, the curve gives the maximum fuel utilization achievable by choosing the optimum fuel system, enrichment, and fuel burnup. Other features of this figure are discussed later.

\section{B. Reduction of Neutron Losses}

\section{Reflecting Blankets}

In any type of core, the use of radial and axial reflecting blankets of natural uranium or thorium could reduce the neutron losses to leakage. Some of the neutrons which would otherwise leak from the core would either be captured in fertile fuel in the blanket, cause fissions in the blanket, or be scattered back into the core. The average power density in a reflecting blanket would be lower than that in the rest of the core. Thus for a fixed power capability, a core with a radial reflecting blanket would either-be larger in diameter or would need to have improved fuel region thermal capability relative to a core without a radial reflecting blanket. Based on data presented in Appendix $A$, it is judged that neutron losses to leakage could be reduced to 2 percent or less by the use of reflecting blankets.

\section{Seed-Blanket Geometry and Movable Fuel Reactivity Control}

The LWBR core presently operating at the Shippingport Atomic Power Station contains two types of assemblies, movable seed assemblies and fixed blanket assemblies. The blanket fuel has a relatively low ratio of fissile uranium-233 to fertile thorium atoms and the seed fuel has a higher ratio of uranium-233 to thorium atoms. Reactivity control is maintained by axially positioning the movable seed assemblies. This changes the relative geometry of seed and blanket fuel so as to change the relative capture rate of neutrons in fissile and fertile material. This concept of movable fuel reactivity control could also be used in a once-through seed-blanket core fueled with uranium-235 as the fissile material and either uranium-238 or thorium as the fertile material. This would eliminate neutron losses to control poison; however, there would be a small increase in neutron losses due to capture in the additional structure that would be associated with movable fuel control. With a combination of movable fuel control and reflecting blankets it is judged that total neutron losses of about 3 percent would be achievable. Figure 1 indicates that a fuel utilization slightly greater than $17 \mathrm{MWY}$ th/ST $\mathrm{U}_{3} \mathrm{O}_{8}$ could be achieved. However, there would be an additional small decrement in fuel utilization due to the non-uniform burnup of the seed fuel. The overall reduction of neutron losses would be obtained at the cost of increased power peaking relative to a uniformly fueled reactor 


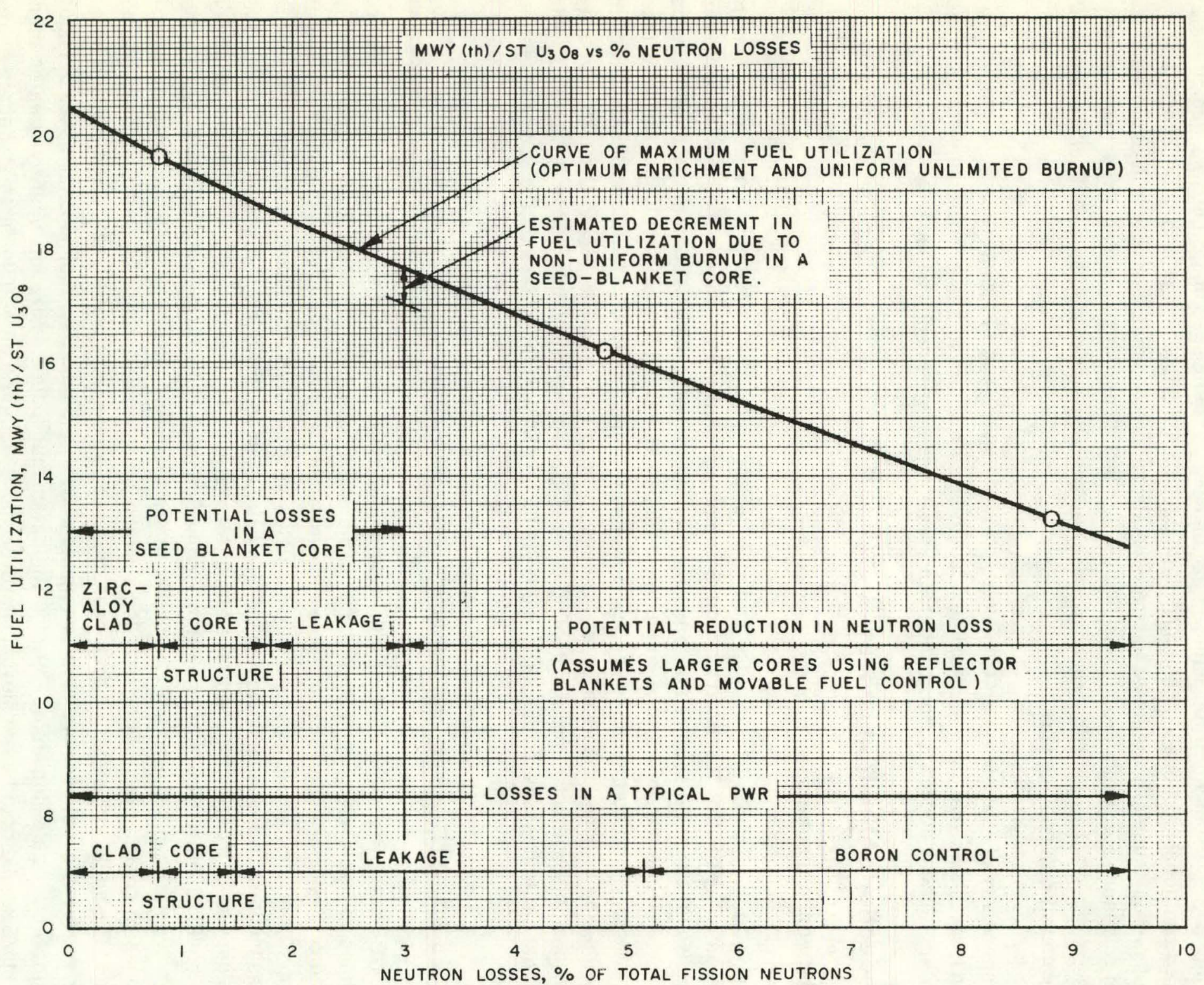

Figure 1. Sensitivity of Once-Through Fuel Utilization to Neutron Losses 
design. The increased power peaking would occur because the seed regions would have a higher concentration of fissile nuclides (for example, gm uranium-233 or uranium-235 per liter) than the blanket regions. This increased power peaking would require either a decrease in core average power density or improved heat transfer capability for the seed regions relative to current commercial designs. These items are discussed further in Appendices A and B.

The thorium seed-blanket converter-burner design in Table 1 used movable fuel for reactivity control in lieu of either control rods or soluble boron. This helped to increase the fuel utilization by eliminating neutron losses in control poisons.

\section{Fuel Management}

In a conventional light water reactor only part of the core is replaced at each refueling. At the start of an irradiation cycle, which typically lasts about one year, the core consists of fresh fuel modules and partially depleted fuel modules which have been in the core for one to three irradiation cycles. During power operation the fresh fuel modules and the depleted modules with the lowest irradiation are producers of excess neutrons; the most highly depleted modules are net absorbers of excess neutrons. Thus, the presence of the most highly depleted modules permits some of the neutrons which would otherwise be captured in control poisons to be captured in an environment where they can produce energy. No mining of uranium is required to supply the partially depleted fuel modules. Referring to the fuel utilization values in Table 1, the Yankee-Rowe and.Indian Point fuel utilization values were low in part because the entire cores were removed at the first refueling. The PWR Core 1 and PWR Core 2 fuel utilization values were relatively higher because the seed-blanket arrangement permitted partial refueling (that is, refueling of the seeds). This amounted to a simple form of fuel management. The higher fuel utilization of current commercial PWR and BWR type cores is due in large part to a fuel management scheme in which only the most depleted modules, typically amounting to one-fourth to one-third of a core, are replaced each year. The CANDU reactors have an almost continuous partial refueling, which is one of the reasons for their high fuel utilization.

In a seed-blanket core with movable fuel reactivity control, the use of fuel management would reduce the amount of reactivity control required from the movable fuel, possibly permitting reduced amount of structural material in the core.

\section{Core Structure and Materials}

In any core some neutrons are lost to structure and fuel rod cladding. In current commercial cores the structure and cladding are Zircaloy, which has a relatively low probability for capturing neutrons. A contributing factor to the low fuel utilization in the Yankee-Rowe first core listed in Table 1 was the use of stainless steel cladding for the fuel rods. In a seed-blanket core with movable fuel reactivity control, additional structure (relative to that in a conventional PWR core) would be required to accommodate the movable fuel. Minimizing the effect of this additional structure on fuel utilization would require minimizing the amount of structure, and using Zircaloy for the structure wherever possible. In the LWBR core presently operating at the Shippingport Atomic Power Station, Zircaloy is used for all of the fuel rod cladding and for all of the structure within the fuel regions except the fuel rod grids. AM-350 stainless steel is used for the fuel rod support grlds. 


\section{Power Density}

Operation of a conventional light water core at reduced power could reduce neutron losses relative to the losses for operation at normal power, if the same refueling frequency (for example, once a year) were used for both modes of operation. Operation of the core at reduced power would make it possible to refuel a smaller fraction of the core at each refueling, thus, approaching closer to continuous refueling. This effect is closely related to fuel management (discussed in Subsection 3 above).

\section{Fuel Materials and Uranium Enrichment}

Other possibilities considered for increasing fuel utilization in light water reactors are the use of thorium and the choice of enrichment for the uranium. It has been found that the fuel utilization does depend on the fuel type and the enrichment. However, it has also been found that the calculated peak fuel utilization (for example, about $17 \mathrm{MWYth} / \mathrm{ST} \mathrm{U}_{3} \mathrm{O}_{8}$ in a seed-blanket core with movable fuel reactivity control and 14 to $15 \mathrm{MWY}$ th/ST $\mathrm{U}_{3} \mathrm{O}_{0}$ in a uniformly enrir.hed sore with soluble boron reactivity control) can be achieved with a variety of fuel types and enrichments. The blanket types which give the same peak fuel utilization in the seed-blanket conses are natural uranium, depleted uranium (enrichment plant tails with an assumed assay of 0.2 percent uranium-235 in uranium), natural thorium, and spiked thorium (thorium containing a small concentration of uranium-235). The seed types which give the same peak fuel utilization in seed-blanket cores are uranium with enrichments of $b$ percent to y3 percent, and mixtures of thorium and uranium with uranium-235 concentrations of 6 to 8 percent in heavy metal. The fuel types which give the same peak fuel utilization in uniform enrichment cores are uranium with enrichment between 3 percent and 10 percent, and mixtures of thorium and uranium similar to those considered for seeds.

The enrichment plant tails assay (percent uranium-235 in uranium) also affects the fuel utilization. A decrease in tails assay would cause an increase in fuel utilization because there would be a reduction in the amount of $\mathrm{U}_{3} \mathrm{O}_{8}$ sent through the enrichment plant to supply a given amount of enriched fuel. All fuel utilization calculations in this report are based on an assumed tails assay of 0.2 percent. At this assay, about 25 percent of the uranium-235 in the ore mined goes into the enrichment plant tails stream.

CANDU cores, which are cooled and moderated by heavy water, are fueled with natural uranium: thus, all of the uranium-235 in the ore mined is used to fuel these reactors.

\section{Fuel Burnup}

It was noted in the preceding subsection that the peak fuel utilization in either a seed-blanket core or a uniformly enriched core could be achieved with a variety of fuel types and enrichment. However, the average fuel burnup required to achieve a given fuel utilization depends on fuel types and enrichment. In seed-blanket cores which give peak fuel utilization, the blanket burnup required is insensitive to the seed enrichment, but the seed burnup required increases as the seed enrichment increases. This trend in seed burnup is related to the fact that peak fuel utilization requires a burnup of about 90 percent of the uranium-235 in the seed, independent of seed enrichment. One constraint on the attainment of the peak fuel utilization would be limits on fuel burnup, which is related to 
maintaining the mechanical integrity of the fuel rods. In current light water cores the limits on average fuel burnup are in the range of 30,000 to $35,000 \mathrm{MWD} / \mathrm{MT}$. This consequently limits the fuel utilization which can be obtained from this type of core. To obtain a fuel utilization of close to $15 \mathrm{MWYth} / \mathrm{ST}$ $\mathrm{U}_{3} \mathrm{O}_{8}$ in a conventional reactor, it would be necessary to increase average burnup to close to $50,000 \mathrm{MWD} / \mathrm{MT}$ with uranium fuel, and to even higher values with thorium fuel. To obtain a fuel utilization of close to $17 \mathrm{MWYth} / \mathrm{ST} \mathrm{U}_{3} \mathrm{O}_{8}$ in a seed-blanket core it would be necessary to increase average burnup beyond 50,000 MWD/MT for both uranium fuel and thorium fuel.

The influence of fuel burnup can be seen in some of the fuel utilization values of Table 1. The use of thorium in the Indian Point core contributed to the low fuel utilization because the thorium, which contains no naturally occurring fissile material, was removed at a very low burnup. In the thorium seed-blanket converter burner conceptual design, the thorium irradiation was also predicted to be relatively low, and tended to produce a low value of fuel utilization relative to that theoretically achievable in such a reactor.

\section{E. Summary}

In current light water cores, fuel utilization is limited by neutron losses. Reduction of neutron losses to leakage and to control poisons constitutes the major means for improvement in fuel utilization. The effect of these and other losses is shown in Figure 1, which summarizes the potential for fuel utilization improvement. Realization of the indicated potential would require increased average burnup (MWD/MT) relative to that in current light water cores. Figure 1 is self-explanatory except for the clad losses and non-uniform burnup effect. In this figure, clad losses include all of the neutrons captured in fuel rod cladding (assumed to be Zircaloy). They are presented as a loss primarily to indicate that the potential gain from reducing capture in cladding (by removing impurities or certain zirconium isotopes or by reducing clad thickness) is modest, less than $0.5 \mathrm{MWYth} / \mathrm{ST} \mathrm{U}_{3} \mathrm{O}_{8}$. Except for this figure all of the calculations and fuel utilization estimates presented in this and later sections include all neutron capture in the clad. The non-uniform burnup effect would be of no significance for a uniform enrichment core. In a seed-blanket core non-uniform seed burnup would have an adverse effect on the number of excess neutrons produced. This small effect is discussed in Appendix B.

Reduction of neutron losses to about 3 percent is judged to be achievable in a practical seedblanket core with movable fuel reactivity control. The resulting fuel utilization would be about $17 \mathrm{MWYth} / \mathrm{ST} \mathrm{U}_{3} \mathrm{O}_{8}$. Average fuel burnup greater than $50,000 \mathrm{MWY}$ th/ST $\mathrm{U}_{3} \mathrm{O}_{8}$ would be required to achieve this. The use of movable fuel for reactivity shim control would have the drawback of producing spatial variations in power density larger than those occurring in current commercial cores. Although this would be of little consequence with respect to fuel utilization, it would require consideration in the design of the core. Relative to a current commercial light water core, a seed-blanket core would have to be larger or have improved fuel element thermal capability. The use of reflecting blankets would have similar effects on core size and fuel element thermal capability.

It is noted that in a conventional type of light water core the losses to control poison could be reduced by an increase in enrichment, an increase in refueling frequency, or a decrease in power density. With an enrichment of about 5 percent, operation at half normal power density, and annual refueling, the neutron losses to soluble boron control poison could be limited to about 2 percent. Figure 1 (located at the end of Section III.A) indicates that a fuel utilization slightly less than $15 \mathrm{MWYth} / \mathrm{ST} \mathrm{U}_{3} \mathrm{O}_{8}$ could be achleved. 


\section{DESIGN CONSIDERATIONS}

\section{A. Fuel System Design}

Current light water cores use rod-type fuel elements consisting of bulk oxide $\mathrm{UO}_{2}$ fuel pellets sealed inside cylindrical Zircaloy tubes. The enrichment of the uranium is about 2 to 3 percent. Although this system is well suited to the current requirements of light water reactors, obtaining improved fuel utilization could change the requirements of the fuel system. These changes could include higher burnups, higher enrichment, the use of thorium, and compatibility with seed-blanket geometry. The use of seed-blanket geometry could place unusual demands on the fuel system because the power density may be substantially different in the seed and blanket regions, and the peak power density in either region may change significantly as the fuel depletes. These demands lead to consideration of plate-type fuel elements, as well as rod-type elemients for seed-blanket geometry.

This section presents a brief discussion on the advantages and disadvantages of the types of fuel elements and fuel systems which could be considered to meet the demands of once-through cores with improved fuel utilization. The fuel element types considered are plates and rods; the fuel systems considered are bulk oxide $\left(\mathrm{UO}_{2}\right.$ or $\left.\mathrm{ThO}_{2}\right)$, a binary system of $\mathrm{UO}_{2}-\mathrm{ZrO}_{2}$, a ternary system of $\mathrm{UO}_{2}-\mathrm{ZrO}_{2}-\mathrm{CaO}$, and a binary system of $\mathrm{UO}_{2}-\mathrm{ThO}_{2}$.

\section{Plate-Type Fuel Elements Versus Fuel Rods}

It is judged that either plate-type or rod-type fuel elements would be capable of acceptable thermal and mechanical performance in a once-through core.

The plate-type fuel element, such as that used in PWR Core 2 and in the seed of PWR Core 1, would have one potential advantage for a seed-blanket core: the plates would be welded together to form a rigid structure with well defined flow boundaries. This would facilitate zoning of the flow, which could be required by thermal-hydraulic considerations as discussed in Section IV.B. However, the disadvantage of the plate-type fuel element relative to the rod-type element would be that more Zircaloy structure would be required per unit volume of fuel. This extra structure would be a disadvantage because it would capture neutrons which would otherwise be captured in fertile nuclides, and thereby reduce fuel utilization. For this reason fuel rods are judged to be the more desirable fuel element for both seed-blanket cores and uniformly enriched cores, provided their use would be compatible with thermal-hydraulic requirements of seed-blanket copes. Fuel rods are used In the LWBR core presently operating at Shippingport. In subsequent sections of this report, calculations of fuel utilization for once-through reactors are based on the use of rod-type fuel.

\section{Fuel Types}

The fuel systems which could be considered for uniformly enriched cores and for seed fuel elements include bulk oxide $\mathrm{UO}_{2}$, a binary system of $\mathrm{UO}_{2}-\mathrm{ZrO}_{2}$, a ternary system of $\mathrm{UO}_{2}-\mathrm{ZrO}_{2}-\mathrm{CaO}$, and a binary system of $\mathrm{UO}_{2}-\mathrm{ThO}_{2}$. Only bulk oxide, $\mathrm{UO}_{2}$ or $\mathrm{ThO}_{2}$, has been considered for blanket fuel elements. Bulk $\mathrm{UO}_{2}$ is used in current commercial light water reactors. Bulk $\mathrm{ThO}_{2}$ containing a small 
amount of highly enriched $\mathrm{UO}_{2}$ was used in the first Indian Point reactor. In the LWBR core currently operating at Shippingport, the fuel system is $\mathrm{ThO}_{2}$ containing from zero to 6 weight percent $\mathrm{UO}_{2}$. Both binary and ternary systems of $\mathrm{UO}_{2}$ in $\mathrm{ZrO}_{2}$ and $\mathrm{UO}_{2}$ in $\mathrm{ZrO}_{2}-\mathrm{CaO}$ were used in the seed fuel elements of PWR Core 2.

In a once-through seed-blanket core, the fuel enrichment in the seed modules could be limited by design to 20 percent or less, with the upper limit determined on the basis of the enriched uranium not being usable for weapon purposes without further enrichment. The actual choice of seed fuel enrichment would be dictated by nuclear design considerations such as achieving adequate reactivity shim control from a movable fuel system and acceptable power distributions, and fuel element design considerations such as mechanical integrity of the fuel pellets and the cladding.

One of the factors involved in mechanical integrity is fission density. The fission density is usually specified in units of fissions per cubic centimeter of fuel volume, and is written as $\mathrm{f} / \mathrm{cc}$. At fission densities up to $12 \times 10^{20} \mathrm{f} / \mathrm{cc}$, the mechanical integrity of the fuel systems considered is known (from both test and operational experience) to be satisfactory for the heat fluxes characteristic of current commercial light water reactors. Additional data and experience would be necessary to prove that current state-of-the-art fuel systems would be capable of acceptable performance at higher fission densities. Due to the non-uniform power distributions in a reactor, it would be necessary to restrict the average fission density to a value well below the peak allowable value.

Fission density is also related to burnup. For bulk oxide $\mathrm{UO}_{2}$, a fission density of $12 \times 10^{20} \mathrm{f} / \mathrm{cc}$ corresponds to a burnup of about $48,000 \mathrm{MWD} / \mathrm{MT}$. The maximum fission density resulting from irradiation of a seed module is determined in part by the reactivity lifetime of the core fuel loading. At the end of reactvity life the most depleted seed modules (that is, the modules with the highest fission density) must be replaced.

In a high fuel utilization once-through seed-blanket reactor with bulk oxide $\mathrm{UO}_{2}$ seed fuel at 5 percent enrichment, the average seed burnup at the end of seed reactivity life could be about 60,000 to $70,000 \mathrm{MWD} / \mathrm{MT}$, corresponding to an average fission density of about 15 to 18 $\times 10^{20} \mathrm{f} / \mathrm{cc}$. It is considered that to obtain satisfactory fuel element performance at this burnup, it could be necessary to dilute the fuel with $\mathrm{ZrO}_{2}$. A seed fuel consisting of 50 volume percent $\mathrm{ZrO}_{2}$ and 50 volume percent $\mathrm{UO}_{2}$ at 5 percent enrichment would yield an average fission density of about 8 to $9 \times 10^{20} \mathrm{f} / \mathrm{cc}$ at the above burnups. However, for the calculations made in this report, no diluent has been used in the fuel with 5 percent enrichment. It is considered possjble that advances in fuel element technology could be made which would permit achieving burnups close to the above without dilution of the fuel.

At enrichments greater than 5 percent it has been assumed necessary to "dilute" the fuel with $\mathrm{ZrO}_{2}$ to obtain a uranium-235 atom density in the fuel which is the same as that in the 5 percent enriched fuel. For example, for the case of fixed burnup in a fuel system containing 20 percent enriched fuel and 25 volume percent $\mathrm{UO}_{2}$, the expected end-of-life average fission density would be about the same as for 5 percent enriched fuel with no $\mathrm{ZrO}_{2}$ diluent. In such binary fuel systems, neutron capture in the zirnnnium would have an adverse effect on fuel utilization. Therefore, the objective of achieving 
the highest possible fuel utilization would require balance between the adverse effect on fuel utilization of zirconium diluent in the fuel, and the positive effects of choosing seed fuel enrichment so as to achieve adequate control from the movable fuel system and using zirconium diluent to limit the fission density.

For blanket fuel the only fuel type considered has been bulk oxide, $\mathrm{UO}_{2}$, or $\mathrm{ThO}_{2}$ (with or without small amounts of $\mathrm{UO}_{2}$ ).

In Appendix $B$ it is noted that the peak fuel utilization for a natural uranium blanket occurs at an average irradiation of about $35,000 \mathrm{MWD} / \mathrm{MT}$. This would very nearly correspond to an acceptable fission density based on current fuel element technology if the peak-to-average ratio could be limited to values typical of current commercial PWR cores. It is also noted in Appendix $B$ that a thorium blanket does not permit the achievement of good fuel utilization until the average burnup reaches $50,000 \mathrm{MWD} / \mathrm{MT}$. If it is possible to obtain burnup in excess of 50,000 MWD/MT in thorium fuel, then thorium fuel could be used in seed-blanket reactors with no compromise in achievable fuel utilization.

\section{Summary}

The fuel elements judged most appropriate for consideration in both uniform enrichment and seedblanket once-through cores are fuel rods. The fuel type considered most appropriate for blanket rods is bulk oxide $\left(\mathrm{UO}_{2}\right.$ or $\left.\mathrm{ThO}_{2}\right)$. For seed rods, bulk $\mathrm{UO}_{2}$, or a solid solution of $\mathrm{UO}_{2}$ and either $\mathrm{ZrO}_{2}$ or $\mathrm{ZrO}_{2}-\mathrm{CaO}$, would probably be required. There has been substantial operating experience with $\mathrm{UO}_{2}$ bulk oxide fuel, and more limited experience with $\mathrm{ThO}_{2}$ bulk oxide fuel and with $\mathrm{UO}_{2}-\mathrm{ZrO}_{2}$ and $\mathrm{UO}_{2}$ $\mathrm{ZrO}_{2}-\mathrm{CaO}$.

\section{B. Thermal and Hydraulic Design}

\section{Background}

If improved fuel utilization could be obtained from a once-through uniformly enriched light water core, it is assumed that the thermal and hydraulic features of such a core would be essentially identical with those of a current conventional uniformly enriched core. Therefore, these features are not discussed here. This section deals exclusively with the thermal-hydraulic features of a seedblanket core.

The thermal-hydraulic requirement is that adequate flow be supplied to each region of the core, with flow velocities limited to values which do not cause unacceptable stress or vibration in fuel rods or structure.

From a thermal-hydraulic standpoint, the key feature of seed-blanket cores is that the seed and blanket regions have potentially large differences in power density and flow characteristics and that the relative power density in seed and blanket regions can change substantially as the fuel depletes. The differences and changes in power density between seed and blanket regions would bc copecially significant in thorium blanket regions, where very little power would be produced when the blanket

regions were fresh, but the power density would increase substantially as uranium-233 built up in the 
region. Differences in flow charateristics between seed and blanket regions could occur as a result of differences in parameters such as rod pitch, rod diameter and/or metal-to-water ratio. These parameters could differ between seed and blanket regions as a result of optimization of core characteristics such as fuel utilization and reactivity shim control by movable fuel.

For any seed-blanket core it is conceptually possible to assure that adequate flow could be supplied to all regions of the core simply by adjusting the pumping power without resorting to any flow distribution devices such as orificing. However, flow velocities would not necessarily be acceptable. Furthermore, there would be an economic incentive to minimize pumping power (thereby also minimizing the size of main coolant pumps, valves, and piping) by delivering the minimum flow required by each region. The fact that constraints on flow velocity and pumping power would be necessary are the basis for considering the methods which could be used for distributing core flow in seed-blanket reactors. This section discusses these methods qualitatively. No studies have been made to determine which, if any, of these methods are needed, or what the relationships would be between these methods and pumping power, core complexity, core performance, and fuel utilization.

\section{Current Methods for Flow Apportionment}

The current method of apportioning flow for operating seed-blanket cores involves the use of shells (cans) to hydraulically separate the seed and blanket regions and the use of flow restrictors (orifices) to apportion the flow, as required, to the seed and blanket regions. These methods have been used for the PWR Core 1, PWR Core 2, and the LWBR core designs.

The blanket fuel assemblies in PWR Core 1 had rod-type fuel elements and were enclosed by shells. The flow to the blanket regions was regulated by orifices; the blanket region was divided into four flow regions with different orifices in each region. The seed assemblies of PWR Core 1 were plate-type.

PWR Core 2 contained plate-type assemblies (for both seed and blanket) which therefore inherently contain a shell by their design. Here, the blanket region flow was divided into 11 different flow regions.

In LWBR, which utilizes fuel rods in all modules, shells are used to form three flow regions: the seed region, the blanket and power-flattening blanket region, and the reflector region. Inlet and exit orifices are used to apportion the flow to these three flow regions.

Important design considerations with respect to shells involve accounting for the effects of neutron absorption, water-hole power peaking in the adjacent fuel rods, and pressure drop forces on the shells.

An alternative to orificing would be to utilize a pass arrangement other than single-pass. For example, PWR Core 2 contained a pass-and-one-half arrangement where the seed was one-pass and the blanket was two-pass. 


\section{Other Methods for Flow Apportionment}

Another way to apportion the flow to each region would be to establish the rod diameter and rod pitch in each region such that the desired flow split would result. This approach would be limited in scope by the nuclear requirements of the design.

Mixing vane grids could also be used to increase the degree of mixing between the blanket and seed subchannels. While this would increase total core resistance and decrease total core flow, the thermal decrement from that flow decrease might be more than offset by the improvement in mixing.

An additional method would be to optimize the relative grid flow resistances for the seed and blanket regions. The grid resistances could be optimized either by changing the design of the individual grids or by simply varying the total number of grids. Note that this concept of apportinning the flow to the seed and blanket regions by varying the grid resistance is similar to apportioning the flow using inlet (or exit) orifice olates. However, this methend might have the advantagc that 3 hells or flow separators between the seed and blanket regions would not be required. One potential problem is that cross flows might exist at axial levels hetween grids, thus reducing the offcotivcne33 of the curicept.

It is noted that some of the seed-blanket reactor concepts considered could require refueling the seed regions two or more times during the blanket region lifetime. During these seed refuelings, the opportunity would be available to use fresh seed modules with hydraulic characteristics tailored to make the flow distribution meet the requirements expected during the subsequent irradiation cycle.

\section{Conclusion}

There are a number of potential methods for optimizing the thermal-hydraulic performance of a seed-blanket core within the constraints imposed by nuclear design and other requirements. Some of these methods have been used successfully in operating seed-blanket cores. A commercial seedblanket core might use a combination of the methods discussed.

\section{Mechanical Design}

\section{Background}

If improved fuel utilization could be obtained from a once-through uniformly enriched light water. core, it is assumed that the mechanical features of such a core would be essentially identical with those of a current conventional uniformly enriched light water core. Therefore, these features are not discussed here. This section deals exclusively with the mechaniral features of a seed-blanket core.

The distinctive mechanical features of a seed-blanket core with high fuel utilization would be determined by the requirement that reactivity shim control during power operation be provided entirely or primarily by movable fuel and the requirements of thermal-hydraulir performance as discussed in Section IV.B. In this section, the discussion will be limited entirely to the features required to accommodate movable fuel reactivity control. 
All light water power reactors which are or have been operational, with the exception of the LWBR, use or have used control rods and/or soluble poison for reactivity shim control during power operation, and have had stationary fuel assemblies. It was noted in Section III that neutron losses to control poisons substantially reduce fuel utilization and it is therefore assumed that a high fuel utilization once-through seed-blanket core would use movable fuel for reactivity shim control.

The movable fuel control systems considered in this report are similar to the LWBR system, in that they involve only lifting and lowering of movable fuel elements relative to stationary fuel elements. The movable elements could be complete modules, as in the LWBR, or they could be fingers of fertile material, geometrically similar to the poison control fingers in current commercial PWR reactors. The mechanical features dictated by the lifting and lowering of movable fuel elements of these types are discussed in the subsections which follow. Other types of movable fuel control arrangement are conceivable; however, no other types have been studied as part of the seed-blanket reactor development program, and they are not considered here.

\section{Mechanical Requirements for Movable Fuel Control}

The mechanical requirements which the movable fuel control system would have to satisfy are as follows:

1. Mechanisms must lift and lower large masses, for example, modules or large numbers of fingertype elements.

2. Movable modules or fingers must be designed to withstand scram forces.

3. Core design must assure free vertical movement of movable fuel under normal conditions and credible accident conditions.

4. If cans are used around movable or stationary fuel assemblies, they must withstand any pressure differentials caused by flow distribution.

5. Hydraulic forces tending to lift movable fuel must be balanced.

6. Ease of fuel management (both module replacement and rearrangement) must be retained.

7. If reactivity worth of movable fuel is not adequate to provide reactivity shutdown, provisions must be made for poison rods or soluble poison.

The LWBR core design satisfies the first 6 requirements, and reactivity shutdown is provided by movable fuel. Briefly, the LWBR features are as follows:

1. The seed assemblies are contained. within Zircaloy shells capable of withstanding the pressure differentials between different flow regions.

2. The seed fuel assemblies at their lowest positions are below the blanket assemblies. 
3. To achieve criticality the seed assemblies are lifted into the core.

4. Each of the seed assemblies is lifted, lowered, and scrammed by a large control drive mechanism via a lead screw.

5. A unique method is used to balance the hydraulic forces on the seed assembly. Bypass inlet flow (BIF) is piped to the top side of a balancing piston on each seed assembly to ensure a net downward scram force for all operating conditions.

6. A buffer piston and cylinder arrangement at the top of each of the seed assemblies limits the velocity with which the seed assembly impacts the bottom-stop following a scram.

The fuel assembly suspension system in LWBR was designed for compatibility with the movable fuel control concept. The suspension system components attach the blanket module to the reactor vessel closure head. The seed is attached to the mechanism lead screw-tie rod at the balance piston. The attachment of the blanket module to the head provides a continuous aligned guide path for the seed from the drive mechanism mounted atop the closure to the scrammed position of the seed, about 5 feet below the core. Ihe suspension system also provides a closed path for the bypass inlet flow (BIF) arrangement required to ensure scram capability of the movable seed fuel assembly. The mechanical design is such that seed modules can be refueled through the pressure vessel head (after removal of the control drive mechanism). Any type of module can be replaced when the pressure vessel head is removed.

A possible alternative to the LWBR system of movable fuel modules would be the use of movable fuel fingers in a configuration similar to that of the shutdown poison finger rods in commercial PWR cores. These fingers would constitute part of the blanket fuel. In commercial PWR cores the shutdown poison is in the form of finger rods distributed throughout certain fuel assemblies referred to as rodded fuel assemblies. Each finger operates in a guide tube not much bigger in diameter than the typical fuel rod. Typically, all the fingers in one fuel assembly are fastened to a common spidershaped bracket so they can be gang-operated by conventional control rod drive mechanism systems. In principle, this commercial control concept could be modified to a movable fuel concept by using fertile material in the fingers instead of poison, and increasing the number of control fingers per fuel assembly. If additional shutdown capability were required, poison shutdown fingers could be used in some locations. This concept could significantly reduce the amount of fuel required to be moved and the amount of core volume used by shells to prevent mechanical interference between moving parts. This concept would permit the core support system to be very similar, if not identical, to that used in commercial PWR cores. Such a control system would require development both for the movable thoria finger control rod and the control drive train to position the control assembly. This concept is being reviewed for possible further development under the DOE Water Cooled Breeder Program.

\section{Conclusion}

There are at least two potential methods for providing reactivity shim control during power operation through the axial positioning of movable fuel. One method is already operating successfully in the LWBR core. The other method would be conceptually similar to the reactivity shutdown control system used in commercial PWR cores; but would require further development before it could be considered for application in future reactor designs. 


\section{FUEL UTILIZATION OF PRIOR DESIGNS WHEN EVALUATED AS ONCE- THROUGH CONVERTER-BURNERS}

Previous sections have described nuclear, fuel, thermal, and mechanical considerations which would arise in the design of once-through seed-blanket reactors with high fuel utilization. These same considerations were involved in previous conceptual design work conducted under the direction of the Department of Energy (and its predecessor organizations, Energy Research and Development Administration and the Atomic Energy Commision) on high fuel utilization seed-blanket reactors. In this earlier work it was assumed that both seed and blanket fuel could be recycled if advantageous; therefore, these previous conceptual designs were not optimized to achieve maximum fuel utilization in a once-through fuel cycle. However, when these conceptual designs are evaluated on the basis of a once-through fuel cycle, some of them have higher fuel utilization than current light water reactors also evaluated on the basis of a once-through fuel cycle. The calculated fuel utilization for a typical conceptual design is presented in Table 2. Two of these concepts are described in Appendix $C$. The values range approximately from 11 to $14 \mathrm{MWYth} / \mathrm{ST} \mathrm{U}_{3} \mathrm{O}_{8}$. It is anticipated that additional design effort on these concepts to optimize seed and blanket burnup through careful fuel management could increase these fuel utilization values to about $17 \mathrm{MWYth} / \mathrm{ST} \mathrm{U}_{3} \mathrm{O}_{8}$. This range would still allow for about 3 percent neutron loss to fuel element support grids, structure other than fuel rod cladding, neutron leakage, and the effect of non-uniform fuel burnup. Based on LWBR experience, it is judged that adequate reactivity shim control during power operation could be provided by a movable fuel control system.

\section{CONCLUSIONS}

The major conclusions derived from this review of pressurized light water reactor fuel utilization potential on a once-through fuel cycle assuming 0.2 percent enrichment plant tails assay are as follows:

1. The maximum practical fuel utilization which could be achieved is about $17 \mathrm{MWYth} / \mathrm{ST} \mathrm{U}_{3} \mathrm{O}_{8}$ with a seed-blanket reactor using either a thorium or uranium blanket. This is about 50 percent greater than the present capability of 11.5 to $12.0 \mathrm{MWYth} / \mathrm{ST} \mathrm{U}_{3} \mathrm{O}_{8}$ for commercial pressurized light water reactors. No detailed engineering work has been done to confirm that the details of such a se日d-blanket concept are prac.tical.

2. The maximum practical fuel utilization in light water reactors discussed above could be accomplished by increasing average fuel burnup beyond 50,000 MWD/MT and by incorporating all of the following neutron conserving methods:

a. Seed-blanket core geometry with movable fuel reactivity control, similar to that in the LWBR now operating at Shippingport

b. Peripheral reflector region containing natural uranium or thorium to use or reflect neutrons that would otherwise be lost

c. Fuel and structural materials containing minimum amounts of neutron poisons. 
Use of movable fuel control and a reflector region would require increased mechanical complexity for the seed-blanket reactor compared to current commercial reactors. This would result in a larger reactor.

3. A seed-blanket reactor achieving optimized once-through fuel utilization would have increased power peaking relative to a uniformly fueled reactor design. This would require a reduction in core power density relative to current commercial reactor designs, or improved heat transfer capability for the seed regions.

4. For a hypothetical ideal situation in which all neutron leakage and losses to control poisons and core structure, including fuel rod cladding, are eliminated and fuel depletion is not limited by design considerations, a maximum fuel utilization of about $20 \mathrm{MWYth} / \mathrm{ST} \mathrm{U}_{3} \mathrm{O}_{8}$ is calculated for either uranium or thorium. This represents a hypothetical increase of a factor less than 1.75 compared to current commercial reactors.

5. Fuel utilization of about $15 \mathrm{MWYth} / \mathrm{ST} \mathrm{U}_{3} \mathrm{O}_{8}$ is judged to be achievable with uranium in a conventionally controlled pressurized light water reactor with average fuel burnup of about 50,000 MWD/MT.

6. For average fuel depletions of 30,000-35,000 MWD/MT, which are characteristic of present light water reactor cores, uranium fuel is better than thorium fuel on a once-through fuel cycle since fresh thorium fuel produces essentially no power. For thorium fuels to provide equivalent fuel utilization, average depletions in excess of 50,000 MWD/MT would be required.

7. The achievable fuel utilization in a once-through seed-blanket reactor:

a. Depends on the fraction of the uranium-235 in the seed that can be consumed. Eighty-five to 95 percent depletion of the seed uranium-235 would be required to obtain maximum fuel utilization.

b. Is nearly independent of seed enrichment over the range of 5 to 93 weight percent uranium-235 in uranium. Although the fuel utilization theoretically achievable in a seed-blanket reactor with fixed neutron losses is nearly independent of seed enrichment, the design features necessary to achieve high fuel utilization at low enrichment have not been developed and may not be practical.

8. Zircaloy-clad bulk oxide fuel rods similar to those currently used in commercial light water reactors are the most favorable choice of known possibilities for high fuel utilization in water reactors with a once-through fuel cycle.

9. The development of practical once-through seed-blanket reactors with optimized, once-through fuel utilization would require extension of current technology in the areas of movable fuel control, peripheral reflector blankets, minimization of neutron losses to structure, and improvements in fuel elements. Although the Naval Reactors Division of the Department of Energy is not working directly to design once-through light water reactors with improved fuel utilization, the technology being developed through the Department of Energy Water Cooled Breeder Program would have application to such once-through light water reactors. 


\section{REFERENCES}

1. "Nuclear Power Growth 1974-2000," WASH-1139-74, February 1974.

2. "Directory of Nuclear Reactors," Vol. 4 Power Reactors, International Atomic Energy Agency, 1962.

3. "Shippingport Operations During PWR Core 1 Depletion," WAPD-294, December 1968.

4. "Proceedings of the American Power Conference," Volume XXV, 1963.

5. "Proceedings of the American Power Conference," Volume XXVIII, 1966.

6. "Shippingport Operations from Initial PWR Core 2 Power Operation to Power Operation After First Refueling," WAPD-332, June 1973.

7. "Study of the Developmental Status and Operational Features of Heavy Water Reactors," EPRI NP-365, February 1977.

8. "Assessment of Thorium Fuel Cycles in Pressurized Water Reactors," EPRI-NP-359, February 1977.

9. "Report on Large Power Reactor (LPR) Program (Supplementing WAPD-LPR-181 dated December 1963)," WAPD-LPR-256, September 1964.

10. "The Shippingport Pressurized Water Reactor Project Catalog of Document Abstracts," WAPDPWR-1606 (Revised), December 1961.

11. "The Shippingport Pressurized Water Reactor Project Catalog of Document Abstracts," WAPDPWR-1606 (Addendum 1), May 1963.

12. "The Shippingport Pressurized Water Reactor Project Catalog of Document Abstracts," WAPDPWR-1606 (Addendum 2), June 1965.

13. "Final Environmental Statement, Light Water Breeder Reactor Program," ERDA 1541, June 1976.

14. The Shippingport Pressurized Water Reactor, Addison-Wesley Publishing Co., Inc., September 1958.

15. "PWR Core 2 Reactor Design Description Report," WAPD-296, March 1969.

16. "Large Power Reactor Program," WAPD-LPR-141, Interim Report, July 1963.

17. "Large Power Reactor Program (Interim Report Supplement, The Design of Seed-Blanket Cores)," WAPD-LPR-154, July 1963.

18. "Report on Large Power Reactor (LPR) Program," WAPD-LPR-181, December 1963. 


\section{GLOSSARY}

Many of the terms used throughout the remainder of this report appear frequently in the literature on nuclear reactors, but have no universally accepted definition. Therefore, the definitions given here are appropriate within the context of this report, but not necessarily outside this context.

\section{Core}

"Core" as used here refers to the fuel assemblies and associated components such as support structure and control rods.

\section{Reactor}

"Reactor" as used in this report refers to the reactor vessel (and head) and its content6. The contents include the core, core support structure, control rods, control drive mechanisms, and so forth. The term "light water reactor" then applies to the reactor vessel and contents in any light water nuclear reactor plant independent of the type of core installed (conventional PWR, seed-blanket, breeder. and so forth).

\section{Uniformly Enriched Core}

A "uniformly enriched core" is one in which, once an equilitrium cycle is attained, all fuel assemblies are essentially identical (with respect to size and number of fuel rods, fuel type, and enrichment) when initially installed in the core and have nearly the same burnup when discharged from the core.

\section{Region of the Conre}

A "region" of the core is a subvolume within the core defined by a set of imaginary boundary surfaces. A "region" may actually consist of a number of unconnected eubvolume3. For example, suppose that in a core every tenth module is of a certain type-say Type $A$-and that these Type $A$ modules are uniformly distributed over the core. Then it is possible to define a Type $A$ region which consists of the aggregate of all Type A modules.

\section{Multiplication Factor, K, of a Region}

Suppose that during some short interval of core operation one could keep track of two types of neutron events in a region, namely, the number of neutrons born in fission and the number of neutrons disappearing because of capture in nuclei (both fuel and non-fuel) within the region. The ratio of the number of neutrons born to the number of neutrons captured is defined to be the "multiplication factor, $\mathrm{K}$, of the region." In a core operating at constant power the $\mathrm{K}$ of the core (considered as a single region which includes all reflectors and thermal shields) has a constant value of 1.0. However, the $\mathrm{K}$ value of any smaller region within the core generally changes with time as fuel is consumed, as fission product poisons build up, and as control poisons are inserted or removed.

\section{Reactivity and Criticality}

"Reactivity" of a region is defined here in terms of the multiplication factor $K$ as follows: reactivity $=(K-1) / K$. Reactivity can be positive or negative. Positive values of reactivity are sometimes called 
excess reactivity. The reactivity of a core operating at constant power is zero; that is, $K$ is equal to unity. When the reactivity of a core is zero, the core is said to be critical or in a state of "criticality."

When a core has been depleted to such a point that further operation will result in the core value of $K$ dropping below unity, or the reactivity becoming negative, then the core is said to have reached the end of reactivity life; or it is no longer possible to maintain criticality.

The reactivity worth of a control system (control poisons or movable fuel) is a calculated number. It is defined here as the difference in calculated $\mathrm{K}$ values for the core with the control system in its two most extreme configurations, one producing the highest value of $K$ (for example, control rods fully withdrawn and soluble poison completely removed) and the other producing the lowest value of $K$.

\section{Excess Neutrons}

When a region has a $\mathrm{K}$ greater than 1.0 , or a reactivity greater than zero, it produces more neutrons than it captures. The difference between the number of neutrons produced and the number of neutrons captured over some interval of time is the number of "excess neutrons." For a region with $\mathrm{K}$ less than 1.0, the number of excess neutrons will be negative.

\section{Seed Region}

A "seed region" is one for which the value of $K$ is greater than unity at the start of irradiation. For this initial value of $K$ to be greater than unity in a light water reactor requires that the fuel be enriched in the isotope $U-235$. Enrichments in the range of 5 percent to 93 percent are considered in this report. During core operation the value of $\mathrm{K}$ for a seed region will decrease and eventually may decrease below unity; however, the region will still be called a seed region.

\section{Blanket Region}

A "blanket region" is one for which the value of $\mathrm{K}$ is smaller than unity at the start of irradiation. For the types of blanket regions considered in this report the value of $\mathrm{K}$ never increases above unity. The blankets considered here, which contain relatively little or no uranium-235, are natural uranium, depleted uranium (enrichment plant tails containing 0.2 percent uranium-235), natural thorium, and spiked thorium (natural thorium containing a small amount of enriched uranium).

\section{Seed and Blanket Composition Parameters}

These parameters define the geometry and material inventory of a seed or blanket region at the start of irradiation. These parameters include fuel rod diameter; clad composition and thickness; fuel system composition, density and enrichment; and fuel-to-coolant ratio.

\section{Burnup}

The "burnup" of a region is a measure of how much energy has been produced in the region. The units for burnup are megawatt-days/metric-ton (MWD/MT) where the "metric tons" are of heavy metal (uranium or thorium). Since energy production comes from fission events, which also produce 
neutrons, burnup is also a measure of fissions per metric ton and neutrons produced per metric ton. At a given enrichment and fuel type, it is also a measure of fission density, $f / c c$. The relationships between these quantities are discussed in detail in Appendix $B$.

\section{Control Poisons}

During operation of a conventional core, the inventory of fissile atoms in the core decreases and the inventory of fission product atoms increases. These effects tend to reduce the core $K$. To compensate for these effects and maintain a core $K$ of unity, or a reactivity of zero, poison must be removed from the core. This removal can be accomplished in whole or in part by any or all of the following: withdrawal of control rods, reduction in the concentration of soluble boron in the coolant, or burnup of fixed burnable poisons. Any poison related to reactivity control (maintaining a reactivity of zero) during core operation is called a "control poison."

\section{Movable Fuel Reactivity Control}

In the LWBR core, no control poisons are used during normal core operation. 7ern reactivity is maintained by lifting or lowering seed fuel assemblies, thereby adjusting the relative rates at which neutrons are captured in fissile and fertile nuclides.

\section{Reactivity Shim}

The use of control poison or movable fuel to maintain a zero level of the core reactivity during operation at power is referred to as "reactivity shim."

\section{Shutdown Reactivity and Shutdown Rods}

When a light water core operating at power is to be shut down, the reactivity must be reduced to a value less than zero; this value is called the "shutdown reactivity." The reduction in reactivity must compensate for reactivity increases caused by the shutdown. Reactivity is increased both by decreasing the power and by decreasing the temperature. In addition, radioactive decay of certain fission product nuclides following shutdown increases reactivity. In current commercial light water cores these effects are compensated by inserting soluble boron or poison control rods (referred to as "shutdown rods"). In the LWBR core this compensation is provided entirely by movable fuel, In any other seed-blanket core with movable fuel, either soluble boron, shutdown rods, movable fuel, or a combination of these could be used to provide the reactivity compensation.

\section{Seed-Blanket Core}

A "seed-blanket core" is a core containing seed regions and blanket regions. All the seed regions may be conceptually lumped together and referred to simply as "the seed." Similarly, the blanket regions may be referred to as "the blanket."

\section{Neutron Losses}

In any core, all neutrons born in fission events are eventually captured in various nuclides. Some of the captures occur in fissile nuclides, destroying the fissile nuclides while producing energy and 
additional neutrons. Some of the captures occur in fertile nuclides, which subsequently undergo radioactive decay and become fissile nuclides. Some of the captures occur in fission products, structure, and moderator. Finally, some of the captures occur in control poisons and in materials external to the core. Capture in materials external to the core are referred to as neutron leakage. Capture in control poisons and through leakage are referred to as neutron losses. The objective of improving fuel utilization is synonymous with the objective of minimizing neutron losses by designing a core in such a way that neutrons which would normally be lost are instead captured in fertile nuclides.

\section{Floating Eigenvalue Calculations}

In many calculations of the neutron flux in a multiplying medium, the capture rate of neutrons is not equal to the production rate because the materials inventory has not been adjusted to achieve this neutron balance. To be able to perform such calculations the neutron production rate is adjusted by dividing by a number - the eigenvalue-which makes the adjusted production rate equal to the capture rate. In a depletion calculation where the materials inventory is not adjusted to achieve neutron balance, the eigenvalue changes as the fuel materials deplete. Such a calculation is called a "floating eigenvalue calculation." 
APPENDIX A

FUEL UTILIZATION CALCULATIONS 
TABLE OF CONTENTS

II. FUEL UTILIZATION CALCULATIONS FOR UNIFORMLY ENRICHED CORES

A. Background

B. Calculations

1. Background

A-3

2. Calculations With Fixed Enrichment

A-4

3. Calculations With Variable Enrichment

IV. FUEL UTILIZATION IN SEED-BLANKET CORES ESTIMATED FROM POINT DEPLETION CALCULATIONS

A. Introduction

B. Fuel Utilization Estimates

1. Base Case Parameters With No Burnup Constraints

A-9

2. Sensitivity Calculations

A-9

3. Constraints on Burnup

A-11

4. Summary

V. NEUTRON LOSSES
A. Typical PWR Neutron Losses
B. PWR With a Radial Blanket
C. Axial Reflecting Blanket
D. Overall Neutron Loss and Non-Uniform Burnup Effects

A-13

A-13

A-14

A-15

VI. RULES OF THUMB FOR FIUFI. UTILIZATION

\section{LIST OF TABLES}

\section{Table}

Title

Page

A-1 Composition Parameters for Seeds and Uniform Enrichment Cores $\quad$ A-17

A-2 Fuel Utilization Dependence on Fuel Rod Diameter, Hydrogen to Heavy Metal 


\section{LIST OF TABLES (Cont)}

A-3 Fuel Utilization Dependence on Uranium-235 Content, Uniformly Enriched

A-19 Cores

A-4 Composition Parameters for Blankets A-20

A-5 Fuel Utilization for Seed-Blanket Cell Calculations $\quad$ A-21

A-6 Peak Fuel Utilization Summary; Point Depletion Calculations $\quad$ A-22

A-7 Neutron Losses in a Large (3800 Mw(th)) PWR $\quad$ A-27

\section{LIST OF FIGURES}

A-1 Fuel Utilization Dependence on Power Density $\quad$ A-28

A-2 Fuel Utilization Dependence on Power Density $\quad$ A-29

A-3 Fuel Utilization Dependence on Hydrogen to Heavy Metal Atom Ratio

A-4 Fuel Utilization Dependence on Uranium-235 Content

A-5 Fuel Utilization Dependence on Uranium-235 Content

A-6 Fuel Utilization Dependence on Maximum Burnup Achievable

A-7 Fuel Utilization Dependence on Maximum Average Burnup Achievable

A-8 Change in Fuel Utilization Due to Effect of Power Density on Fractionn nf r.are Refueled at Annual Refueling

A-9 $\quad \mathrm{U}_{3} \mathrm{O}_{8}$ and Separative Work Investment Schedule to Support a $1000 \mathrm{MWe}$ PWR

A-10 Fuel Utilization, Sensitivity to Seed and Blanket Average Burnup

A-1 1 Fuel Utilization, Sensitivity to Seed and Blanket Average Burnup 


\section{LIST OF FIGURES (Cont)}

Figure

Title

Page

A-13 Peak Fuel Utilization Dependence on Seed Hydrogen to Heavy Metal Atom Ratio

A-40

A-14 Fuel Utilization Dependence on Blanket Power Density

$A-41$

A-15 Fuel Utilization Dependence on Seed Burnup and Enrichment

A-42

A-16 Fuel Utilization Dependence on Seed Burnup and Enrichment

$A-43$

A-17 Fuel Utilization Dependence on Seed Average Burnup and Enrichment

A-44

A-18 Fuel Utilization Dependence on Seed and Blanket Average Burnup

A-45

A-19

Conversion of Commercial Design to More Fuel Conservative Once-Through

A-46 


\section{APPENDIX A-FUEL UTILIZATION CALCULATIONS}

\section{INTRODUCTION}

This appendix presents the results of fuel utilization calculations for uniformly enriched cores and seed-blanket cores for a variety of composition parameters and seed and blanket variables. The composition parameters are enrichment, metal-to-water ratio, relative uranium and thorium content, and fuel rod diameter. The seed and blanket variables are seed radius, seed volume fraction, and relative seed and blanket burnup. The calculations include both seed-blanket radial geometry cell calculations, point depletion calculations on seed compositions and blanket compositions, and the simulation of uniformly enriched reactors with soluble boron reactivity control. The effect of neutron losses to leakage and control poisons and the effects of non-uniform seed burnup are also considered. The terminology used is defined in the glossary. All calculations of fuel utilization assume an enrichment plant tails assay of 0.2 percent uranium-235 in uranium.

Section II of this appendix presents the results of floating eigenvalue point depletion calculations which simulate the operation of a uniformly enriched core. Section III presents the results of floating eigenvalue seed-blanket cell calculations which simulate the operation of a core consisting of a collection of such cells. In Section IV the results of floating eigenvalue point depletion calculations on seed compositions and on blanket compositions are combined so as to simulate the operation of a seed-blanket core. Section $V$ considers neutron losses, which play a major role in determining fuel utilization in any core. Section VI presents some useful rules of thumb regarding fuel utilization.

The principal conclusions resulting from the data in this appendix are as follows:

1. For light water reactors the fuel utilization achievable from any fuel system and any core configuration depends on the neutron losses and on the burnup limits placed on the fuel.

2. To achieve a fuel utilization greater than the 11.5-12.0 MWYth/ST $\mathrm{U}_{3} \mathrm{O}_{8}$ provided by current commercial light water reactors would require the following improvements relative to current commercial light water reactors:

a. A decrease in neutron losses

b. An increase in limits on fuel burnup.

3. In a conventional core, neutron losses could be reduced and fuel utilization could be increased by decreasing the fraction of the core replaced at each refueling. This could be accomplished in one or more of the following ways:

a. Increase fuel enrichment

b. Decrease time between refuelings

c. Operate at reduced power density. 
4. Neutron losses could also be reduced through the use of reflecting blankets, and through movable fuel reactivity control which would most readily be applied in a seed-blanket type of reactor.

5. For a reasonably optimistic neutron loss fraction of 3 percent (judged to be achievable in a practical seed-blanket core with movable fuel reactivity control), a fuel utilization of about $17 \mathrm{MWYth} / \mathrm{ST} \mathrm{U}_{3} \mathrm{O}_{8}$ could be achieved. This fuel utilization could be obtained using a variety of fuel types, including natural uranium and thorium blankets, slightly or highly enriched uranium seeds, or seeds containing both thorium and highly enriched uranium. The maximum burnups required to achieve peak fuel utilization would depend on the fuel types and enrichments.

6. The achievement of a fuel utilization of $17 \mathrm{MWYth} / \mathrm{ST} \mathrm{U}_{3} \mathrm{O}_{8}$ would require an average seed burnup of at least $60,000 \mathrm{MWD} / \mathrm{MT}$.

7. The chief advantage of using a thorium blanket would probably lle In the area of permittlng the achievement of movable fuel reactivity control with a minimum of complexity in the core design.

8. If neutron losses could be eliminated completely, the maximum fuel utilization would be about $19 \mathrm{MWYth} / \mathrm{ST} \mathrm{U}_{3} \mathrm{O}_{8}$. This limit applies to a variety of fuel types, including natural uranium and thorium blankets, slightly or highly enriched uranium seeds, or seeds containing thorium and highly enriched uranium.

With the exception of movable fuel reactivity control, many of the methods discussed here for improving fuel utilization are also being studied by commercial industry (as reported in References $A-1, A-2$, and $A-3$ ). The reported improvement in fuel utilization is consistent with the improvement that would be predicted by the calculational methods presented here.

\section{FUEL UTILIZATION CALCULATIONS FOR UNIFORMLY ENRICHED CORES}

\section{A. Background}

Current conventional light water cores use a fuel management scheme in which approximately one-fourth to one-third of the core is replaced each year; the most highly depleted fuel modules are replaced with fresh fuel modules. Once an equilibrium or a near equilibrium fuel cycle has been established, all fresh modules have the same fuel composition, and all discharged modules have very nearly the same burnup. The once-through fuel utilization of such a system is determined by the amount of $\mathrm{U}_{3} \mathrm{O}_{8}$ required to supply the fuel for a typical module, and by the amount of energy which has been obtained from the module at the time of discharge. Because of this, it is possible to estimate the fuel utilization of such a core by means of a point depletion calculation on a typical module. Such a calculation simulates the depletion history of the module from the time of insertion in the reactor to the time of removal. (Sections IV and VII of Appendix B discuss the use of point depletion calculations to simulate the operation of a full core.) Point depletion calculations have been made for a variety of fuel composition parameters. The fuel utilization estimates obtained from these calculations are presented in this section.

The fuel utilization estimates depend on the assumed neutron losses. Neutron losses are discussed in detail in Section $V$ of this appendix. There are two cases of interest identified in Section V; these are neutron losses of 8 percent (comparable with present conventional light water cores) and 
4 percent (comparable with what is considered achievable with modifications in core size and refueling strategy). In addition, the case of no neutron losses is of interest as a reference point.

The principal results of these uniformly enriched calculations are that for neutron losses of zero, 4 , and 8 percent, the respective maximum fuel utilization values are approximately 19, 16, and $13 \mathrm{MWYth} / \mathrm{ST} \mathrm{U}_{3} \mathrm{O}_{8}$. These values are for fuel region parameters (such as fuel rod diameter and pitch and power density) which are similar to those in current commercial pressurized light water reactors; however, the fuel utilization is found to be insensitive to variations in these parameters.

\section{B. Calculations}

\section{Background}

The fuel composition parameters used in the point depletion calculations for uniformly enriched cores are presented in Table A-1. This table gives the base case parameters and the variations from the base case. These variations were all made individually; the effects of making two or more variations simultaneously were not examined. It is expected, however, that the effect of combined variations would approximately equal the sum of the effects of individual variations. In some compositions, for example, 1, 2, 3, and 5, the fuel rod outer diameter, clad thickness, and pellet diameter were identical with those in a reference PWR core (Reference A-4). In addition, the ratio of coolant area to heavy metal area in these compositions was identical with the corresponding ratio over an entire module of the reference core. Thus, the point depletion calculations on these compositions are representative of the operation of a fuel region having the geometry of the reference core. In compositions 4,6 , and 7 the fuel rod diameter was decreased, and the ratio of coolant area to heavy metal area was increased relative to the values in the remaining compositions. The resulting composition parameters represent a seed region with a thermal capability which is theoretically higher than that of the reference PWR core. Such an increase in seed thermal capability would be necessary if a seedblanket core were to replace a conventional core in a given pressure vessel while maintaining similar power capability. In compositions 6,7 , and 8 , where the fuel is $\mathrm{UO}_{2}$ and the enrichment of uranium235 in uranium is greater than 5 percent, the fuel was diluted with $\mathrm{ZrO}_{2}$ to keep the uranium-235- $\mathrm{O}_{2}$ content to 5 percent of the fuel pellet volume. As noted in Section IV of the main text, such dilution would be required to assure that the peak accumulated fission density $(\mathrm{f} / \mathrm{cc}$ ) would be acceptable. The use of 5 percent uranium $-235-\mathrm{O}_{2}$ by volume is judged to provide a limit on accumulated fission density which is consistent with potential improvements in current fuel element technology.

Compositions $10,11,13$, and 14 consist mainly of thorium oxide with the content of uranium-235 in heavy metal being greater than 5 percent. Two important features of this fuel are:

1. This fuel was not diluted with $\mathrm{ZrO}_{2}$.

2. In a light water reactor, the uranium-233 produced from the thorium is a better fuel, with respect to neutron utllization, thair uranium-235.

If limits on fission density (related to mechanical integrity of the fuel rods) are disregarded and only neutron economy is considered in a depletion calculation, then both of these features contribute to these fuels having very high potential burnups. These high burnups would yield high values of fission 
density in the absence of dilution with $\mathrm{ZrO}_{2}$. Although there is some evidence that thorium oxide fuel may be capable of withstanding a higher fission density than uranium oxide fuel, the practical limits on fission density are not known today.

The results of the calculations are grouped into two sets. In the first set, the enrichment, that is, the ratio of uranium-235-to-uranium (and to thorium if present), is fixed. Power density and the remaining composition parameters, namely, hydrogen-to-heavy metal atom ratio (H/HM ratio) and fuel rod diameter are variables. The results of these calculations are presented in Table A-2 and in Figures A-1 through A-3.

In the second set, the fuel region geometry and power density are fixed, but the ratio of uranium235-to-total heavy metal is a variable. The results for this second set are presented in Table A-3 and in Figures A-4 through A-7. In these and all subsequent tables wherever burnup ia liated, the values of $f / c c$ are also listed. The uranium fuels with 10. 20 or 9.3 perreent enrichment have very high burnups, but when they are diluted with $\mathrm{ZrO}_{2}$ their $t / c c$ values are comparable with the 5 percent enrichment fuel.

\section{Calculations With Fixed Enrichment}

The results of the first set of calculations show that with fixed neutron losses, and except for the effect of power density in thorium-uranium fuel, fuel utilization depends only slightly on the power density and the composition parameters considered. Further, the dependence is essentially the same for no neutron losses and 4 percent neutron losses.

For the $\mathrm{UO}_{2}$ fuel with an enrichment of 5 percent, the maximum fuel utilization occurs at a hydrogen-to-heavy metal $(\mathrm{H} / \mathrm{HM})$ atom ratin of ahnut 4.2 . However, over the range of 3.5 to 5.5 in values of this ratio, the fuel utilization varies by only 3 percent. Increasing fuel rod diameter also slightly increases fuel utilization. This increase is attributable to an increasing fast fissinn rate in the uranium-238. As the fuel rod diameter increases the probability increases for a fast ncutron born in a fuel rod to collide with a uranium-238 nucleus before leaving the rod. The larger rod also has a higher resonance escape probability. These effects increase the multiplication factor of the fuel region.

Fuel utilization also increases as power density decreases. For the $\mathrm{UO}_{2}$ fuel this effect is quite small; a decrease in power density from $40 \mathrm{kw} / \mathrm{kg}$ to $20 \mathrm{kw} / \mathrm{kg}$ increases the fuel utilization by lese than 4 percent with no neutron losses, and by less than 3 percent with 4 percent neutron losses. For the $\mathrm{ThO}_{2}$ fuel the effect is larger; the same decrease in power density increases the fuel utilization by close to 8 percent for both no neutron losses and 4 percent neutron losses. This large effect is attributed to neutron capture in protactinium-233. Some of the protactinium-233 atoms, which in a very low neutron flux would have beta decayed (with a half-life of 27 days) to uranium-233, are converted instead to protactinium-234 which beta decays to non-fissile uranium-234.

The relative insensitivity of fuel utilization to composition parameters and power density indicates that in designing a once-through reactor to achieve optimum fuel utilization, small adjustments in fuel rod diameter, metal-to-water ratio, and power density made to achieve acceptable thermal performance would not significantly impact on fuel utilization. 


\section{Calculations With Variable Enrichment}

The results of the second set of calculations are presented in Figures A-4 and A-5. These figures illustrate how the fuel utilization predicted for a uniformly enriched reactor depends on the relative content of uranium-235 in heavy metal.

Figure A-4 indicates the potential for improved fuel utilization in current pressurized light water cores with no changes in geometry, reactivity control method, or refueling strategy to reduce neutron losses. Neutron losses in such current cores are about 8 percent. As shown in Figure A-4, it appears that with neutron losses of about 8 percent the use of fuel with an enrichment of slightly less than 4 percent could yield a fuel utilization slightly greater than $13 \mathrm{MWYth} / \mathrm{ST} \mathrm{U}_{3} \mathrm{O}_{8}$. This would be about an 11 percent improvement over current fuel utilization values. To obtain a fuel utilization of $13 \mathrm{MWYth} / \mathrm{ST} \mathrm{U}_{3} \mathrm{O}_{8}$ from fuel with 4 percent enrichment would require an average burnup of about 45,000 MWD/MT.

Figure A-4 also indicates the potential for improved fuel utilization if the neutron losses could be reduced to 4 percent. It appears that at enrichments as low as 3.5 percent to 4 percent the fuel utilization could be increased to 15.5 to $16 \mathrm{MWYth} / \mathrm{ST} \mathrm{U}_{3} \mathrm{O}_{8}$. The burnup required would be between 47,000 and 57,000 MWD/MT.

At this point it should be noted that for a uniformly enriched core with poison control there is an interaction between enrichment and neutron losses. If the refueling schedule is fixed (for example, once a year), then as the enrichment increases the fraction of the core replaced at each refueling decreases and neutron losses also decrease. This point is illustrated in Appendix $B$ by fuel management calculations on uniformly enriched cores.

Figures A-4 and A-5 also indicate that the peak fuel utilization achievable in a uniformly enriched reactor is about the same for uranium fuel as for thorium-uranium fuel. (The peak fuel utilization for the thorium-uranium fuel is calculated to be slightly lower.) However, for the thorium-uranium fuel a burnup of over $80,000 \mathrm{MWD} / \mathrm{MT}$ would be required before the peak fuel utilization would be comparable with that from uranium fuel. It should be noted at this point that the thorium-uranium fuel considered in the calculations consisted of 93 percent enriched uranium in thorium. There are some who consider the use of 93 percent enriched uranium prejudicial to proliferation resistance. However, this fuel system has been considered here because it is a realistic technical alternative and provides a bound on the performance of $\mathrm{ThO}_{2}-\mathrm{UO}_{2}$ systems. At a given content of uranium-235 in heavy metal (for example, 8 percent), the fuel consisting of 20 percent enriched uranium in thorium has characteristic behavior which is intermediate between that of the uranium fuel and the thorium 93 percent enriched uranium fuel.

Another interesting observation is that the mathematical treatment of the neutron economy in these point depletion calculations indicates that, at a given neutron loss fraction, the peak fuel utilization values are about the same as those obtained from the seed-blanket cores discussed in later sections. These peak fuel utilization values are about $19 \mathrm{MWYth} / \mathrm{ST} \mathrm{U}_{3} \mathrm{O}_{8}$ with no neutron losses and about $16 \mathrm{MWYth} / \mathrm{ST} \mathrm{U}_{3} \mathrm{O}_{8}$ with 4 percent neutron losses. However, it must be noted that in a uniformly enriched light water core, maintaining reactivity control during depletion without significant neutron losses to control poisons would require nearly continuous refueling. A uniformly enriched core 
operating with annual refueling would use poison reactivity shim control and the resulting neutron losses would adversely affect the fuel utilization. It is judged unlikely that the neutron losses to control poison in a uniformly enriched core could be kept below 2 percent. This points up the essential feature of a movable fuel-controlled seed-blanket core with respect to improving fuel utilization, namely, that reactivity control could be achieved by absorbing excess neutrons in fertile material rather than in control poisons.

Two comments are appropriate on the burnup values in Table A-3 and in Figures A-6 and A-7. The first concerns the fisson density in the 10 percent enriched $\mathrm{UO}_{2}$. Because this fuel is diluted with 50 volume percent $\mathrm{ZrO}_{2}$, the fission density at a given burnup is the same as the fission density in undiluted fuel at half the burnup. For example, in the 10 percent enriched fuel at a burnup of $135,000 \mathrm{MWD} / \mathrm{MT}$, the fission density would be the same as that in the 3 percent or 5 percent enriched fuel at a burnup of 67,500 MWD/MT. The second comment concerns the high values of the burnup (Figure A-7) required to achieve peak fuel utilization with 4 percent or higher neutron losses. Average burnups on the order of $33,000 \mathrm{MWD} / \mathrm{MT}$ are charecteristir. nf rurrent convontional light water cores which use $\mathrm{UO}_{2}$ fuel. Fuel development effort could probably demonstrate capability for withstanding higher burnups.

The Department of Energy, in cooperation with industry, is conducting an extensive program to develop and demonstrate light water reactor fuels with higher burnup capability. However, the practical limits on burnup are not known today.

An additional comment is appropriate on the observation that for a given neutron loss fraction, the peak fuel utilization achievable from a uniformly enriched core is almost the same as that for a seedblanket core. This result is not surprising if one views a seed-blanket core as simply a spatial rearrangement of the materials, including fuel and fission products, from a uniformly enriched core. Furthermore, It has already been noted that for a uniformly enriched core. the peak fuel utilization achievable is relatively insensitive to the metal-to-water ratio and to the fuel rod diameter. Hence, even if the average values of these composition parameters for a seed-blanket core are not the $3 a m e$ as for a uniformly enriched core, it might still be expected that theoretically, approximately the sama peak fuel utilization would be achievable from both cores in the absence of constraints such as burnup limits and the need to maintain reactivity control.

The next point for discussion is the interartion between tho oporation of a uniformly ellu iclied cure at reduced power density, the associated changes in refueling strategy, and the effect on neutron losses and fuel utilization. This is an important point because it is expected that a practical seedblanket core would have a lower core average power density than a uniformly enriched core. If low power density seed-blanket cores were being considered as replacement for conventional cores because of their improved fuel utilization, then it would be important to consider the lut ulilizatlon which could be achieved by a conventional core operating at a low power density. It turns out that for a uniformly enriched core where the fuel has a fixed enrichment and the core is partially refueled at fixed intervals, there is a potential gain in fuel utilization when the core is operated at a reduced power density with no changes in enrichment or fuel-to-coolant ratio. The potential gain in fuel utilization from decreased power density operation comes from two components. 
The first component is the gain due to the reduction in capture rates in fission products and the neptunium-239 and/or protactinium-233 relative to the capture rate in fuel. The effect of this component is seen in Figure A-1. For the 3 percent enrichment uranium, a factor of 2 reduction in power density increases fuel utilization by about 3 percent. This component will be referred to as the "relative capture rate component." Another small effect which has not been included in these calculations is change in fuel temperature. The power density sensitivity calculations were run at a fixed fuel temperature, corresponding to the nominal power density. If a given core were actually operated at reduced power density, the fuel temperature would also be reduced. This would have a small effect on the neutron economy becuase of the so-called Doppler effect, whereby as the fuel temperature in a given fuel region decreases, the neutron capture rate in fertile atoms decreases relative to that in fissile atoms.

The second component is a gain due to the reduction in fractional fuel depletion between refuelings, because the refuelings take place at fixed intervals, for example, once a year. A simple way of viewing this second component is that the refueling strategy approaches closer to continuous refueling. This reduces neutron losses to control poisons and thereby increases fuel utilization. This second component will be called the "refueling strategy component." The methods described in Section III.C of Appendix $B$ have been used to estimate the size of this second component. (Reference A-5 also presents a discussion of this effect.) The results are shown in Figure A-8; it is observed that a factor of 2 decrease in power density increases fuel utilization by about 16 percent. Combining the two components, it is estimated that a factor of 2 decrease in power density could increase fuel utilization by about 20 percent. For current conventional cores this would increase fuel utilization from approximately $11.7 \mathrm{MWY}$ th/ST $\mathrm{U}_{3} \mathrm{O}_{8}$ to about $14 \mathrm{MWY}$ th/ST $\mathrm{U}_{3} \mathrm{O}_{8}$.

With regard to reduced power density in a conventional core, it should be noted that the benefit of increased fuel utilization would be obtained at the cost of an increase in the short-term commitment of $\mathrm{U}_{3} \mathrm{O}_{8}$ relative to current cores. Consider, for example, a reactor plant with a specified generating capacity and a conventional core. The core size and power density are assumed to be variable within the constraint that the rated heat output is fixed. Fuel enrichment and fuel-to-coolant ratio are also fixed. As the power density would decrease, the core size and loading would increase and the amount of $\mathrm{U}_{3} \mathrm{O}_{8}$ required to fuel the first core would increase. This increase would be offset over the course of time by the decrease in annual $\mathrm{U}_{3} \mathrm{O}_{8}$ requirement. The separative work and fabrication requirements would behave in the same way.

The change in initial investment and cumulative requirement is illustrated in Figure A-9. It is assumed that with operation at half power density the annual $U_{3} \mathrm{O}_{8}$ and separative work requirements are 80 percent of the requirement for operation at full power density. This figure indicates that within 10 to 11 years the total amount of $\mathrm{U}_{3} \mathrm{O}_{8}$ and separative work required becomes equal for the two levels of power density. By the end of 30 years with operation at half power density, the cumulative $\mathrm{U}_{3} \mathrm{O}_{8}$ and separative work requirements are about 86 to 87 percent of the requirements for operation at full power density.

In addition to the 30-year savings indicated in Figure A-9, there would be additional potential savings whir.h rnuld be obtained by continued use of the partially spent fuel remaining in the cores. At the end of the 30-year period of operation in this figure, the PWR operating with normal power density would have an inventory of about $54 \mathrm{MT}$ (about $2 / 3$ of a core) of partially spent fuel, while the 
PWR operating with half normal power density would have an inventory of about 135 MT (about 5/6 of a core) of partially spent fuel. Thus, much of the initial added investment for the low power density core would still be available for the production of energy, for example, by pooling the partially spent fuel from several cores.

The final point of discussion is the estimate of the peak fuel utilization which could be obtained from a uniformly enriched core with optimum enrichment and operating at 50 percent of normal power density. It is assumed that in such a reactor the neutron economy would be such that the curve for 4 percent losses in Figure A-4 would apply. From this curve it is inferred that at an enrichment close to 3.5 percent, the achievable fuel utilization would be almost $0.5 \mathrm{MWYth} / \mathrm{ST} \mathrm{U}_{3} \mathrm{O}_{8}$ greater than that achievable at 3 percent enrichment. Coupling this result with the one above for fuel utilization at 50 percent of normal power density ( $14 \mathrm{MWYth} / \mathrm{ST} \mathrm{U}_{3} \mathrm{O}_{8}$ ), it is concluded that at 50 percent of normal power density a fuel utilization of nearly $14.5 \mathrm{MWYth} / \mathrm{ST} \mathrm{U}_{3} \mathrm{O}_{\mathrm{g}}$ could be aohieved in a unce-through unlformly enriched core with a fuel enrichment of about 3.5 percent and soluble poioon control. The avei aye burnup réquired would be ahnıt 44,000 MWD/MT.

\section{TWO-DIMENSIONAL SEED-BLANKET CELL CALCULATIONS}

This section describes the results of a series of two-dimensional seed-blanket cell calculations which were made to identify the effects of seed-blanket geometry details and to obtain a oet of reference points for the analytic calculations described in Section IV. Basically, these seed-blanket cell calculations establish how the neutron economy is affected by blanket type, seed radius, and incore seed volume fraction for an ideal seed-blanket core in which no neutrons are lost to leakage or control poison. In these cell calculations, the seed was represented as an axially uniform homogeneous cylinder completely surrounded by an axially uniform and homogeneous blanket in the form of an annulus. Calculations were made using a variety of seen enrichments; however, all seeds liad a hydrogen-to-uranium atom ratio of 3.0. For the blankets, the hydrogen-to-heavy metal atom ratio was also 3.0. The blanket composition parameters are presented in Table A-4; the calculational methods are descrlbed briefly in Appendix B, Section VI. The spatial-depletion calculations were made as eigenvalue calculations with the end of reactivity life being defined as the point at which the net number of excess neutrons which had been produced by the seed was equal to the net number of excess neutrons which had been captured by the blanket. At this point, the net number of excess neutrons produced by the entire cell was zero. It is shown in Section VII of Appendix B that with this definition of end of reactivity life, the cell calculations simulated the operation of a core with a combination of movable fuel reactivity control and fuel management, and no neutron losses.

The results of these calculations are presented in Table A-5. These results, especially for cells 1,2, and 3 , are evidence that high fuel utilization values can actually be attained in seed-blanket geometry. These results are also used in Section IV of Appendix B as the basis for demonstrating that point depletion calculations on seed compositions and on blanket compositions can be used, as they are used in the following section, to give reliable estimates of the fuel utilization achievable in seedblanket geometry. 


\section{FUEL UTILIZATION IN SEED-BLANKET CORES ESTIMATED FROM POINT DEPLETION CALCULATIONS}

\section{A. Introduction}

In the course of the investigations into seed-blanket core performance it has been found that given a pair of seed and blanket compositions, the fuel utilization attainable subject to various constraints, and the corresponding lifetime average seed and blanket power fractions can be estimated with good accuracy from point depletion calculations on seed and blanket compositions, without the need for spatial calculations on seed-blanket geometry. This finding indicated that it is possible to analytically estimate the peak fuel utilization obtainable from a given set of seed and blanket compositions. All that is needed is a simple functional relationship between the energy produced in each composition (seed and blanket) and the neutron economy in that composition. This functional relationship is provided in numerical form by the point depletion calculations. This section presents the results for typical seed and blanket combinations. The mathematics of the method for finding the peak fuel utilization and the justification for using point depletion calculations are presented in Appendix $B$.

It can be concluded that for a given neutron loss fraction, the theoretically achievable peak fuel utilization values from a variety of fuel types fall into a relatively narrow range. These fuel types include natural uranium and thorium blankets, slightly or highly enriched uranium seeds, or seeds containing thorium and highly enriched uranium. The maximum burnups required to achieve peak fuel utilization would depend on the fuel types. It is concluded that to obtain a fuel utilization of $17 \mathrm{MWYth} / \mathrm{ST} \mathrm{U}_{3} \mathrm{O}_{8}$ with 3 percent neutron losses would require a seed average burnup of over $50,000 \mathrm{MWD} / \mathrm{MT}$. By themselves these results would not indicate any advantage to the use of thorium fuel; however, the core complexity associated with achieving movable fuel reactivity control would also depend on the fuel types. It is judged that the use of a thorium blanket with a uranium seed would permit movable fuel reactivity control with only moderate added core complexity relative to current commercial light water cores.

\section{B. Fuel Utilization Estimates}

\section{Base Case Parameters With No Burnup Constraints}

Parts 1 and 2 of Table A- 6 present the estimated peak fuel utilization from seed-blariket cores with and without neutron losses for a variety of seed and blanket combinations, assuming that there are no constraints due to limits on fission density (or equivalently on burnup). The methods for determining the peak fuel utilization are presented in Section III of Appendix B. The seed and blanket composition parameters are listed in Tables A-1 and A-4. The peak fuel utilization yalues with no neutron losses, in rart 1 of Table $A=6$, are academic because it appears impractical to design a reactor for no neutron losses. These fuel utilization values, which range from about 17 to $19 \mathrm{MWYth} / \mathrm{s}^{\prime} \mathrm{U}_{3} \bar{U}_{8}$, Indleale the fuel utilization upper limit, without realistic constraints on neutron losses. For more realistic neutron losses of 4 percent the peak fuel utilization values in Part 2 of Table A-6 are all in the range of 15 to $16 \mathrm{MWYth} / \mathrm{ST} \mathrm{U}_{3} \mathrm{O}_{8}$. These results indicate that for realistic neutron losses of 3 percent, all four blanket types (natural or depleted uianium, natural or spik.ed thnrium) and the entire range of 5 to 93 percent uranium enrlchment in the seed would give a peak fuel utilization close to $17 \mathrm{MWY}$ th/ST $\mathrm{U}_{3} \mathrm{O}_{8}$. provided that the required burnup could be achieved. 
Each value of fuel utilization in Part 1 of Table A-6 corresponds to particular values of seed burnup and blanket burnup. (Burnup values are not listed in Part 2 of Table A-6 because, as is shown in Section III.B of Appendix B, the burnup values which give the peak fuel utilization when there are no neutron losses also give the peak fuel utilization when there are neutron losses.) These burnup values depend strongly on the fuel type. However, one of the useful features of a seed-blanket core is that the seed and blanket burnup can be varied independently in order to obtain acceptable thermal performance while still achieving good fuel utilization. To illustrate this point, the fuel utilization is presented in Figures A-10 and A-11 for a range of values of seed and blanket burnup for two of the seed-blanket combinations.

In Figures A-10 and A-11, the connecting link between seed burnup and blanket burnup is the net number of excess seed neutrons. The net number of excess neutrons produced by seed modules at the given seed burnup must equal the sum of the net number of neutrons which must be captured by the blanket modules to achieve the given blanket burnup, plus the number of neutrons lost to leakage or capture in control poisons. At a given seed and blanket burnup, this relationship determiries the long-term ratio MTB/MTS, where MTB represents the long-term metric tons of heavy metal loaded into blanket modules and MTS represents a similar quantity for the seed modules. It Is observed that the fuel utilization is very insensitive to seed and blanket average burnup. In fact, to display the sensitivity, or lack of it, the scale for the axis of ordinates, MWYth/ST $\mathrm{U}_{3} \mathrm{O}_{8}$, in Figures A-10 and A-11 is expanded by a factor of 5 relative to the corresponding 3cale for the other figures in this section. For example, the average burnup of the 5 percent enriched seed in Figure A-11 can be reduced from $65,000 \mathrm{MWD} / \mathrm{MT}$ to $60,000 \mathrm{MWD} / \mathrm{MT}$ with a loss of less than $0.1 \mathrm{MWY}$ th/ST $\mathrm{U}_{3} \mathrm{O}_{8}$, in fuel utilization.

The preceding result may seem surprising at first, since one might expect that as seed and blanket burnup both increase, the fuel utilization would also increase. However, the key to the explanation of the observed insensitivity is that the long term ratio of blariket loading to seed loading (MTB/MTS) decreases as either seed burnup or blanket burnup increases. One way of viewing this behavior is that the blanket is an inexpensive device for augmenting the energy produced by the seed; the blanket supplies energy at a low cost (relative to the seed) in terms of short tons of $\mathrm{U}_{3} \mathrm{O}_{8}$ required per MWD of energy produced. As the seed burnup increases, thereby tending to increase the fuel utilization, the net number of excess neutrons available to the blanket must decrease. The number of neutrons must decrease because of accumulating fission products in the seed, thereby decreasing the amount of blanket material which can be irradiated to a given burnup, and also tending to decrease the fuel utilization. These offsetting effects nearly cancel, so the fuel utilization remains essentially unchanged. To illustrate how this ratio (MTB/MTS) changes, the values of the ratio are shown in Figures $A-10$ and $A-11$ for several points on the fuel utilization curves.

An additional comment is necessary on the ratio MTB/MTS. In general, seed and blanket modules would not necessarily be irradiated for the same length of time (calendar days). Thus, the ratio of seed heavy metal-to-blanket heavy metal in the core at any time might be different from the ratio of seed heavy metal-to-blanket heavy metal loaded into the core over the long-term - say the entire reactor plant life. The ratio MTB/MTS represents a long-term average rather than a value based on the materials in the core at any time

As a final point, a common feature of all of the seed burnup values listed in Table A-6 is that they assume achievement of about 90 percent depletion of the uranium-235 initially present in the seed. This is discussed in more detail in Appendix B. 


\section{Sensitivity Calculations}

The results of the calculations with neutron losses in Part 2 of Table A-6, and of sensitivity calculations presented in Part 3 of Table A-6 and in Figures A-12 through A-14, are consistent with the results of the sensitivity calculations on the uniform enrichment cores. The effects of 4 percent neutron losses are to reduce the fuel utilization by approximately 2.5 to $3.5 \mathrm{MWYth} / \mathrm{ST} \mathrm{U}_{3} \mathrm{O}_{8}$ for both the seed-blanket cores and the uniform enrichment cores. For variations in power density and hydrogen-to-heavy metal ratio, the sensitivities in the seed-blanket combinations are smaller than those in the uniform enrichment reactors. This can be attributed to the variations in the seed-blanket combinations being made only in the seed, or only in the blanket, and therefore affecting only part of the material inventory of the combination.

\section{Constraints on Burnup}

It was noted earlier that the calculations presented above were made without any constraints on seed burnup or blanket burnup due to requirements of fuel element mechanical integrity. The average seed burnups at which the fuel utilization peaks (for example, 65,000 MWD/MT for the 5 percent enriched uranium seed and 100,000 MWD/MT for the thorium-uranium seed), are possibly beyond the limits which could be supported in the foreseeable future by improvements in fuel element technology. An additional consideration is that non-uniform power distributions would lead to peak burnups even higher than the average burnups. Acknowledging the likelihood of lower limits, additional calculations have been made in which the blanket average burnup is held fixed at a lower value $(30,000$ to $45,000 \mathrm{MWD} / \mathrm{MT}$ for natural uranium and 50,000 to $60,000 \mathrm{MWD} / \mathrm{MT}$ for natural thorium) and the seed average burnup is allowed to vary.

The results of these calculations are presented in Figures A-15 through A-18. These calculations are presented only for the uranium seeds because excessive burnups are required for the thoriumuranium seeds to achieve good fuel utilization, and only for the natural uranium and natural thorium blankets because the fuel utilization values for the other blankets have been found to be comparable to the values for the natural uranium and natural thorium blankets.

The uranium seeds with enrichment of 10 percent and 20 percent were diluted with $\mathrm{ZrO}_{2}$ to maintain 5 volume percent $U-235 \mathrm{O}_{2}$ in the fuel pellets. The axis of abscissas in Figures A-15 through A18 which is labeled " $\mathrm{f} / \mathrm{cc}$ " reflects the effect of this dilution on the relationship between burnup and fission density $\left(\mathrm{f} / \mathrm{cc}\right.$ ). For example, for the 10 percent enriched seed with 50 volume percent $\mathrm{ZrO}_{2}$, the fission density at a given burnup, that is, $13 \times 10^{20} \mathrm{f} / \mathrm{Cc}$ at $100,000 \mathrm{MWD} / \mathrm{MT}$, is the same as the fission density in undiluted seed fuel at one-half the burnup, that is, $13 \times 10^{20} \mathrm{f} / \mathrm{cc}$ at $50,000 \mathrm{MWD} / \mathrm{MT}$. Similarly, for the 20 percent enrichment seed with 75 volume percent $\mathrm{ZrO}_{2}$, the fission density at $200,000 \mathrm{MWD} / \mathrm{MT}$ would also be $13 \times 10^{20} \mathrm{f} / \mathrm{cc}$. On the assumption that limits on fission density (related to fuel element mechanical integrity) would be the same for all fuel enrichments, Figures A-15 through A-18 permit a meaningful direct comparison of achievable fuel utilization at equal fission densities.

Figure $A-15$ shows the results for a natural uranium blanket with average burnup between 30,000 and $45,000 \mathrm{MWD} / \mathrm{MT}$. (Over this range of blanket burnups, the fuel utilization is almost completely independent of blanket burnup, varying by less than 1 percent over the range. This burnup range yields the peak fuel utilization for this type of blanket. This result is consistent with the sensitivity 
shown in Figure A-10 in the vicinity of the peak fuel utilization for no neutron losses.) Figure A-15 shows that with no neutron losses the 10 percent enrichment seed gives the highest fuel utilization (almost $18 \mathrm{MWY}$ th/ST $\mathrm{U}_{3} \mathrm{O}_{8}$ ) at seed average burnups below $90,000 \mathrm{MWD} / \mathrm{MT}$, which has the same $\mathrm{f} / \mathrm{cc}$ value as the 5 percent enriched seed at a burnup of 45,000 MWD/MT. However, Figure A-16 shows that with 4 percent neutron losses the 20 percent enrichment seed gives the highest fuel utilization (about $15 \mathrm{MWYth} / \mathrm{ST}_{3} \mathrm{O}_{8}$ ) at seed average burnups below 180,000 MWD/MT, which also has the same f/cc value as the 5 percent enriched seed at a burnup of $45,000 \mathrm{MWD} / \mathrm{MT}$.

The calculations in Figures A-15 and A-16 are for natural uranium blankets. Figure A-17 is similar to Figure A-16 except that the blanket is natural thorium at an average burnup of $50,000 \mathrm{MWD} / \mathrm{MT}$. The fuel utilization values in Figure A-17 (natural thorium blanket) are almost identical with those in Figure A-16 (natural uranium blanket). Figure A-18 shows how the fuel utilization with the 20 percent enriched seed depends on the burnup of the natural thorium blanket. It is observed that increasing the blanket average burnup from 50,000 to 60,000 MWD/MT increases the fuel utilization by less than $0.5 \mathrm{MWY}$ th/ST $\mathrm{U}_{3} \mathrm{O}_{8}$. On the basis of these results, it is concluded that In a seed-blanket core with 4 percent neutron losses and limits on average fission density equivalent to an average burnup of $45,000 \mathrm{MWD} / \mathrm{MT}$ for $\mathrm{UO}_{2}$, the highest fuel utilization achievable would be about $1 \mathrm{~h} \mathrm{MWYth/ST}$ $\mathrm{U}_{3} \mathrm{O}_{8}$

If limits on burnup are removed and the average burnup of the 5 percent enriched seed is allowed to increase to $60,000 \mathrm{MWD} / \mathrm{MT}$, the fuel utilization can be increased by about $1 \mathrm{MWYth} / \mathrm{ST}_{3} \mathrm{O}_{8}$. If neutron losses are reduced by about 1 percent, the fuel utilization can again be increased by about $1 \mathrm{MWYth} / \mathrm{ST} \mathrm{U}_{3} \mathrm{O}_{8}$. Thus, for the 5 percent enriched seed with 3 percent neutron losses and a burnup of about $60,000 \mathrm{MWD} / \mathrm{MT}$, a fuel utilization close to $17 \mathrm{MWYth} / \mathrm{ST} \mathrm{U}_{3} \mathrm{O}_{8}$ could be achieved. The fuel utilization achievable with the seeds of higher enrichment would be somewhat lower.

\section{Summary}

The results presented in Table A-6 and Figures A-10 through A-18 can he summarized ae follows:

a. The peak fuel utilization achievable (with no restriction on burnup) is about the same for all seed and blanket combinations. For no neutron losses, this value is between 18 and $20 \mathrm{MWY}$ th/ST $\mathrm{U}_{3} \mathrm{O}_{8}$, and with 4 percent neutron losses the value is between 15 and $16 \mathrm{MWYth} / \mathrm{ST} \mathrm{U}_{3} \mathrm{O}_{8}$. From these results it is inferred that with neutron losses of about 3 percent a peak fuel utilization of about $17 \mathrm{MWY} / \mathrm{l} / \mathrm{ST} \mathrm{U}_{3} \mathrm{O}_{8}$ would be achievable.

b. To achieve a fuel utilization of $17 \mathrm{MWYth} / \mathrm{ST} \mathrm{U}_{3} \mathrm{O}_{8}$ with 3 percent losses and a 5 percent enriched uranium seed the seed average burnup required would be about $60,000 \mathrm{MWD} / \mathrm{MT}$.

c. The fuel utilization is relatively insensitive to changes in blanket average burnup when the blanket burnup is sufficiently high. For a natural uranium blanket, varying the average burnup from 30,000 to $45,000 \mathrm{MWD} / \mathrm{MT}$ changes the fuel utilization by less than $0.2 \mathrm{MWYth} / \mathrm{ST} \mathrm{U}_{3} \mathrm{O}_{8}$. For a natural thorium blanket, increasing the average burnup from 50,000 to 60,000 MWD/MT increases fuel utilization by less than $0.5 \mathrm{MWY}$ th/ $\mathrm{ST} \mathrm{U}_{3} \mathrm{O}_{8}$.

d. The idealized, no neutron loss, seed-blanket cores appear to offer slightly better fuel utilization than an optimized, idealized, no neutron loss, uniformly enriched core. As discussed later, this 
slight benefit is likely to be lost as the result of non-uniform depletion and additional structures required for a practical seed-blanket core.

e. Fuel utilization is relatively insensitive to changes in metal-to-water ratio and to fuel rod diameter. Fuel utilization is also relatively insensitive to power density.

\section{NEUTRON LOSSES}

This section will discuss in more detail neutron losses and the potential for their reduction. These losses were identified in Section III of the main text as having a significant effect on fuel utilization, and based on Figures A-4 and A-5 and on Part 2 of Table A-6, a neutron loss of 4 percent costs a minimum of 3 to $4 \mathrm{MWYth} / \mathrm{ST} \mathrm{U}_{3} \mathrm{O}_{3}$. As discussed below, neutron losses as large as 8 percent occur in conventional PWR cores. The presence of soluble boron restricts the effectiveness of some methods which might be used to limit the losses.

\section{A. Typical PWR Neutron Losses}

Neutron losses in a typical large PWR core are tabulated in Table A-7. These were calculated for the core described in Reference $A-4$; this core will be referred to as the reference core. A brief description of the model used for these calculations is presented in Appendix B, Section VI. C. The losses in Table A-7 are based on neutron capture rates at the midpoint of a one-year irradiation cycle, after an equilibrium cycle has been attained. As such, they are not exact values of what the neutron losses would be when integrated over a full cycle. However, these values are adequate for purposes of the present discussion.

The largest loss indicated in Table A-7 is to soluble boron, and is about 4 percent. Based on the experience with the LWBR at Shippingport, it should be possible to eliminate such losses using a seed-blanket design with movable fuel control. This has been discussed in detail in preceding sections.

The second largest loss shown in Table A-7 is to radial leakage, and is about 3 percent. This loss was obtained from the spatial calculations as the fraction of the total neutron absorption rate occurring in matcrials (moderator, structure, and thermal shield) outside the core.

\section{B. PWR With a Radial Blanket}

It was suggested in earlier sections that the loss to radial leakage could be reduced substantially through the use of a radial blanket, that is, modules loaded with natural uranium, depleted uranium, or thorium. To estimate the effectiveness of a blanket in reducing the radial leakage, a calculation was made in which the reference core was completely surrounded by 52 natural uranium blanket modules (see Figure A-19). These modules were identical to the reference core modules with the exception that the fuel pellets were natural uranium rather than slightly enriched uranium. Depletion calculations were again carried out until an equilibrium cycle for core modules was attained. The neutron losses were then calculated at the midpoint of a one-year equilibrium irradiation cycle. The loss was again determined as the fraction of the total neutron absorption rate occuring in the thermal 
shield and the moderator and structure outside of the blanket. The leakage fraction for this case is also presented in Table A-7. It is observed that the leakage has been reduced to about 0.8 percent. Before discussing this result further, it is important to note that the addition of blanket modules to a core would require either that the core power rating be reduced or that the diameter of the thermal shield and pressure vessel be increased. This point will be discussed in more detail later.

The reduction in radial leakage from 2.9 percent to 0.8 percent was substantial, but does not necessarily represent the best improvement possible. Conceivably, optimization of blanket parameters such as fuel rod diameter and pitch could further reduce the leakage. Alternatively, through optimization it might be possible to reduce the leakage to 0.8 percent with a "thinner" blanket (a blanket with rectangular rather than square modules), which would produce less of a change in core size or average power density.

An important consideration mentioned above with respect to a peripheral blanket is the effect on core size. In the subsequent discuscion it will be assumed that the total power output of the core with the peripheral blanket is to be kept the same as that of the reference core. In the present calculations. the addition of 52 blanket modules increased the core area by almost 22 percent. To a first approximallon, this would require about an 11 percent increase in pressure vessel diameter. However, the blanket contributes about 7.5 percent of the core power, so that the power density in the reference modules has dropped by 7.5 percent. If the core were resized so as to increase the power density in the reference modules by 7.5 percent then the core area would be reduced by about 7.5 percent, and the pressure vessel diameter would decrease by about 3.7 percent. On the basis of this reasoning, it is estimated that the addition of peripheral blanket modules of the type used in the calculation would require approximately a 7.3 percent increase in pressure vessel ID. For the reference reactor this would increase the ID from a value of 195 inches to a value of about 209 inches. This estimate should be regarded as an upper limit on the pressure vessel ID, since the blanket modules used in the calculations were not optimized in any way.

Ani important observation is that the use of a peripheral blanket in a core with movable fuel reactivity control would cause a much larger improvement in fuel utllization than lt would in a core with poison reactivity control. The reason for this is that the soluble poison would also be present in the blanket and would reduce the blanket efficiency; that is, it would reduce the energy produced per neutron captured.

\section{Axial Reflecting Blanket}

An additional reduction in leakage might be achievable through the use of axial reflector blankets, which would consist of blanket-type fuel pellets at the ends of the fuel rods. One potential drawback to the use of an axial hlanket would bc that when seed fuel rods would be removed, the blanket pellets at the ends of the seed fuel rods would also be removed. These blanket pellets would probably not have the burnup required for optimum fuel utilization, and this would tend to offset some of the gain from reducing the axial leakage. 


\section{Overall Neutron Loss and Non-Uniform Burnup Effects}

If the radial leakage could in fact be reduced to 0.8 percent, the axial leakage reduced to 0.4 percent, and the control poison eliminated completely, then the total neutron losses would be 1.7 percent. However, the elimination of control poison through the use of movable fuel control would require additional structure and associated water regions, and these would act as poisons. Therefore, it is judged that a reasonable expectation for a practical seed-blanket once-through core would be neutron losses of about 2 percent.

A probable side effect of the use of movable fuel control and the seed blanket concept would be to make the burnup of both seed and blanket regions less uniform than is the burnup in a current commercial core. The non-optimum burnup of an axial reflecting blanket at the ends of the seed fuel can also be regarded as contributing to the non-uniform burnup of the blanket.

Non-uniform burnup of seed regions would have an adverse effect on fuel utilization. This effect can be included in the fuel utilization calculations by assuming increased neutron losses but uniform burnup of both seed and blanket. A neutron loss of 1 percent, which would be worth from 0.6 to $0.8 \mathrm{MWY}$ th/ST $\mathrm{U}_{3} \mathrm{O}_{8}$, is a reasonable equivalence for the effect of non-uniform burnup. This effect is discussed in Section $V$ of Appendix $B$.

\section{RULES OF THUMB FOR FUEL UTILIZATION}

Some numerical data which can help to develop a perspective on fuel utilization are presented below.

1. If all of the uranium-235, but none of the uranium-238, in a ton of $\mathrm{U}_{3} \mathrm{O}_{8}$ could be consumed (with 80 percent being fissioned and the remainder converted to uranium-236 by parasitic neutron capture) in a light water reactor, the fuel utilization would be close to $11 \mathrm{MWY}$ th/ST $\mathrm{U}_{3} \mathrm{O}_{8}$.

2. When uranium is enriched, only 5/7 of the initial uranium-235 content appears in the product; the remaining $2 / 7$ is in the enrichment plant tails. (This assumes a tails assay of 0.2 percent uranium235 in uranium.) If a ton of $\mathrm{U}_{3} \mathrm{O}_{8}$ were converted to UF6 and sent through an enrichment plant, and all of the uranium-235 in the enriched product (but none of the uranium-238) were consumed in a light water reactor, the fuel utilization would be about $8 \mathrm{MWYth} / \mathrm{ST} \mathrm{U}_{3} \mathrm{O}_{8}$.

3. In current commercial light water reactors about 75 percent of the uranium-235 input (in fresh fuel) is consumed. If no uranium-238 were consumed, this would yield a fuel utilization of about $6 \mathrm{MWYth} / \mathrm{ST}_{3} \mathrm{O}_{8}$.

4. In current commercial light water reactors the fuel utilization is about $12 \mathrm{MWYth} / \mathrm{ST} \mathrm{U}_{3} \mathrm{O}_{8}$. This Implies that about $6 \mathrm{MWYth} / \mathrm{ST} \mathrm{U}_{3} \mathrm{O}_{8}$ is obtained from conversion of uranium-238 to plutonium-239 and subsequent consumption of the plutonium-239, with a small supplement from direct fast fission of uranium-238. 


\section{REFERENCES}

A-1. C. M. Hove, et al, "PWR Once-Through Fuel Cycle Improvements," Trans. Am. Nuc. Soc., 30, 275, 1978.

A-2. N. L. Shapiro and Y. Liu, "Improvement of Fuel Utilization for Once-Through PWR Cycles," Trans. Am. Nuc. Soc., 30, 276, 1978.

A-3. S. R. Specker, et al, "Optimization of the BWR for Once-Through Fuel Cycles," Trans. Am. Nuc. Soc., $30,277,1978$.

A-4. "Babcock and Wilcox Standard Safety Analysis Report (B-SAR-241)," Docket Number STN50481.

^ 6. II. N. Aırurews, E. U. Fuller, et al, "Optimizing the Refuel Cycle: Two Views," Nuclear News, September 1973, p. 71. 
TABLE A-1. COMPOSITION PARAMETERS FOR SEEDS AND UNIFORM ENRICHMENT CORES

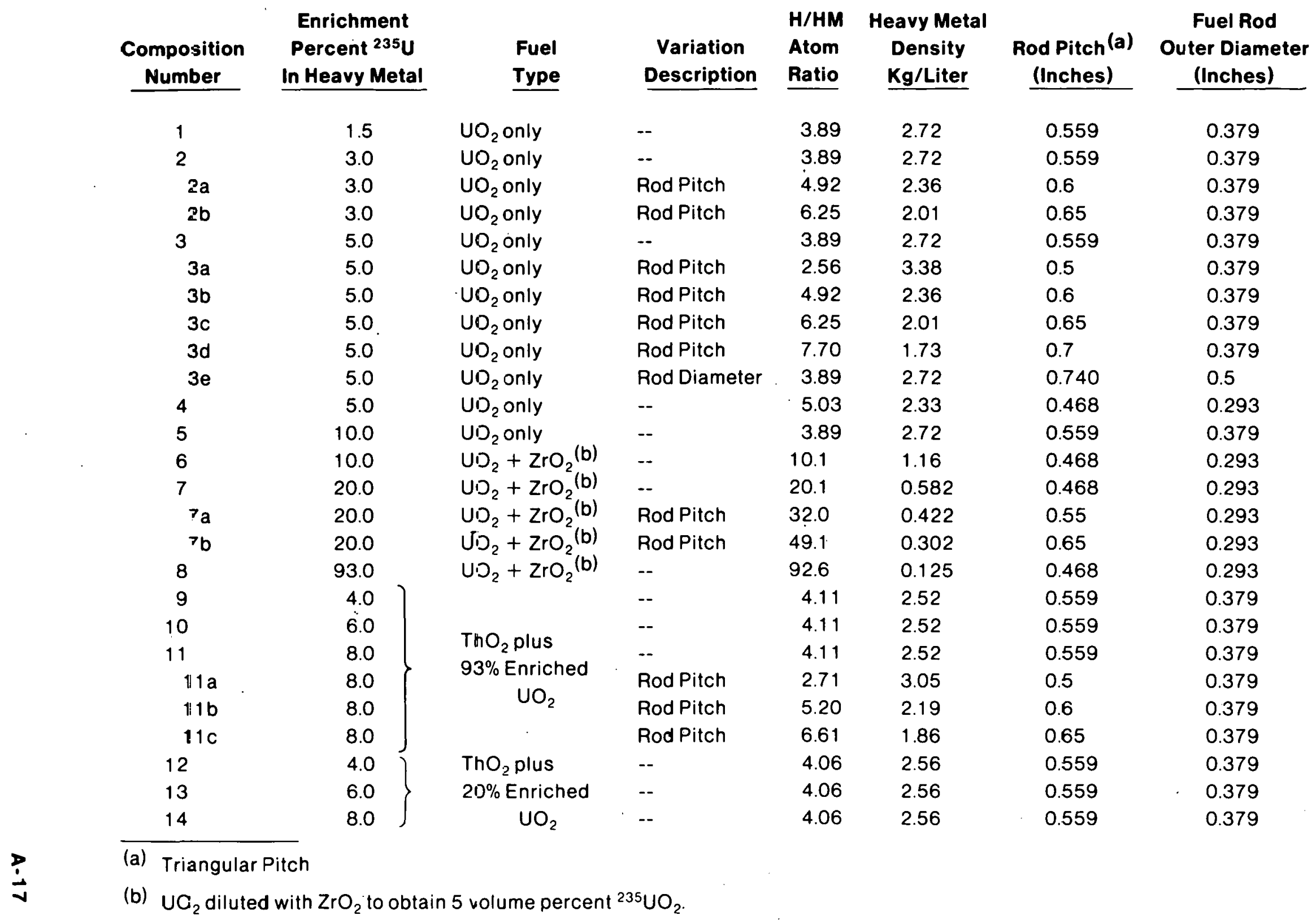


TABLE A-2. FUEL UTILIZA TION DEPENDENCE ON FUEL ROD DIAMETER, HYDROGEN TO HEAVY METAL RATIO AND POWER DENSITY IN A UNIFORMLY ENRICHED CORE

\begin{tabular}{|c|c|c|c|c|c|c|c|}
\hline \multirow[b]{2}{*}{$\begin{array}{l}\text { Fuel } \\
\text { Type }\end{array}$} & \multirow[b]{2}{*}{$\begin{array}{l}\text { Composition } \\
\text { Number From } \\
\text { Table A-1 }\end{array}$} & \multirow[b]{2}{*}{$\begin{array}{l}\text { Fuel Rod } \\
\text { Ouler Diameter } \\
\text { (Inches) } \\
\end{array}$} & \multicolumn{3}{|c|}{$\begin{aligned} \text { Fuel Tyce } 1 & =\mathrm{UO}_{2}, 3 \text { percent enrichment } \\
2 & =\cup \mathrm{O}_{2}, 5 \text { percent enrichment } \\
3 & =\mathrm{UO}_{2}, 20 \text { percent enrichment } \\
4 & =\mathrm{ThO}_{2}+\mathrm{UO}_{2}\left(8 \%{ }^{235} \mathrm{U} \text { in Th }\right)\end{aligned}$} & \multirow{2}{*}{$\begin{array}{l}\text { Average } \\
\text { Burnup at } \\
\text { Peak Fuel } \\
\text { Utilization } \\
\text { MWD/MT }\end{array}$} & \multirow{2}{*}{$\begin{array}{c}\text { f/cc at } \\
\text { Peak Fuel } \\
\text { Utilization } \\
\text { Units of } \\
10^{20} \text { f/cc }\end{array}$} \\
\hline & & & $\begin{array}{l}\text { Hydrogen to } \\
\text { Heavy Metal } \\
\text { Atom Ratio }\end{array}$ & $\begin{array}{c}\text { Power Density } \\
\text { kni/kg Heavy Metal }\end{array}$ & $\begin{array}{l}\text { Peak Fuel } \\
\text { Uti ization (a) (No } \\
\text { Neutron Losses) (b) } \\
\end{array}$ & & \\
\hline \multirow[t]{3}{*}{1} & 2 & 0.379 & 3.89 & 20.3 & 19.6 & 51,100 & 13.3 \\
\hline & 2 & 0.379 & 3.89 & 40.6 & 18.9 & 49,300 & 12.8 \\
\hline & 2 & 0.379 & 3.89 & 60.9 & 18.6 & 48,300 & 12.6 \\
\hline \multirow[t]{9}{*}{2} & $3 a$ & 0.379 & 2.56 & 40.5 & 15.3 & 68,200 & 17.1 \\
\hline & 3 & 0.379 & 3.89 & 40.5 & 18.6 & 82,800 & 21.5 \\
\hline & $3 b$ & 0.379 & 4.92 & 40.5 & 18.5 & 82,500 & 21.5 \\
\hline & $3 c$ & 0.379 & 6.25 & 40.5 & 17.6 & 78,500 & 20.4 \\
\hline & $3 d$ & 0.379 & 7.70 & 40.5 & 16.6 & 73,800 & 19.2 \\
\hline & $3 e$ & 0.5 & 3.89 & 40.5 & 18.7 & 83,200 & 21.6 \\
\hline & 4 & .0 .293 & 5.03 & 33.5 & 18.7 & 83,000 & 21.6 \\
\hline & 4 & 0.293 & 5.03 & 67.0 & 18.2 & 81,200 & 21.1 \\
\hline & 4 & 0.293 & 5.03 & 101.0 & 18.0 & 80,200 & 20.9 \\
\hline \multirow[t]{5}{*}{3} & 7 & 0.293 & 20.1 & 135.0 & $1 \cdot .2$ & 205,600 & 13.4 \\
\hline & 7 & 0.293 & 20.1 & 270.0 & $1: 9$ & 218,500 & 14.2 \\
\hline & 7 & 0.293 & 20.1 & 405.0 & $1 \mathrm{i} .1$ & 203,300 & 13.2 \\
\hline & $7 a$ & 0.293 & 32.0 & 270.0 & 10.5 & 193,900 & 12.6 \\
\hline & $7 b$ & 0.293 & 49.1 & 270.0 & 10.2 & 188,200 & 12.2 \\
\hline \multirow[t]{3}{*}{4} & 11 & 0.379 & 4.11 & 21.9 & 19.1 & 141,800 & 36.9 \\
\hline & 11 & 0.379 & 4.11 & 43.8 & 17.7 & 131,100 & 34.1 \\
\hline & 11 & 0.379 & 4.11 & 65.7 & 16.7 & 123,900 & 32.2 \\
\hline
\end{tabular}


TABLE A-3. FUEL UTILIZATION DEPENDENCE ON URANIUM-235 CONTENT, UNIFORMLY ENRICHED CORES

\begin{tabular}{|c|c|c|c|c|c|c|}
\hline $\begin{array}{l}\text { Fuel Type } \\
\text { (a) }\end{array}$ & $\begin{array}{c}\text { H/(Heavy } \\
\text { Metal) } \\
\text { Atom } \\
\text { Ratio } \\
\end{array}$ & 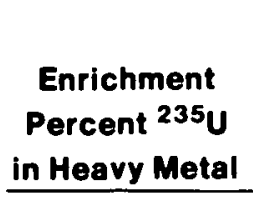 & $\begin{array}{c}\text { Neutron } \\
\text { Losses(b) } \\
\text { Percent }\end{array}$ & $\begin{array}{c}\text { Peak } \\
\text { Fuel } \\
\text { Utilization (a) } \\
\text { MWrth } / \mathrm{ST} \mathrm{U}_{3} \mathrm{O}_{8} \\
\end{array}$ & 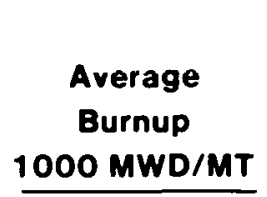 & $\begin{array}{c}\text { t/cc } \\
\text { Units of } \\
10^{20} \text { f/cc } \\
\end{array}$ \\
\hline \multirow[t]{11}{*}{$\mathrm{uO}_{2}$} & 3.9 & 1.5 & 0 & 13.6 & 16.5 & 4.3 \\
\hline & & 3.0 & 0 & 18.9 & 49.3 & 12.8 \\
\hline & & 5.0 & 0 & 18.6 & 82.8 & 21.5 \\
\hline & & 10.0 & 0 & 16.3 & 153.0 & 19.9 \\
\hline & & 1.5 & 4 & 7.4 & 8.9 & 2.3 \\
\hline & & 3.0 & 4 & 15.2 & 39.5 & 10.3 \\
\hline & & 3.0 & 4 & 15.8 & 70.5 & 18.3 \\
\hline & & 10.0 & 4 & 14.8 & 135.0 & 17.6 \\
\hline & & 3.0 & 8 & 11.5 & 30.0 & 7.8 \\
\hline & & 5.0 & 8 & 13.2 & 59.0 & 15.3 \\
\hline & & 10.0 & 8 & 13.0 & 118.0 & 15.3 \\
\hline $\mathrm{ThO}_{2}$ & 4.1 & 4.0 & 0 & 16.1 & 59.8 & 15.5 \\
\hline$+93 \%$ & & 6.0 & 0 & 17.9 & 99.5 & 25.9 \\
\hline enriched & & 8.0 & 0 & 17.7 & 131.0 & 34.1 \\
\hline \multirow{5}{*}{$\mathrm{UO}_{2}$} & & 4.0 & 4 & 11.8 & 44.0 & 11.4 \\
\hline & & 6.0 & 4 & 14.8 & 82.5 & 21.5 \\
\hline & & 8.0 & 4 & 15.2 & 113.0 & 29.4 \\
\hline & & 6.0 & 8 & 12.0 & 67.0 & 17.4 \\
\hline & & 8.0 & 8 & 13.1 & 97.0 & 25.2 \\
\hline
\end{tabular}

\footnotetext{
(a) All fuel utilization calculations assume enrichment plant tails assay of 0.2 percent uranium-235 in uranium.

(b) Neutron capture in Zircaloy fuel rod cladding is included in the calculations and is not counted as a loss.
} 
TABLE A-4. COMPOSITION PARAMETERS FOR BLANKETS(a)

\section{Blanket \\ Number}

1

2

3

4

\section{Fuel Type}

Natural $\mathrm{UO}_{2}$

Natural $\mathrm{ThO}_{2}$

Depleted $\mathrm{UO}_{2}$

$\mathrm{ThO}_{2}$ with $93 \%$ enriched $\mathrm{UO}_{2}$
Enrichment

Percent ${ }^{235} \mathrm{U}$

in Heavy Metal

0.71

0

$0.20^{(b)}$

0.71

(a) Fuel rod outer diameter $=0.5783$ inches for all cases.

$\mathrm{H} /$ Heavy Metal atom ratio $=2.99$ for all cases.

(b) Assumed value for this report. 
TABLE A-5. FUEL UTILIZATION FOR SEED-BLANKET CELL CALCULATIONS

\begin{tabular}{|c|c|c|c|c|c|c|c|c|}
\hline \multirow{2}{*}{$\begin{array}{c}\text { Cell } \\
\text { Number }\end{array}$} & \multirow{2}{*}{$\begin{array}{c}\text { Seed } \\
\text { Number } \\
\text { (Table A-1) }\end{array}$} & \multirow{2}{*}{$\begin{array}{c}\text { Seed } \\
\text { Radius } \\
(\mathrm{cm}) \\
\end{array}$} & \multirow{2}{*}{$\begin{array}{c}\text { Seed } \\
\text { Volume } \\
\text { Fraction } \\
\end{array}$} & \multirow{2}{*}{$\begin{array}{c}\text { Blanket } \\
\text { Number } \\
\text { (Table A-4) } \\
\end{array}$} & \multirow{2}{*}{$\begin{array}{c}\text { Fuel } \\
\text { Utilization (a) } \\
\left(\text { MWYth/ST } U_{3} O_{8}\right)\end{array}$} & \multicolumn{2}{|c|}{$\begin{array}{c}\text { Average } \\
\text { Burnup } \\
\text { (1000 MWD/MT) }\end{array}$} & \multirow{2}{*}{$\begin{array}{c}\text { Seed } f / c c \\
\text { Units of } \\
10^{20} f / c c\end{array}$} \\
\hline & & & & & & Seed & Blanket & \\
\hline 1 & 4 & 10 & 0.5 & 1 & 18.6 & 58.8 & 26.8 & 15.3 \\
\hline 2 & 4 & 15 & 0.5 & 1 & 18.5 & 58.2 & 26.8 & 15.1 \\
\hline 3 & 4 & 20 & 0.5 & 1 & 18.5 & 59.1 & 25.6 & 15.4 \\
\hline 4 & 7 & 10 & 0.2 & 1 & 15.3 & 142 & 13.6 & 9.2 \\
\hline 5 & 7 & 15 & 0.2 & 1 & 15.9 & 159 & 13.6 & 10.3 \\
\hline 6 & $T$ & 20 & 0.2 & 1 & 15.9 & 171 & 13.1 & 11.1 \\
\hline 7 & 7 & 10 & 0.35 & 1 & 17.8 & 183 & 22.5 & 11.9 \\
\hline 8 & 7 & 20 & 0.35 & 1 & 17.3 & 190 & 20.9 & 12.4 \\
\hline 9 & $?$ & 10 & 0.5 & 1 & 17.1 & 199 & 28.8 & 12.9 \\
\hline 10 & 7 & 15 & 0.5 & 1 & 16.8 & 200 & 27.6 & 13.0 \\
\hline 11 & 7 & 20 & 0.5 & 1 & 16.6 & 201 & 26.7 & 13.1 \\
\hline
\end{tabular}

(a) All fuel utilization calculations assume enrichment plant tails assay of 0.2 percent uranium-235 in uranium. 
TABLE A-6. PEAK FUEL UTILIZATION SUMMARY; POINT DEPLETION CALCULATIONS

\section{PART 1 - NO NEUTRON LOSSES (a), BASE CASE PARAMETERS}

\begin{tabular}{|c|c|c|c|c|c|c|c|}
\hline $\begin{array}{c}\text { Case } \\
\text { No. }\end{array}$ & $\begin{array}{l}\text { Seed or Core Data } \\
\text { (Composition Number } \\
\text { From Table A-1) }\end{array}$ & Core Type & Blanket Type & $\begin{array}{l}\text { Peak } \\
\text { Fuel } \\
\text { Utilization (b) }\end{array}$ & $\begin{array}{l}\text { Burn! } \\
\text { Seed }\end{array}$ & $\begin{array}{l}\text { planket } \\
\text { Bla }\end{array}$ & $\begin{array}{c}\text { Seed } f / c c \\
\text { Units of } \\
10^{20} f / c c\end{array}$ \\
\hline 1 & $\mathrm{UO}_{2}, 5 \%$ enrichment ( 4 ) & Seed-Blanket & Natural Uranium & 18.3 & 70 & 35 & 18 \\
\hline 2 & $\mathrm{UO}_{2}, 5 \%$ enrichment (4) & Seed-Blanket & Depleted Uranium & 18.5 & 70 & 40 & 18 \\
\hline 3 & $\mathrm{UO}_{2}, 5 \%$ enrichment (4) & Seed-Blanket & Natural Thorium & 19.6 & 65 & 110 & 17 \\
\hline 4 & $\mathrm{UO}_{2}, 5 \%$ enrict nent (4) & Seed-Blanket & Spiked Thorium & 19.6 & 65 & 110 & 17 \\
\hline 5 & $\mathrm{UO}_{2}, 5 \%$ enrichment (4) & Uniformly Enriched & -- & 18.2 & 80 & - & 21 \\
\hline 6 & $\begin{array}{l}\mathrm{UO}_{2}, 10 \% \text { enrichment (6) } \\
\left(0.5 \mathrm{UO}_{2}, 0.5 \mathrm{ZrO}_{2}\right)\end{array}$ & Seed-Blanke: & Natural Uranium & 17.9 & 100 & 35 & 13 \\
\hline 7 & $\begin{array}{l}\mathrm{UO}_{2}, 10 \% \text { enrichment (6) } \\
\left(0.5 \mathrm{UO}_{2}, 0.5 \mathrm{ZrO}_{2}\right)\end{array}$ & Seed-Blankel & Depleted Uranium & 17.2 & 100 & 40 & 13 \\
\hline 8 & $\begin{array}{l}\mathrm{UO}_{2}, 10 \% \text { enrichment (6) } \\
\left(0.5 \mathrm{UO}_{2}, 0.5 \mathrm{ZrO}_{2}\right)\end{array}$ & Seed-Blanket & Natural Thorium & 19.4 & 100 & 110 & 13 \\
\hline 9 & $\begin{array}{l}\mathrm{UO}_{2}, 10 \% \text { enrict ment (6) } \\
\left(0.5 \mathrm{UO}_{2}, 0.5 \mathrm{ZrO}_{2}\right)\end{array}$ & Uniformly Enriched & -- & 14.5 & 130 & - & 17 \\
\hline 10 & $\begin{array}{l}\mathrm{UO}_{2}, 20 \% \text { enrichment }(7) \\
\left(0.25 \mathrm{UO}_{2}, 0.75 \mathrm{ZrO}_{2}\right)\end{array}$ & Seed-Blanket & Natural Uranium & 17.7 & 180 & 35 & 12 \\
\hline 11 & $\begin{array}{l}\mathrm{UO}_{2}, 20 \% \text { enrichment }(7) \\
\left(0.25 \mathrm{UO}_{2}, 0.75 \mathrm{ZrO}_{2}\right)\end{array}$ & Seed-Blanket & Depleted Uranium & 16.8 & 180 & 40 & 12 \\
\hline
\end{tabular}


TABLE A-6 (Cont)

\begin{tabular}{|c|c|c|c|c|c|c|c|}
\hline $\begin{array}{l}\text { Case } \\
\text { No. }\end{array}$ & $\begin{array}{c}\text { Seed or Core Data } \\
\text { (Composition Number } \\
\text { From Table A-1) }\end{array}$ & Core Type & Blanket Type & $\begin{array}{l}\text { Peak } \\
\text { Fuel } \\
\text { Utilization(b) }\end{array}$ & $\begin{array}{l}\text { Burn } \\
\text { Seed }\end{array}$ & $\begin{array}{l}\text { op (c) } \\
\text { Blanket }\end{array}$ & $\begin{array}{c}\text { Seed f/cc } \\
\text { Units of } \\
10^{20} f / \infty C\end{array}$ \\
\hline 12 & $\begin{array}{l}\left.\mathrm{UO}_{2}, 20 \% \text { enrichment ( } 7\right) \\
\left(0.25 \mathrm{UO}_{2}, 0.75 \mathrm{ZrO}_{2}\right)\end{array}$ & Seed-Blanket & Natural Thorium & 19.3 & 170 & 110 & 11 \\
\hline 13 & $\begin{array}{l}\mathrm{UO}_{2}, 2 \mathrm{C} \% \text { enrichment }(7) \\
\left(0.25 \mathrm{UO}_{2}, 0.75 \mathrm{ZrO}_{2}\right)\end{array}$ & Uniformly Enriched & -- & 11.9 & 220 & - & 14 \\
\hline 14 & $\begin{array}{l}\mathrm{UO}_{2}, 93 \% \text { enrichment (8) } \\
\left(0.054 \mathrm{UO}_{2}, 0.946 \mathrm{ZrO}_{2}\right)\end{array}$ & Seed-Blanket & Natural.Uranium & 17.6 & 650 & 30 & 9.1 \\
\hline 15 & $\begin{array}{l}\left.\mathrm{UO}_{2}, 93 \% \text { enrichment ( } 8\right) \\
\left(0.054 \mathrm{JO}_{2}, 0.946 \mathrm{ZrO}_{2}\right)\end{array}$ & Seed-Blanket & Natural Thorium & 19.6 & 635 & 110 & 8.9 \\
\hline 16 & $\begin{array}{l}\mathrm{UO}_{2} \text { in } \mathrm{ThO}_{2}(10) \\
6 \%{ }^{235} \mathrm{U} \text { in heavy metal } \\
93 \% \text { enriched uranium }\end{array}$ & Seed-Blanket & Natural Uranium & 17.9 & 95 & 35 & 25 \\
\hline 17 & $\begin{array}{l}\mathrm{UO}_{2} \text { in } \mathrm{ThO}_{2}(10) \\
6 \%{ }^{235} \mathrm{U} \text { in heavy metal } \\
93 \% \text { enriched uranium }\end{array}$ & Uniformly Enriched & -- & 17.9 & 100 & - & 26 \\
\hline 18 & $\begin{array}{l}\mathrm{UO}_{2} \text { in } \mathrm{ThO}_{2}(11) \\
8 \%{ }^{235} \mathrm{U} \text { in heavy metal } \\
93 \% \text { eririched uranium }\end{array}$ & Seed-Blanket & Natural Uranium & 18.0 & 115 & 35 & 30 \\
\hline 19 & $\begin{array}{l}\mathrm{UO}_{2} \text { in } \mathrm{ThO}_{2}(11) \\
8 \%{ }^{235} \mathrm{U} \text { in heavy metal } \\
93 \% \text { enriched uranium }\end{array}$ & Seed-Blanket & Natural Thorium & 18.7 & 105 & 110 & 27 \\
\hline
\end{tabular}


TABLE A-6 (Cont)

Seed or Core Data

Case (Composition Number

No. From Table A-1)

20

$\mathrm{UO}_{2}$ in $\mathrm{ThO}_{2}(11)$

$8 \%{ }^{235} \mathrm{U}$ in heavy metal

$93 \%$ enriched uranium

$21 \quad \mathrm{UO}_{2}: 3 \%$ enrichment (2)

$22 \mathrm{UO}_{2}, 10 \%$ enrichment (5) $\mathrm{No} \mathrm{ZrO} 2$

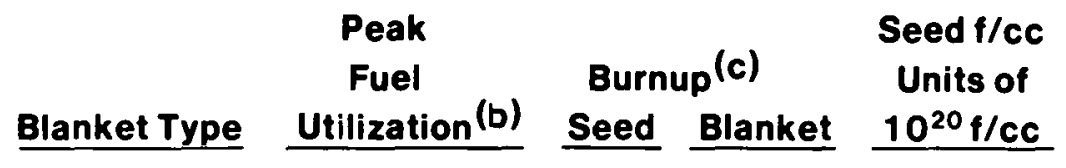

Uniformly Enriched

17.7

131

34

18.7

50

13

16.5

150

39

(a) Neutron capture in the Zircaloy fuel rod cladding is included in the calculations and is not counted as a loss.

(b) In units of MWYth/ST $\mathrm{U}_{3} \mathrm{O}_{8}$. All calzulations assume enrichment plant tails assay of 0.2 percent uranium-235 in uranium.

(c) In units of 1000 MWDiMT. 
TABLE A-6. PEAK FUEL UTILIZATION SUMMARY; POINT DEPLETION CALCULATIONS

PART 2 - WITH NEUTRON LOSSES - BASE CASE PARAMETERS ALL SEED-BLANKET CORES ${ }^{(a)}$

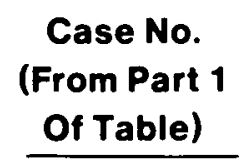

1

2

3

4

10

12

14

15
Peak Fuel Utilization (b), (c)

Units of MWYth/ST $\mathrm{U}_{3} \mathrm{O}_{8}$

No Neutron Losses

18.8

4 Percent Neutron Losses

16.1

18.5

16.0

19.6

15.8

19.6

16.1

17.7

15.0

19.3

15.9

17.6

14.9

19.6

(a) Seed and blanket burnup values are not presented here because they are the same with neutron losses as without neutron losses.

(b) All fuel utilization calculations assume enrichment plant tails assay of 0.2 percent uranium-235 in uranium.

(c) Neutron capture in the Zircaloy fuel rod cladding Is included in the calcullations and is not counted as a loss. 
TABLE A-6. PEAK FUEL UTILIZATION SUMMARY; POINT DEPLETION CALCULATIONS

\section{PART 3 - NO NEUTRON LOSSES - WITH VARYING POWER DENSITY AND} HYDROGEN TO HEAVY METAL ATOM RATIO

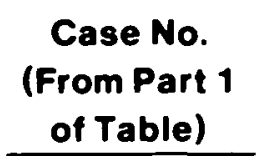

3

4.9
6.3
7.7
$19 \quad$ Seed $\mathrm{H} / \mathrm{HM}=3.9$

4.9

6.3

7.7

3

1

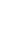

Seed power donsity =

J4kwiky

$$
67 \mathrm{kw} / \mathrm{kg}
$$

$101 \mathrm{kw} / \mathrm{kg}$

Blanket power density $=8.4 \mathrm{kw} / \mathrm{kg}$

$16.8 \mathrm{kw} / \mathrm{kg}$

$25.2 \mathrm{kw} / \mathrm{kg}$

Blanket power density $=13.8 \mathrm{kw} / \mathrm{kg}$

$27.5 \mathrm{kw} / \mathrm{kg}$

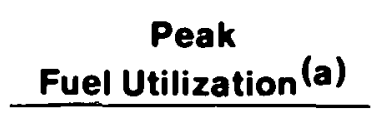

19.6

20.3

20.5

20.1

18.7

19.2

19.3

19.1

20.1

19.6

19.3

18.9

18.8

18.7

19.6

19.2

(a) All fuel utilization calculations assume enrichment plant tails assay of 0.2 percent uranium-235 in uranium. 
TABLE A-7. NEUTRON LOSSES(a) IN A LARGE (3800 MW(th)) PWR

Fraction of Neutron Capture Rate At Midpoint of

One Year Equilibrium Cycle

\begin{tabular}{|c|c|c|}
\hline Item & Reference Reactor & $\begin{array}{c}\text { Reactor With } \\
\text { Peripheral Blanket }\end{array}$ \\
\hline Soluble Boron & 0.044 & 0.044 \\
\hline Radial Leakage & 0.029 & 0.008 \\
\hline Axial Leakage & 0.008 & 0.008 \\
\hline Fuel Rod Support Grids & 0.005 & 0.005 \\
\hline $\begin{array}{l}\text { Total Excluding Soluble } \\
\text { Boron }\end{array}$ & 0.042 & 0.021 \\
\hline
\end{tabular}

(a) Neutron losses are defined as the fraction of the total neutron capture rate occurring in each item.

(b) Peripheral blanket consisted of 52 modules; power fraction in this blanket was 0.075 . 


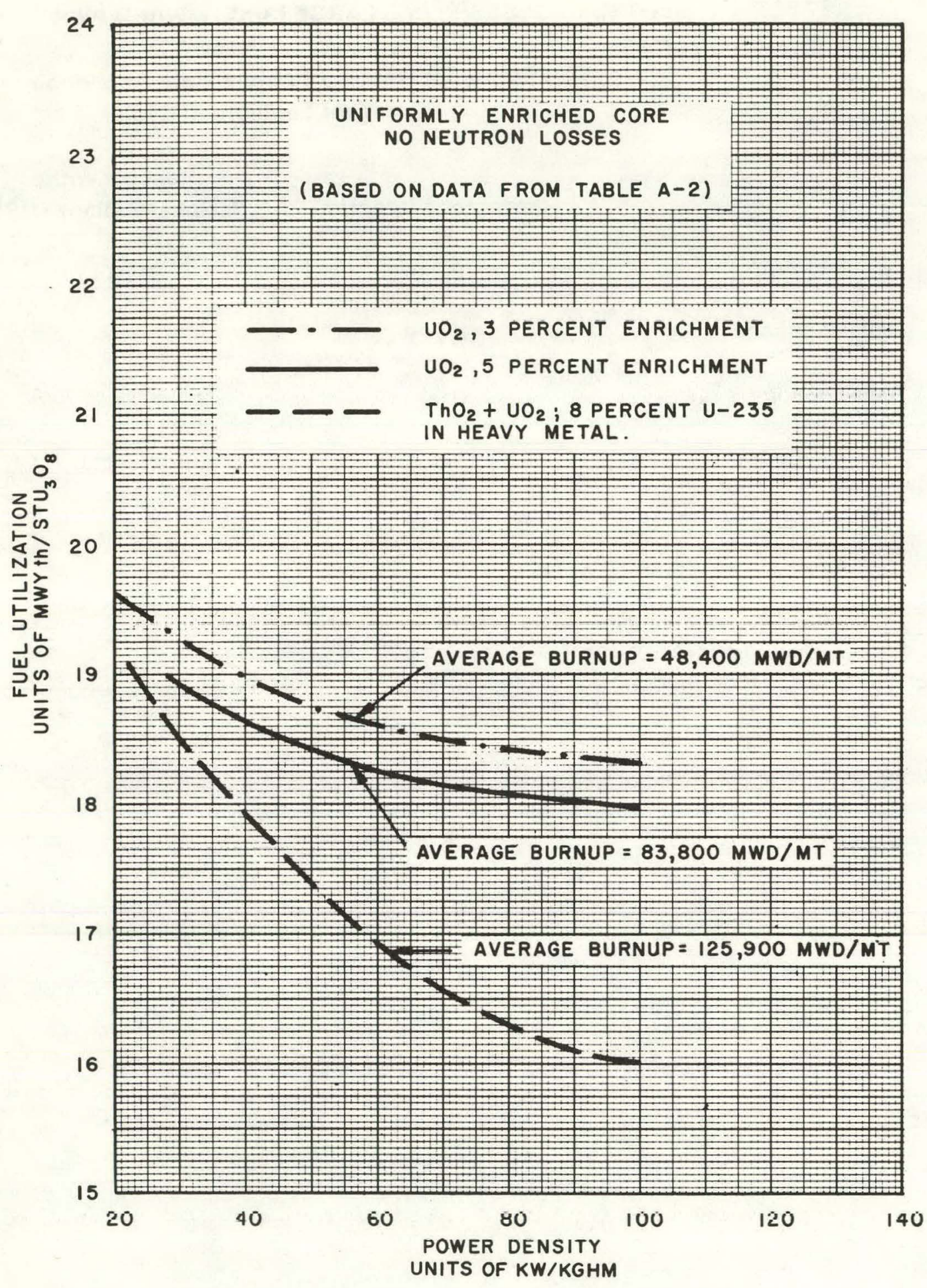

Figure A-1. Fuel Utilization Dependence On Power Density 


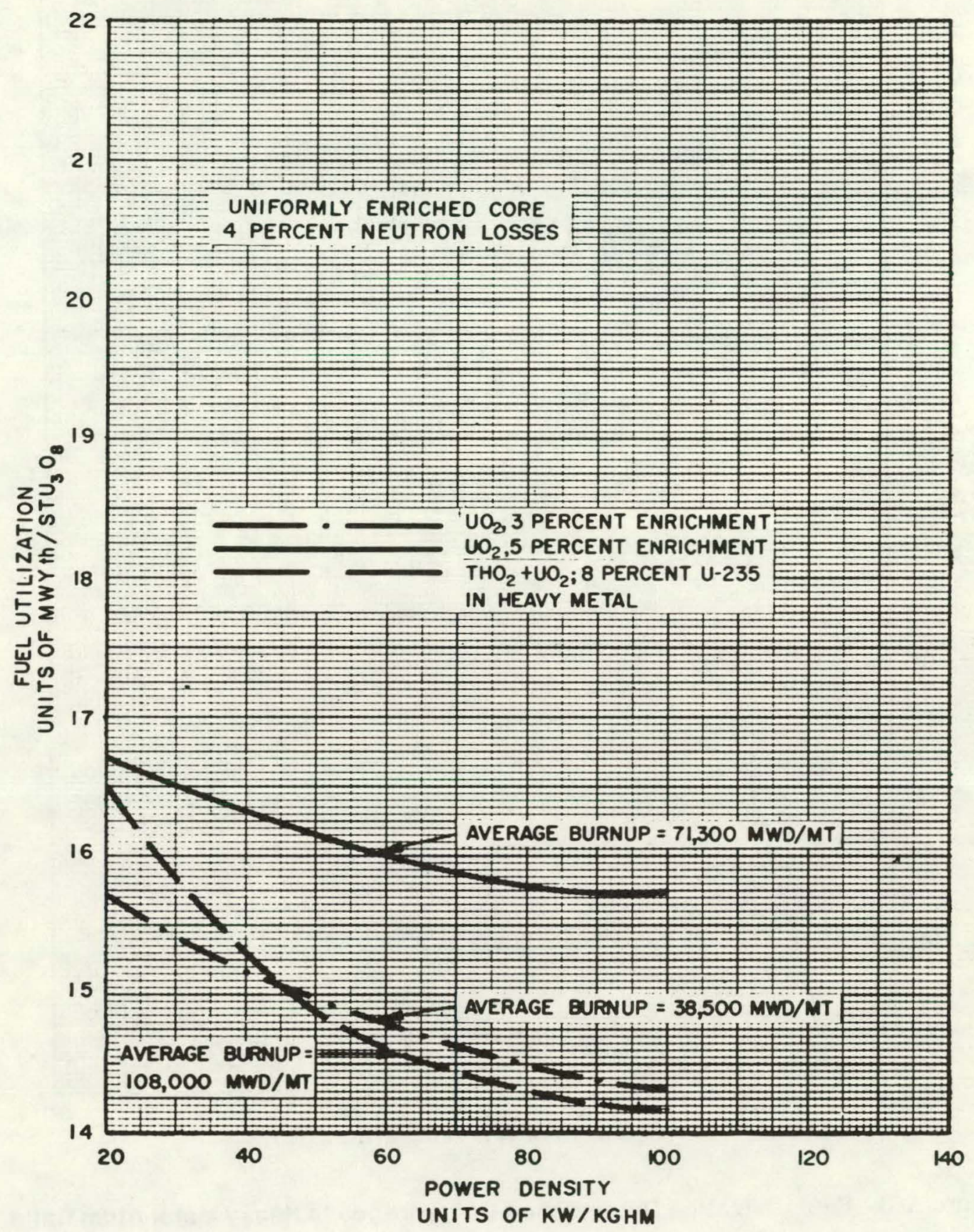

Figure A-2. Fuel Utilization Dependence On Power Density 


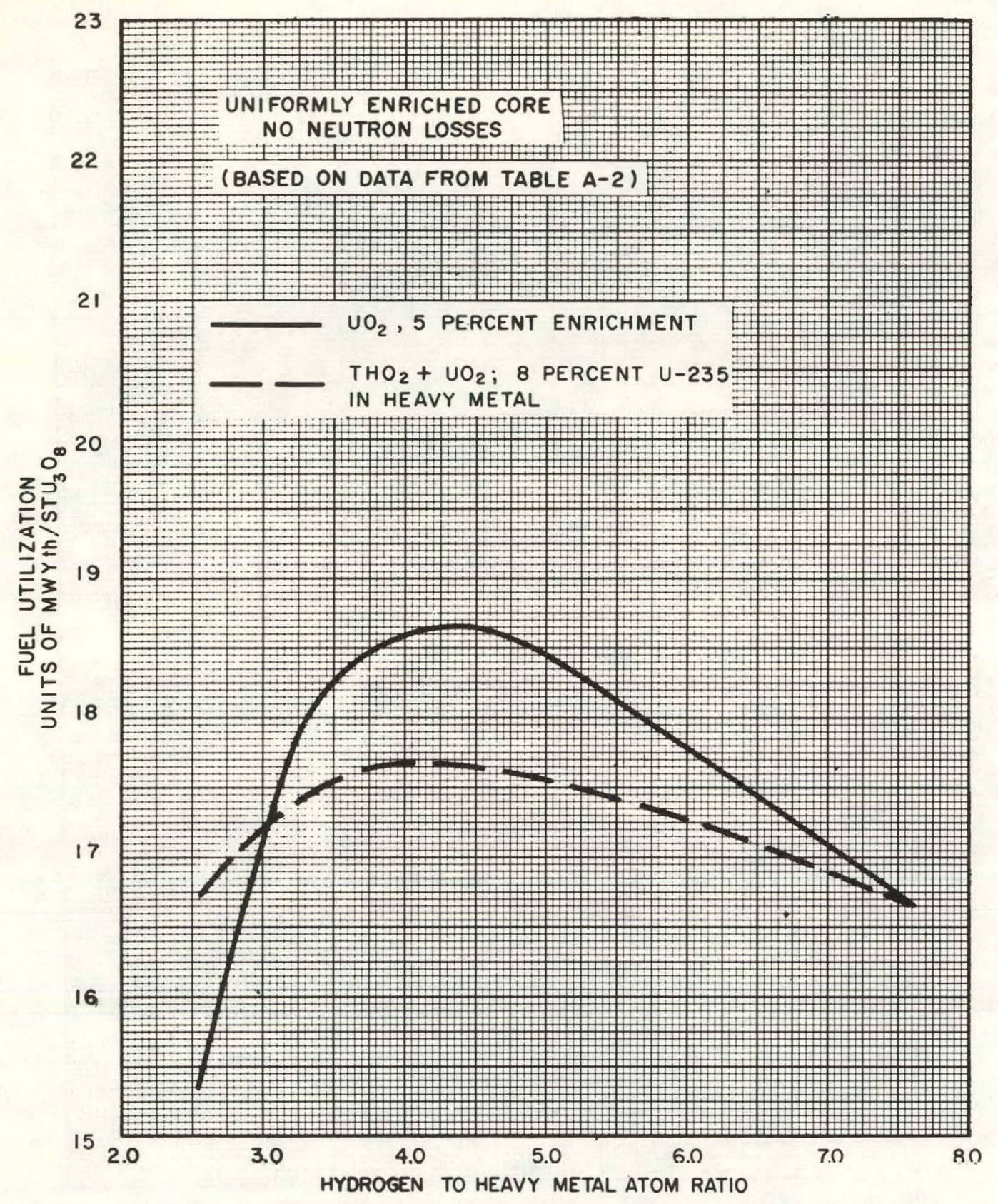

Figure A-3. Fuel Utilization Dependence On Hydrogen to Heavy Metal Atom Ratio 


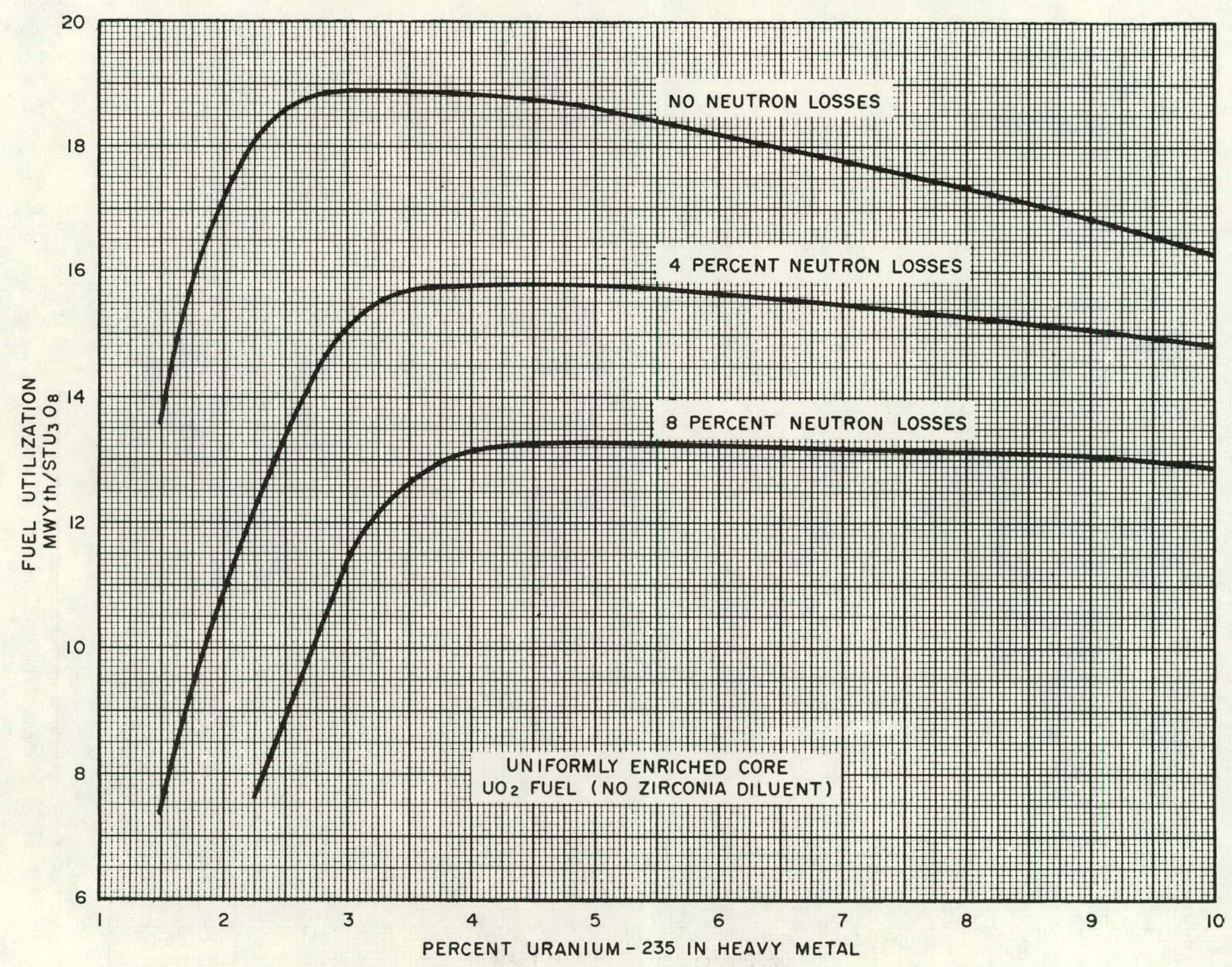




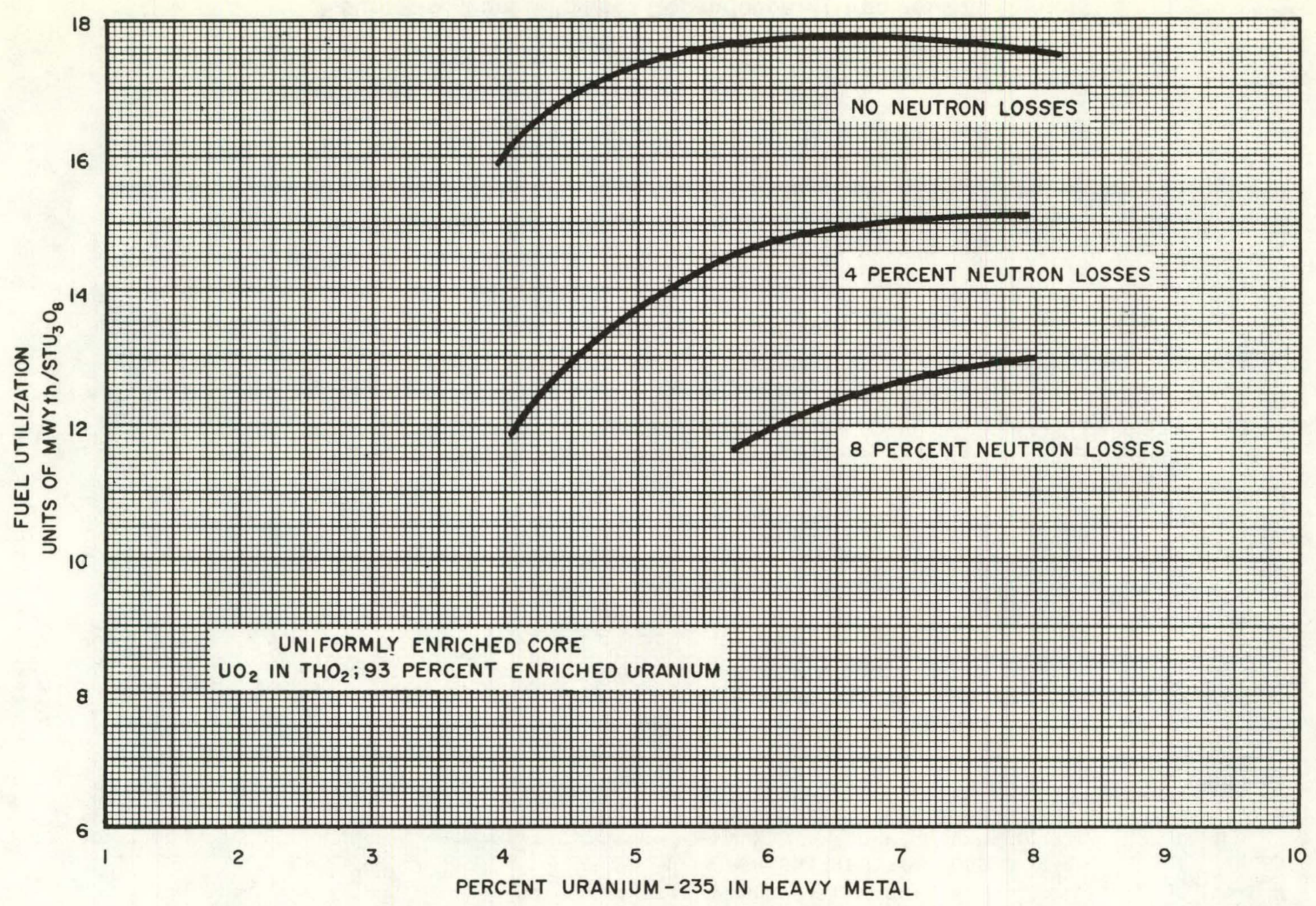

Figure A-5. Fuel Utilization Dependence on Uranium-235 Content 


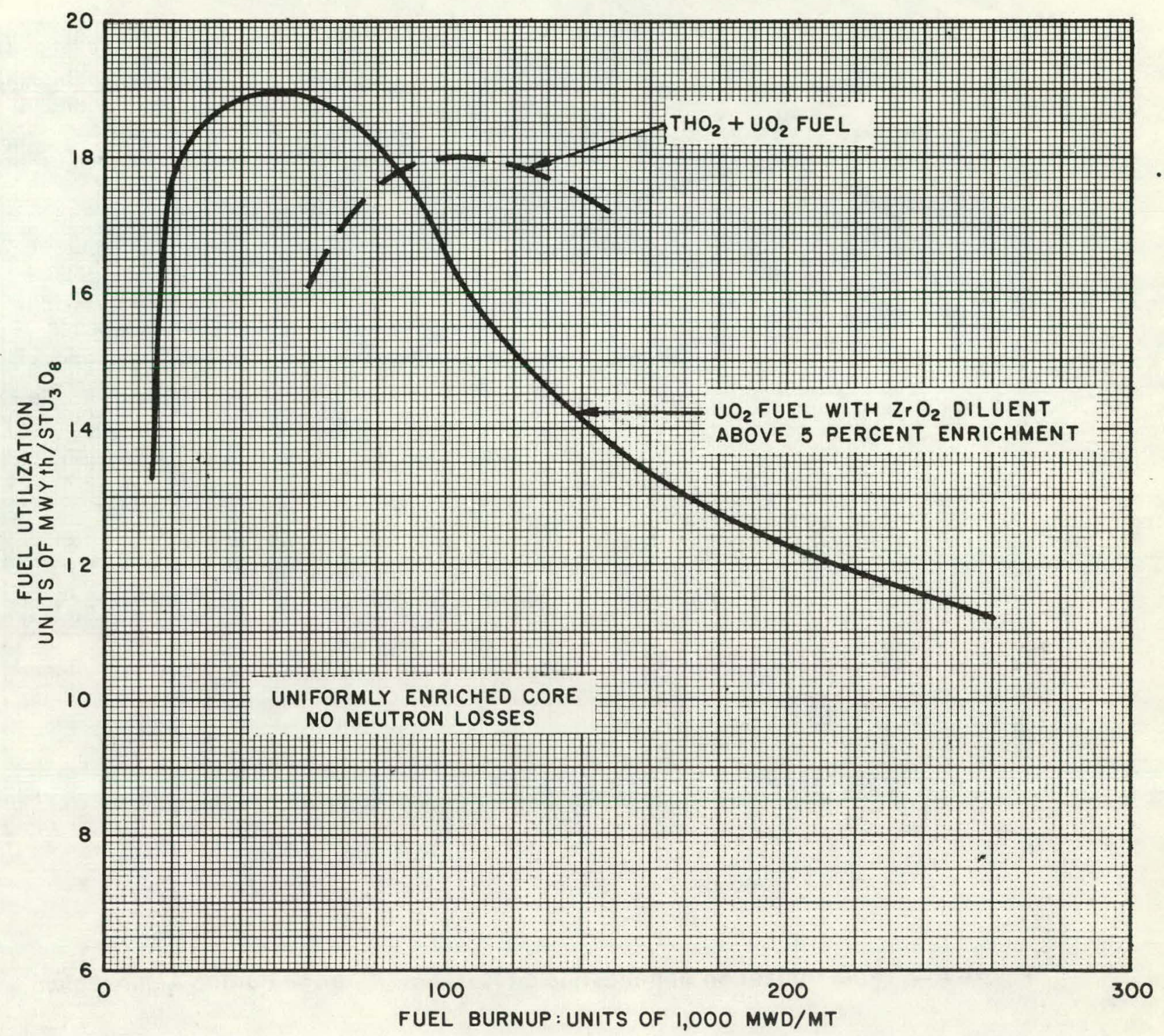

Figure A-6. Fuel Utilization Dependence on Maximum Burnup Achievable 


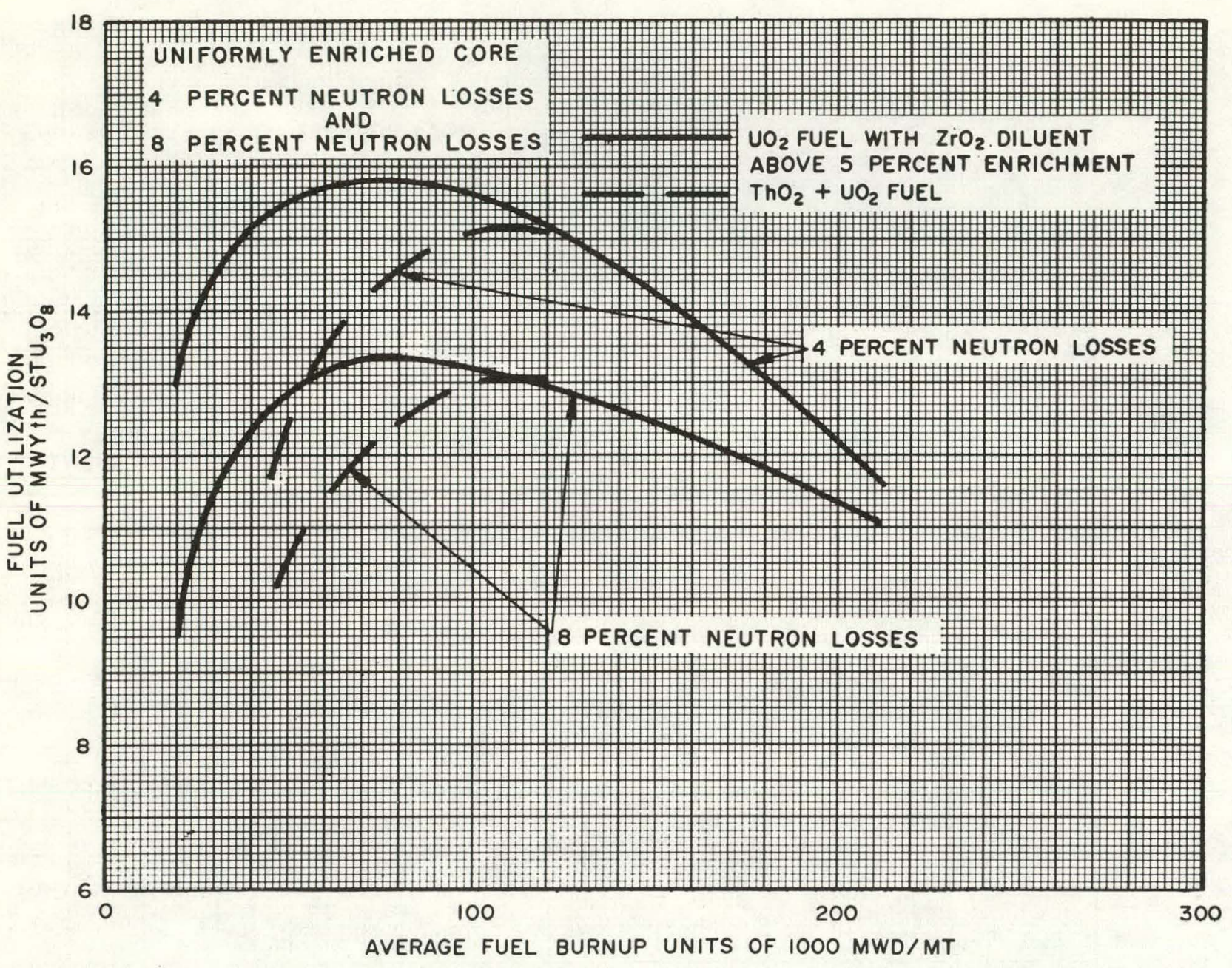

Figure A-7. Fuel Utilization Dependence on Maximum Average Burnup Achievable 


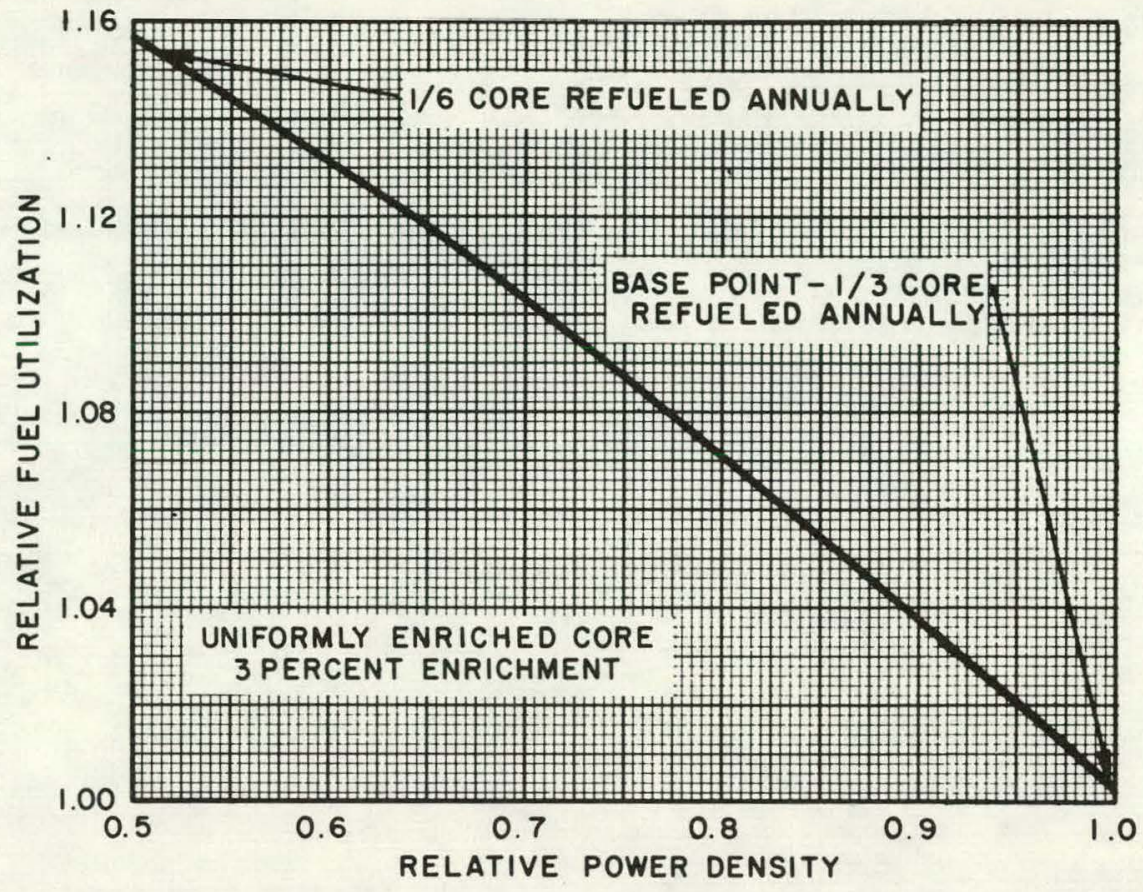

Figure A-8. Change in Fuel Utilization Due to Effect of Power Density On Fraction of Core Refueled At Annual Refueling 


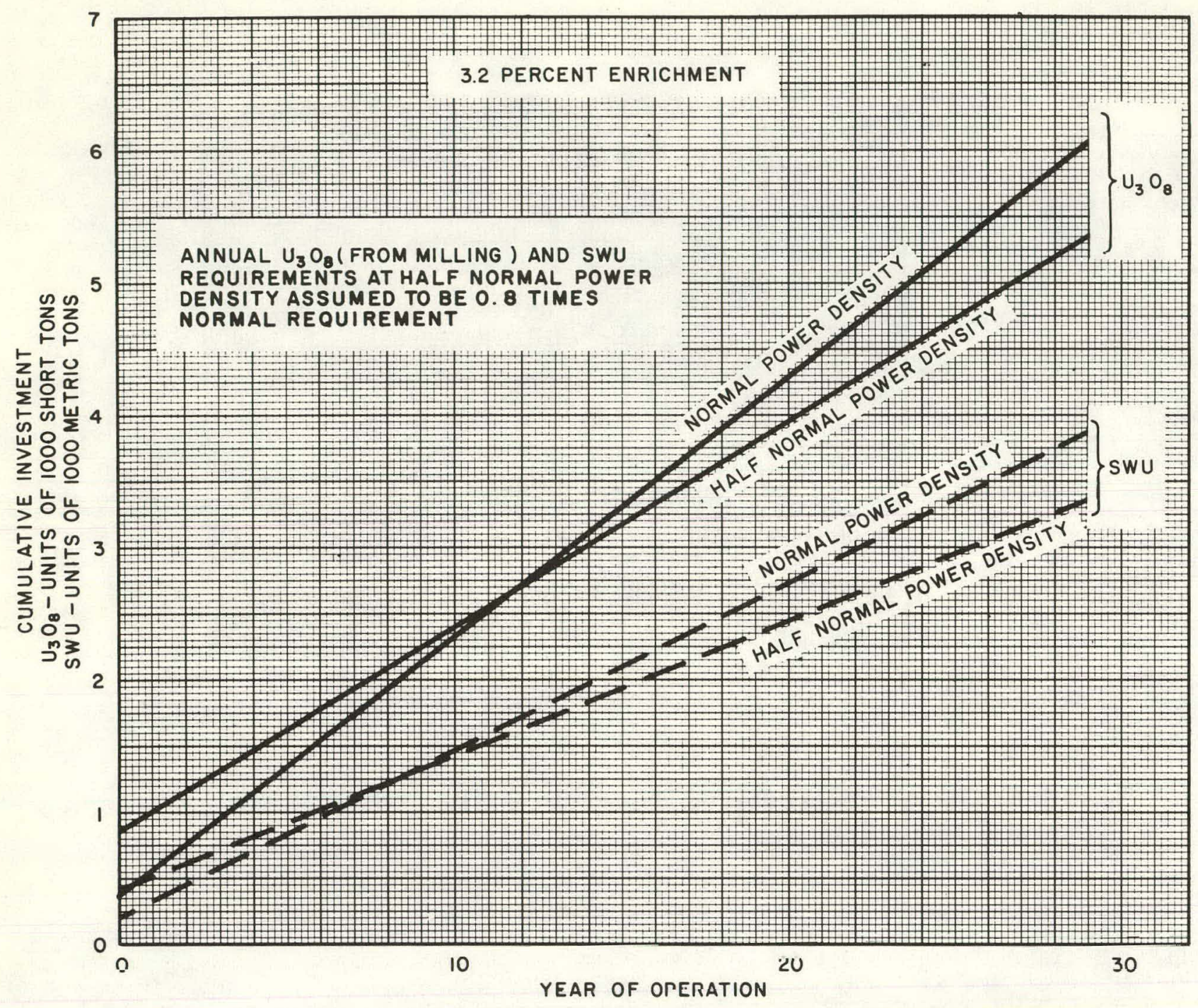

Figure A-9. $\mathrm{U}_{3} \mathrm{O}_{8}$ and Separative Work Investment Schedule To Support a 1000 MWE PWR 


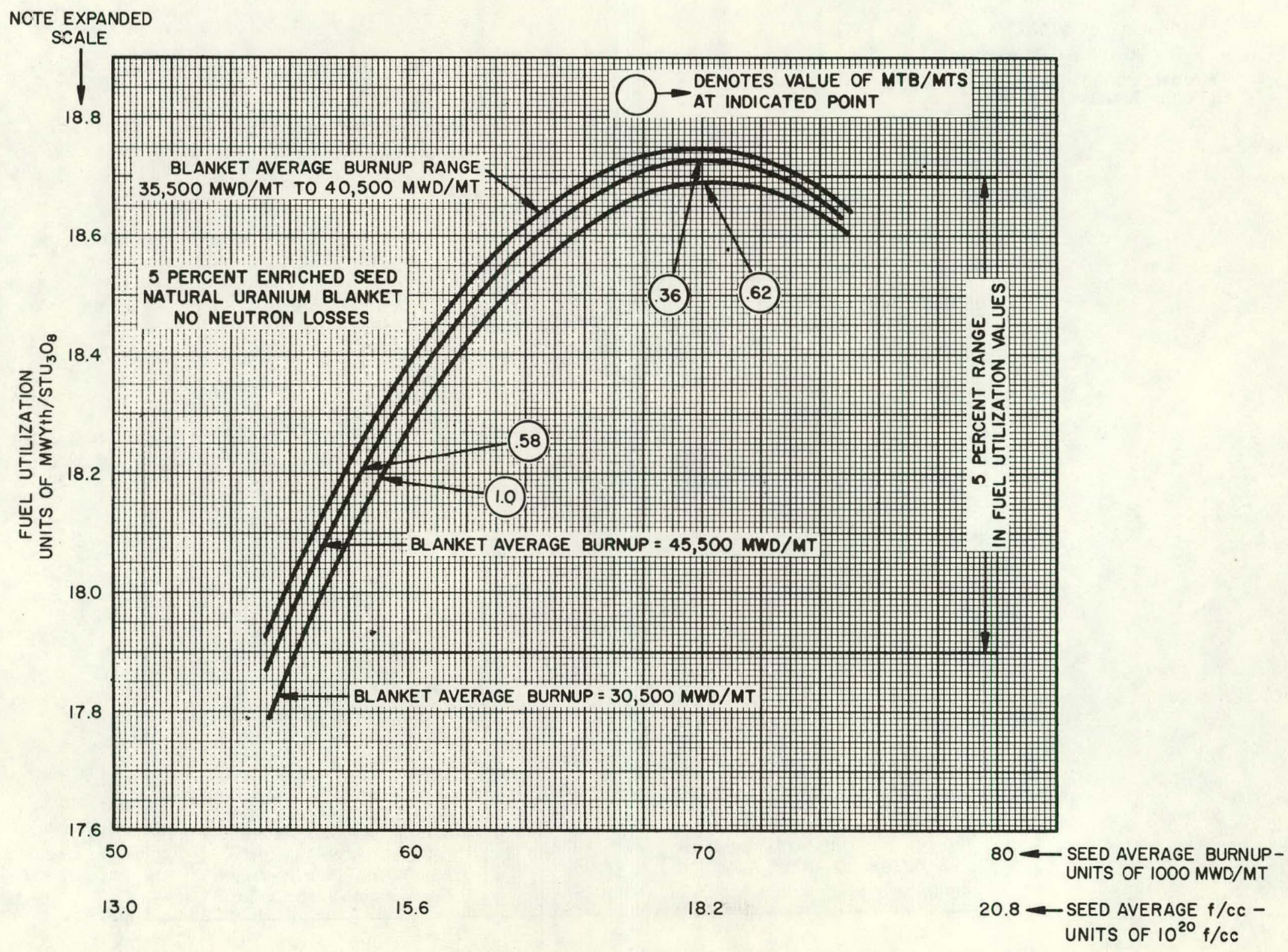




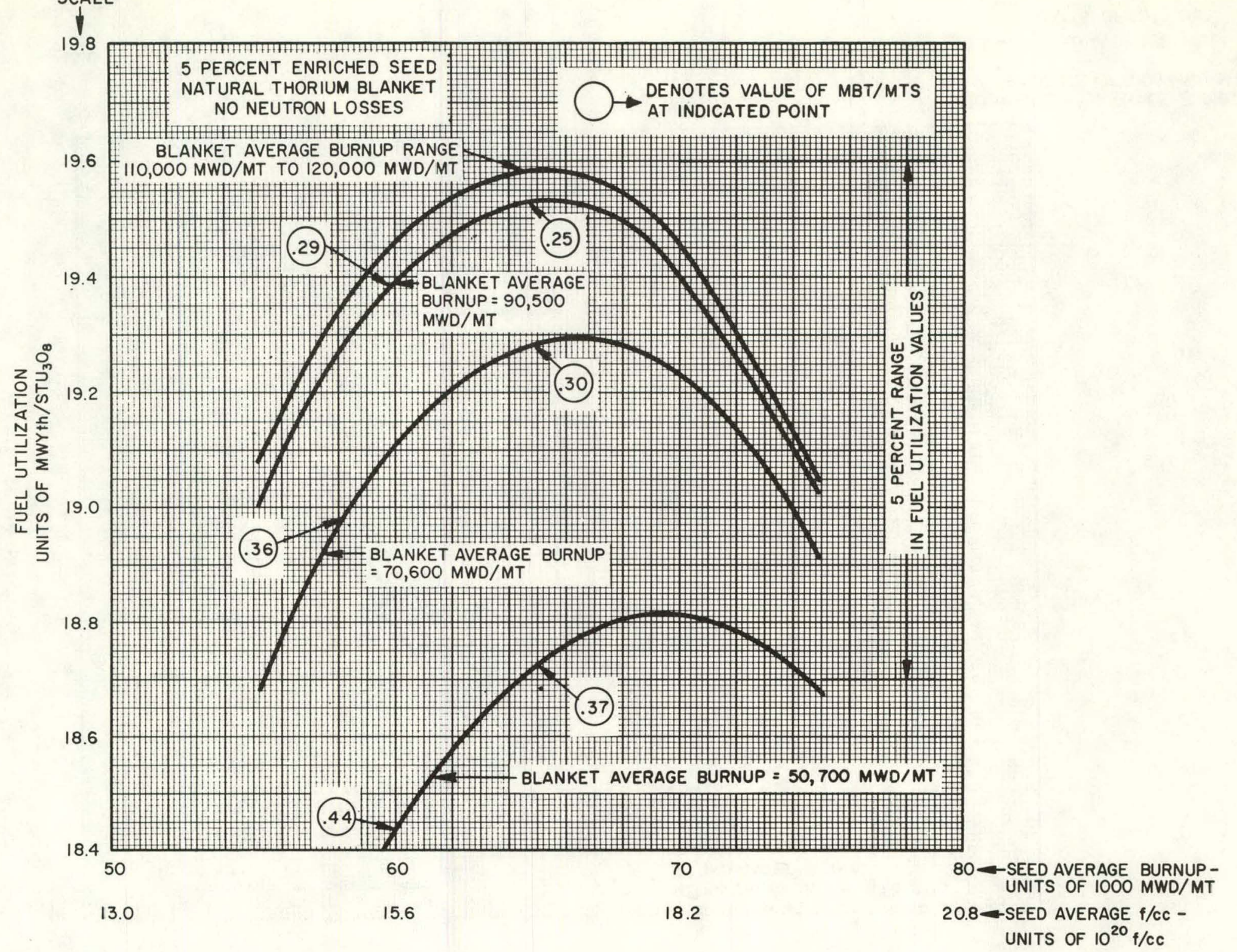

Figure A-11. Fuel Utilization, Sensitivity to Seed and Blanket Average Burnup 


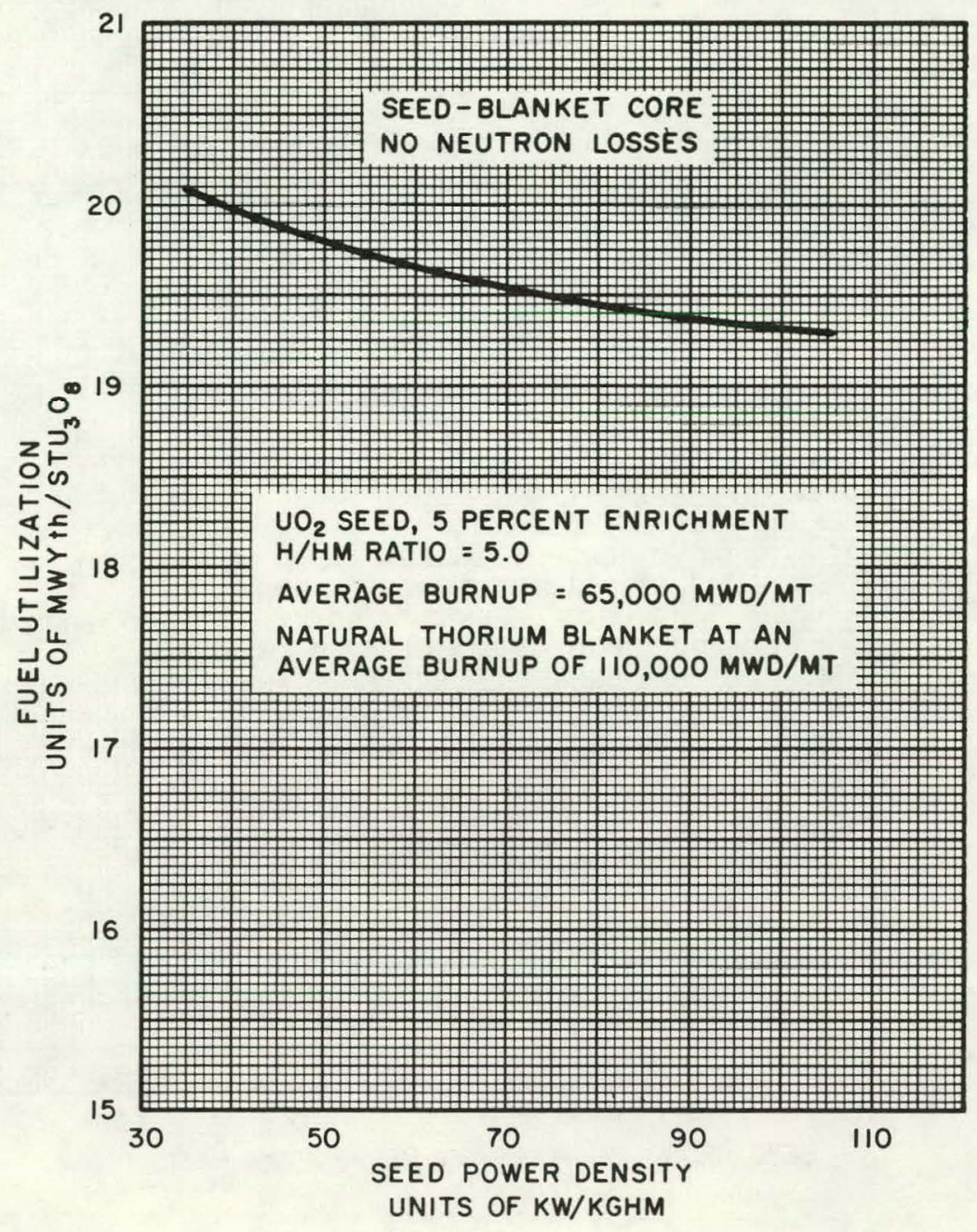

Flgure A-12. Peak Fuel Utilization Dependence On Seed Powcr Density 


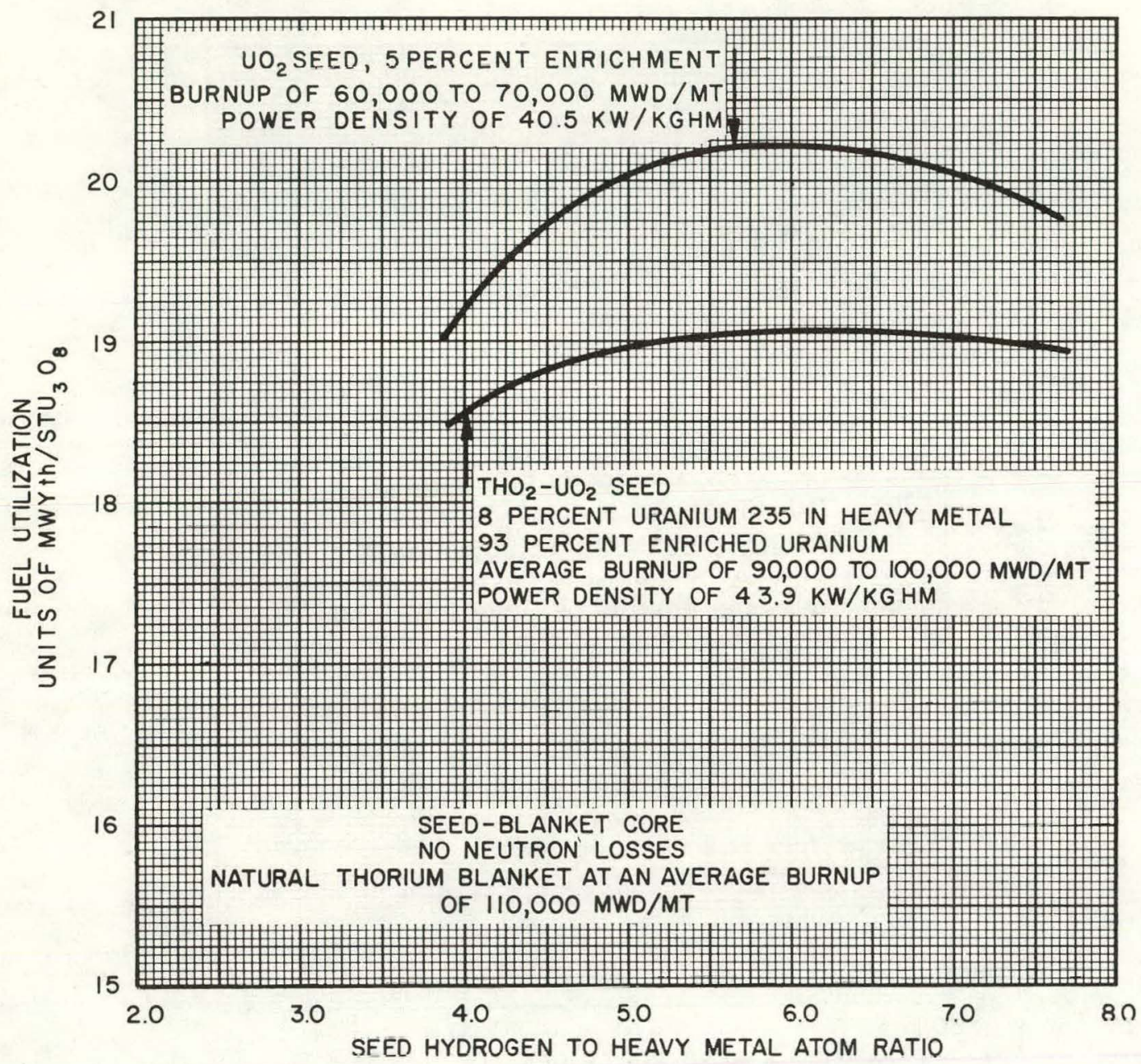

Figure A-13. Peak Fuel Utilization Dependence On Seed Hydrogen to Heavy Metal Atom Ratio 


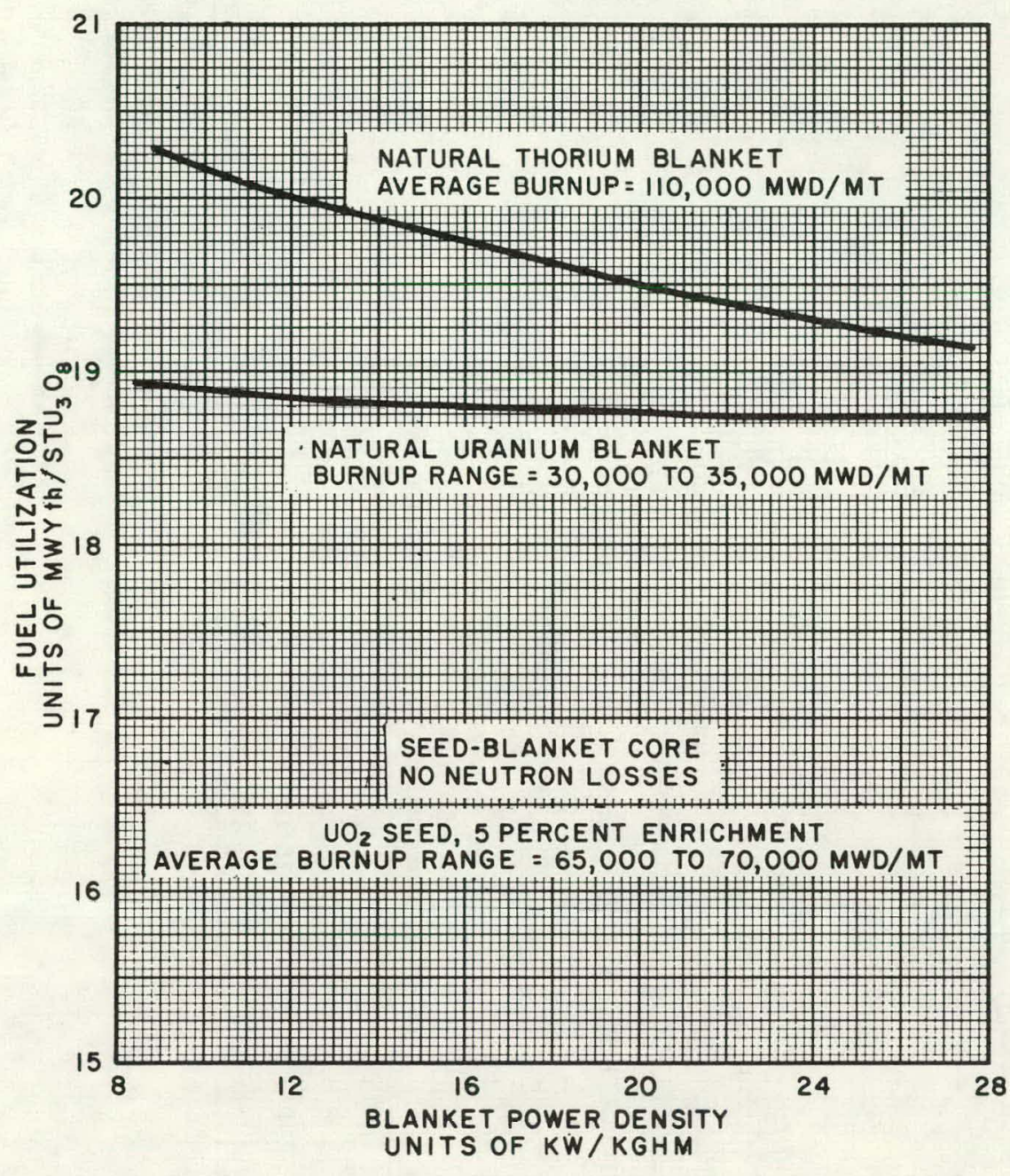

Figure A-14. Fuel Utilization Dependence On Blanket Power Density 


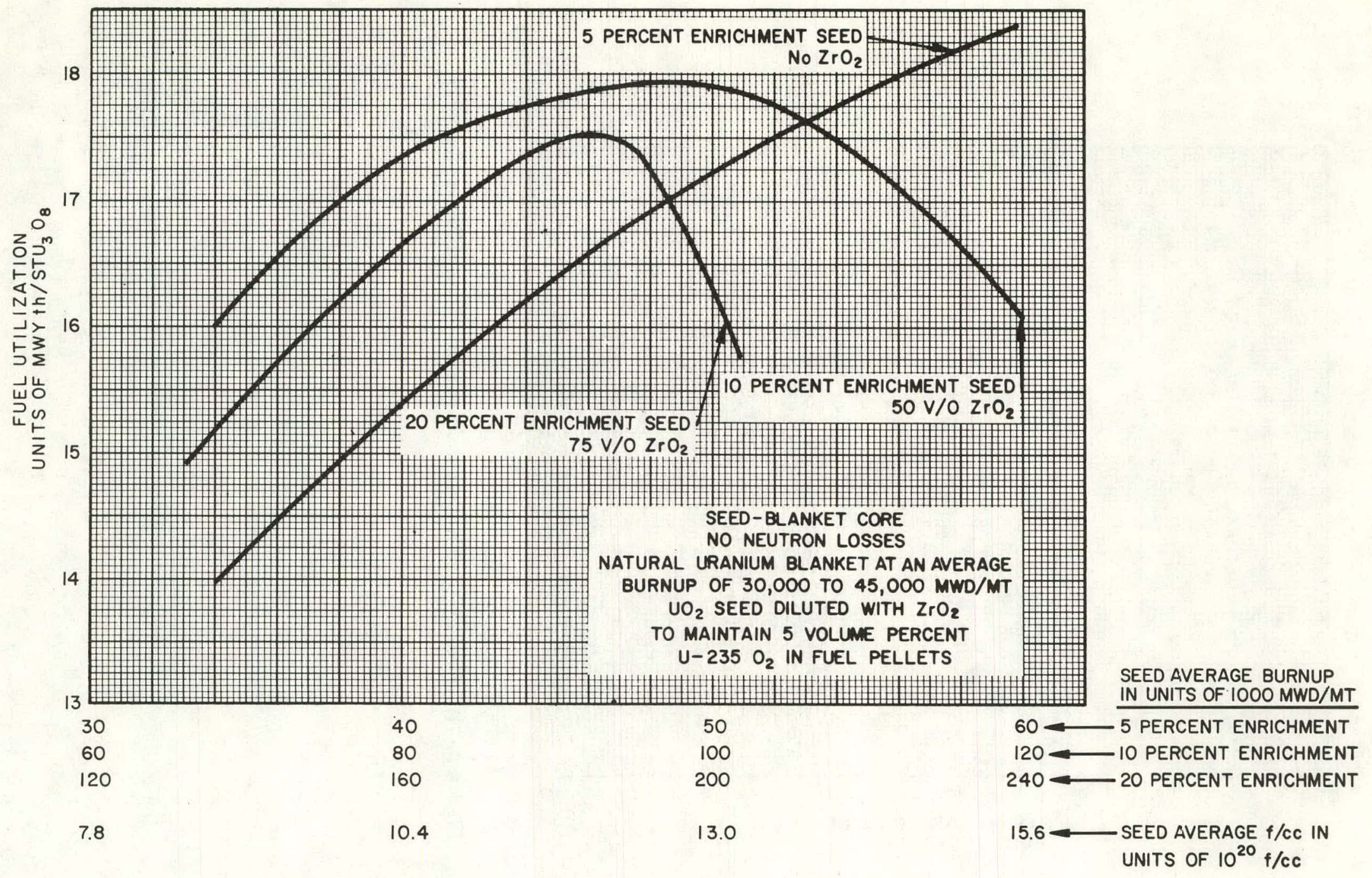

Figure A-15. Fuel Utilization Dependence on Seed Burnup and Enrichment 


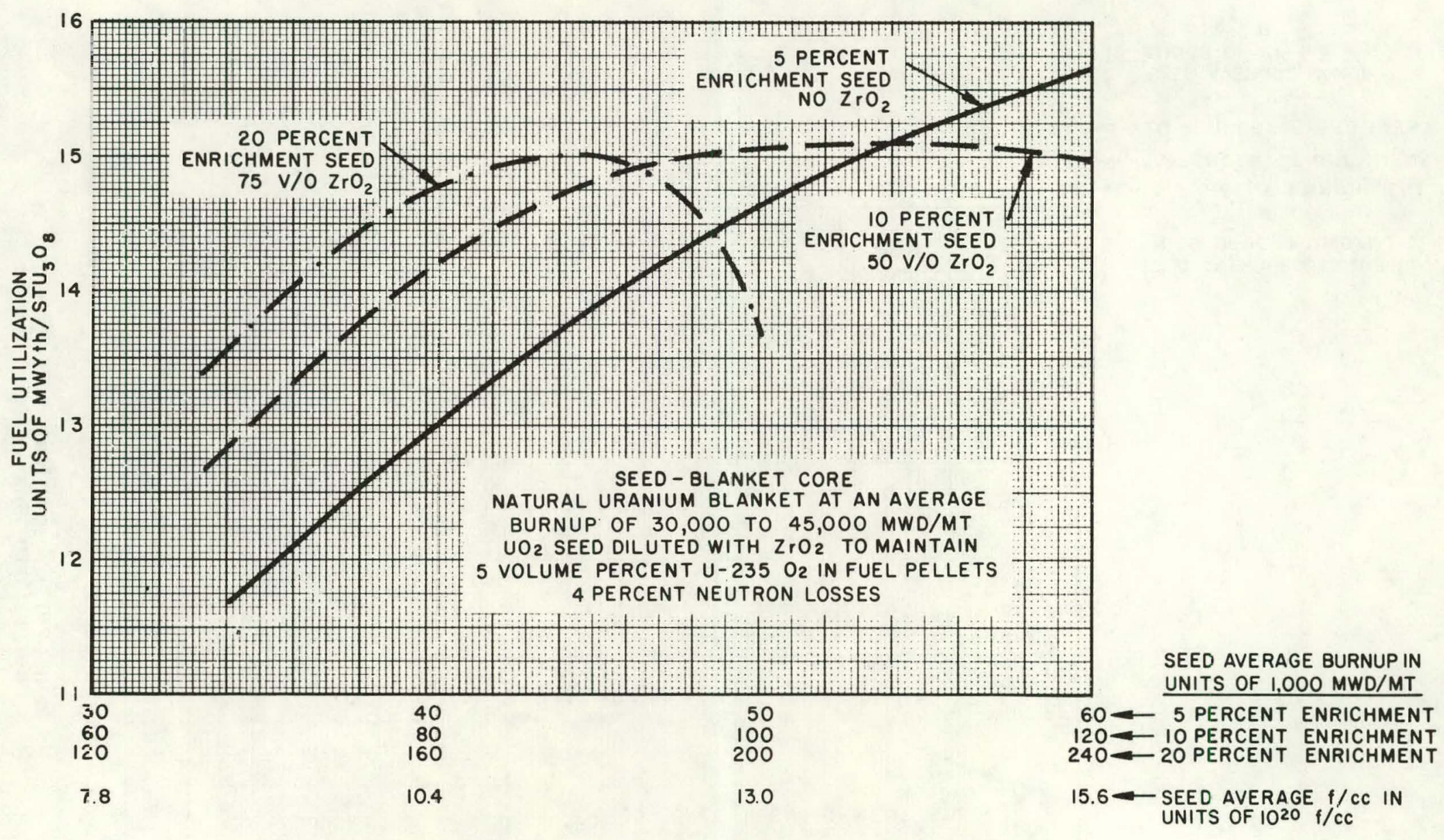

Figure A-16. Fuel Utilization Dependence on Seed Burnup and Enrichment 
SEED-BLANKET CORE

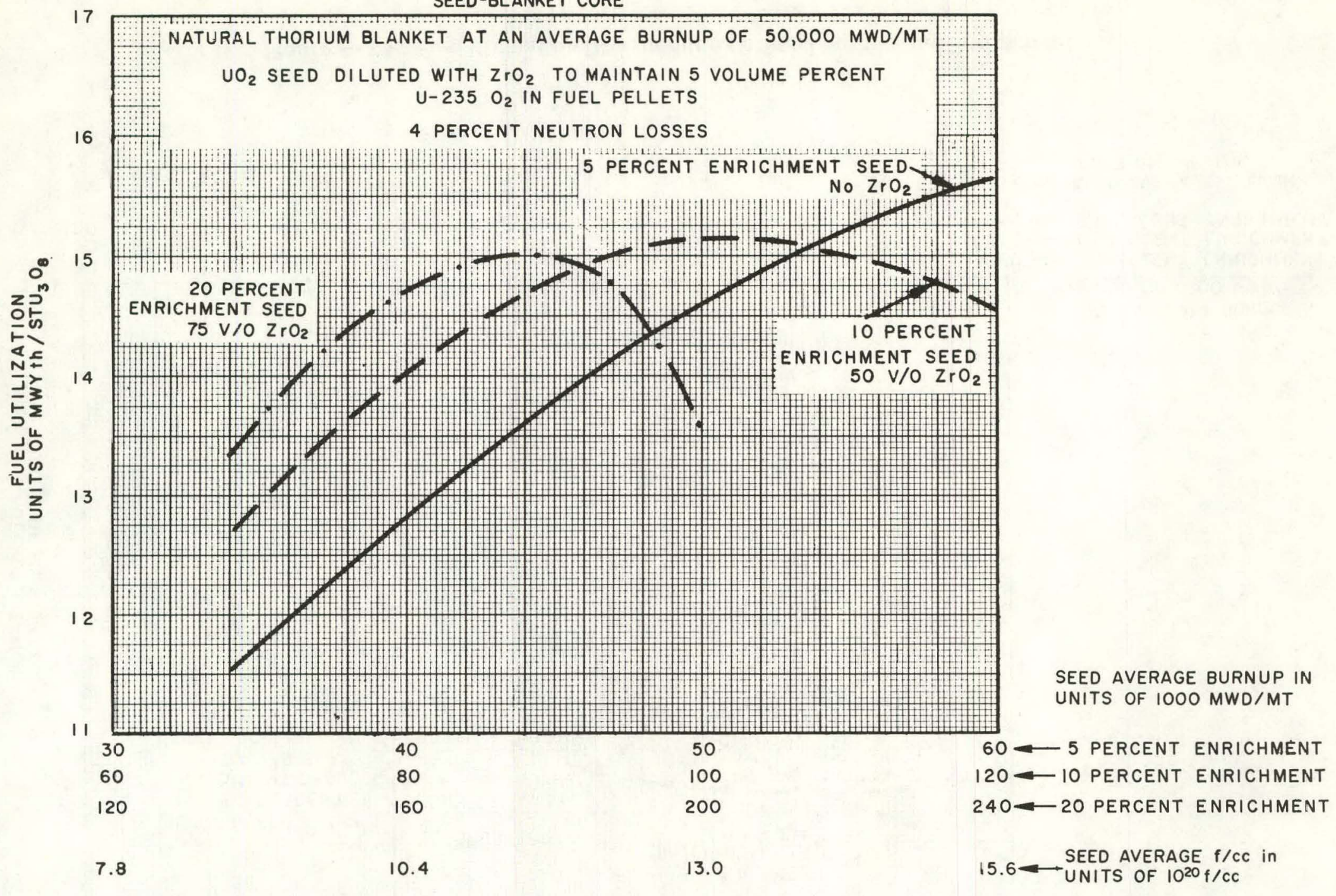

Figure A-17. Fuel Utilization Dependence on Seed Average Burnup and Enrichment 


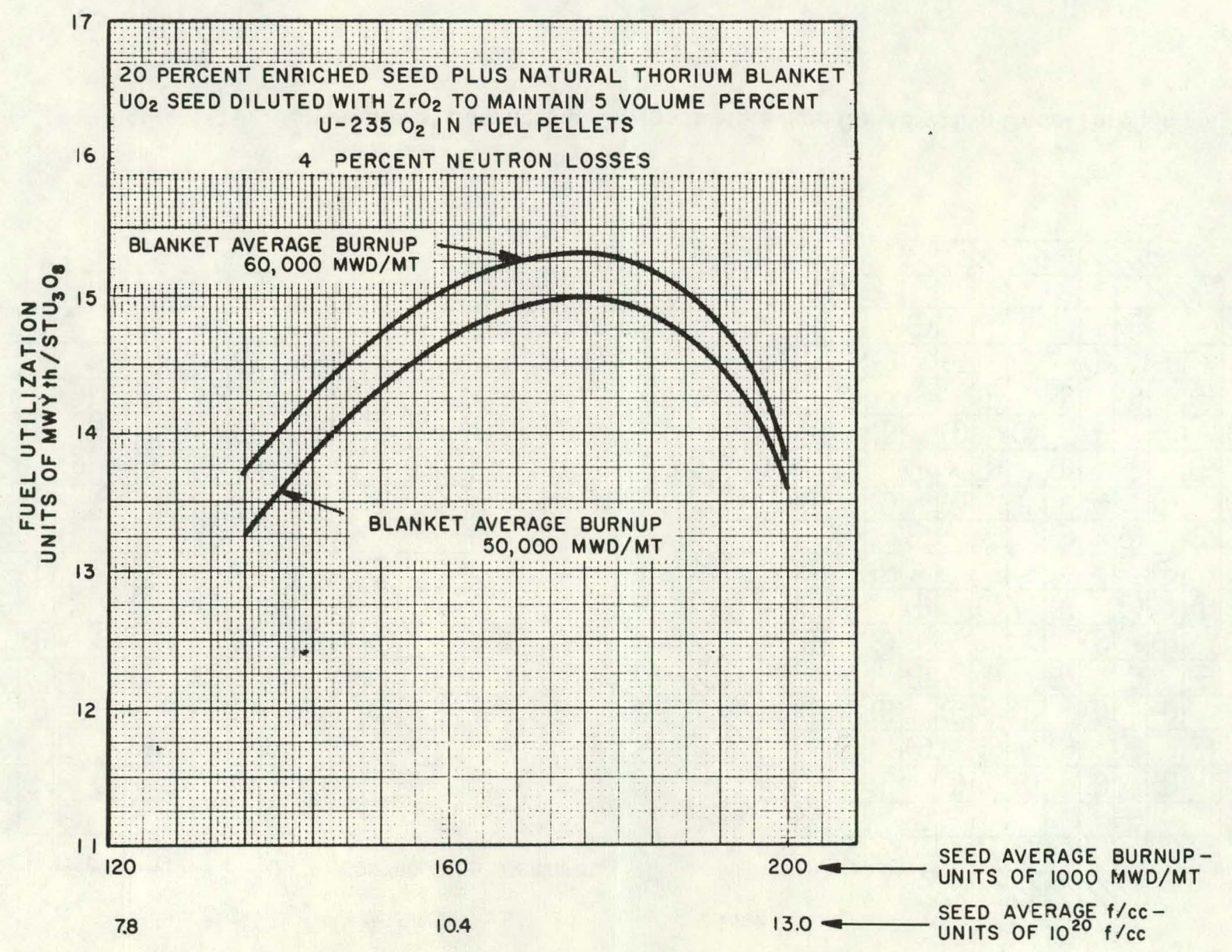

Figure A-18. Fuel Utilization Dependence on Seed and Blanket Average Burnup 


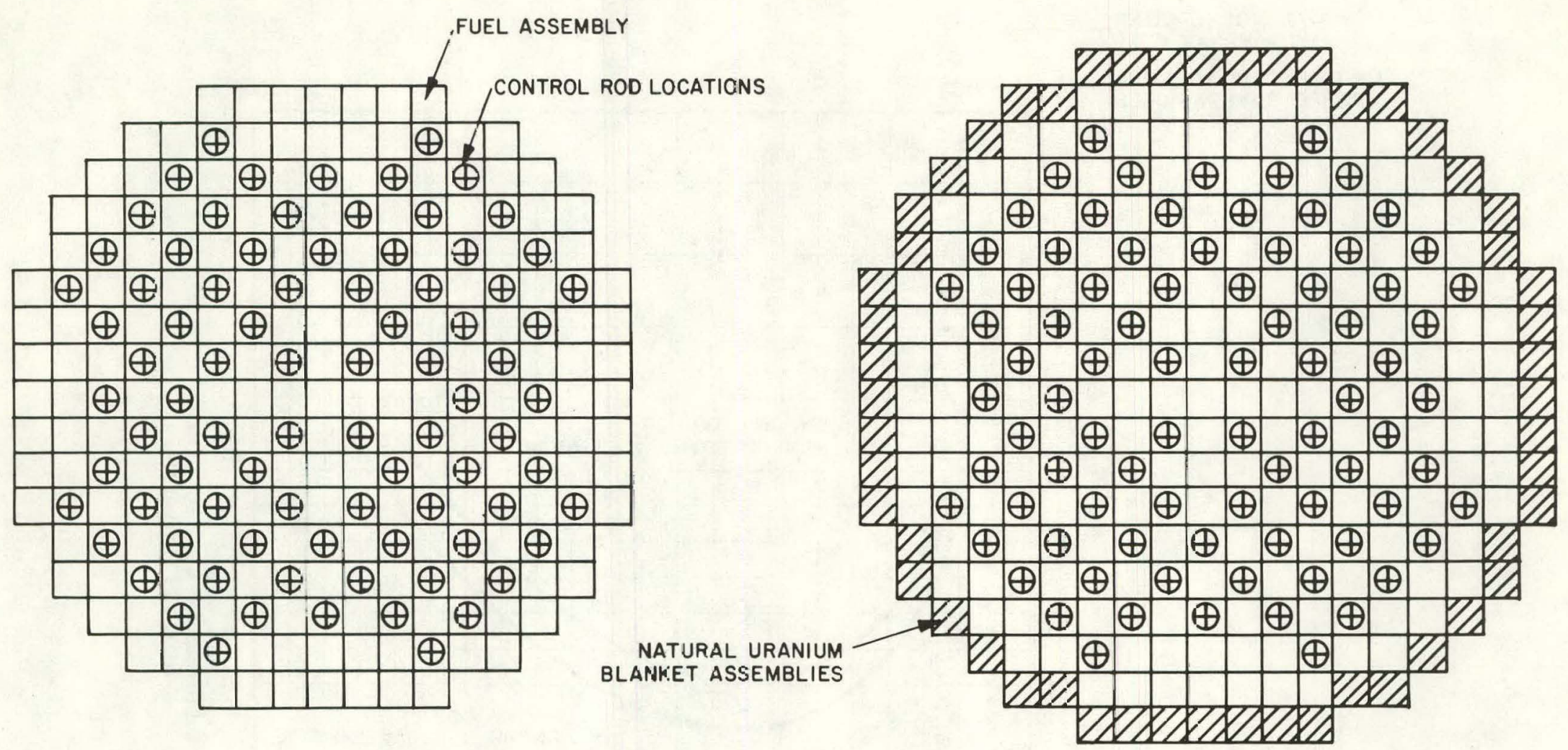

Figure A-19. Conversion of Commercial Design to More Fuel Conservative Once-Through 


\section{APPENDIX B}

FUEL UTILIZATION PRINCIPLES AND METHODS OF ANALYSIS 


\section{TABLE OF CONTENTS}

I. INTRODUCTION

II. FUEL UTILIZATION PRINCIPLES

A. Physics of Fuel Utilization in an Idealized Conventional Light Water Reactor

B. Physics of Fuel Utilization in an Idealized Seed-Blanket Reactor

B-3

C. Reactivity Shim Control and Seed-Blanket Geometry

B-3

D. Connection Between Seed Energy, Blanket Energy, and Neutron Production

B-4

E. Optimizing Fuel Utilization With No Constraints

B-5

F. Neutron Losses

B-5

G. Summary

B-6

III. ANALYTIC METHOD FOR ESTIMATING PEAK FUEL UTILIZATION WITH UNIFORM

B-6 SEED AND BLANKET BURNUP
A. No Neutron Losses
B. Analytic Method with Neutron Losses
C. Use of Point Depletion Calculations to Estimate Fuel Utilization Achievable in a Uniformly Enriched Core With Fuel Management

B-6

B-9

IV. JUSTIFICATION FOR USE OF POINT DEPLETION CALCULATIONS

V. ADDITIONAL TOPICS AND DATA
A. Additional Data From Point Depletion Calculations
B-13
B. Non-Uniform Burnup in Seed-Blanket Cores With Movable Fuel Control
B-14
1. Background
B-14
2. Analytical Method
B-14
3. Magnitude of Non-Uniform Burnup Effect on Fuel Utilization
B-15
C. Spiked Thnrium Rlankets
B-16
D. Power Peaking in a Seed-Blanket Core
B-17

VI. NUCLEAR DESIGN CALCULATIONAL METHODS
A. Methods for Early Studies of Seed-Blanket Core Concepts
B-17
B. Methods for Theoretical Fuel Utilization Studies
B-18
C. Methods for Detailed Calculations on Reference Core
B-18

VII. SIMULATION OF FULL CORE CALCULATIONS

R-19
A. General Discussion
B-19
B. Sources of Uncertainty
B-20

VIII. NOTATION AND DEFINITIONS 


\section{TABLE OF CONTENTS (Cont)}

Page

IX. ANALYTIC SOLUTION FOR FUEL MANAGEMENT EQUATION

B-23

REFERENCES

B-24

\section{LIST OF TABLES}

Table

Title

Page

B-1 Fuel Utilization, Seed-Blanket Cells and Point Depletion Calculations B-25

B-2 Peak Fuel Utilization Summary; Point Depletion Calculations B-26

B-3 Fuel Utilization With Non-Uniform Seed Burnup, Natural Uranium Blanket $\quad$ B-27 With Uniform Burnup of 35,000 MWD/MT, No Neutron Losses

\section{LIST OF FIGURES}

Figure Title

Page

B-1 Case 1 Neutron Economy

B-2 Case 2 Neutron Economy

B-3 Case 3 Neutron Economy

B-4 Neutron Economy

B 6 Noutron Economy

B-6 Dependence of Reactivity Lifetime Control Swing on Seed-Blanket Geometry

B-7 Seed Excess Neutron Derivative Curve

B-8 Seed Excess Neutron Derivative Curve

B-9 Seed Excess Neutron Production

B-10 Seed Excess Neutron Production 


\section{LIST OF FIGURES (Cont)}

B-11 Net Neutron Absorption in Natural Uranium Blanket

B-12 Seed Excess Neutron Production

B-40

B-13 Seed Excess Neutron Production

B-41

B-14 Seed Excess Neutron Production

B-42

B-15 Seed Excess Neutron Production

B-43

B-16 Seed Excess Neutron Production

- B-17 Seed Excess Neutron Production

B-45

B-18 Seed Excess Neutron Production

B-19 Seed Excess Neutron Production

B-47

B-20

Seed Excess Neutron Production

B-48

B-21

Blanket Net Neutron Absorption

B-49 


\section{INTRODUCTION}

This appendix discusses fuel utilization principles and methods of analysis. Section II includes a qualitative discussion of fuel utilization principles which expands on the discussion presented in Section III of the main text. Section III presents the development of an analytical method for estimating peak fuel utilization achievable in a seed-blanket core based on point depletion calculations. Section IV contains a comparison of data from seed-blanket radial geometry cell calculations with data from point depletion calculations. This comparison supports the use of point depletion calculations to simulate the behavior of seed and blanket fuel regions in a seed-blanket core, or of the fuel region in a uniformly enriched core. Section $V$ presents miscellaneous topics, namely, additional data for the point depletion calculations discussed in Appendix A, fuel utilization as a function of seed volume fraction, the effects on fuel utilization of non-uniform seed burnup, thorium blankets spiked with small concentrations of uranium-235, and power peaking in a seed-blanket core. Section VI includes a description of the calculational model which was used for the point depletion calculations and the seed-blanket cell calculations. Section VII contains a discussion which provides additional support for the use of point depletion or cell calculations to simulate the operation of a core with fuel management and/or movable fuel reactivity control. Section VIII lists the notation and definitions used in this appendix.

\section{FUEL UTILIZATION PRINCIPLES}

An elementary explanation of the physics of fuel utilization in uniformly enriched cores and in seed-blanket cores will be presented first. This serves as a prelude to the theoretical and quantitative presentation in later sections.

\section{A. Physics of Fuel Utilization in an Idealized Conventional Light Water Reactor}

An idealized conventional light water reactor is defined here as one in which all modules have the same fuel loading when initially installed in the reactor, and all modules have exactly the same depletion history when removed from the reactor. In addition, there is no neutron leakage. This discussion begins by considering the simplest type of fuel management, referred to as Case 1, where the entire core is replaced at each refueling, poison reactivity shim control is used, and the time of refueling is defined by the poison shim concentration or length of control rods inserted being reduced to zero. At the start of irradiation, each of the modules produces excess neutrons which are captured in the removable poison. At the end of irradiation, each of the modules is neither a net producer nor a net consumer of neutrons; no poison shim is required because of the combined effects of reduced fissile inventory and increased fission product inventory. For convenience, the module history up to this point will be referred to as Phase 1. A plot of the history of neutron production versus energy production is shown in Figure B-1.

In Figure B-1 the ordinate is the net number of excess neutrons produced per metric ton of fuel in the reactor, and the abscissa is the energy produced (in megawatt days thermal) per metric ton of fuel (uranium and thorium) initially fueled in the reactor. The energy per metric ton is referred to as the burnup, and for a particular density of fuel material is an indicator of how many fissions have 
occurred in each cubic centimeter of fuel. At the time of refueling, each module has produced energy $E_{1}$ per metric ton and excess neutrons $N_{1}$ per metric ton. All of the $N_{1}$ excess neutrons have been captured in the poison shim.

The next type of fuel management to be considered is referred to as Case 2, in which only half of the core (the most depleted modules) is replaced at each refueling. However, it is assumed that the module loadings are identical with those of Case 1 . The burnup achieved between refuelings will necessarily be shorter than in Case 1 because at the time of refueling the modules which remain in the core have not yet reached the end of Phase 1 (defined above). The modules to be replaced have been depleted beyond the end of Phase 1 .

In Case 2 some of the excess neutrons from modules in Phase 1 are captured in modules which are beyond Phase 1. A plot of the history of neutron production versus energy uruduction for modules up tn the time they are removed trom the core at each relueliny is shown in rigure $B=2$. In thic case, at the time of refueling energy $E_{2}$ per metric ton has been produced in each module removed, and $E_{2}$ is greater than $E_{1}$. The number of excess neutrons per metric ton produced in each module removed is $N_{2} . N_{2}$ is smaller than $N_{1}$ because the module has been a net absorber of neutrons since the end of Phase 1. At the time of refueling, the modules which are not being removed are at point $\left(N_{A}, E_{A}\right)$; they are still net producers of neutrons. Again, the condition for refueling is that the poison concentration has been reduced to zero, so that summed over the entire core the net rate of excess neutron production is zero. This means that the modules at point $\left(N_{A}, E_{A}\right)$ are producing excess neutrons at exactly the same rate that the modules at point $\left(N_{2}, E_{2}\right)$ are capturing them. Three points emerge from this discussion.

1. For each metric ton of fuel discharged the energy produced is greater in Case 2 than it is in Case 1. The fuel utilization in Case 2 is therefore greater than in Case 1.

2. For each metric ton of fuel discharged, the number of excess neutrons captured in poison in Case 2 is smaller than that in Case 1 . The lifetime average number ol removable poison atoms in the core in Case 2 is therefore smaller than the number in Case 1.

3. The fuel burnup in Case 2 is higher than that in Case 1. Increased fuel utilization would require that fuel elements be capable of withstanding increased burnup.

In the limiting case of almost continuous refueling (which is done in the CANDU reactors but which would not be feasible in current commercial light water reactors), the amount of removable poison required would be very small. In this case, Case 3, almost all excess neutrons from modules in Phase 1 would be captured in modules which had passed Phase 1. This would result in a higher burnup and fuel utilization than would be obtained from Case 2. The neutron economy would now be as depicted in Figure B-3. In this figure the number of excess neutrons produced by a module up to the the time of refueling is shown as being slightly greater than zero. This is because without movable fuel reactivity control some small amount of control poison would be required and some excess neutrons would be captured in this poison. In addition, in any practical reactor there would be some loss of excess neutrons through leakage. 


\section{B. Physics of Fuel Utilization in an Idealized Seed-Blanket Reactor}

In an idealized seed-blanket reactor the neutron economy of the seed modules would follow the path shown in Figures B-1 and B-2. However, the net excess neutrons would be captured in blanket fuel. Blanket fuel would be a net absorber of excess neutrons. A typical plot of blanket neutrons captured versus energy output for a nalural uranium blanket is shown in Figure $\bar{B}-4$.

The curve looks very much like the portion of the curve beyond Phase 1 shown in Figures B-2 and B-3. This is an important point; the behavior of a blanket module is similar to the behavior of a seed module which has passed Phase 1 (that is, has become a net absorber of neutrons).

The curve for a thorium blankel has more structure than that for a natural uranium blanket (Figure $B-5)$. The shape of this curve is explained below.

Initially there would be no fissile atoms in a thorium blanket and the capture of excess neutrons would produce very little energy (a small amount of energy would be produced by fast fission in thorium). However, as the uranium-233 inventory would build up (due to neutron capture in thorium) the energy produced per excess neutron captured would increase rapidly. Eventually, the average energy produced per excess neutron captured would become comparable to that attainable in a natural uranium blanket.

In a seed-blanket reactor, the fuel utilization achieved depends on both the seed and blanket composition parameters and on the relative amounts of energy obtained from seed and blanket. For fixed composition parameters the maximum fuel utilization will be achieved at a point where an increase or decrease in energy from the seed is just offset by a corresponding decrease or increase in energy from the blanket. The quantitative method for determining this point will be developed later. For the present, simply note that the seed-blanket core designer has four principal degrees-offreedom for achieving maximum fuel utilization. These are the seed and blanket composition parameters and seed and blanket burnup. The calculations presented in Appendix A indicate that the peak fuel utilization achievable in a seed-blanket core is insensitive to the seed enrichment over the range from 5 percent to 93 percent. When the burnups have been found which give the maximum fuel utilization, the fuel utilization value actually achieved is not very sensitive to the relative values of energy from the seed and the blanket. This illustrates another key point: in a seed-blanket design there is a great deal of flexibility in choosing seed and blanket burnup so as to achieve both a high value of fuel utilization and acceptable thermal and mechanical performance.

The insensitivity of fuel utilization to seed enrichment is especially important because it would allow the nuclear designer to choose whatever seed enrichment was required to achieve reactivity control through the use of movable fuel. However, as noted in Appendix A, for seed enrichments greater than 5 percent, it would probably be necessary to dilute the fuel with $\mathrm{ZrO}_{2}$ in order to restrict the fuel compartment fission density to acceptable values.

\section{Reactivity Shim Control and Seed-Blanket Geometry}

It has been noted that to obtain significantly improved fuel utilization in any once-through light water reactor will require the use of movable fuel for reactivity shim control during operation at power. 
Some appreciation of the influence of seed-blanket arrangements on the reactivity control requirement can be obtained from Figure B-6 (Reference B-1). This figure is based on one-dimensional calculations on alternating slabs of seed and blanket regions and displays the required reactivity worth of the control system (which is equal to the excess reactivity) as a function of the time the reactor has operated at full power, for several values of seed thickness. This figure also illustrates how the lifetime control swing (defined as the maximum required reactivity worth of the control system during the life of the reactor) varies as a function of seed and thorium blanket geometry. Here, the mass ratio refers to uranium-235 mass in the seed relative to total seed and blanket heavy metal mass. It will be noted that proper selection of seed and blanket dimensions can greatly minimize the reactivity control swing relative to that in a homogeneous reactor (the case labelled zero seed thickness).

\section{Connection Between Seed Energy, Blanket Energy, and Neutron Production}

A more detailed consideration of the neutron economy in a seed-blanket reactor is presented in this section.

The first item to consider is the connection between seed energy, denoted by ES, and blanket energy, denoted by EB. When a self-sustaining chain reaction exists in a seed-blanket core, the seed regions in the aggregate are net producers of neutrons; that is, on the average lover all seed modules in the reactor) for every neutron which is absorbed in the seed modules more than one neutron is produced in the seed modules. Similarly, the blanket modules are net absorbers of neutrons; that is, for every neutron which is absorbed in the blanket modules, less than one neutron is produced in blanket modales. During the irradiation, energy ES is produced in seed modules and some of the excess seed neutrons are absorbed in blanket modules, leading to the production of energy EB. Thus, it is the excess seed neutrons that connect ES and EB, so that ES arrd EB ditu iul indeneriderit.

The next item to consider is the functional relationship between ES and NNS and between EB and NNB, where NNS is the net number of excess neutrons produced by seed modules and NNB is the net number of these excess neutrons captured by the blanket. There is a delinite ielatiunslitip between energy produced per module and number of excess neutrons produced per module. It is more convenient to use as the common denominator the module loading in metric tons of heavy metal, denoted by MTS (for seed) or MTB (for blanket). Hence, there is a definite relationship between ES/MTS and NNS/MTS, and between EB/MTB and NNB/MTB. The nature of these relationships - that is, for example, the shape of the curve of ES/MTS plotted against NNS/MTS -turns out to depend strongly on composition parameters such as fuel type and enrichment. The relationship also depends weakly on other seed or blanket parameters such as power density, metal-to-water ratio and fuel rod diameter. In a seed-blanket core the relationship also depends very slightly on such variables as seed radius and volume fraction; however, this dependence turns out to be of no significance. In the developments which follow it is assumed that all important composition and other parameters are fixed, so that the functions ES/MTS and EB/MTB may be considered to depend only on NNS/MTS and NNB/MTB, respectively. 


\section{E. Optimizing Fuel Utilization With No Constraints}

At this point it is possible to consider what could be done to optimize fuel utilization with fixed seed and blanket composition parameters. For a seed-blanket reactor, fuel utilization (FU) is given by

$$
F U=\frac{E S+E B}{S T S+S T B}
$$

where

$$
\begin{aligned}
& E S=\text { energy from the seed in MWYth } \\
& E B=\text { energy from the blanket in MWYth } \\
& \text { STS }=\text { short tons of } \mathrm{U}_{3} \mathrm{O}_{8} \text { required to provide the seed fuel } \\
& \text { STB }=\text { short tons of } \mathrm{U}_{3} \mathrm{O}_{8} \text { required to provide the blanket fuel. }
\end{aligned}
$$

To simplify the discussion, the case of a thorium blanket where STB is zero (that is, no $U_{3} \mathrm{O}_{8}$ is required to supply the blanket) will be considered first. It might seem at first glance that the maximum fuel utilization could be achieved in this case by maximizing the amount of energy obtained from the blanket relative to that from the seed by adjusting the blanket volume fraction in the reactor. However, it can be seen that this is not necessarily the case by recasting Equation (1) for the case of STB $=0$ in the following form

$$
\mathrm{FU}=\left[\frac{\mathrm{ES}}{\mathrm{STS}}\right] \times\left[1+\frac{\mathrm{EB}}{\mathrm{ES}}\right]
$$

It has already been noted that EB/ES can be increased by increasing the blanket volume fraction. However, the seed modules must then be removed at lower depletion, and this will decrease ES/STS. Whether or not FU increases then depends on the derivatives of the terms on the right-hand side of Equation (2). Increasing the blanket volume fraction will cause FU to increase only if the fractional increase in the term $1+E B / E S$ is greater than the fractional decrease in ES/STS. In the case of a natural uranium blanket the analog of Equation (2) is as follows

$$
\mathrm{FU}=\frac{\mathrm{ES}}{\mathrm{STS}} \times\left[\frac{1}{1+\mathrm{STB} / \mathrm{STS}}\right] \times\left[1+\frac{\mathrm{EB}}{\mathrm{ES}}\right]
$$

Here the effect of increasing the blanket volume fraction adds to the complexity by changing the term $[1 /(1+$ STB/STS $)]$. These points will be developed quantitatively in later sections.

\section{F. Neutron Losses}

So tar, nothıng has been said about neutron losses, but in fact the preceding discussion and principles are all valid when there are neutron losses provided the neutron losses do not depend on the seed and blanket irradiation levels and geometrical arrangement. The neutron losses here are defined as the fraction of all neutrons generated in fission in seed plus blanket which are captured 
outside of the seed plus blanket region. The effect of neutron losses is easiest to explain qualitatively for the case of a blanket which requires no uranium mining, and for which STB is zero, for example, thorium or depleted uranium with fuel utilization given by Equation (2). For added simplicity, consider neutron losses as if they occur entirely while neutrons are on their way from the seed to the blanket, so that the only effect of losses is to make NNB smaller than NNS. In other words, not all excess seed neutrons are captured in the blanket. This means that for a given amount of seed energy produced, ES, the blanket energy produced, EB, is reduced by neutron losses because fewer neutrons are captured in the blanket. Hence, the term EB/ES in Equation (2) is decreased by neutron losses, and FU is also decreased.

Fuel utilization turns out to be quite sensitive to neutron losses as defined above. This is largely due to the fact that each excess seed neutron absorbed in the blanket leads to several fissions. The sensitivity will be examined quantitatively in subsequent sections.

\section{G. Summary}

The preceding discussion can be condensed by looking at a seed-blanket core as a collection of Phase 1 seed modules and blanket modules which may be any combination of seed modules depleted beyond Phase 1, thorium modules, natural uranium modules, or depleted uranium modules. The collection of blanket modules absorbs excess neutrons from the Phase 1 seed modules and produces energy. The fuel utilization attainable from the reactor depends on the effective neutron efficiency with which the excess neutrons can be used to produce energy. Effective neutron efficiency here involves not only the average neutron efficiency, that is, the average energy per neutron absorbed in the blanket, but also the cost in terms of short tons of $\mathrm{U}_{3} \mathrm{O}_{8}$ supplied to the blanket per unit of energy produced. Thorium modules and depleted uranium (enrichment plant tails with an assay of 0.2 percent uranium-235 in uranium) modules require no mining of additional $\mathrm{U}_{3} \mathrm{O}_{8}$. Seed modules which have been depleted to the end of Phase 1 and are available for additional irradiation can also be regarded as blanket modules which require no mining of additional $\mathrm{U}_{3} \mathrm{O}_{8}$.

The final point concerns the effect of non-uniform burnup. In an operating seed-blanket reactor with movable fuel control the burnup of seed and blanket would be non-uniform. This would have a small adverse effect on fuel utilization (discussed in detail in Section V.B).

\section{ANALYTIC METHOD FOR ESTIMATING PEAK FUEL UTILIZATION WITH UNI- FORM SEED AND BLANKET BURNUP}

\section{A. No Neutron Losses}

This section presents an analytic method for determining the fuel utilization achievable from any pair of seed and blanket compositions assuming that all spent seed fuel and blanket fuel has a uniform burnup. The first case considered will be that where the neutron loss term, $L$, is zero and NNB equals NNS. The case where NNB is smaller than NNS is more realistic, but is somewhat more difficult to develop and will be treated later. However, in anticipation of the final result, it is noted here that the equations for determining the seed and blanket burnup for optimum fuel utilization in the presence of neutron losses turn out to be identical with, or nearly identical with, the equations when there are no neutron losses. 
All terms are defined in Section VIII.

The fuel utilization is again given by Equation (1)

$$
F U=\frac{E S+E B}{S T S+S T B}
$$

where ES is a function of NNS and EB is a function of NNB.

This can be rearranged to obtain the following equation

$$
\mathrm{FU}=\frac{\widetilde{\mathrm{ES}}+\widetilde{\mathrm{EB}} \times \frac{\mathrm{MTB}}{\mathrm{MTS}}}{1+\left(\frac{\mathrm{MTB}}{\mathrm{MTS}}\right) \times\left(\left(\frac{\mathrm{STB}}{\mathrm{MTB}}\right)\right) \times\left(\left(\frac{\mathrm{MTS}}{\mathrm{STS}}\right)\right)} \times\left(\frac{\mathrm{MTS}}{\mathrm{STS}}\right) \times\left(\frac{1}{365}\right)
$$

In Equation (4) there are four independent variables, namely NNS, NNB, MTS and MTB. However, the quantities inside of double parentheses are dependent only on the seed or blanket compositon parameters, that is, metal-to-water ratio and initial fuel loading. In the developments which follow, these parameters will be fixed; hence, the quantities inside of the double parentheses will be constants. Further, $\widetilde{E S}$ is a function only of $\widetilde{N S}$, and $\widetilde{E B}$ is a function only of $\widetilde{N B}$, so that FU has a homogeneous property such that if each of the independent variables NNS, NNB, MTS and MTB are multiplied by the same factor, the value of FU does not change. Because of this property, FU is completely characterized by just three of the independent variables; for example, if the variable MTS is fixed, the entire range of $F U$ can be found by varying the other three independent variables. Finally, in an ideal seed-blanket core, all excess seed neutrons are absorbed in the blanket so that NNS is equal to NNB. Therefore, FU is completely characterized by just two independent variables. These will be chosen to be $\widetilde{N S}$ and MTB.

Now for convenience write FU as follows

$$
\mathrm{FU}=\alpha \times \frac{\widetilde{\mathrm{ES}}+\widetilde{\mathrm{EB}} \times(\mathrm{MTB} / \mathrm{MTS})}{1+\beta \times(\mathrm{MTB} / \mathrm{MTS})}
$$

where

$$
\begin{aligned}
& \alpha=\left(\frac{1}{365}\right) \times\left(\left(\frac{\text { MTS }}{\text { STS }}\right)\right) \\
& \beta=\left(\left(\frac{\text { STB }}{\text { MTB }}\right)\right) \times\left(\left(\frac{\text { MTS }}{\text { STS }}\right)\right) \quad(\beta=0 \text { for a thorium blanket or a depleted uranium blanket })
\end{aligned}
$$

In order to find the maximum value of FU, denoted by Fî̀, given functional forms for $\tilde{E} \bar{S}$ and $\tilde{E B}$, take the partial derivatives with respect to $\widetilde{N S}$ and MTB and require that they vanish simultaneously. The relationships which give the seed and blanket burnup leading to peak fuel utilization turn out to be as follows: 


$$
\begin{gathered}
\frac{\partial \widetilde{E S}}{\partial \widetilde{N S}}+\frac{\partial \widetilde{E B}}{\partial \widetilde{N B}}=0 . \\
\widetilde{E B}-\beta \times \widetilde{E S}-\left(1+\beta \times \frac{\widetilde{N S}}{\widetilde{N B}}\right) \frac{\partial \widetilde{E B}}{\partial \widetilde{N B}} \times \widetilde{N B}=0 .
\end{gathered}
$$

An additional relationship, which represents neutron conservation is

$$
\frac{\text { MTB }}{\text { MTS }}=\frac{\tilde{N S}}{\widetilde{N B}} \text {. }
$$

From point depletion calculations it is possible to determine $\widetilde{E S}, \widetilde{E B}, \widetilde{N S}$, and $\widetilde{N B}$ at which Equations (6) and (7) are satisfied. Equation (5) is then used to calculate the fuel utilization.

With respect to the ratio MTS/MTB, it is important to note that this is the ratio of seed loading to blanket loading for long term core operation. It is not necessarily the ratio of incore loadings since, for example, blanket modules may be irradiated for more than one seed life. Similarly, the ratio STS/STB does not necessarily represent the ratio of loading requirements to produce the seed and blanket loadings present in a core. This point has been discussed in Appendix A, IV. B.1.

Equations (6) and (7) are convenient for calculations; however, they can be put in a form where they can be given a simple physical interpretation. The new form is as follows:

$$
\begin{aligned}
& \frac{\partial E S}{\partial N N S}=-\frac{\partial E B}{\partial N N B} \\
& \frac{\partial E B}{\partial N N B}=\left[\frac{E B}{N N B}-\frac{S T B}{S T S} \times \frac{E S}{N N S}\right] \times \frac{1}{1+\text { STB/STS }} .
\end{aligned}
$$

Equation (6a) states that at the peak value of $F U$, ( $\hat{F U})$, the energy obtained by investing one more neutron in the blanket is equal to the energy lost by investing one less neutron in the seed. This is an obvious condition for a maximum.

To interpret Equation ( $7 \mathrm{a}$ ), it is convenient to start with a case where STB is zero; that is, no mining of $\mathrm{U}_{3} \mathrm{O}_{8}$ is required to supply the blanket loading. This would be the case for a thorium blanket, or a blanket of uranium enrichment plant tails having 0.2 percent uranium-235 content. In this case, the equation reduces to the following

$$
\frac{\partial E B}{\partial N N B}=\frac{E B}{N N B}
$$

This equation states that at $\widehat{F U}$ the energy obtained from the blanket by investing one additional neutron is equal to the average energy per neutron from all prior neutrons invested. One might say that at this point the instantaneous efficiency of the blanket (for producing energy from neutrons invested) is equal to the maximum value of the average efficiency. Beyond this point, that is at higher burnups, the instantaneous efficiency of a spent blanket falls below the maximum average efficiency attainable from a fresh blanket, so a fresh blanket should replace a spent blanket. In the case where 
STB is not zero, the blanket has to be paid for. This means that the peak value of FU occurs at a burnup where the instantaneous efficiency is smaller than the maximum average efficiency. In this case, the penalty for investing additional neutrons in the blanket with lower than maximum average efficiency is offset by the gain due to deferring the payment for a fresh blanket until more energy has been extracted from the old one. However, it turns out that FU is very insensitive to variations in blanket burnup values about the burnup value which yields $\hat{F U}$.

\section{B. Analytic Method With Neutron Losses}

Now consider the case where the neutron loss term $L$ is not zero. Here the fuel utilization FU becomes a function of $L$, and NNB is no longer equal to NNS. However, NNB is still related to NNS through the term $L$, so FU may be considered to be a function of $\widetilde{N S}, M T B$, and $L$. For this case, consider the total number of neutrons generated, NGS and NGB. These are related to the energy produced as follows:

$$
\begin{aligned}
& \mathrm{NGS}=\mathrm{ES} \times \mathrm{MTS} \times \mathrm{QS} \\
& \mathrm{NGB}=\mathrm{EB} \times \mathrm{MTB} \times \mathrm{QB} .
\end{aligned}
$$

The neutron loss is $L$ times the total number of neutrons generated

$$
\text { Neutron Loss }=L \times(N G S+N G B)
$$

But this loss is the difference between NNS and NNB

$$
N S^{\prime}-N N B=(\widetilde{E S} \times M T S \times Q S+\widetilde{E B} \times M T B \times Q B) \times L
$$

Equations (1), (4), and (5) for the fuel utilization still apply. To obtain the optimum fuel utilization for a fixed value of $L$, again differentiate Equation (5) with respect to $\widetilde{N S}$ and MTB and require that the derivatives vanish.

It happens that one of the equations which determine the seed and blanket burnup for maximum fuel utilization is identical with Equation (7) and the other equation is identical with Equation (6), except for terms which are negligible for neutron losses between 0 and 10 percent. This means that the values of $\widetilde{E S}, \widetilde{E B}, \widetilde{N S}$, and $\widetilde{N B}$ which give peak fuel utilization are the same with or without neutron losses. The ratio MTB/MTS is no longer given by Equation (8), but must be obtained from Equation (12). The result is

$$
\frac{M T B}{M T S}=\frac{\widetilde{N S}-\widetilde{E S} \times Q S \times I_{w}}{\widetilde{N B}+\widetilde{E B} \times Q B \times L}
$$

If the ratio MTB/MTS is considered to be the only variable in Equation (5) which depends on $L$, then it is also possible to differentiate this equation with respect to $L$ to determine the dependence of fuel utilization on L. This exercise will not be carried out here, as it is easier to calculate the fuel ullilizatiun for different values of $L$. 
At this point it is appropriate to note that in practice the analytic method presented here is not the easiest way to determine the seed and blanket burnups which give the peak fuel utilization. It has already been seen in Figures $A-10, A-11$, and $A-15$ through $A-18$ that the fuel utilization near the peak value is relatively insensitive to seed and blanket burnup. Hence, in practice it is easier to find the peak fuel utilization and corresponding burnup for no neutron losses by choosing several values of seed and blanket burnup and calculating the fuel utilization using Equation (5). The ratio MTB/MTS in Equation (5) is found using Equation (8). Plotting the resulting values of fuel utilization permits a rapid and adequately accurate determination of both peak fuel utilization and corresponding seed and blanket burnups. These burnup values are also appropriate for calculations with neutron losses. (See discussion following Equation (12).) To calculate fuel utilization with neutron losses, Equation (13) can now be used to obtain the appropriate ratio of MTB to MTS, and Equation (5) can again be used with the new value of MTB/MTS to calculate the fuel utilization.

\section{Use of Point Depletion Calculations to Estimate Fuel Utilization Achievable in a Uniformly Enriched Core With Fuel Management}

The concept of excess neutron conservation used in the preceding section can also be applied to floating eigenvalue point depletion calculations to estimate the average burnup attainable (and, hence, the fuel utilization achievable) when fuel management is used. The fuel management. strategy here is defined by the fraction of the core which is to be replaced at each refueling and the condition that, at the time of refueling, the poison shim content of the reactor has been reduced to zero; that is, all shim control rods have been withdrawn or all soluble boron has been removed from the coolant.

Only two assumptions are required to estimate the burnup attainable. The first assumption concerns the burnup history of an average module. Let the operation of the reactor between refuelings be referred to as one irradiation cycle, and let the fraction of the core discharged at each refueling be $1 / N$ where $N$ is an integer. At discharge each module will have experienced $N$ irradiation cycles. Let $B_{n}$ denote the burnup of an average module at the end of its $n$th irradiation rycle. Then the first assumption is a set of ratios of the form $B_{n} / B_{N d}$ These ratios give the fraction of the final burnup which is achieved by the end of the module's nth irradiation cycle. The simplest assumption would be a uniformly increasing burnup such that $B_{n}=\left(n B_{N}\right) / N$; this would correspond to an ideal case in which the power produced by the average module would be constant throughout the life of the module. The second assumption required is a neutron loss fraction due to leakage.

The data required from the point depletion calculation is the excess neutron derivative curve, that is, the same type of curve used to obtain $\partial \widetilde{E S} / \partial \widetilde{N S}$ in Equation (6) as a function of the burnup, and the total neutron production rate QS where QS has units of (fission neutrons/MT)/(MWD/MT). In what follows, the derivative $\partial \widetilde{N S} / \partial \widetilde{E S}$ will be denoted by the symbol $R$.

As a simple example of this use of point depletion calculations consider the following case.

Fuel region-Composition 2 of Table A-1 (This composition represents the large PWR for which neutron loss data appears in Table A-7.) 


$$
\begin{aligned}
& L=0.04 \text { (4 percent neutron losses to leakage) } \\
& Q S=\text { (neutron production rate) }=0.67 \times 10^{22} \text { neutrons } / \mathrm{MWD} \\
& 1 / 3 \text { core refueled each year } \\
& B_{1}=B_{3} / 3 \\
& B_{2}=2 B_{3} / 3 .
\end{aligned}
$$

Neutron derivative values obtained from the point depletion data used for the fuel utilization estimates of Appendix A are indicated in Figure B-7 by encircled points. The straight line shown in the figure very nearly intercepts all of the points. The assumed module conditions at the time of refueling are indicated by points 1,2 , and 3 enclosed in diamonds. The corresponding excess neutron production rates will be designated as $R_{1}, R_{2}$, and $R_{3}$. During power operation just prior to refueling, there are no neutrons being captured in control poison. All excess neutrons being produced are either captured by modules with burnup $B_{3}$ or lost to leakage. The neutron balance for this condition is given by Equation (14)

$$
R_{1}+R_{2}+R_{3}=3 \times Q S \times L .
$$

The factor of 3 appears on the right-hand side of Equation (14) because the left-hand side represents the net excess neutron production rate in 3 MT of fuel. By trial and error one can find a value of $B_{3}$, and corresponding values of $B_{1}, B_{2}$ (and the $R$ 's from Figure $B-7$ ) such that Equation (14) is satisfied. One can also fit a straight line to the derivative data of Figure B-7 and obtain the solution to Equation (14) analytically. The development is presented in Section IX.

The value of $\mathrm{B}_{3}$ which leads to Equation (14) being satisfied with 4 percent neutron losses to leakage is $29,900 \mathrm{MWD} / \mathrm{MT}$. This differs by less than 1 percent from the value of $30,100 \mathrm{MWD} / \mathrm{MT}$ obtained by actually performing the two-dimensional spatial-depletion calculations for the fuel managed core for which the neutron losses appear in Table A-7 and for which the initial composition of the modules was also composition 2 of Table A-1. The fuel utilization corresponding to this burnup of 29,900 MWD/MT is $11.5 \mathrm{MWYth} / \mathrm{ST} \mathrm{U}_{3} \mathrm{O}_{8}$. Based on the developments in Section IX, with continuous refueling the fuel utilization would be $4 / 3$ times this value, or $15.3 \mathrm{MWYth} / \mathrm{ST} \mathrm{U}_{3} \mathrm{O}_{8}$. Continuous refueling would eliminate neutron losses to soluble boron. Based on data in Table A-7 this would reduce neutron losses to about 4 percent. Hence, both of the preceding fuel utilization results are in agreement with the values presented in Table A-3 (15.2 MWYth/ST $\mathrm{U}_{3} \mathrm{O}_{8}$ for 4 percent total neutron losses and $11.5 \mathrm{MWY}$ th/ST $\mathrm{U}_{3} \mathrm{O}_{8}$ with 8 percent total neutron losses) which were based on the use of the excess neutron production curve of Figure B-13.

The derivative curve can also be used to estimate the neutron capture rate in control poison at any time during the cycle. For example, consider the neutron production rate at the start of an irradiation cycle for the present case where $1 / 3$ of the core is replaced at each refueling. At the start of an irradiation cycle the burnups of the three fuel management regions of the core are zero, $B_{1}$, and $B_{2}$. Using the neutron derivative curve one can obtain the total excess neutron production rate at this time; this must equal the neutron capture rate in control poison plus the neutron loss rate to leakage. Assuming that the loss rate to leakage is 4 percent, the calculations indicate an 8.3 percent loss rate 
to control poison. This implies that over the entire irradiation cycle the loss rate to control poison would average out to 4.1 to 4.2 percent-a result in good agreement with the value of 4.4 percent in Table A-7.

An additional assumption inherent in this procedure is that at a given burnup, when all of the shim control poison is removed, the production rate of excess neutrons (in NN/MT per MWD/MT) is almost independent of the amount of shim control poison which was actually present during the depletion. The degree of agreement between the two burnup values and the two poison worth values mentioned above serves as an indication that the assumptions are quite reasonable.

Now consider fuel management calculations for the $\mathrm{UO}_{2}$ fuel with 5 percent enrichment for the case of 4 percent neutron losses to leakage. The neutron derivative curve is shown in Figure $B-8$. It is assumed that each fuel module experiences a burnup ul close to 10,000 MWD/MT during ear.h year of aperation so that the power densily, in $(\mathrm{kw}) /(\mathrm{kg}$ of fuel), is essentially the same as the nominal power density for the 3 percent enriched fuel. Annual refueling is assumed, and lie liaction of thc core replaced is to be determined by the calculations. Just prior to refueling, when the soluble boron content of the core is close to zero, the core will consist of modules with burnups which are multiples of a number close to $10,000 \mathrm{MWD} / \mathrm{MT}$. By trial and error it is found that an annual burnup of $10,333 \mathrm{MWD} / \mathrm{MT}$, with $1 / 6$ of the core refueled annually, just satisfies the neutron balance requirement. (This means that an enrichment of slightly less than 5 percent would actually be sufficient to permit achieving an annual burnup of $10,000 \mathrm{MWD} / \mathrm{MT}$ with $1 / 6$ of the core refueled annually.) The burnups and neutron derivative values of the fuel at the time of refueling are also shown in Figure B-8.

The discharge burnup is then $62,000 \mathrm{MWD} / \mathrm{MT}$, corresponding to a fuel utilization of about $13.9 \mathrm{MWY}$ th $/ \mathrm{ST} \mathrm{U}_{3} \mathrm{O}_{8}$. If the same fuel system were operated at about half the power density (actually at a power density leading to a burnup of $5500 \mathrm{MWV} / \mathrm{MT}$ per yeur), then $1 / 12$ of the core could be refueled annually; the discharge burnup would be $66,000 \mathrm{MWD} / \mathrm{MT}$, and the fuel utilization would be $14.8 \mathrm{MWY}$ th/ST $\mathrm{U}_{3} \mathrm{O}_{8}$. Based on this result it appears that with an optimum choice of enrichment, low power density, and high limits on burnup, a fuel utilization of olose to $15 \mathrm{MWYth} / \mathrm{ST} \mathrm{U}_{3} \mathrm{O}_{8}$ could be achieved in a light water reactor of conventional design. This value of fuel utilization is consistent with the results presented in Figure A-4 for 4 percent neutron losses and the assumption that with $1 / 12$ core annual refueling, soluble boron reactivity control would cost about an additional 1 percent in neutron losses. (In Section $V$ of Appendix $A$ it is noted that the neutron losses to soluble boron are about 4 percent in current PWR cores, where $1 / 3$ of the core is refueled annually.)

\section{JUSTIFICATION FOR USE OF POINT DEPLETION CALCULATIONS}

In applying the methods developed in Section III to the calculation of fuel utilization achievable in a seed-blanket reactor, the functional dependence of $\widetilde{E}$ on $\widetilde{N S}$ and of $\widetilde{E B}$ on $\widetilde{N B}$ must be determined by means of depletion calculations. For the estimates presented in Appendix $A$, the functional dependence was based on so-called "point depletion calculations" for the seed and for the blanket. In these point depletion calculations the fluxes are obtained from infinite homogeneous medium spectrum calculations (one set for the seed and one set for the blanket). (The term "point depletion" originated from the fact that in a normal spatial calculation the depletion equations are solved at many spatial points, while for an infinite homogeneous medium, the depletion equations need to be solved only at one spatial point.) The basic premise underlying this use of point depletion calculations is that the functional dependence of $\widetilde{E S}$ (or $\widetilde{E B}$ ) in a seed-blanket core (where $\widetilde{E S}$ or $\widetilde{E B}$ is 
defined in terms of integrals over the entire seed or blanket volume) will be very close to that in an infinite homogeneous medium. This premise is supported by a comparison of the functional dependence obtained from the point depletion calculations with that obtained from the seed-blanket cell calculations described in Section III of Appendix A.

The results of this comparison are presented in Figures B-9 and B-10 for the seed and Figure B-11 for the blanket. In these figures the curves are based on values of $\widetilde{E S}$ and $\widetilde{E B}$ from point depletion calculations on compositions listed in Table $A-1$, while values of $\widetilde{E S}$ and $\widetilde{E B}$ from certain seedblanket calculations listed in Table A-5 are indicated by enclosed points. The maximum burnup values for the enclosed points correspond to the maximum burnups achieved in the seed-blanket cells.

Figures B-9 and B-10 indicate that if the seed point depletion calculations are run at the correct power density the seed net excess neutron production at a given burnup will be very nearly the same as it would be in a seed-blanket cell calculation. Figure B-11 on the other hand indicates that, relative to the results of the seed-blanket cell calculations, the point depletion calculation yields a fairly constant bias in the net neutron absorption in the blanket. The effect of the bias due to the use of point depletion calculations can be estimated by actually using the point depletion calculation curves to estimate the fuel utilization in the seed-blanket cells. The results of these estimates are presented in Table B-1. It is observed that the use of point depletion calculations tends to underpredict the fuel utilization by 0.3 to $0.5 \mathrm{MWYth} / \mathrm{ST} \mathrm{U}_{3} \mathrm{O}_{8}-$ a relative error of about 2 percent. Figures $\mathrm{B}-9$ through B-11, along with the results presented in Table B-1, provide ample evidence to justify the use of point depletion calculations to define the functional relationships between $\widetilde{E S}$ and $\widetilde{N S}$ and between $\widetilde{E B}$ and $\widetilde{N B}$.

\section{v. ADDITIONAL TOPICS AND DATA}

\section{A. Additional Data From Point Depletion Calculations}

The purpose of this section is to provide some additional data from point depletion calculations relative to the results presented in Appendix $A$ on combinations of seeds and blankets. This includes additional data for the seed-blanket combinations and additional data on seed and blanket neutron production.

The first set of additional data is presented in Table B-2, which is similar to Table A-6, but has four columns of added data, namely, the ratios MTB/MTS and STB/STS, the fraction of the energy which is produced by the blanket, and the fraction of the seed uranium-235 consumed. Two trends of interest are:

1. The fraction of the energy produced by the blanket increases as the seed enrichment increases

2. The peak fuel utilization achievable from a given type of blanket remains nearly constant as the seed enrichment increases. 
The fraction of the energy produced by the blanket is given by

$$
\frac{\widetilde{E B} \times(\text { MTB/MTS })}{\widetilde{E S}+\widetilde{E B} \times(\text { MTB/MTS })}
$$

where $\widetilde{E B}$ and $\widetilde{E S}$ are the burnups which yield the peak fuel utilization.

One way of viewing these trends is in terms of various arrangements which can be made of given quantities of fissile and fertile atoms. For example, the fissile and fertile atoms can be uniformly mixed to form a uniformly enriched reactor, or some of the fissile atoms can be concentrated to form a small high enrichment seed, with the remaining fissile atoms and fertile atoms forming a blanket. Independent of the physical arrangement of the atoms, a given number of fissions produces a given number of fission product atoms, a given amount of energy, a given number of neutrons and consumes a given number of fisslle atoms. In the absence of neutron losses the fuel utilization shnuld he nearly independent of the physical arrangement of the fissile and fertile atoms. This view is consistent with the last column of data in Table B-2, which indicates that achievement of peak fuel utilization with any fuel enrichment requires about 90 percent burnup of the uranium-235 initially present in the seed.

Figures B-12 through B-20 present the curves of excess neutron production versus burnup for the seed fuel compositions listed in Table A-1 of Appendix A. Figure B-21 presents curves of burnup versus excess neutron absorption, $\widetilde{N B}$, for the blanket fuel compositions listed in Table A-4 of Appen$\operatorname{dix} A$.

\section{B. Non-Uniform Burnup in Seed-Blanket Cores With Movable Fuel Control}

\section{Background}

It has been noted earlier that the power distribution in a seed-blanket core with movable fuel control is likely to be less uniform than the power distribution in a conventional PWR. This nonuniform power distribution would have a small adverse effect on fuel utilization because, at a given average seed burnup, the number of net excess neutrons produced would be smaller than that produced with uniform burnup. It is estimated that this effect could be between 0.3 and $0.7 \mathrm{MWrth} / \mathrm{ST} \mathrm{U}_{3} \mathrm{O}_{8}$.

In this section two aspects of this problem will be considered. The first is the development of a method to calculate the effect, and the second is an estimate of the magnitude of the effect.

\section{Analytical Method}

This method consists of defining an effective number of excess net neutrons produced by the seed (or absorbed by the blanket) when the seed or blanket burnup is non-uniform. The method will be developed using a seed as a basis but the method is also applicable to a blanket. The following additional notation is required:

$P(\widetilde{E S})=$ probability density function (p.d.f.) for the burnup values in discharged seed fuel 
$P(\tilde{N S})=$ probability density function (p.d.f.) for the net excess neutron production per MT of discharged seed fuel.

$\overline{\widetilde{E S}}=$ average value of burnup for discharged seed fuel

$\widetilde{\widetilde{N S}}=$ average value of net excess neutrons produced per MT of discharged seed fuel. $\overline{\widetilde{N S}}$ is used in place of $\widetilde{N S}$ in Equation (8) to obtain the ratio MTB/MTS.

Because they are p.d.f.'s, $P(\tilde{E S})$ and $P(\tilde{N S})$ are related as follows:

$$
P(\tilde{E S}) \times d(\tilde{E S})=P(\tilde{N S}) \times d(\tilde{N S})
$$

$\overline{\widetilde{E S}}$ and $\overline{\widetilde{N S}}$ are then defined as follows:

$$
\begin{aligned}
& \overline{\widetilde{E S}}=\int P(\tilde{E S}) \times \tilde{E S} \times d(\tilde{E S}) \\
& \overline{\widetilde{N S}}=\int P(\widetilde{N S}) \times \tilde{N S} \times d(\tilde{N S})=\int P(\tilde{E S}) \times N S(\tilde{E S}) \times d(\tilde{E S})
\end{aligned}
$$

where the integration is over the complete range of burnup values in the discharged seed fuel.

Because the seed burnup curve is concave downward, (Figures B-13 through B-20) the following inequality is true

$$
\overline{\widetilde{N S}}<\widetilde{N S}(\overline{\widetilde{E S}})
$$

This means that the number of net excess neutrons produced by a seed with non-uniform burnup will be smaller than the number produced by a seed with uniform burnup.

For blanket burnups in the ranges which give high fuel utilization $\widetilde{N B}$ is very nearly a linear function of $\widetilde{E B}$, and in this case $\widetilde{\widetilde{N B}}$ and $\widetilde{N B}(\widetilde{E B})$ are essentially equal.

If the p.d.f. $\mathrm{P}(\widetilde{E S})$ were known it would be straightforward to calculate $\overline{\widetilde{N S}}$. In general, it would be expected that, for given seed and blanket compositions, $P(\tilde{E S})$ would depend both on the particular seed and blanket geometry chosen (for example, seed radius and volume fraction) and on the average burnup to which the seed and blanket were irradiated. The determination of $P(\widetilde{E S})$ for all of the cases which would have to be examined to determine the optimum fuel utilization would be a formidable problem. Fortunately, it appears that the magnitude of the non-uniform burnup effect is relatively small-on the order of 0.3 to $0.7 \mathrm{MWYth} / \mathrm{ST} \mathrm{U}_{3} \mathrm{O}_{8}$-and therefore an accurate knowledge of $P(\widetilde{E S})$ is not necessary.

\section{Magnitude of Non-Uniform Burnup Effect on Fuel Utilization}

The potential effect of non-uniform burnup has been estimated by assuming various functional forms for $\mathrm{H}(\widetilde{E S})$ to determine their effect on $\hat{N S}$ and subsequently their effect on the fuel utilization. 
During operation of a real reactor, it would be possible to have some regions of the seed irradiated to such high burnups that the net number of excess neutrons produced by those regions is actually negative. The only physical constraint on net excess neutrons is that the number be non-negative for the discharge seed fuel as a whole.

The effect of various assumptions regarding $\mathrm{P}(\tilde{\mathrm{ES}})$ are displayed in Table $\mathrm{B}-3$. For each enrichment value it is observed that even the most spread out distributions (a uniform \pm 25 to 30 percent about the mean) lead to a decrease in fuel utilization relative to that for uniform burnup of no larger than about $0.7 \mathrm{MWY}$ th/ST $\mathrm{U}_{3} \mathrm{O}_{8}$.

It is recognized that in practice the p.d.f. $\mathrm{P}(\widetilde{\mathrm{ES}})$ could have non-zero values at even higher and lower burnups than those considered in the example. However, with careful fuel management, it is judged likely that the amount of seed fuel with exceptionally high or low burnup could be kept small enough to have relatively little effect on the average neutron production.

\section{Spiked Thorium Blankets}

Additional comments are appropriate on thorium blankets which contain small amounts of uranium-235 either as natural uranium or slightly enriched uranium. A blanket of thorium spiked with uranium will be referred to as a spiked thorlum blankel. A spiked thorium blanket would not substantially affect fuel utilization; however the maximum power density obtainable from fresh spiked blanket material would be larger than that obtainable from fresh natural thorium. In addition, the reactivity control characteristics of movable fuel would be modified. These points are amplified below.

In a core with given seed composition and geometry, the power density in fresh natural thorium blanket material would be very low due to the absence of tissile atoms. Adding uranlum-235 lu llie thorium would increase the power density. The magnitude of the increase would depend on both the uranium-235 content and the uranium enrichment. For a fixed uranium-235 content the enrichment would determine the relative content of uranium-238 and thoplum. In a waler muderated core, thorium has a higher average neutron capture cross section than does uranlum-238. Iherefore, replacing thorium atoms with uranium-238 atoms would increase the blanket beginning-of-life multiplication factor. This means that, at a fixed uranium-235 content in the spiked thorium blanket, decreasing the uranium enrichment, and thereby increasing the uranium-238 content, would Increase the blankel beginning-of-life multiplication factor and power density. An increase in blanket beginning-of-life power density would decrease the power density required from the seed.

With respect to fuel utilization, it has been noted that the maximum theoretically attainable fuel utilization in a seed-blanket core with 3 percent neutron losses and no restrictions on burnup is about $17 \mathrm{MWYth} / \mathrm{ST} \mathrm{U}_{3} \mathrm{O}_{8}$ over a wide range of core types. This range includes seed enrichments between 5 percent and 93 percent with natural thorium or natural uranium blankets, spiked thorium blankets, and depleted uranium blankets. However, the blanket burnup required to achieve high fuel utilization would be a function of both the uranium-235 content and the uranium enrichment.

In the area of movable fuel reactivity control, the spiking of a thorium blanket would increase the blanket beginning-of-life multiplication factor, bringing it closer to the multiplication factor of the seed. The amount of reactivity control available from movable fuel would therefore be reduced (again assuming fixed seed composition and geometry) at the beginning of the blanket irradiation. 
From the preceding discussion, it is apparent that the use of a spiked thorium blanket would not be expected to affect the fuel utilization achievable from a hypothetical seed-blanket arrangement designed for maximum fuel utilization; however, the option of spiking all or part of a thorium blanket would give the reactor designer an additional degree-of-freedom in working toward a practical seedblanket design with high fuel utilization.

For the spiked thorium blanket (Table B-2, Case 4), the peak fuel utilization value of 19.6 MWY Y th/ST $\mathrm{U}_{3} \mathrm{O}_{8}$ is very close to that obtained with a natural uranium or natural thorium blanket (Cases 1 and 3 ). The average seed burnup required for peak fuel utilization is about 65,000 MWD/MT. which is also very close to the seed burnup which gives peak fuel utilization for the natural uranium and thorium blankets. However, the average blanket burnup for peak fuel utilization is about $110.000 \mathrm{MWD} / \mathrm{MT}$, which is about the same as the burnups required of the natural thorium blanket.

\section{Power Peaking in a Seed-Blanket Core}

The fuel utilization calculations based on neutron conservation do not yield any information on the relative power density in seed and blanket regions. It is expected that the average power density (in $\mathrm{kw} / \mathrm{kg}$ heavy metal) in the blanket would be lower than that in the seed for two reasons. First, the ratio of heavy metal volume to coolant volume would be higher in the blanket than in the seed; second, the fissile content in heavy metal would be lower in the blanket than in the seed. The effect of the difference in fissile loading can be seen qualitatively by considering a core in which seed and blanket regions are small enough in the radial dimension that the neutron flux is nearly the same in both regions; the power density in each region would then be proportional to the density of fissile nuclides. In a practical seed-blanket core, local power peaks due to local inventory variations between seed and blanket regions would be superposed on the regional differences in power density.

\section{NUCLEAR DESIGN CALCULATIONAL METHODS}

\section{A. Methods for Early Studies of Seed-Blanket Core Concepts}

The early studies described in this section were performed on the thorium seed-blanket converterburner (Table 1 of the main text) and the CB6.2 converter-burner discussed in Appendix C.

For specified loadings and distributions of fissile and fertile materials and core power levels, the nuclear design calculations determined the movable fuel positions required for criticality and the power distributions during the depletion of the cores. These calculations also determined the reactivity life of the cores, which together with the uranium loadings and power levels determined the fuel utilization values. The methods used for calculation are described in the Appendices of Reference B2.

Microscopic cross sections for thorium-232 and uranium-233 were based on experimental data available at the time Reference B-2 was published. The spatial-depletion calculations were made using four-grnup diffusion theory (three fast groups covering the range from $10 \mathrm{Mev}$ to $0.625 \mathrm{ev}$ and one thermal group) and the PDQ-4 computer program (References B-3 and B-4). Two-dimensional radial calculations were synthesized in the axial dimension. The three fast group. diffusion theory 
constants were obtained using the MUFT program (Reference B-5), which performed a 54 group spectrum calculation. Resonance self-shielding factors for the MUFT program were calculated using Monte Carlo methods in the NUREP and REPETITIOUS program (Reference B-6). The one thermal group diffusion theory constants were obtained using the KATE program (Reference B-7), which performed a 36-group thermal spectrum calculation. Thermal self-shielding factors for fuel rods were calculated using Monte Carlo methods in the MARC program (Reference B-8). The entire calculational model was verified by the analysis of critical experiments which included thorium and uranium233 , and which were run at both room temperature and about $480 \mathrm{~F}$. This verification included comparison of calculation and experiment for criticality, power distributions, and activation of various materials. This work is described in References B-2 and B-9.

\section{B. Methods for Theoretical Fuel Utilization Studies}

These studies included the seed and blanket radial geometry cell studies and the point depletion studies. The studies are based on data generated by the AWBA program to develop information on light water prebreeder and breeder reactors. The calculational model is very similar to that used for the design of the LWBR at Shippingport. The basic fission product nuclear cross section data in these studies were primarily from ENDF/B-IV, while the remaining nuclear cross section data were derived from ENDF/B-III and IV data. Radial geometry spatial depletion calculations were made using four group diffusion theory (three fast groups covering the range from $10 \mathrm{MeV}$ to $0.625 \mathrm{ev}$ and one thermal group) and the PDQO8 program, (Reference B-10). Few group diffusion theory cross sections were obtained using the PAX03 program. The point depletion calculations were made entirely using the PAX03 program. The calculational methods have been verified by comparison with the results of RCPO1 Monte Carlo full energy range explicit three-dimensional calculations. The RCPO1 program is described in Reference B-11 and has in turn been verified by analysis of a number of critical experiments (References B-12 and B-13).

\section{Methods for Detailed Calculations on Reference Core}

These detailed calculations on the reference core (Reference B-14) served as part of the basis for validating the point depletion method used for the majority of the fuel utilization calculations. As noted in Section III.C of this appendix the point depletion calculations on the reference core gave essentially the same fuel utilization as the detailed calculations on the reference core. In turn, the detailed calculations gave nuclear performance indicators, including fuel utilization, which were very close to those reported in Reference B-14.

The calculation methods were in many respects identical with or similar to those described above in Methods for Theoretical Fuel Utilization Studies. The basic nuclear cross section data were taken from ENDF/B. Two and three-dimensional spatial depletion calculations were made using four group diffusion theory (three fast groups covering the range from $10 \mathrm{MeV}$ to $0.625 \mathrm{ev}$ and one thermal group) and the PDQ08 program (Reference B-10). Few group diffusion theory cross sections were obtained using the RCPO1 Monte Carlo program (Reference B-11). The RCPO1 calculations were made on cells consisting of one-quarter of a fuel assembly with explicit representation of the location, size and composition of fuel rods, instrument and guide tubes, and water. Quarter core few group diffusion theory depletion calculations were made to determine the fuel loadings required to achieve 
the desired core life, and the radial power distributions for thermal and fuel rod performance calculations. These calculations were made using fuel management to minimize radial power peaks and soluble boron in the coolant to maintain reactivity control.

\section{SIMULATION OF FULL CORE CALCULATIONS}

\section{A. General Discussion}

The purpose of this section is to show that the point depletion calculations and the seed-blanket cell calculations used for fuel utilization calculations simulate the operation of an ideal core, that is, a core with movable fuel control and fuel management and no neutron losses to leakage or control poisons. This simulation is a good indicator of the fuel utilization attainable in an ideal core, but does not give any indication of what the power distributions would be in the seed and blanket modules at various stages of depletion.

The calculations were made as a series of steps, with zero neutron leakage. At the start of each step an eigenvalue calculation was made to determine the neutron fluxes for the most up-to-date materials inventory. The flux levels were chosen to give a reasonable power density, that is, from 50 to $150 \mathrm{kw} /$ liter depending on the type of region. This was followed by a depletion calculation using these neutron fluxes. The depletion was carried out for a short period of time (a time step) corresponding to a small fractional depletion (typically no more than 5 percent) of the fissile inventory present at the start of the step. By performing some calculations with shorter time steps, it was shown that the results would not be changed by using shorter time steps. For each time step, the eigenvalue, $\lambda$, and the total neutron production rate determined the total number of excess neutrons produced during the time step as follows

$$
\begin{gathered}
\text { number of excess } \\
\text { neutrons produced }
\end{gathered}=\frac{\lambda-1}{\lambda} \times \begin{gathered}
\text { total number of } \\
\text { neutrons produced }
\end{gathered}
$$

This number is positive when the eigenvalue is greater than unity and negative when the eigenvalue is less than unity. The cumulative sum of excess neutrons produced since the first time step was calculated at the end of each time step. The point at which this sum vanished defined the end of reactivity life of the system for the case of no neutron losses.

The key point is that in both an ideal core and the point depletion and seed-blanket cell calculations there are no neutron losses. If any region of an ideal core were a net producer of neutrons, then some other region or regions would be net absorbers of neutrons, with the number of excess neutrons coming from net producing regions exactly equal to the number of excess neutrons captured in net absorbing regions. In the point depletion and seed-blanket cell calculations, all the excess neutrons producied Juring the depletion stages where the eigenvalue is greater than unity just offset the neutron deficit during the depletion stages where the eigenvalue is less than unity. For a point depletion calculation on a seed-type module, where the depletion is carried out to the point of zero net excess neutrons, there is an obvious interpretation in terms of operation of a uniformly enriched core with fuel management and with no neutron losses. At any time in life the real core would consist of relatively fresh seed modules, which would be net producers of excess neutrons, and relatively highly depleted seed modules, which act as net absorbers of excess neutrons. In the point depletion calculation, the time when the cigenvalue is greater than unily represents the operation of a seed 
module while it is a net producer of excess neutrons; the time when the eigenvalue is less than unity represents the operation of a seed module while it is a net absorber of excess neutrons. For the seedblanket cells, the obvious interpretation is that the core consists of a collection of such cells; at any time in life there would be relatively fresh cells, which would be net producers of excess neutrons, and relatively highly depleted cells, which would be net absorbers of excess neutrons. Thus, the point depletion and seed-blanket cell calculations do approximately simulate the operation of an ideal core.

\section{B. Sources of Uncertainty}

In a real core consisting of modules or cells in varying stages of depletion, the neutrons appearing at any time in a module or a cell are a mixture of neutrons born in fission in the materials of the module or cell and neutrons leaking in from other cells. The neutrons disappearing from a module or a cell include neutrons captured in materials in the module or cell plus neutrons leaking into other modules or ralls. The principle approximatlon irlierent in the simulation of an ideal core using point depletion or seed-blanket cell calculations is that at each step of the eigenvalue calculation on a inudule vi a ooll, all of the nẹtitrnns appearing in the calculation are born as a result of fission in the materials of the module or the cell, and all neutrons disappearing are captured in the materials of the module or the cell. This approximation is not expected to produce significant errors in the estimated values of fuel utilization because, as discussed in Section IV, for both seed and blanket modules the curves of energy produced versus net excess neutrons produced are relatively insensitive to the environment in which the seed and blanket materials are depleted. Although the comparisons of Section IV were made only for the case of individual seed or blanket modules versus the seed-blanket cells, it is expected that a comparison of seed-blanket cell results with full core calculations would yleld a similar conclusion.

An additional source of uncertainty is introduced when neutron losses are assumed, bul dre rul present in the point depletion calculations or the seed-blanket cell calculations with which the point depletion calculations have been compared. This source of error is expected to have a relatively sman! effer.t on calculated fuel utilization because neutron losses to control polson or leakage from the core are no different from the neutron losses discussed above due to leakage from seed mudulésto-blanket modules or vice-versa. Further, only a small fraction of neutrons are involved since the Insses of interest are only on the order of 3 to 4 percent of the total number of neutrons produced in seed plus blanket. On this basis it seems reasonable to assume that the uncertainty in fuel utllizatlun due to the method of treating neutron losses is no larger than I perceul of the calculated valuc.

Now consider the overall uncertainty in the calculation of fuel utilization for a core. On the basis of the comparisons presented in Section IV, it was concluded that the fuel utilization calculated from point depletion calculations could differ by about 2 percent from the fuel utilization obtained from a seed-blanket cell calculation. It seems reasonable to assume that the fuel utilization from the seedblanket cell calculation might differ by the same amount ( 2 percent) from the fuel utilization obtained from a full.core calculation. These two sources of uncertainty could therefore produce a combined uncertainty of 4 percent. An additional 1 percent uncertainty is attributed to the treatment of neutron losses. Therefore, the total uncertainty in fuel utilization values calculated using point depletion calculations is estimated to be about 5 percent relative to the most accurate values which would be obtained from full core calculations. There are additional but unknown uncertainties due to the nuclear data and other calculational approximations. 
Another aspect of the uncertainty has to do with certain situations in which relative values of fuel utilization (FU) are being compared. Consider, for example, the FU values in Figures A-10 and A-11 of Appendix A. In these figures the FU values cover relatively small ranges of seed and blanket burnup for only one type of seed and one type of blanket. In this situation, the relative errors are expected to be very small because the sources of error would have nearly the same effect on all of the calculations.

\section{NOTATION AND DEFINITIONS}

The notation used throughout this appendix is presented below.

$\mathrm{FU}=$ fuel utilization in units of MWYth/ST $\mathrm{U}_{3} \mathrm{O}_{8}$ (Megawatt Years Thermal per Short Ton $\mathrm{U}_{3} \mathrm{O}_{8}$ )

$\widehat{F U}=$ peak fuel utilization resulting from optimizing the irradiation of seed and blanket

ES (or EB) = energy produced in seed (or blanket) in units of MWYth

STS (or STB) $=$ short tons of $U_{3} \mathrm{O}_{8}$ required to produce seed (or blanket) loading (STB $=0$ if the blanket is thorium or 0.2 percent uranium enrichment plant tails). See comment at end of this section

MTS (or MTB) = metric tons of uranium or thorium in the seed (or blanket). See comment at end of this section

NNS $=$ net number of excess neutrons from the seed

NNB = number of excess neutrons from the seed which are absorbed in the blanket

$\widetilde{E S}=365 \dot{x}$ ES/MTS in units of Megawatt Days Thermal per Metric Ton

$\widetilde{E B}=365 \times$ EB/MTB in units of Megawatt Days Thermal per Metric Ton

$\widetilde{N S}=$ NNS/MTS in units of Neutrons per Metric Ton

$\widetilde{N B}=N N B / M T B$ in units of Neutrons per Metric Ton

NGS = total number of ncutrons generated by fissiun In the seed

$\mathrm{NGB}=$ total number of neutrons generated by fission in the blanket

QS (or QB) = number of neutrons born in fission in the seed (or blanket) per MWDth produced in the seed (or blanket)

$L=$ fraction of neutrons generated by fission in the seed plus blanket which are lost by capture in control poison or by leakage

$R=\partial \widetilde{N S} / \partial \widetilde{E S}=$ excess neutron derivative. 
Some of these terms are defined below.

First consider NGS, NGB, QS, and QB. NGS represents the total number of neutrons produced by fission in the seed modules during the lifetime of a reactor-say 30 years. Dividing NGS by the amount of energy (in MWYth) produced in the seed modules during this lifetime yields QS. NGB and QB are determined in a similar fashion for the blanket modules. QS and QB have some dependence on the irradiation history and the irradiation level (or burnup) of the modules. There are two reasons for this dependence. The first, and main reason, is that the average number of neutrons born in a fission event depends on the nucleus (for example, uranium-233, uranium-235, plutonium-239) which is fissioned. In a seed or blanket module, the relative number of fissions which has occurred in each type of nucleus depends on the irradiation level, or burnup, because the mix of fissile nuclides changes as the module is irradiated. The second reason is that the number of neutrons born in a fission event in a particular nuclide depends on the energy of the neutron causing the fission. As a module depletes, the inventory of fissile and fertile and fission product atoms changes; this changes the distribution in energy (or the spectrum) of neutrons which cause fission. However, for a given type of module, QS and QB are slowly varying functions of the irradiation level because the mix of nuclides and the fission product inventories are slowly varying. In addition, QS and QB will be used only to calculate the number of neutrons lost to leakage or control poisons. The focus here will be primarily relatively narrow ranges of seed and blanket irradiation levels which give high fuel utilization. Hence, there will be little loss in accuracy from using a constant value of QS and a constant value of $Q B$.

Next consider the terms NNS, NNB, and L. If at the end of reactor life one could count all of the neutrons which had been captured in the seed modules and subtract this number from NGS, the result would be NNS. NNS must be a positive number, since by definition the seed is a region which over its irradiation life produces more neutrons than it captures. The relationship for the blanket is similar, but is defined in reverse. If at the end of the reactor lifetime one could count all of the neutrons which had been captured in the blanket and subtract NGB from this number, the result would be NNB. NNB must also be a positive number because by definition the blanket is a region which over its irradiation life captures more neutrons than it produces. In an ideal seed-blanket core where all neutrons are captured in the seed or blanket, it must be true that NNS = NNB. In a non-ideal core where some neutrons are lost by leakage into, and capture in, regions which are outside of the seed and blanket, it must be true that NNB < NNS, and the difference must be accounted for by the loss term L.

The neutron loss term $L$ will be used to account for the disappearance of all neutrons which are not captured in the regions called seed or blanket. The loss would therefore account for all neutrons which leak out of the seed plus blanket region and are captured in the external reflector (which contains no fissile or fertile material) or in control regions and structure (which are either physically or conceptually outside of the seed-blanket regions). For example, consider a core in which Zircaloy cans surround each seed module for the purpose of separating the seed and blanket coolant flow. From one point of view this structure could be considered to be physically separated from the seed and blanket. In the calculations of NNS and NNB the neutron capture by this structure would be omitted, but would be accounted for later as a neutron loss. From another point of view this structure could be considered an integral part of the seed or blanket (or part of it could be assigned to each region). The neutron capture by the structure could be included in the calculation of NNS and NNB. From this point of view there would be no neutron loss to structure. For another example, consider neutron capture in soluble boron used as a control poison. It would seem natural to include neutron 
captures in this poison in the calculation of NNS and NNB. However, conceptually one could think of the boron atoms as somehow being outside of the seed and blanket region, and one would therefore consider neutron capture in this boron as constituting a neutron loss from the seed-blanket region. In the theoretical developments the interpretation of neutron losses will not matter; neutron losses will be represented by a general term. However, in the actual calculation of fuel utilization, care must be taken to determine which losses are already included in the calculation of NNS and NNB and which losses must be accounted for in other ways.

A comment is necessary here on the terms STS, STB, MTS, and MTB. In general, seed and blanket modules would not be irradiated for the same length of time (calendar days). Thus, the ratio of seed heavy metal-to-blanket heavy metal in the core at any time will be different from the ratio of seed heavy metal-to-blanket heavy metal loaded into the core over the long-term, for example, over the entire reactor plant life. The above terms are defined in such a way that the ratios STB/STS and MTB/MTS represent long-term averages, rather than values based on the materials in the core at any time.

\section{ANALYTIC SOLUTION FOR FUEL MANAGEMENT EQUATION}

This section presents the analytic solution to Equation (14).

The neutron excess production rate $\mathrm{R}$ and the burnup are assumed to be related as follows

$$
\mathrm{R}=\alpha \mathrm{B}+\dot{\gamma}
$$

In general, a fraction $1 / \mathrm{N}$ of the core is to be removed at each refueling. The burnup of the modules removed is $B_{N}$. During an irradiation cycle (the operation time between refuelings) each module experiences burnup $B_{N} / N$, so that for a module which has experienced $j$ irradiation cycles the burnup, $B_{j}$ is given by

$$
B_{j}=j \times \frac{B_{N}}{N}
$$

During core operation prior to shutdown for refueling, when the concentration of soluble poison required for reactivity control is assumed to be zero, the sum of the neutron production rates from all modules must equal the total neutron loss rate. This neutron balance is given by

$$
\sum_{j=1}^{N} R_{j}=N \times \text { QS } \times L
$$

where $R_{j}$ is the excess neutron production rate in a module which has just completed $\mathrm{j}$ irradiation cycles. The quantity $\mathrm{N}$ appears on the right-hand side of this equation because the left-hand side represents the excess neutron production rate in $\mathbf{N}$ modules (one module for each burnup value). 
Putting together the preceding three equations yields the following result for the burnup of the modules which are removed:

$$
\mathrm{B}_{\mathrm{N}}=\frac{\mathrm{N}}{\mathrm{N}+1} \times \frac{2}{\alpha}[\mathrm{QS} \times \mathrm{L}-\gamma]
$$

Since $B_{N}$ is proportional to fuel utilization, this equation can also be used to determine the effect on fuel utilization of changing the frequency of refuelings, or equivalently of changing the fraction of the core removed at each refueling. As a simple example, consider the case of nearly continuous refueling $(N \rightarrow \infty)$ as compared with refueling $1 / 3$ of the core each year $(N=3)$. Here

$$
\frac{B_{\infty}}{B_{3}}=\frac{4}{3}
$$

This means that, at a fixed enrichment with continuous refueling, the fuel utilization will be approximately one-third greater than it is with a refueling strategy where one-third of the core is replaced each year

The above method is very similar to that presented in Chapter 6 of Reference B-15; the ratio $4 / 3$ is exactly that obtained by using equation 6.7 of the reference.

\section{REFERENCES}

B-1. Patent No. 3,252,867-Long Lifetime Nuclear Reactor, 1966, G. H. Conley.

B-2. "Large Power Reactor Program (Interim Report Supplement, The Design of Seed-Blanket Cores)," WAPD-LPR-154, July 1963.

Bn3. W. R. Cadwell, "PDQ-4-A Program for the Solution of Neutron-Diffusion Equations in Two Dimensions on the Philco-2000," WAPD-TM-230, June 1961.

B-4. O. J. Marlowe, "Nuclear Reactor Depletion Programs for the Philco-2000 Computer," WAPDTM-221, January 1961.

B-5. H. Bohl, Jr. and A. P. Hemphill, "MUFT-5-A Fast Neutron Spectrum Program for the Philco2000," WAPD-TM-218, February 1961.

B-6. "The Monte Carlo Calculation of Resonance Capture in Reactor Lattices" in "Proceedings of the Second United Natıons International Conference un llie Pedcelul Uses of Atomie Cnergy, Geneva, 1958, Vol. 16, pp. 180-186, United Nations, Geneva, 1958.

B-7. H. J. Amster and J. B. Callaghan, "KATE-1-A Program for Calculating Wigner-WIIkIns and Maxwellian Averaged Thermal Constants on the Philco-2000," WAPD-TM-232, October 1960.

B-8. E. M. Gelbard, H. B. Ondis, and J. Spanier, "MARC-A Multigroup Monte Carlo Program for the Calculation of Capture Probabilities," WAPD-TM-278, May 1962. 
B-9. "Report on Large Power Reactor (LPR) Program (Supplementing WAPD-LPR-181 dated December 1963)," WAPD-LPR-256, September 1964.

B-10. C. J. Pfeifer and C. J. Spitz, "PDQ-8 Reference Manual," WAPD-TM-1266, May 1978.

B-11. N. R. Candelore, R. C. Gast, and L. A. Ondis II "A Monte Carlo Program for Solving Neutron and Photon Transport Problems in Three-Dimensional Geometry with Detailed Energy Description," WAPD-TM-1267, August 1978.

B-12. J. Hardy, Jr., "Monte Carlo Analyses of TRX Slightly Enriched Uranium- $\mathrm{H}_{2} \mathrm{O}$ Critical Experiments with ENDF/B-IV and Related Data Sets," WAPD-TM-1307, December 1977.

B-13. J. J. Ullo and J. Hardy, Jr., "Analysis of Homogeneous U-233 and U-235 Critical Assemblies with ENDF/B-IV Data," WAPD-TM-1299, October 1977.

B-14. Babcock and Wilcox, Standard Safety Analysis Report (B-SAR-241), Docket Number STN-50481.

B-15. P. Silvennoinen, "Reactor Core Fuel Management," Pergamon Press, 1976.

TABLE B-1. FUEL UTILIZATION, SEED-BLANKET CELLS AND POINT DEPLETION CALCULATIONS

\author{
Average \\ Burnup \\ (In $1000 \mathrm{MWD} / \mathrm{MT})$
}

Cell Number

(Refer to Table A-5)

1

5

7

11

$\begin{array}{cc}\begin{array}{cc}\text { Seed } \\ \text { S8.8 }\end{array} & \text { Blanket } \\ 159 & 26.8 \\ 183 & 13.6 \\ 201 & 22.5 \\ & 26.7\end{array}$

From Cell

Calculation

18.8

15.9

17.8

16.6
Fuel Utilization In MWYth/ST $\mathrm{U}_{3} \mathrm{O}_{8}$
From Point Depletion Calculation

18.2

15.6

17.3

16.2 
TABLE B-2. PEAK FUEL UTILIZATION SUMMARY; POINT DEPLETION CALCULATIONS

(Table A-6 with Additional Data, No Neutron Losses)

\begin{tabular}{|c|c|c|c|c|c|c|c|c|}
\hline $\begin{array}{c}\text { Case No. } \\
\text { (From Table } \\
\text { A-6) }\end{array}$ & $\begin{array}{c}\text { Seed } \\
\text { Enrichment }\end{array}$ & $\begin{array}{c}\text { Peak Fuel } \\
\text { Utilization } \\
\text { MWYth/ST } U_{3} O_{8}\end{array}$ & $\begin{array}{r}A \\
B \\
(100 J \\
\text { Seed }\end{array}$ & $\begin{array}{l}\text { rage } \\
\text { nup } \\
\text { (WD/MT) } \\
\text { Blanket }\end{array}$ & $\frac{\text { MTE }}{\text { MTS }}$ & $\frac{\text { STB }}{\text { STS. }}$ & $\begin{array}{l}\text { Elanket } \\
\text { Energy } \\
\text { F:action }\end{array}$ & $\begin{array}{c}\text { Fraction of Seed } \\
\text { Uranium-235 } \\
\text { Consumed }\end{array}$ \\
\hline 1 & $5 \%$ & 18.8 & 70 & 35 & 0.50 & 0.05 & 0.20 & 0.94 \\
\hline 2 & $5 \%$ & 18.5 & 70 & 40 & 0.30 & 0 & 0.15 & 0.94 \\
\hline 3 & $5 \%$ & 19.6 & 65 & 110 & 0.20 & 0 & 0.25 & 0.91 \\
\hline 4 & $5 \%$ & 19.6 & 65 & 110 & 0.23 & 0.03 & 0.28 & 0.91 \\
\hline 6 & $10 \%$ & 17.9 & 100 & 35 & 2.60 & 0.15 & 0.47 & 0.91 \\
\hline 7 & $10 \%$ & 17.2 & 100 & 40 & 1.40 & 0 & 0.36 & 0.91 \\
\hline 8 & $10 \%$ & 19.4 & 100 & 110 & 0.69 & 0 & 0.43 & 0.91 \\
\hline 10 & $20 \%$ & 17.7 & 180 & 35 & 5.95 & 0.18 & 0.53 & 0.94 \\
\hline 11 & $20^{\circ}$ & 16.8 & 180 & 40 & 3.20 & 0 & 0.42 & 0.94 \\
\hline 12 & $20^{\alpha}$ & 19.3 & 170 & 110 & 1.69 & 0 & 0.49 & 0.89 \\
\hline
\end{tabular}


TABLE B-3. FUEL UTILIZATION WITH NON-UNIFORM SEED BURNUP, NATURAL URANIUM BLANKET WITH UNIFORM BURNUP OF 35,000 MWD/MT, NO NEUTRON LOSSES

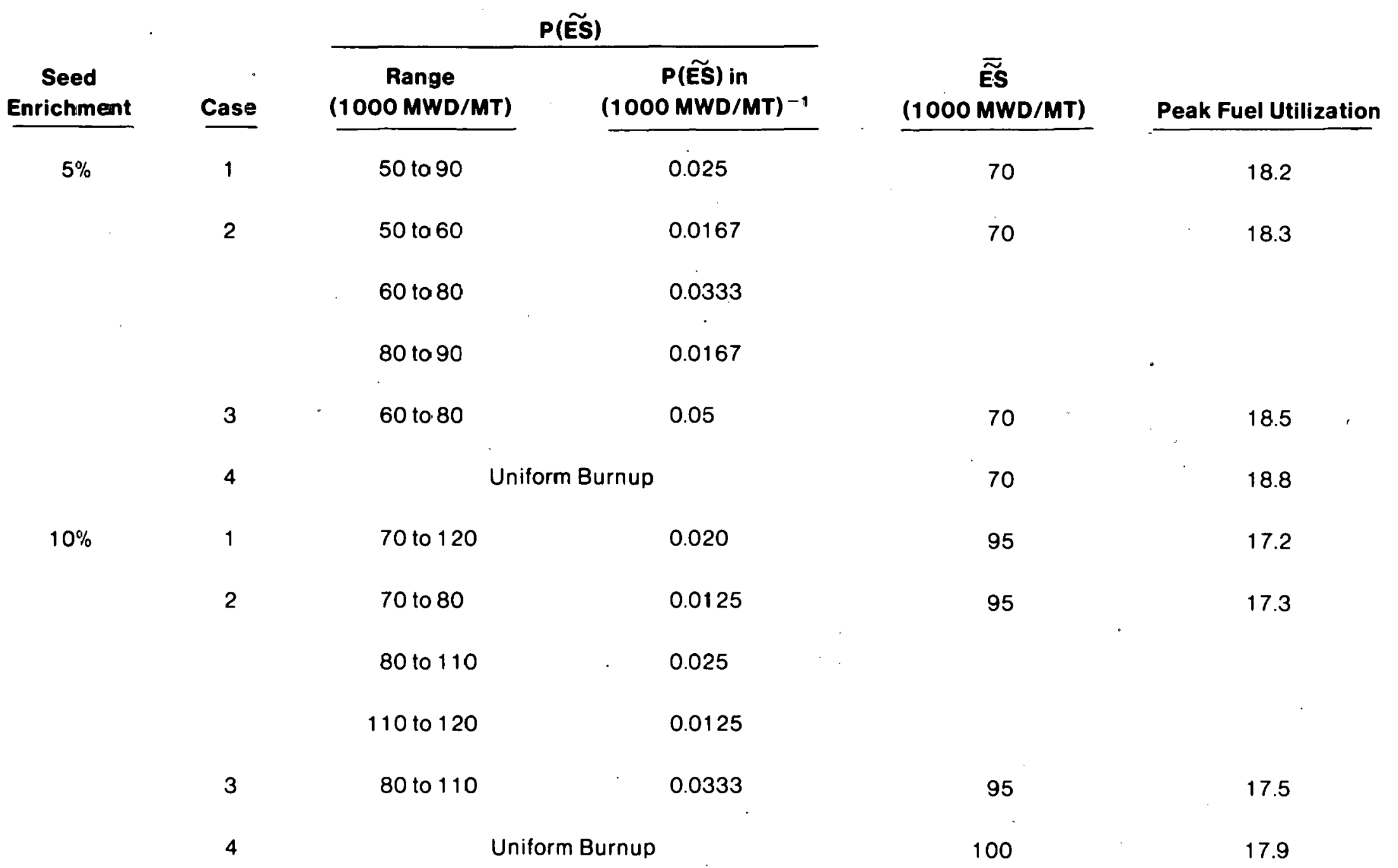


TAELE B-3 (Cont)

\begin{tabular}{|c|c|c|c|c|c|}
\hline \multirow[b]{2}{*}{$\begin{array}{c}\text { Seed } \\
\text { Enrichment }\end{array}$} & \multirow[b]{2}{*}{ Case } & \multicolumn{2}{|c|}{$P(\tilde{E S})$} & \multirow[b]{2}{*}{$\begin{array}{c}\overline{\widetilde{E S}} \\
(1000 \mathrm{MWD} / \mathrm{MT})\end{array}$} & \multirow[b]{2}{*}{ Peak Fuel Utilization } \\
\hline & & $\begin{array}{c}\text { Range } \\
(1000 \mathrm{MWD} / \mathrm{MT})\end{array}$ & $\begin{array}{c}P(\tilde{E S}) \text { in } \\
(1000 \mathrm{MWD} / \mathrm{MT})^{-1}\end{array}$ & & \\
\hline \multirow[t]{6}{*}{$20 \%$} & 1 & 130 to 210 & 0.0125 & 170 & 17.1 \\
\hline & 2 & 130 to 150 & 0.0100 & & \\
\hline & & 150 to 190 & 0.0200 & 170 & 17.1 \\
\hline & & $19 \mathrm{C}$ to 210 & 0.0100 & & \\
\hline & 3 & $15 \mathrm{C}$ to 210 & 0.0167 & $\cdot 80$ & 17.1 \\
\hline & 4 & \multicolumn{2}{|c|}{ Uniformı Burnup } & -80 & 17.7 \\
\hline
\end{tabular}




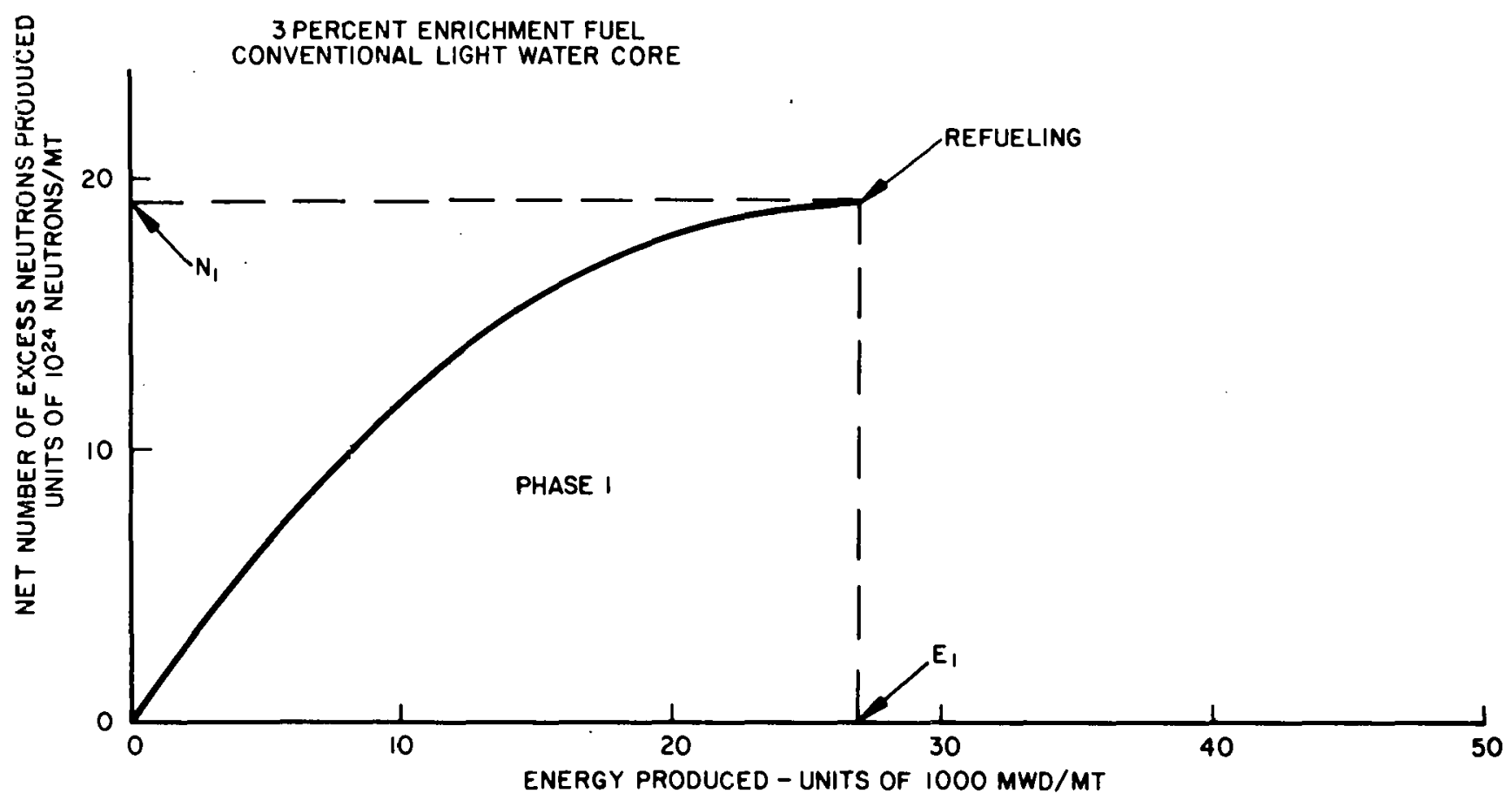

Figure B-1. Case 1 Neutron Economy 


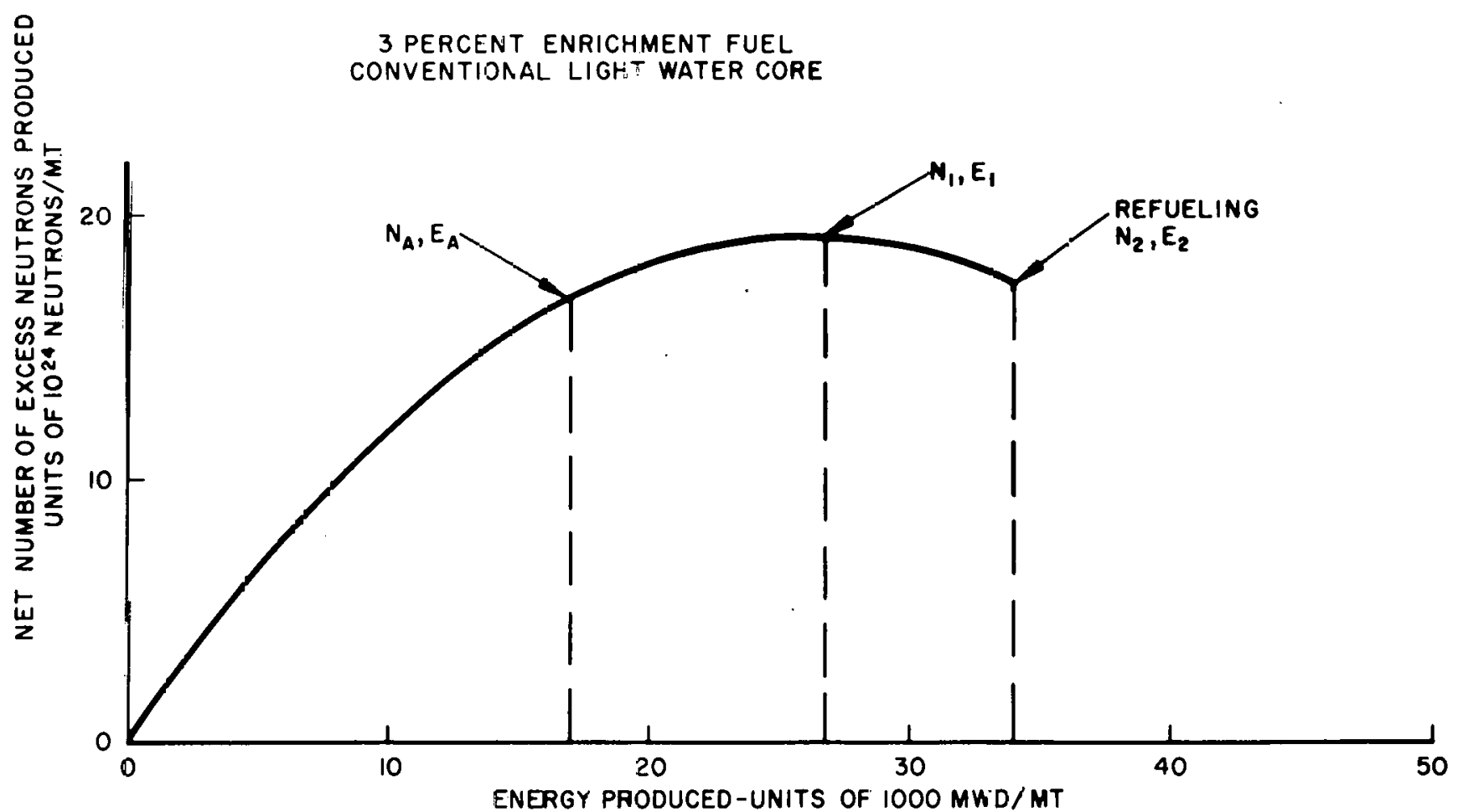

Figure B-2. Case 2 Neutron Economy 


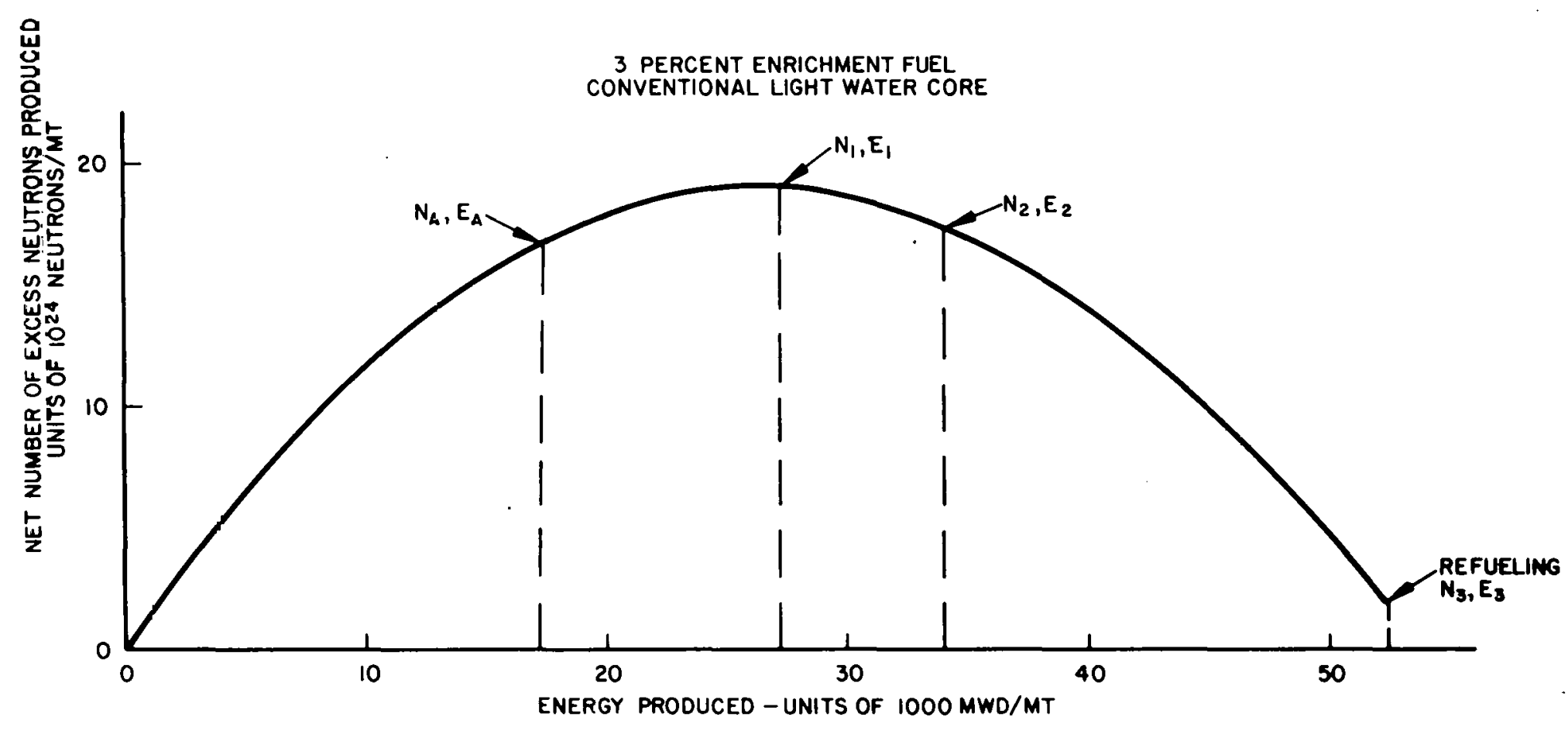

Figure B-3. Case 3 Neutron Economy 


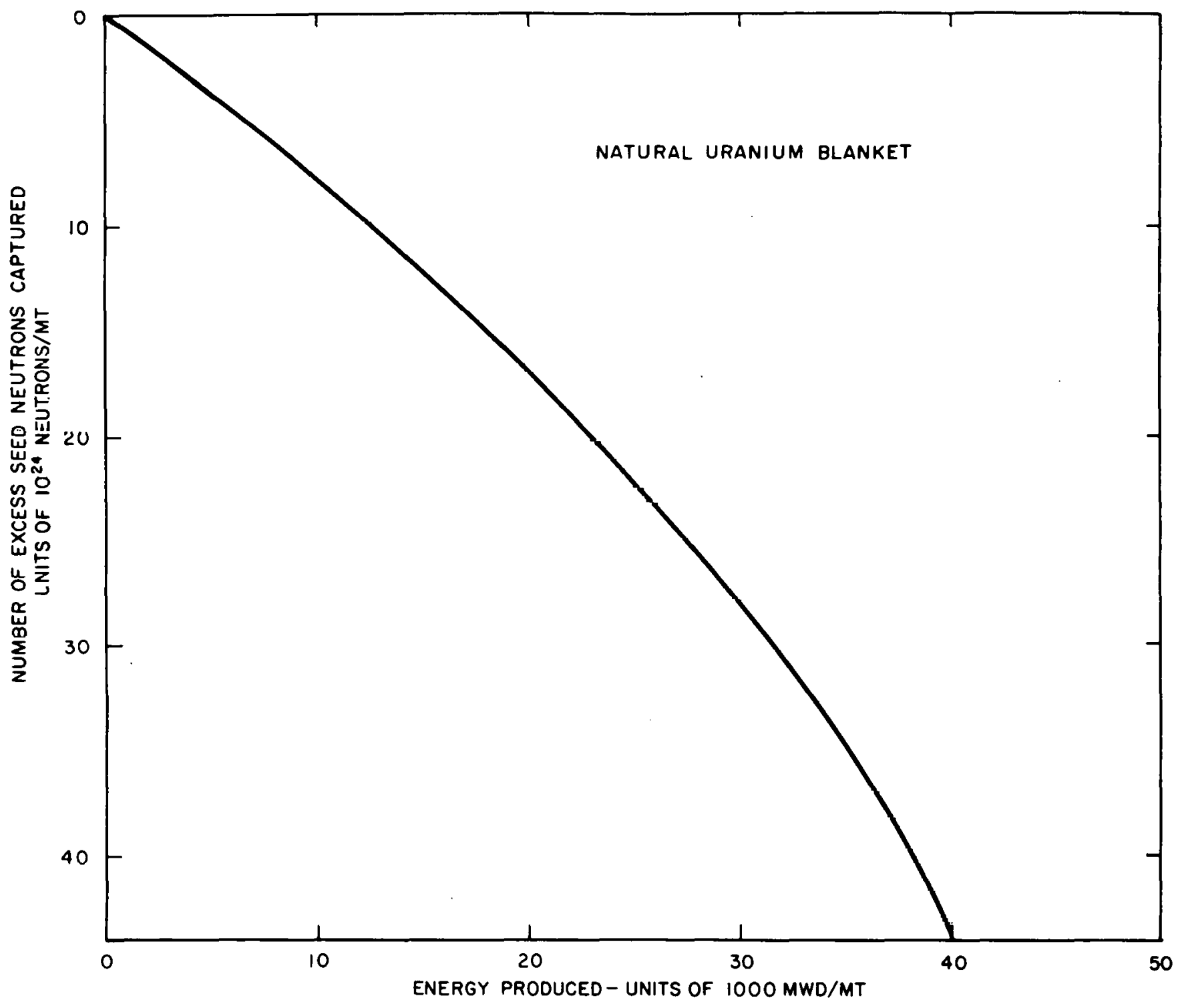

Figure B-4. Neutron Economy 


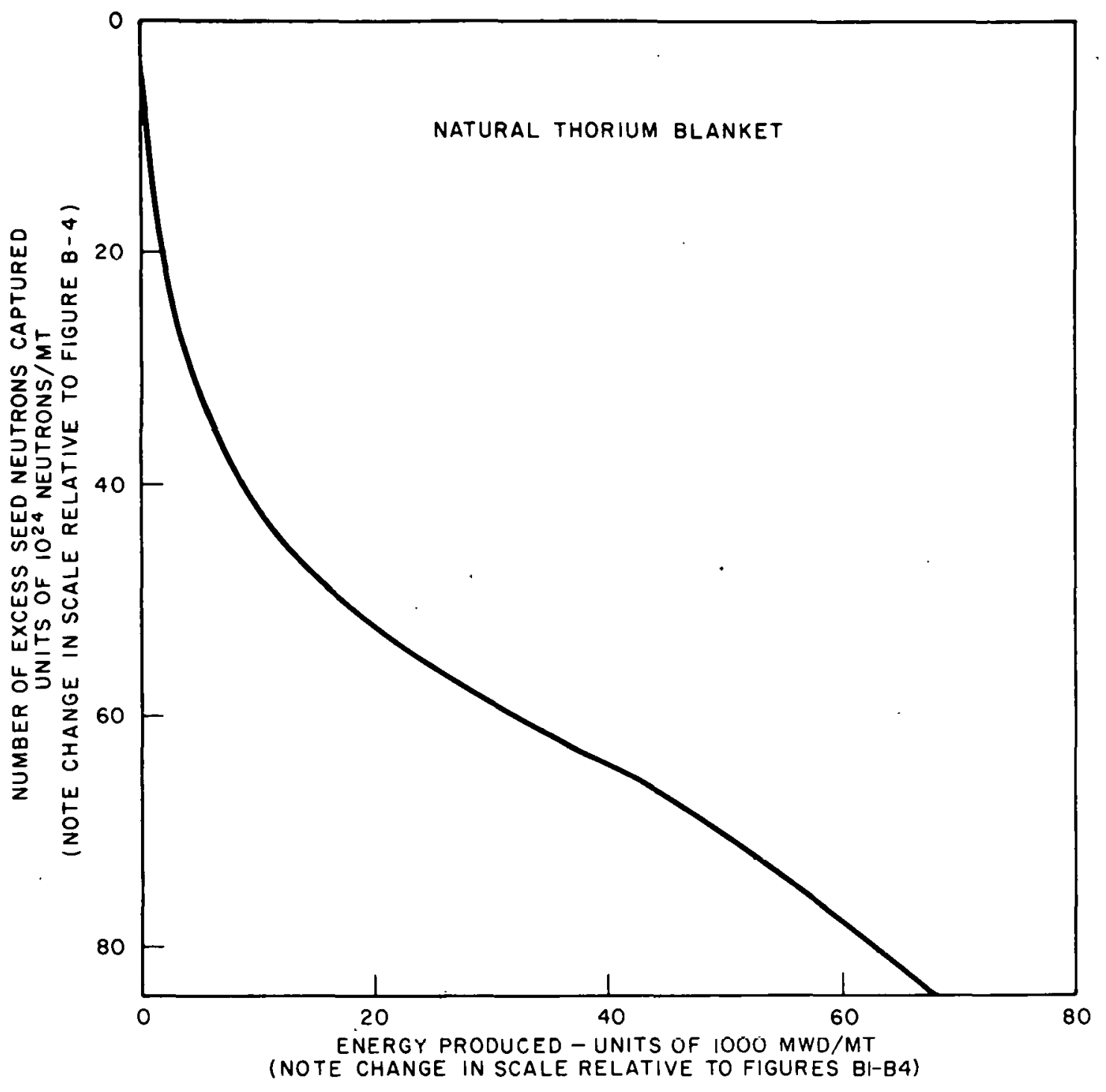

Figure B-5. Neutron Fconomy 


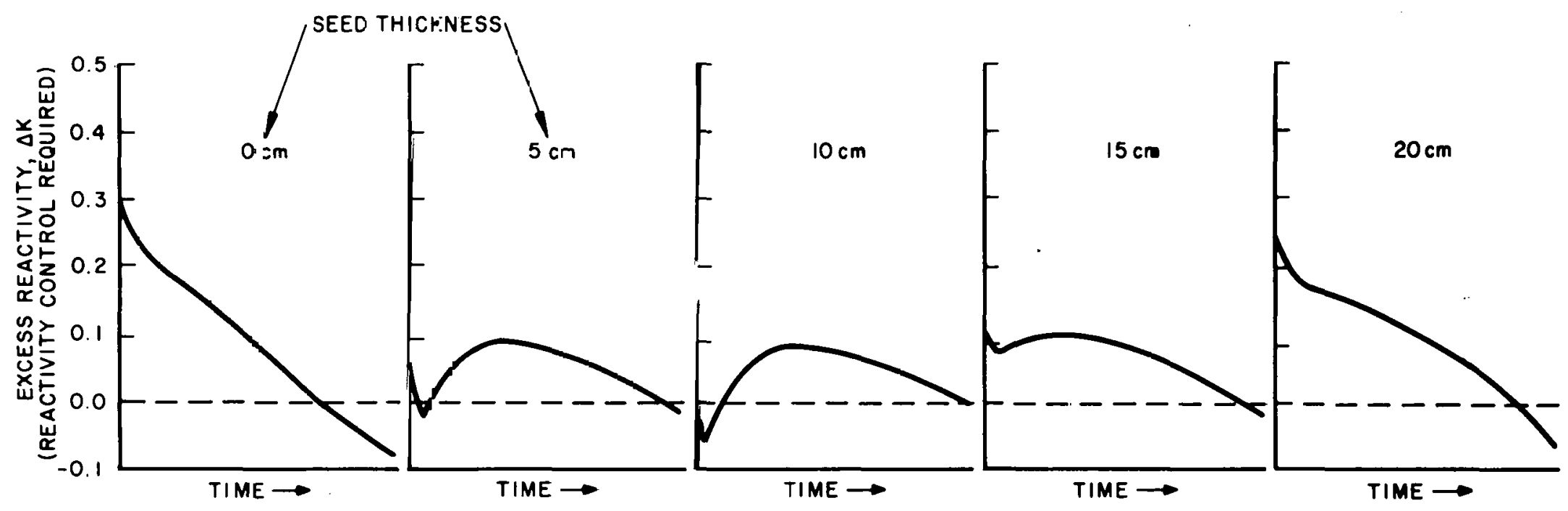

Figure B-6. Dependence of Re.activity Lifetime Control Swing on Seed-Blanket Geometry (All Cases Have the Same Fissile-to-Fertile Fuel Mass Ratio (0.05) 


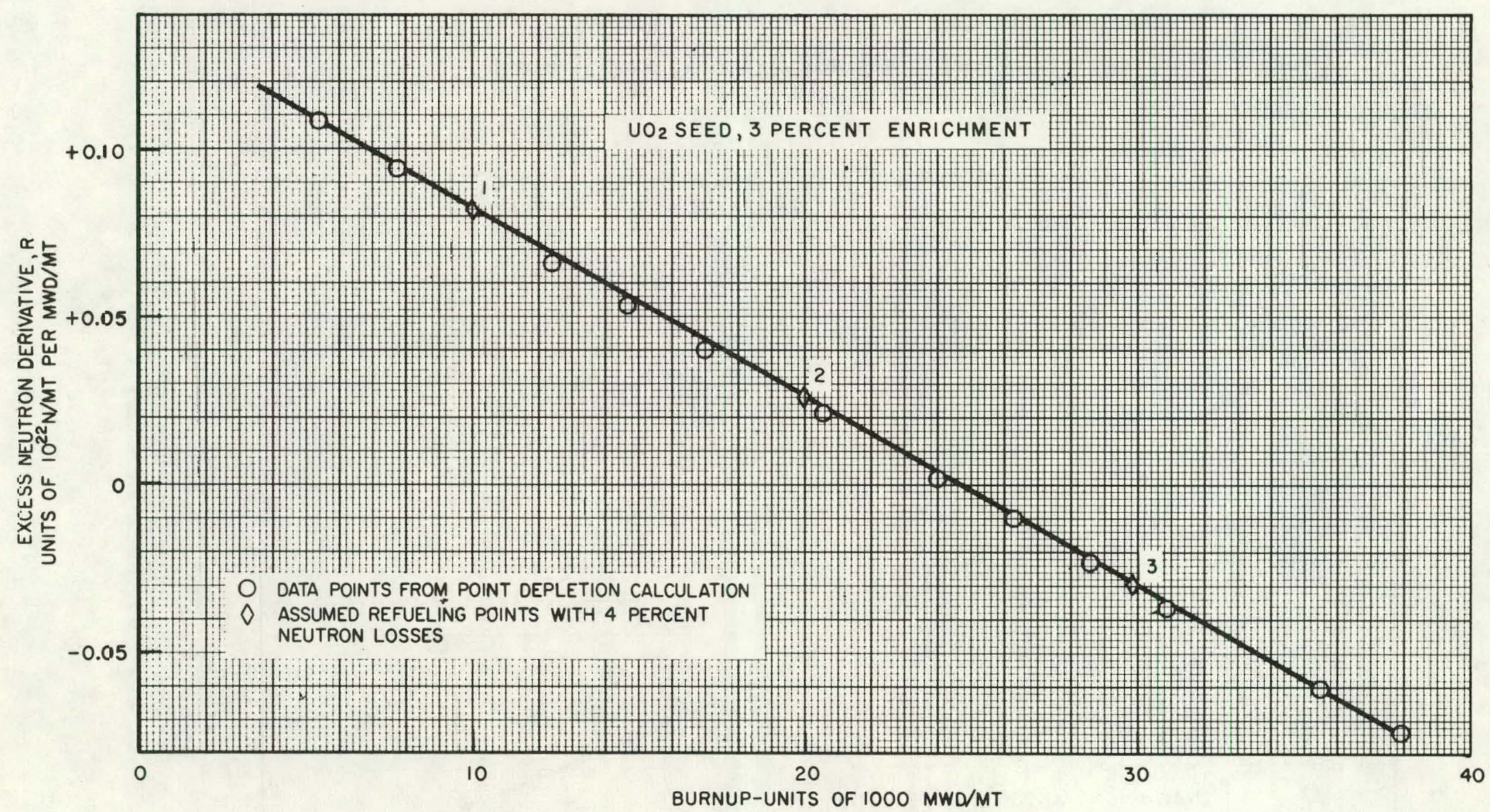

Figure B-7. Seed Excess Neutron Derivative Curve 


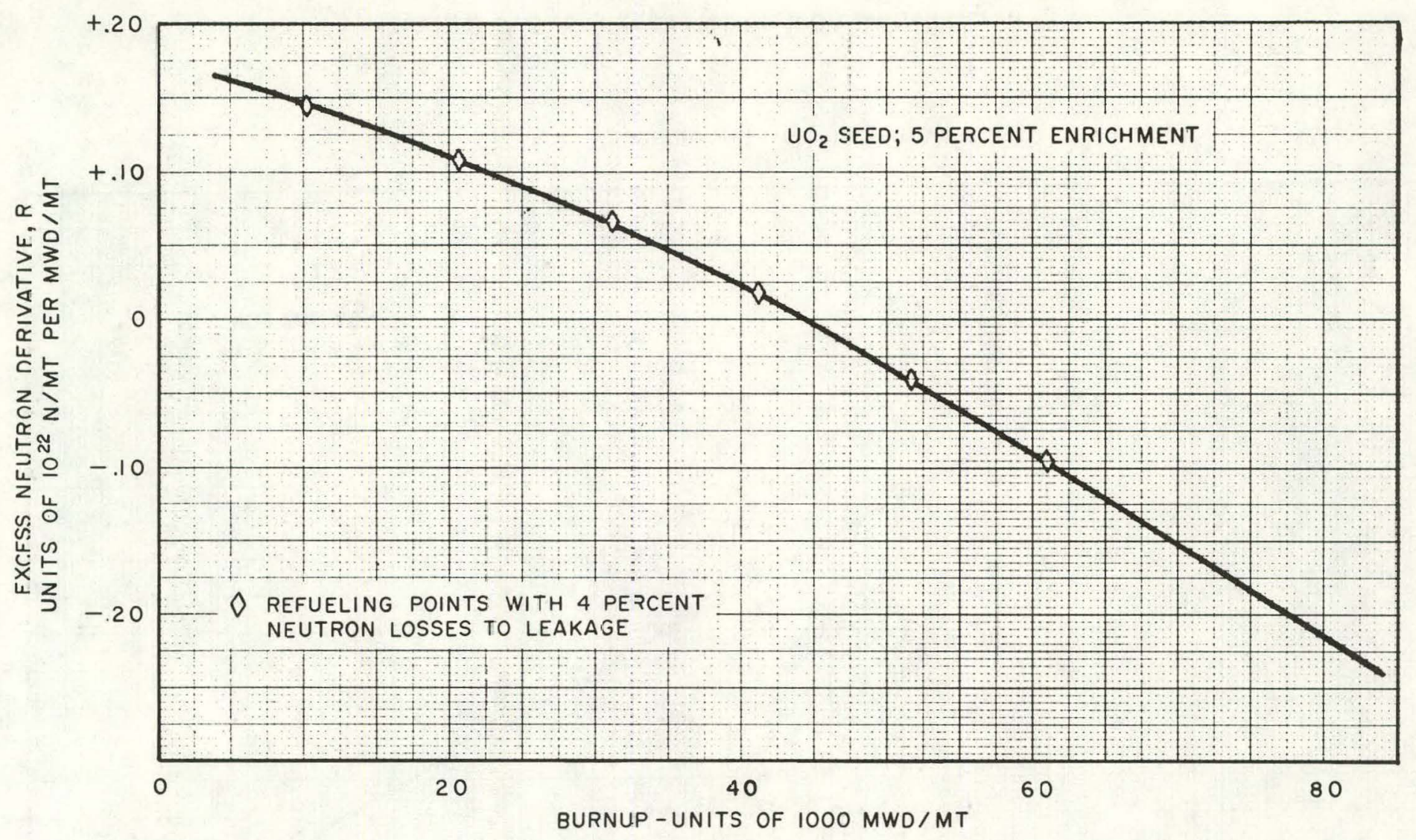

Figure B-8. Seed Excess Neutron Derivative Curve 


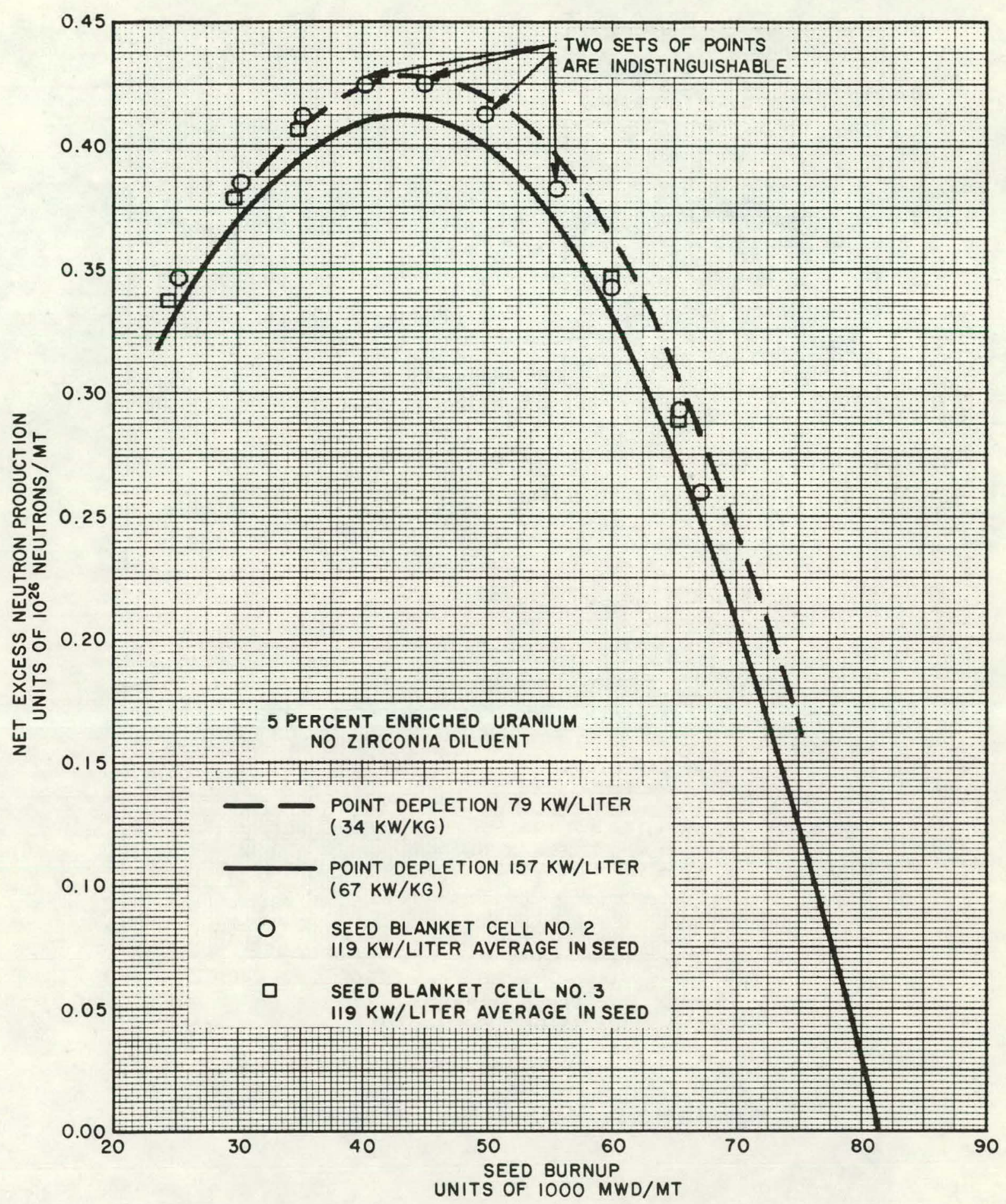

Figure B-9. Seed Excess Neutron Production 


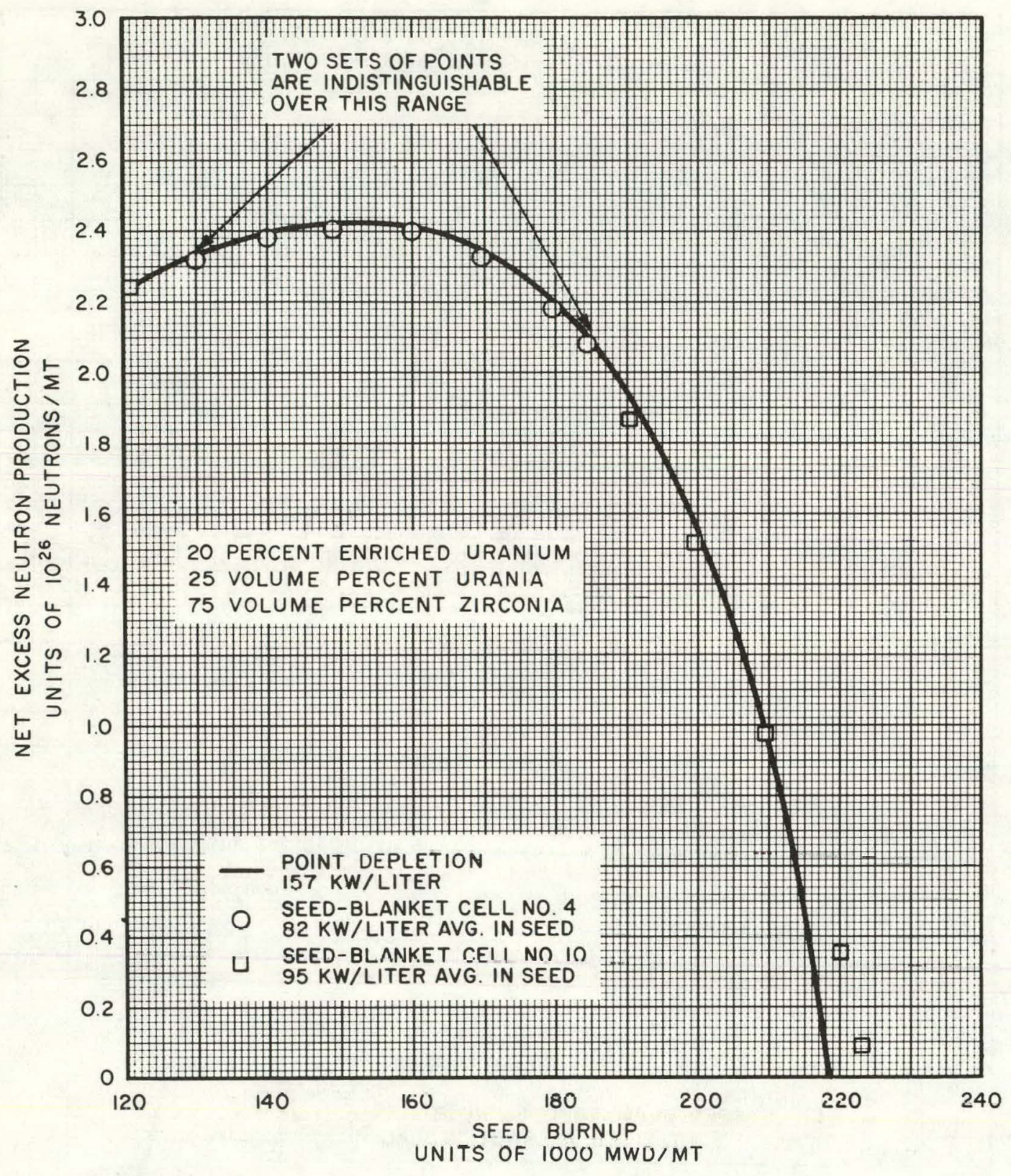

Figure B-10. Seed Excess Neutron Production 


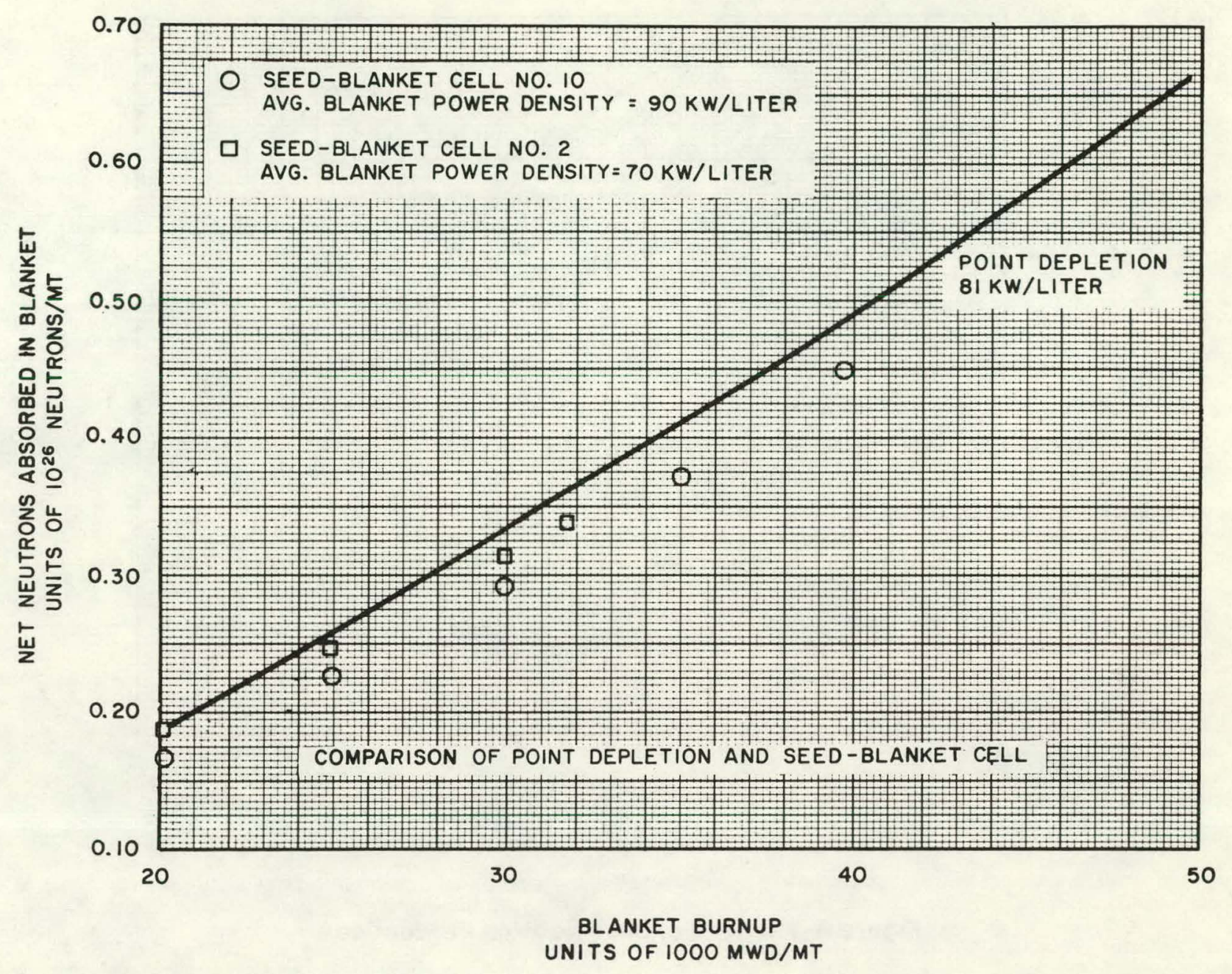

Figure B-11. Net Neutron Absorption in Natural Uranium Blanket 


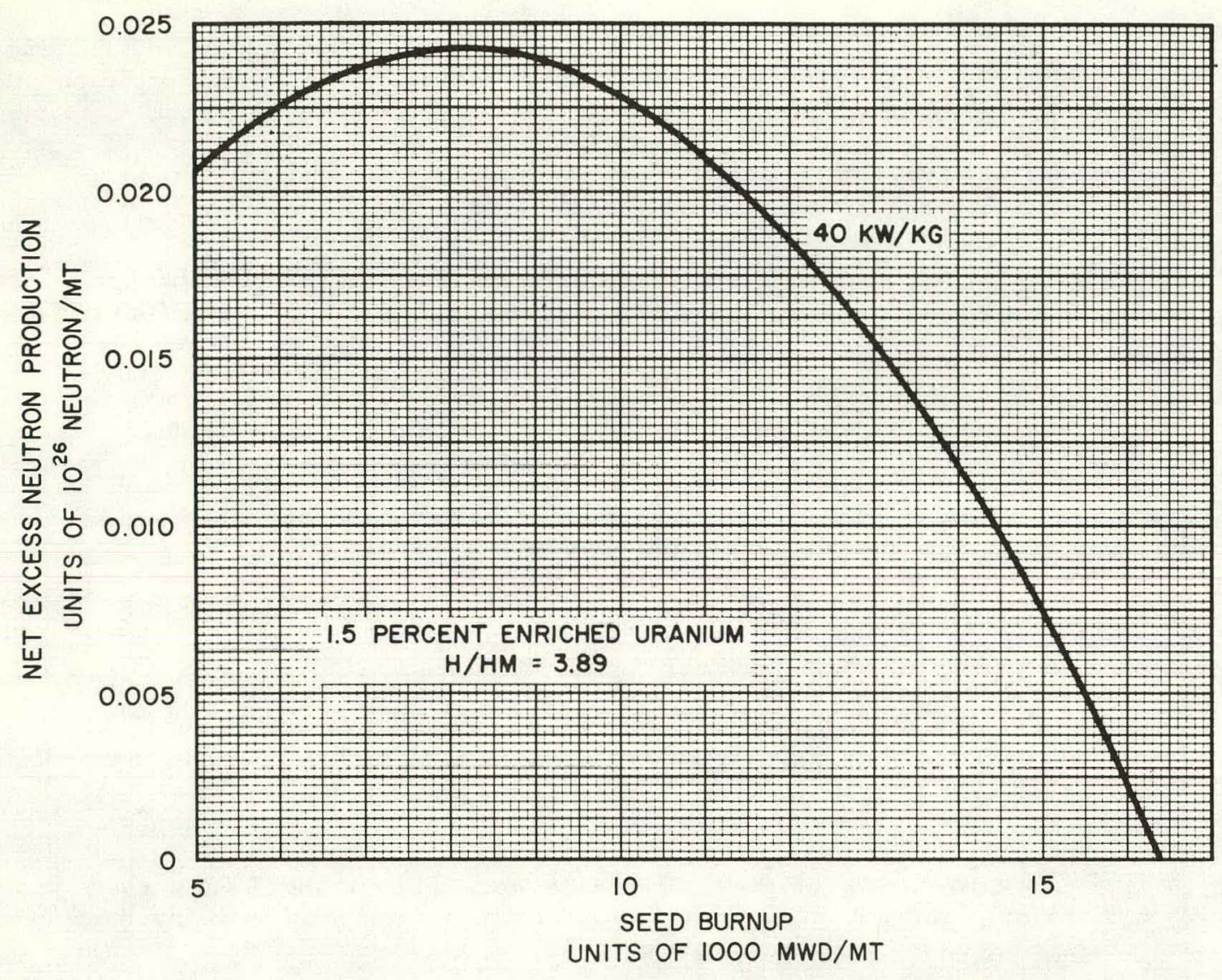

Figure B-12. Seed Excess Neutron Production 


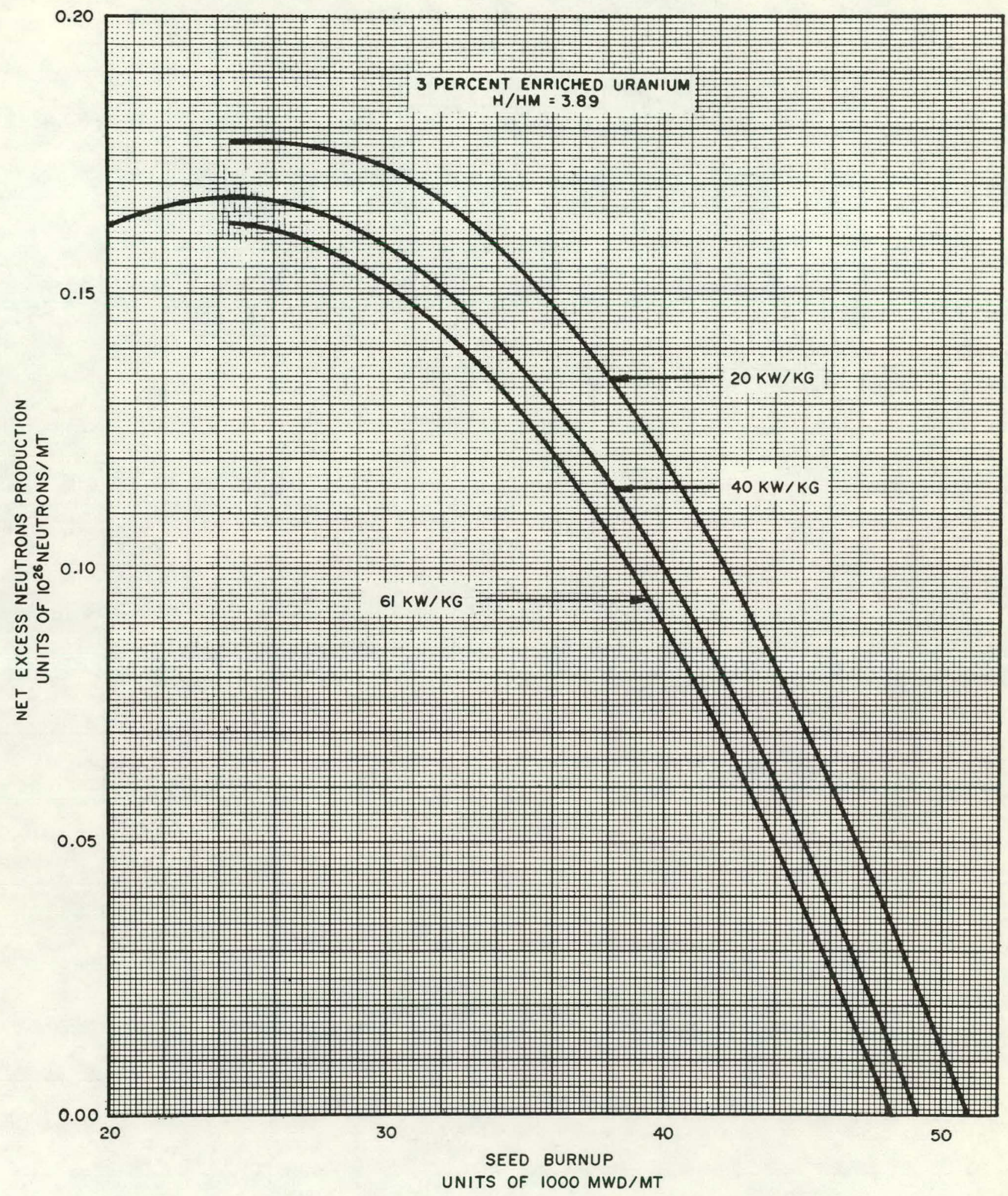

Figure B-13. Seed Excess Neutron Production 


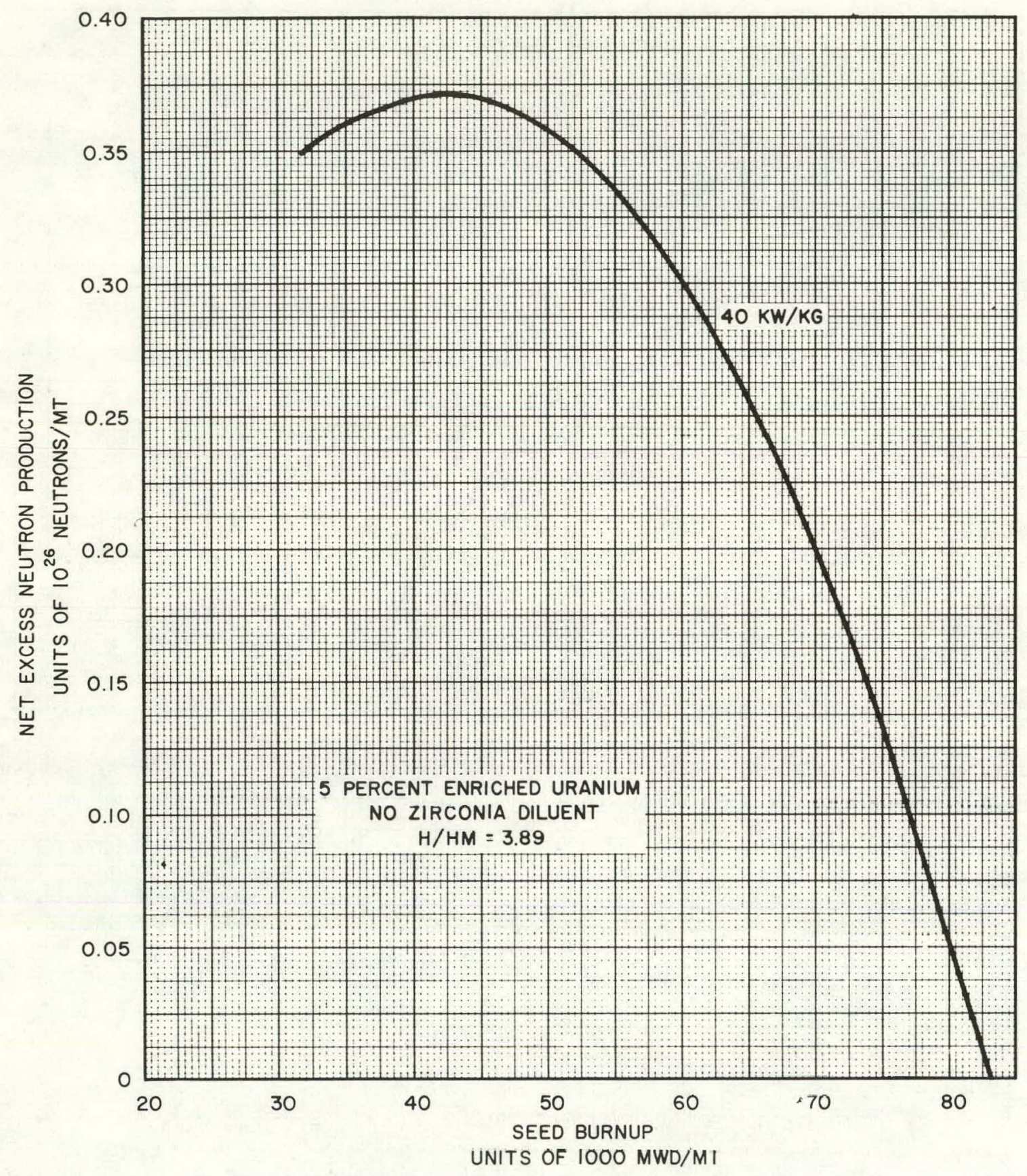

Figure B-14. Seed Excess Neutron Production 


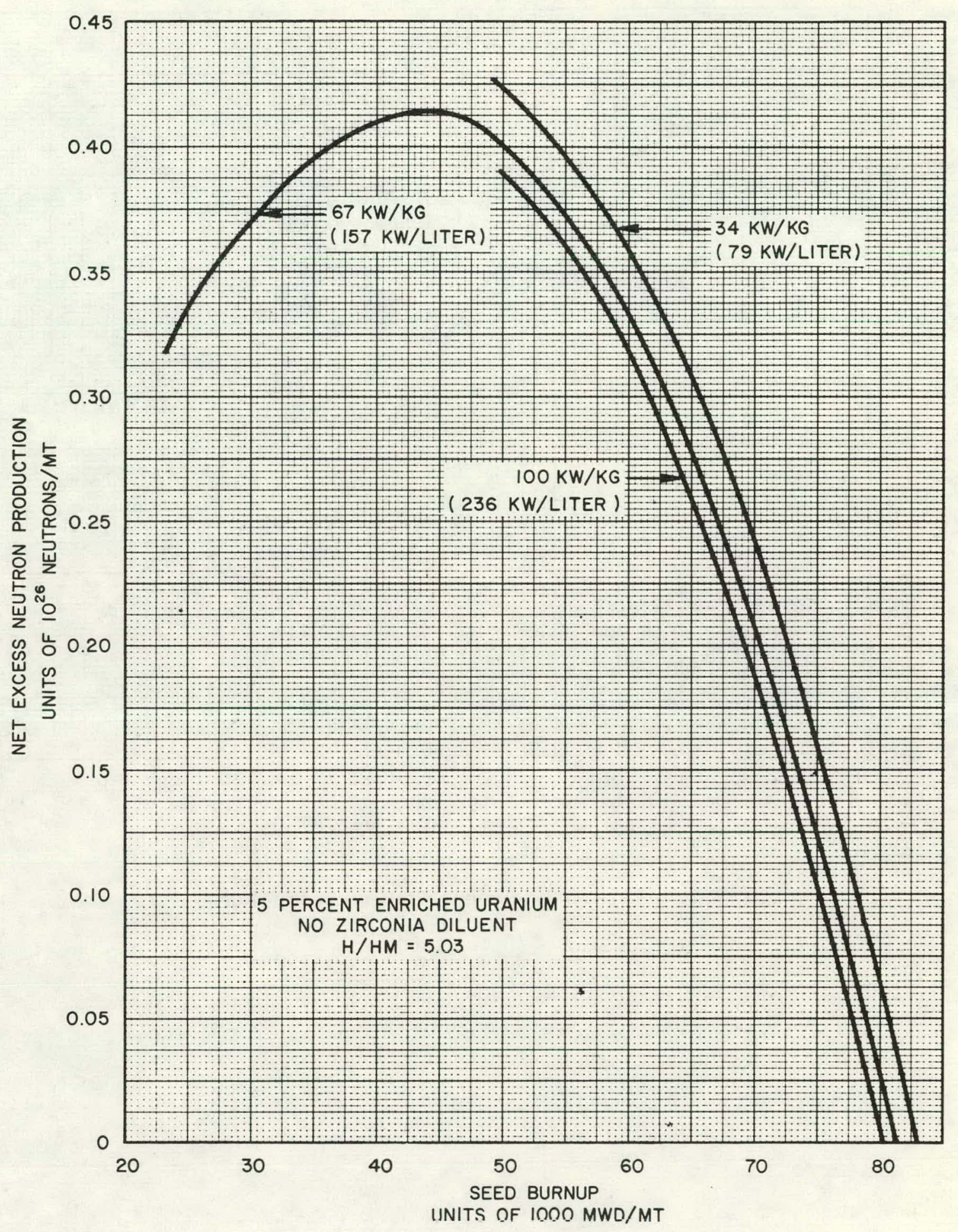

Figure B-15. Seed Excess Neutron Production 


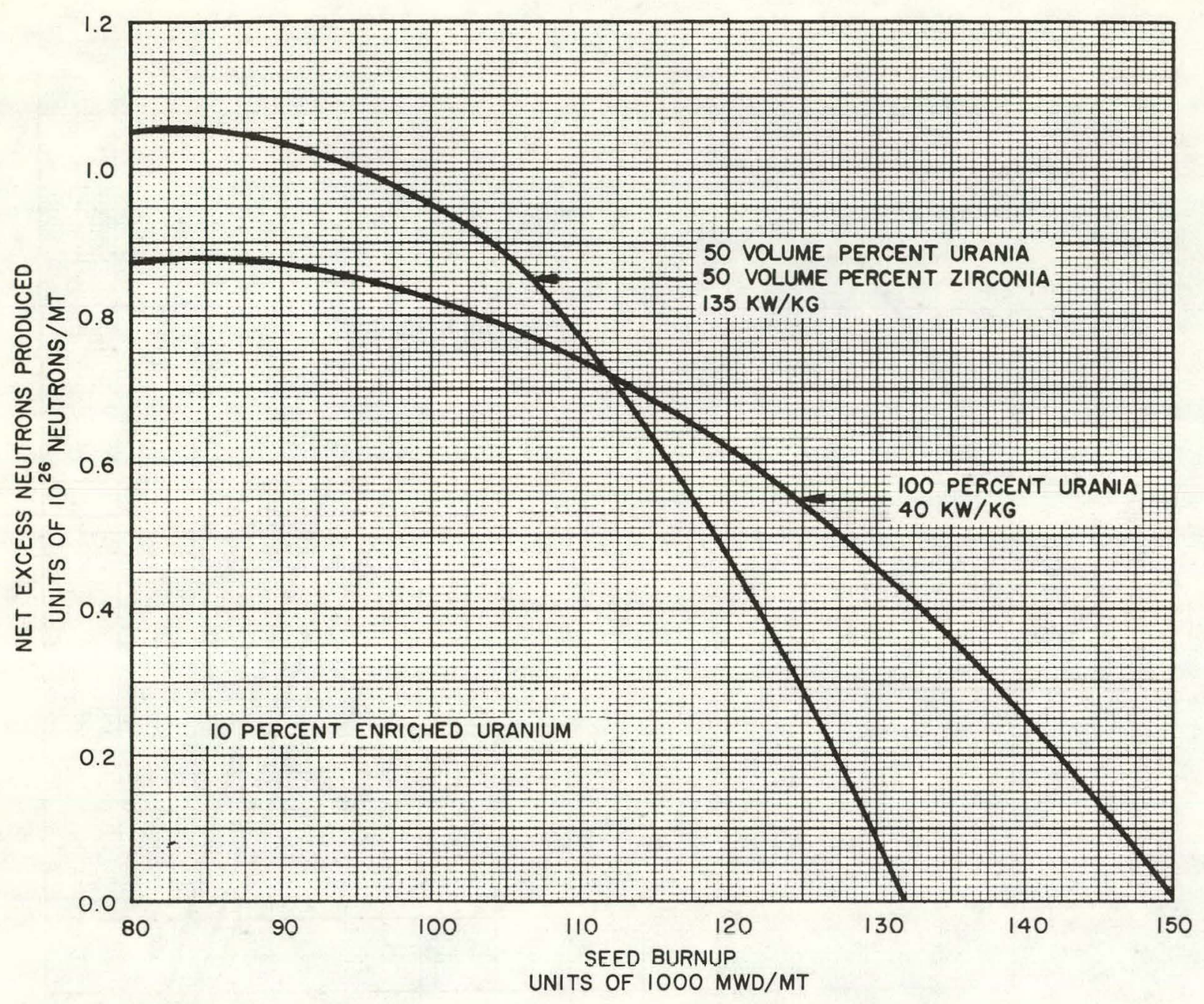

Figure B-16. Seed Excess Neutron Production 


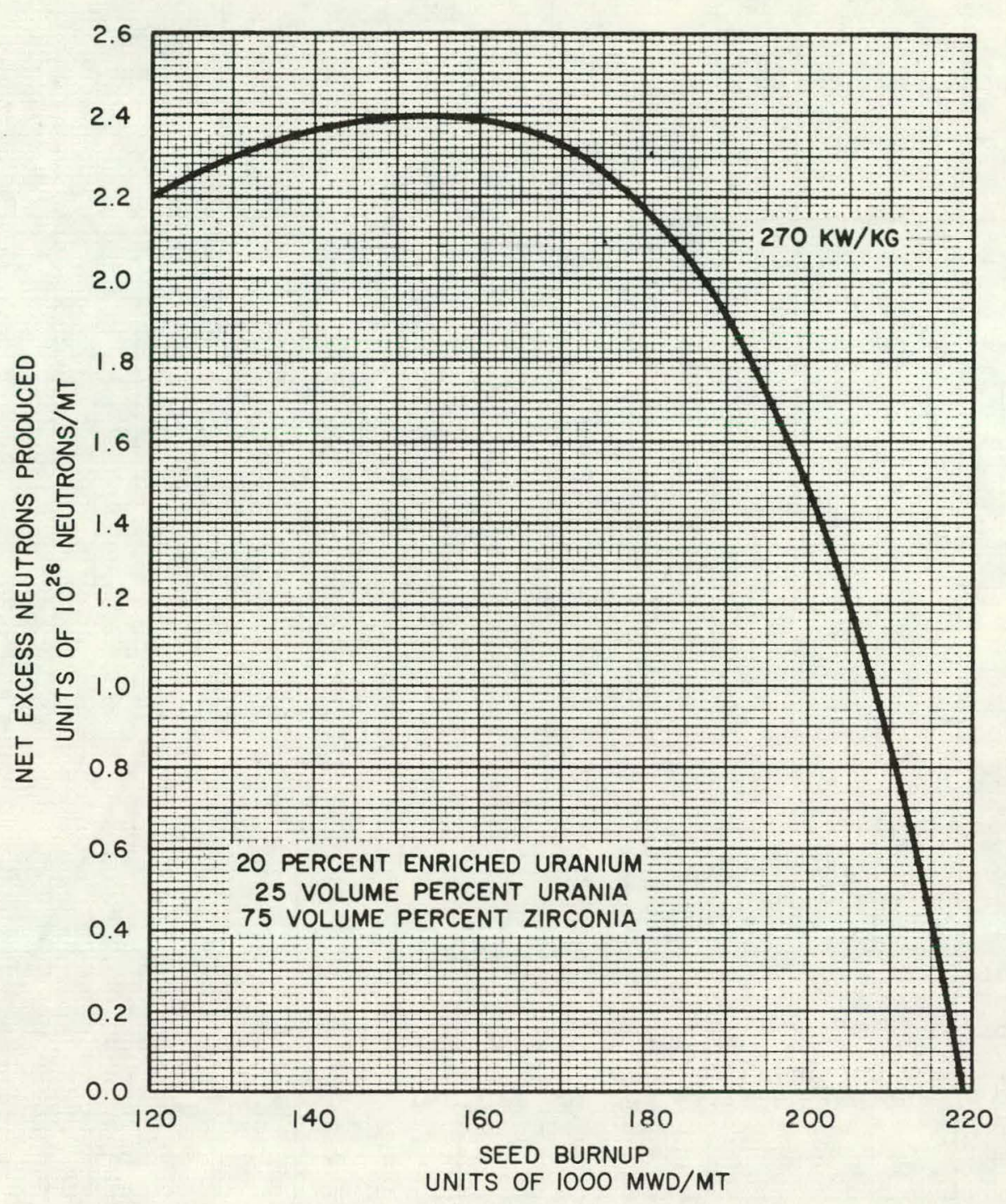

Figure B-17. Seed Excess Neutron Production 


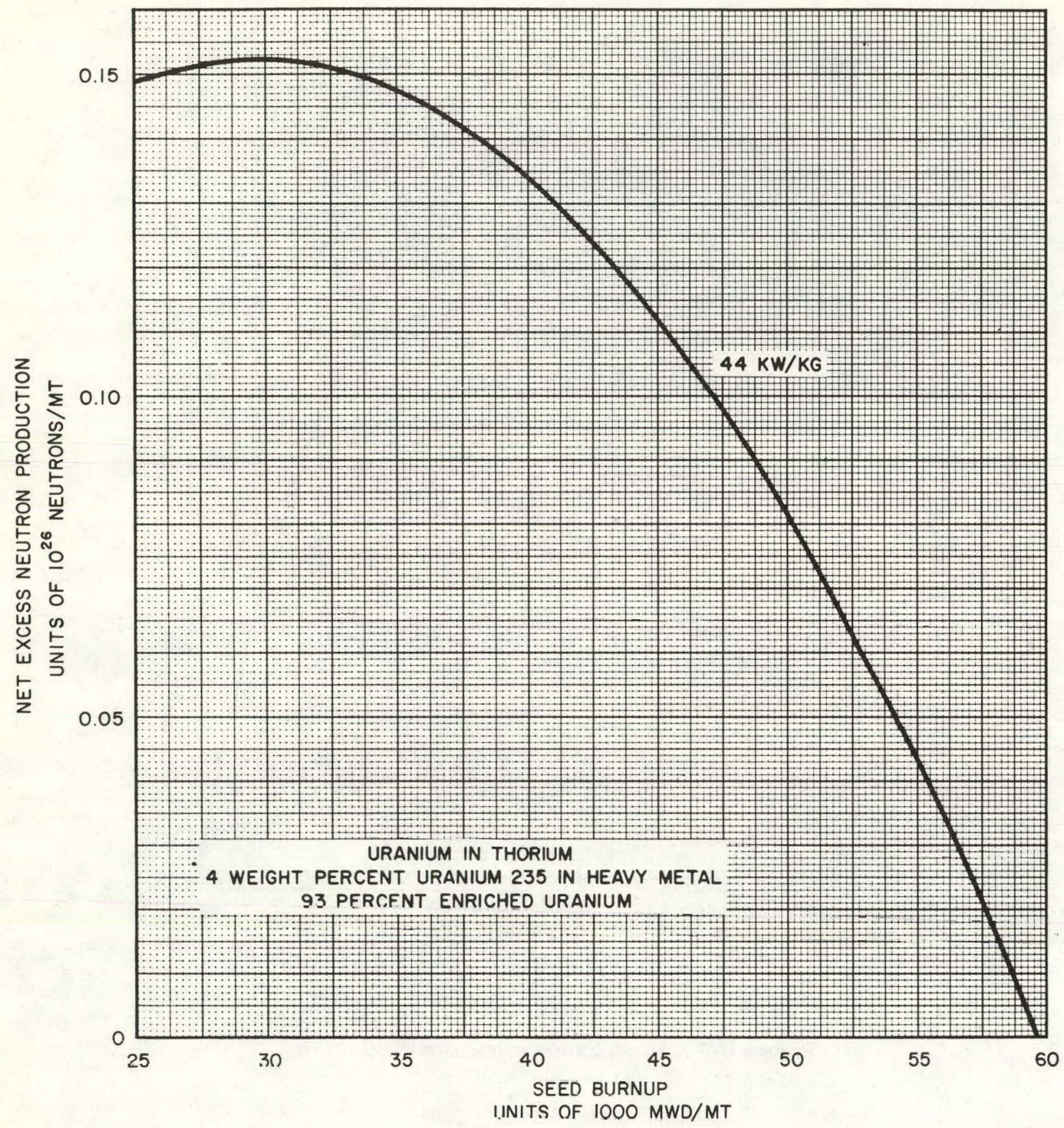

Figure B-18. Seed Excess Neutron Production 


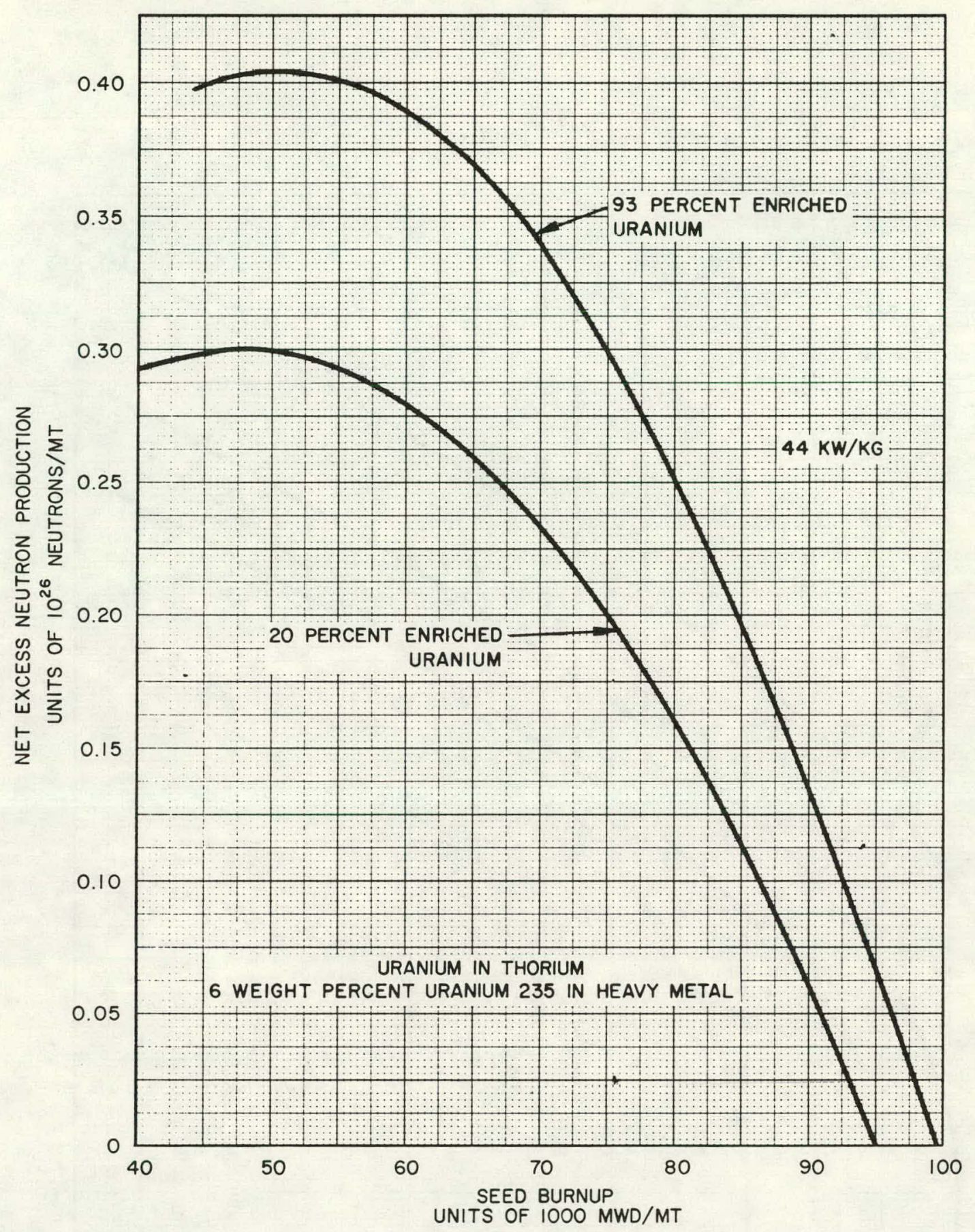

Figure B-19. Seed Excess Neutron Production 


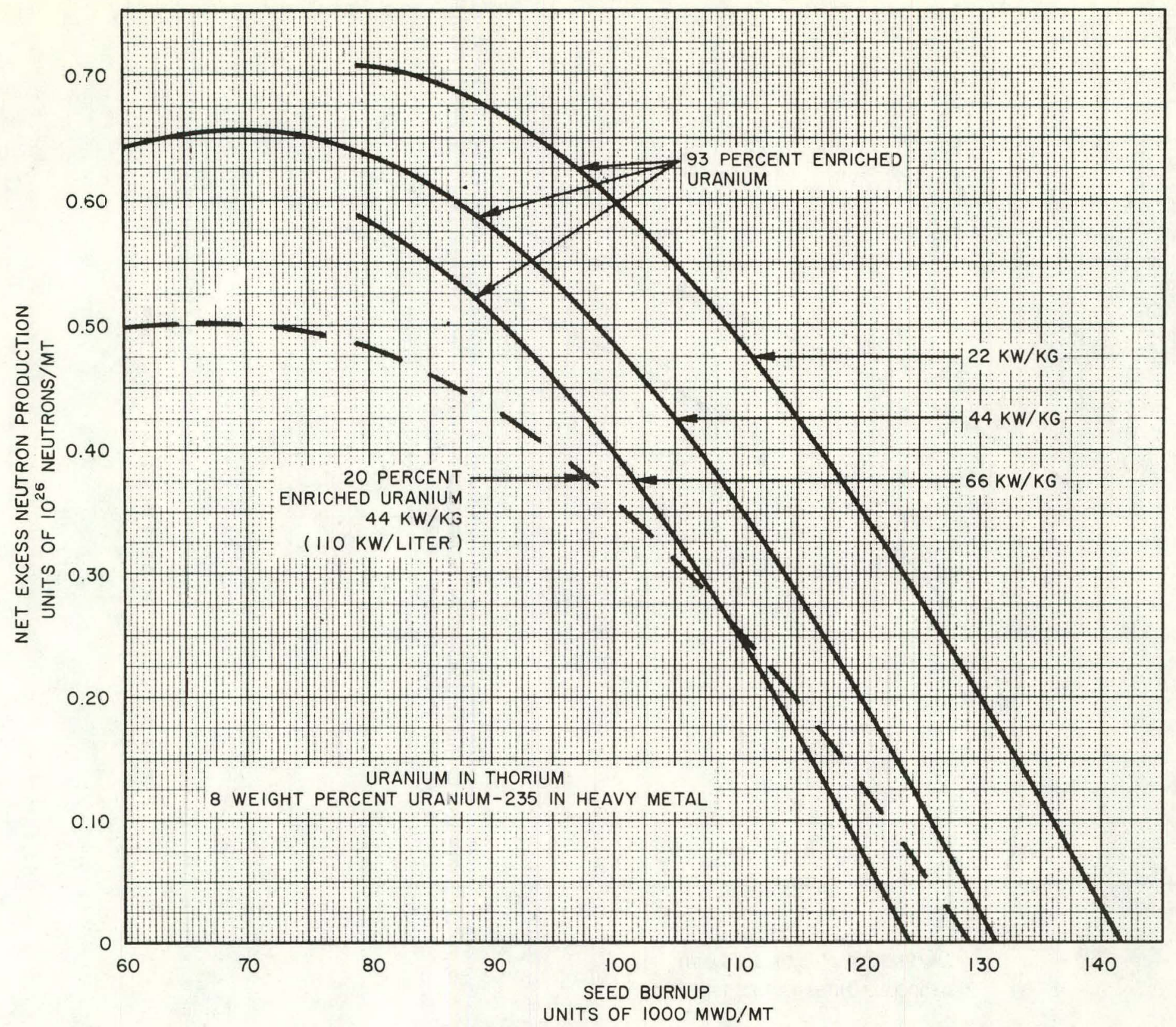

Figure B-20. Seed Excess Neutron Production 


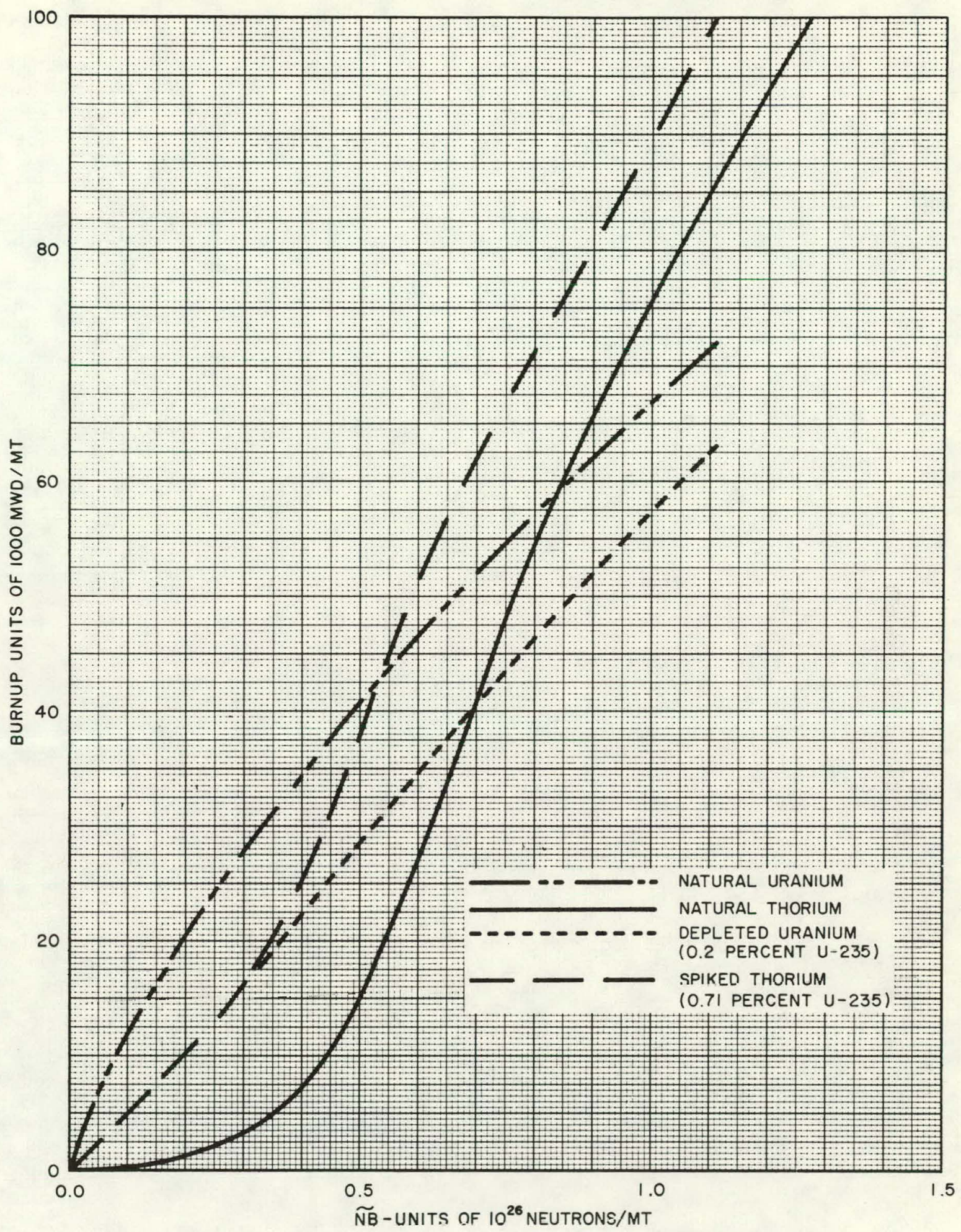

Figure B-21. Blanket Net Neutron Absorptiun 
APPENDIX C

DESCRIPTION OF PREVIOUS SEED-BLANKET REACTORS AND REACTOR CONCEPTUAL DESIGN STUDIES 
APPENDIX C-DESCRIPTION OF PREVIOUS SEED-BLANKET REACTORS AND REACTOR CONCEPTUAL DESIGN STUDIES

II. OPERATIONAL CORES

A. PWR Core 1

C-3

B. PWR Core 2

C-8

C. LWBR

III. MOVABLE FUEL CONTROLLED SEED BLANKET CONVERTER-BURNER STUDIES

A. Introduction

B. Conceptual Design Core Description

1. WAPD-LPR-256 Thorium Converter-Burner

2. CB6.2 Converter-Burner

\section{LIST OF TABLES}

Table

Title

C-1 Summary of Core Design

C-2

C-2 PWR Core 1 Characteristics

C-4

C-3 PWR Core 2 Characteristics

C-9

C-4 Light Water Breeder Reactor Core Characteristics

C-15

C-5 WAPD-LPR-256 Batch-Loaded Thorium Converter-Burner Core Characteristics

C-23

C-6 CB6.2 Converter-Burner Core Characteristics

\section{LIST OF FIGURES}

C-1 Comparison of PWR Core 2 and PWR Core 1

C-2 PWR Core 1 Seed and Blanket Cluster Arrangement

C-6

r.-3

PWR Core 1 Seed Fuel Cluster

C-6 


\section{LIST OF FIGURES (Cont)}

Figure

Title

Page

C-4 PWR Core 1 Blanket Bundle

C-7

C-5

PWR Core 2 Cross Section

C-10

C-6 PWR Core 2 Blanket Fuel Assembly

C-11

C-7

PWR Core 2 Seed Fuel Cluster with Cruciform Control Rod Channel

C-12

C-8

PWR Core 2 Cross Section Showing Seed 2 Fuel Wafers and Compartments

C-13

C-9

LWBR Reactor

C-16

C-10

LWBR Cross Section Module Identification

C-17

C-11

Typical LWBR Seed-Blanket Module Cross Section

C-18

C-12

1000 MW(e) Seed-Blanket Core, Typical Conceptual Core Cross Section

C-22

C-13

WAPD-LPR-256 Thorium Converter-Burner Fuel Module C̣ross Section

C-21

C-14

CB6.2 Converter-Burner Fuel Module Assembly Cross Section

C-26 


\section{APPENDIX C-DESCRIPTION OF PREVIOUS SEED-BLANKET REACTORS AND REACTOR CONCEPTUAL DESIGN STUDIES}

\section{INTRODUCTION AND SUMMARY}

Starting with development work on the Pressurized Water Reactor (PWR Core 1) in 1953, the Division of Naval Reactors has conducted an ongoing program to develop the technology for improving the utilization of nuclear fuel resources in water-cooled nuclear reactors. This led to the development of two reactors which operated satisfactorily in the Shippingport Atomic Power Station: PWR Core 1 and PWR Core 2. A third reactor, the Light Water Breeder Reactor (LWBR), is currently operating in the Shippingport Plant. In addition, a substantial amount of design data was developed on seed-blanket core concepts which would utilize movable fuel reactivity control for potential commercial application. This appendix presents a brief description of the operating cores and some of the conceptual designs which were evaluated considering such various factors as fuel utilization, lifetime, fission density and alternate fuels. These descriptions include schematics and tables of thermal, mechanical, and nuclear characteristics for each of the designs and concepts.

Table C-1 presents a summary of the core designs and concepts discussed in this appendix. The two concepts included here are a representative sample from a large number of concepts which were examined during the development program on seed-blanket cores. Not all of these concepts were carried to the same stage of engineering effort. Some of the studies performed included physics, thermal, hydraulic, and mechanical analyses. Other studies comprised only a physics analysis of concepts obtained by making small changes in geometry and composition parameters of a base case.

In all of the concepts, the seed fuel was highly enriched uranium oxide. The blankets fall into the following three categories:

1. Natural uranium (uranium dioxide)

2. Natural thorium (thorium dioxide)

3. Natural uranium (uranium dioxide) and thorium (thorium dioxide).

For all of the operating reactor designs and concepts reported here, good fuel utilization was an objective. At the time the design work was performed, it was assumed that eventually in the commercial nuclear industry, spent fuel would be reprocessed to recover uranium and thorium. Hence, the objective in these designs (excluding LWBR) was to minimize the amount of uranium-235 consumed (rather than the amount of uranium-235 in the initial loading) per megawatt hour thermal of reactor operation; alternatively stated, the objective was to maximize the amount of energy obtained from thorium and uranium-238. Additional objectives for PWR Core 2 were high power density and high burnup to minimize core size and the frequency of refueling. For the LWBR, the objective was to achieve breeding. Further objectives for PWR Core 1 and PWR Core 2 and for LWBR were to prove technology and reliability. To meet these objectives required balancing fuel utilization with fuel element and thermal-hydraulic design. Such balancing was not considered for the conceptual studies. 
All of the operational and conceptual cores described here have seed-blanket geometry. This geometry is characterized by an alternating pattern of seed modules or assemblies and blanket modules or assemblies. Seed module fuel has a relatively high ratio of fissile to fertile atoms, while blanket module fuel has a relatively low ratio of fissile to fertile atoms. For the LWBR the fissile fuel is uranium-233 and the fertile fuel is thorium. For the PWR cores the fissile fuel was uranium-235 and the fertile fuel was uranium-238. For the conceptual cores the fissile fuel would be uranium-235 and the fertile fuel would be uranium-238 or thorium. In the PWR cores reactivity control was achieved by hafnium control rods and by burnable boron; in the LWBR, reactivity control is achieved by axially positioning of movable fuel. The conceptual design studies assumed the use of movable fuel reactivity control as well. Movable fuel reactivity control leads to efficient use of neutrons because excess neutrons are captured in the fertile fuel rather than in control poisons. In the LWBR the use of movable fuel permits breeding to be achieved. The assumption of the use of movable fuel in the conceptual cores would lead to good once-through fuel utilization. Because a breeder fuel cycle is based on fuel reprocessing and recycle, it is not meaningful to define a fuel utilization with oncethrough fuel irradiation for the LWBR. For the PWR cores the once-through fuel utilization was about $7 \mathrm{MWYth} / \mathrm{ST} \mathrm{U}_{3} \mathrm{O}_{8}$. For the conceptual cores presented here the once-through fuel utilization would be about 12 to $14 \mathrm{MWY}$ th/ST $\mathrm{U}_{3} \mathrm{O}_{8}$.

TABLE C-1. SUMMARY OF CORE DESIGNS

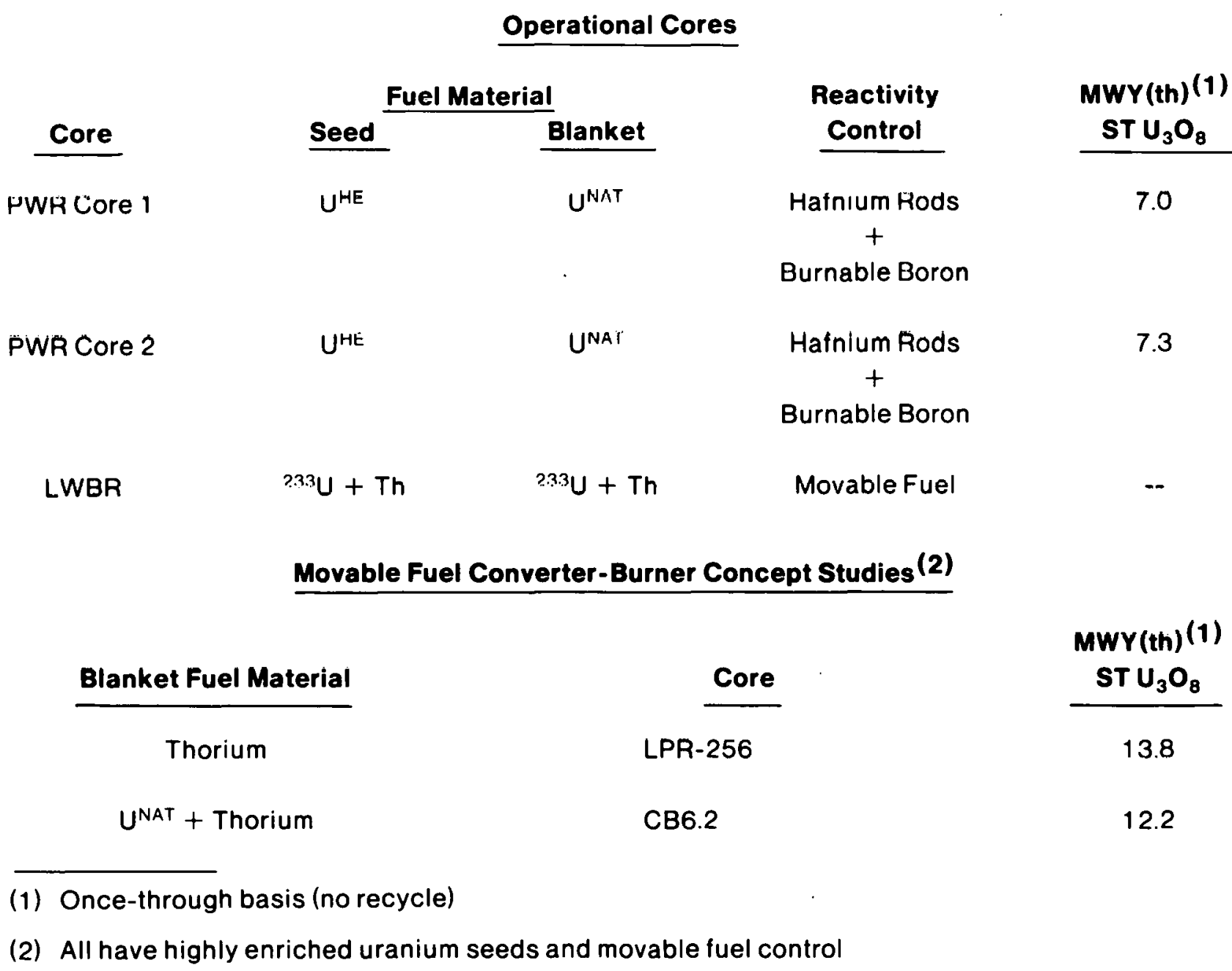




\section{OPERATIONAL CORES}

\section{A. PWR Core 1 (References C-1 through C-3)}

PWR Core 1 was the first core operated in the United States in a central-station nuclear power plant for generating electricity. It was a seed-blanket design, consisting of 32 seed and 113 blanket assemblies. Features of the core are shown in Figures $\mathrm{C}-1$ through $\mathrm{C}-4$ and Table C-2. Each assembly (seed or blanket) was approximately 5.5 inches square in cross section and had an active fuel height of 6 feet. The pressure vessel head and core support structures were designed to permit through-the-head refueling of either type of assembly. The seed fuel was in the form of full-length plates consisting of an uranium-zirconium alloy fuel bonded with Zircaloy-2 cladding. Some of the seed plates contained small amounts of boron in the uranium-zirconium alloy which acted as a burnable poison. These plates were welded longitudinally to form the seed assemblies.

The blanket assemblies were made from approximately 10 -inch long fuel rods consisting of natural uranium dioxide pellets in Zircaloy-2 tubing. The blanket fuel rods were assembled in parallel groups called bundles. In each bundle, the rods were welded at the top and bottom ends to a tube sheet which contained flow holes and holes to position the rods. Seven such bundles were stacked vertically within a Zircaloy can to form a blanket assembly with a stack height of about 6 feet.

All seed and blanket assemblies were supported and positioned by a bottom plate. Reactivity control was achieved by means of 32 cruciform-hafnium control rods, with one rod in each seed assembly. Soluble boron was not used for reactivity control during either normal core operation or shutdown. The coolant flow arrangement was single-pass for both the seed assemblies and the blanket assemblies.

During the more than 27,000 EFPH of PWR Core 1 operation from December 1957 through February 1964, the seed was refueled three times. The original blanket remained in place during all four seed lives. During operation of the core, all design objectives were met. Subsequent examination of spent seed and blanket assemblies indicated that all fuel performance objectives were also met. 
TABLE C-2. PWR CORE 1 CHARACTERISTICS

Reactor Power, MW(th)

$$
\begin{gathered}
225^{(1)} \\
2000 \\
508^{(1)} \\
538^{(1)} \\
22.8^{(1)} \\
40.5^{(1)} \\
32 \\
113 \\
6.0
\end{gathered}
$$

Pressure, psia

Inlet Temperature, $F$

Outlet Temperature, $F$

Coolant Flowrate, $10^{6} \mathrm{lb} / \mathrm{hr}$

Reactor Vessel Pressure Drop, psi

Number of Modules

Seed

Blanket

Module Pitch, inches

Core Reactivity Lifetime, EFPH, Seeds 1 through 4

27,781

Lifetime Average Power Fraction, Seeds 1 through 4

Loading

Blankot

$75 \mathrm{~kg}^{235} \mathrm{U}$

Seed 1

Seends 2 through 4 , each

Fuel Composition, w/o

Average Fuel Depletion, fissions/cc

Average Fuel Depletion, MWD/MTU-Blanket

Maximum Fuel'bepletion, fissions/cc

Maximum Fuel Depletion, MWD/MTU-Blanket

Fuel Rod Outside Diameter, inches

Clad Thickness, inches

Fuel Pellet Diameter, inches

Fuel Plate Thickness, inches,

Fuel Alloy Thickness, inches

$90 \mathrm{~kg}^{235 \mathrm{U}}$

$6.7 \mathrm{~W} / \mathrm{O} \mathrm{U}^{\mathrm{E}}$

$93.3 \mathrm{w} / \mathrm{O} \mathrm{Zr}$

$$
\frac{\text { Blanket }}{0.633}
$$

Fuel Clad Thickness, inches

Seed Uranium-235 Burnup, \% (average of 4 seeds)

Metal/Water Ratio

Flow. $10^{6} \mathrm{lb} / \mathrm{hr}$

Mass Velocity, $10^{6} \mathrm{lb} / \mathrm{hr}^{-\mathrm{ft}^{2}}$

Coolant Velocity, $\mathrm{ft} / \mathrm{sec}$

Orifice Pressure Drop, psi

Maximum Average Power Density, kw/liter

Maximum Average Heat Flux, Btu/hr-ft ${ }^{2}$

Fuel Utilization, MWY(th)/ST $\mathrm{U}_{3} \mathrm{O}_{8}$ (once-through)

98,400

1416 tons

U INAT

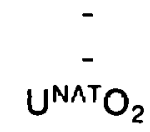

11,270

$-$

$22,000^{(2)}$

- $\quad 0.413$

$-\quad 0.027$

$-0.3575$

0.069

0.038

0.015

47

0.901

$8.2^{(1)}$

1.299

$10.2^{(1)}$

$24^{(1)}$

$-$

3.5 to $9.6^{(3)}$

(1) Parameters are for 3-loop operation.

(2) For Seeds 1 through 3 only.

(3) Covers range of velocities in four blanket regions 
CDRE 2

20 CONTROL ROD MECHANISMS

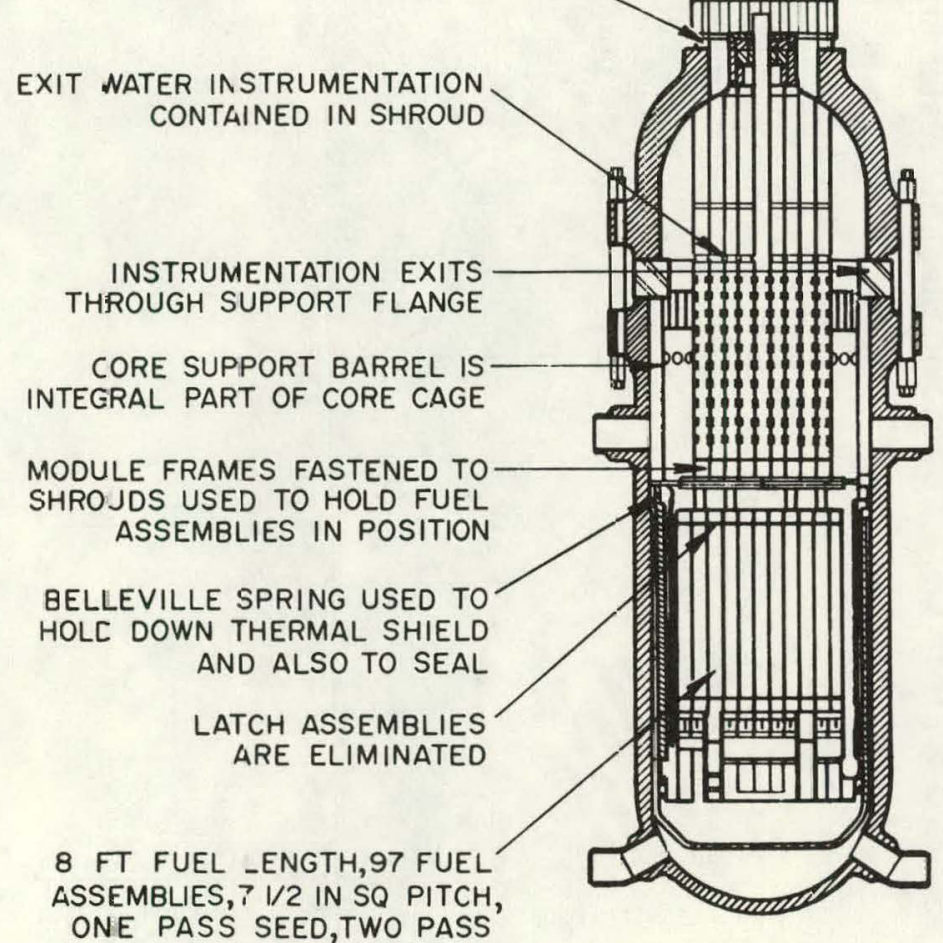

ONE PASS SEED TWO PASS BLANKET FLOW ARRANGEMENT
CORE I

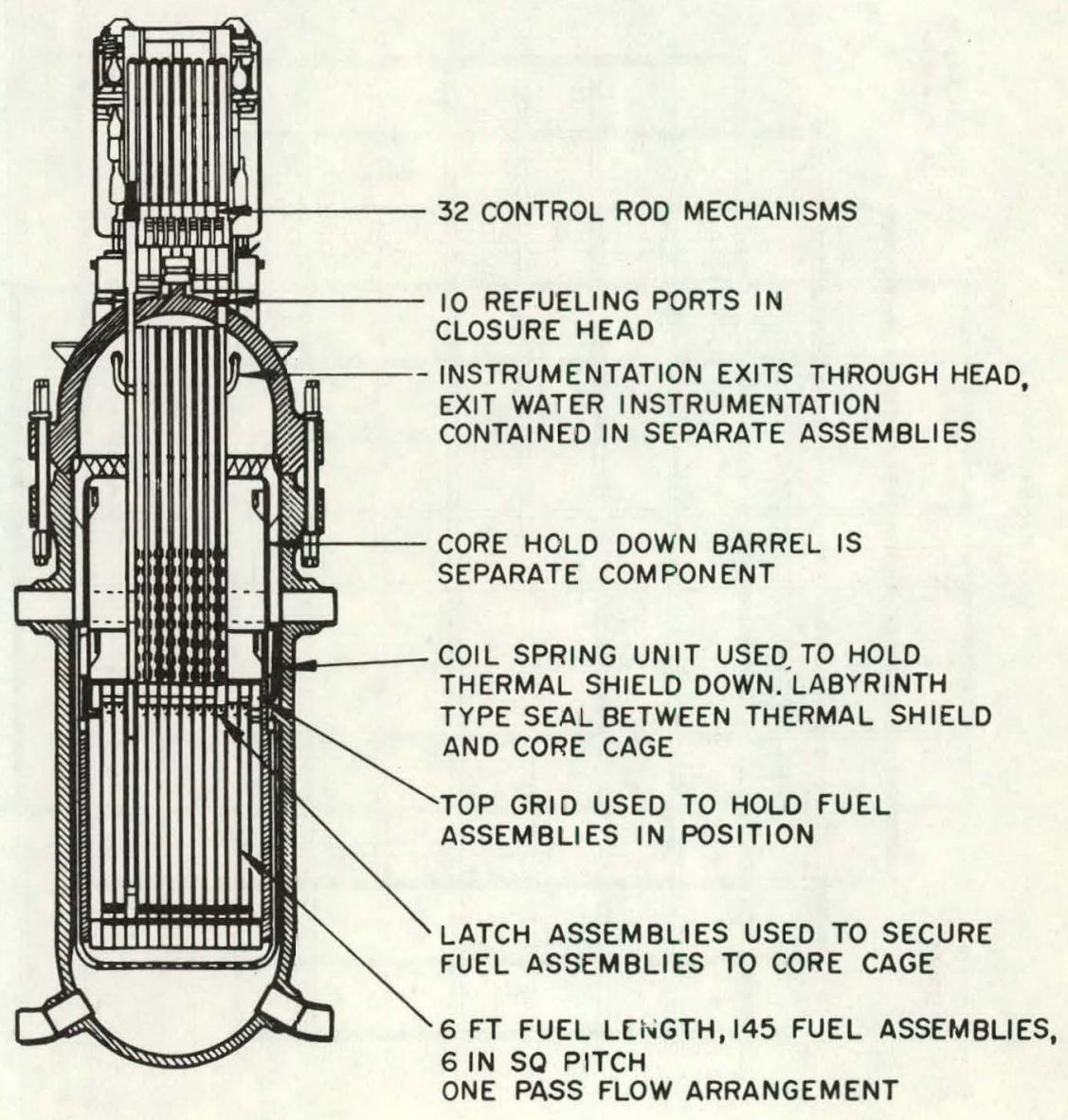




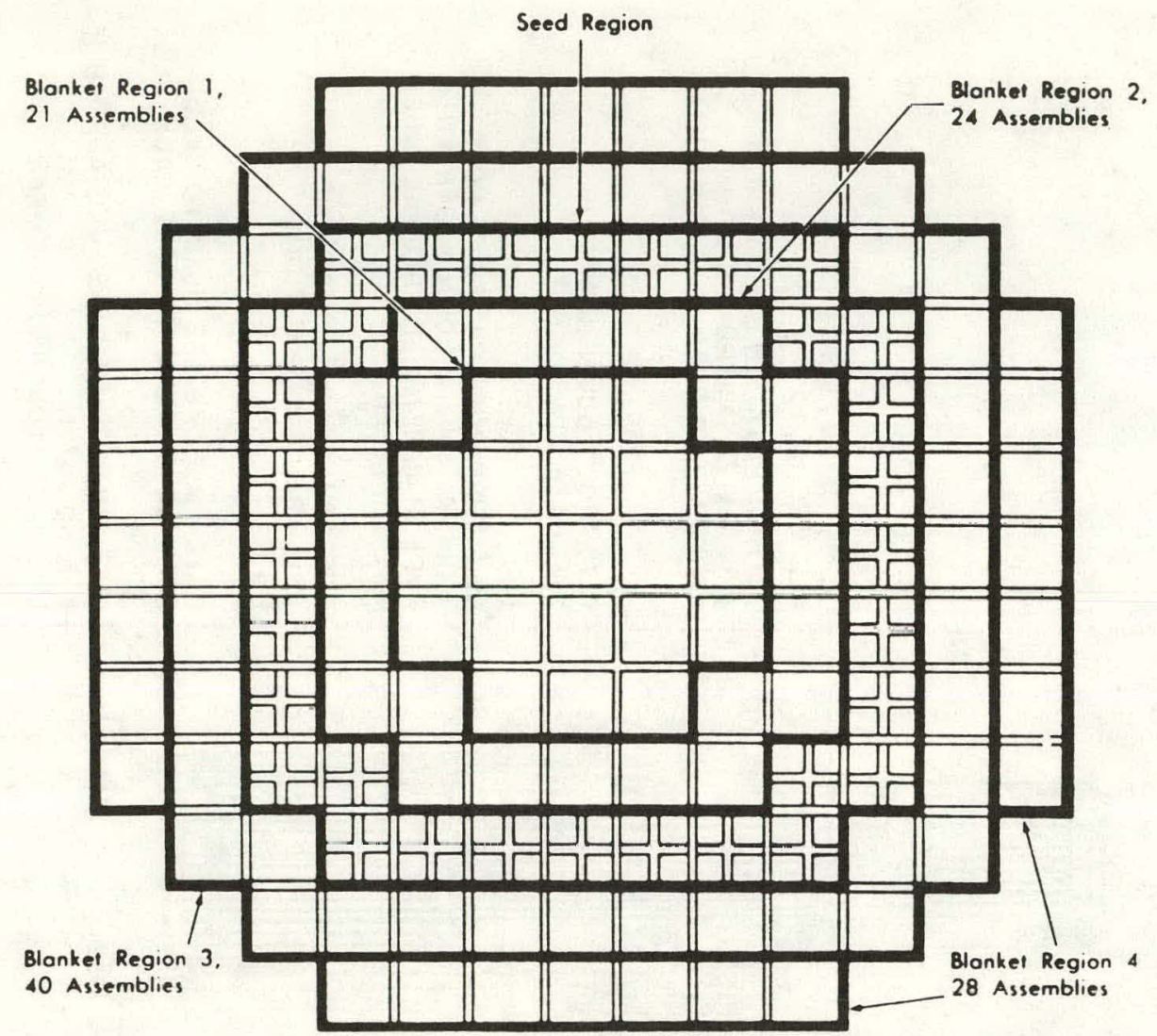

Figure C-2. PWR Core 1 Seed and Blanket Cluster Arrangement

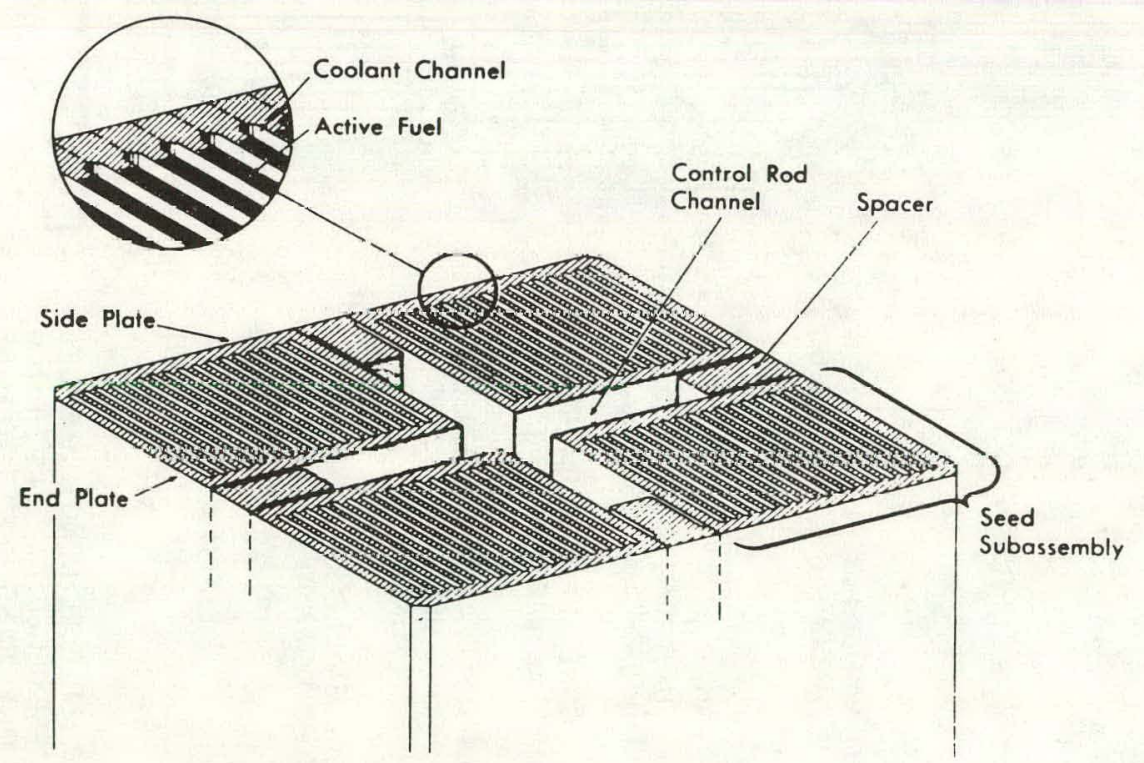

Figure C-3. PWR Core 1 Seed Fuel Cluster 


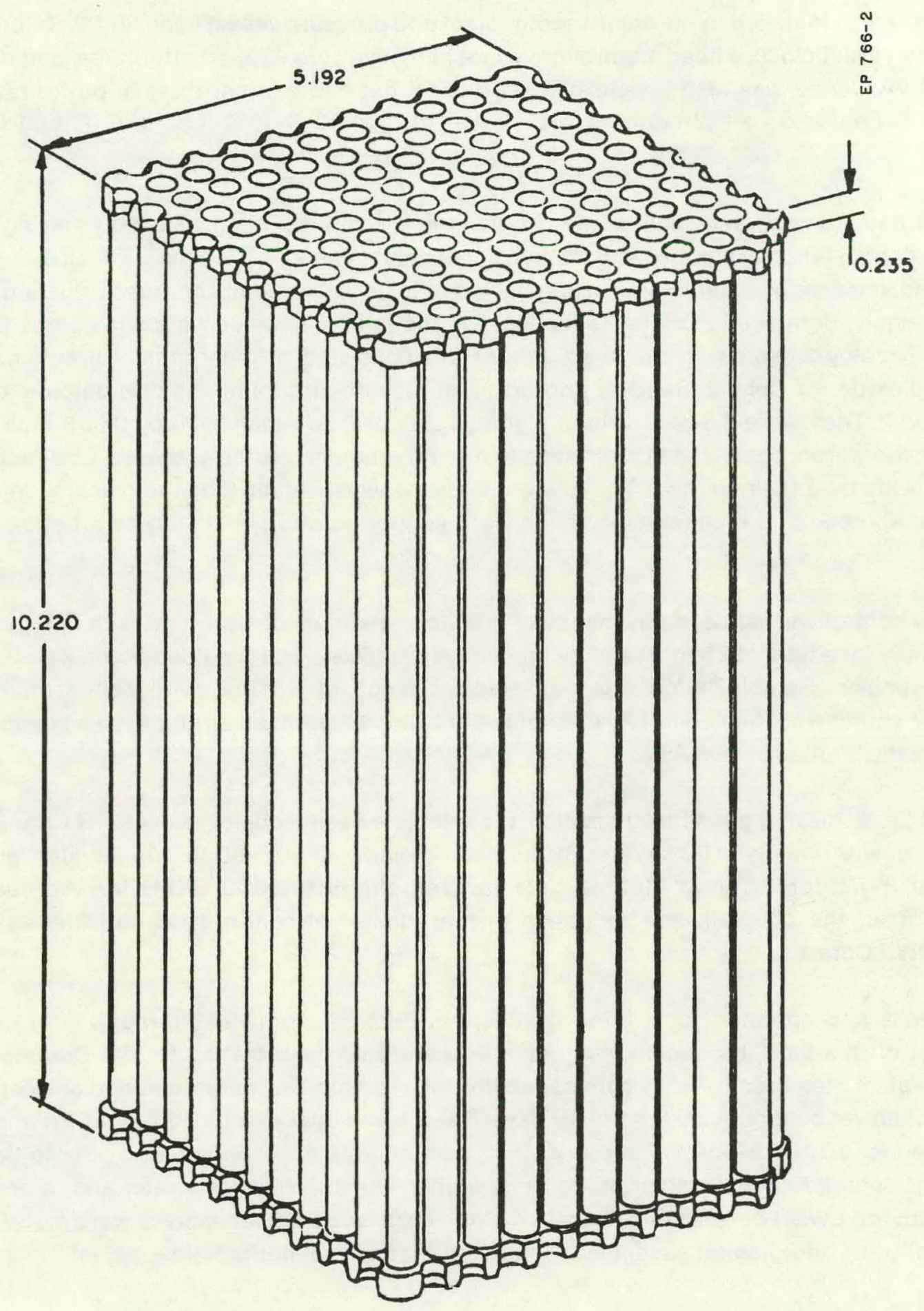

Figure C-4. PWR Core 1 Blanket Bundle 


\section{B. PWR Core 2 (References C-2, C-4, and C-5)}

PWR Core 2 was installed in the same reactor plant and pressure vessel used for PWR Córe 1. Only the pressure vessel closure head, control drive mechanisms, core support structures, and core were changed. PWR Core 2 was also a seed-blanket design, but had a larger thermal power rating than PWR Core 1. Features of PWR Core 2 are shown in Figures C-1, C-5, C-6, C-7, and C-8, and Table C-3.

The core had 20 seed assemblies and 77 blanket assemblies, each assembly having a cross section of about 7.4 inches square, with an active fuel height of about 97 inches. The pressure vessel closure head and core structures were again designed to permit through-the-head refueling of either type of assembly. Both seed and blanket fuel was in the form of ceramic wafers in compartments of full-length Zircaloy-2 plates. In the seed, the wafers consisted of high-density uranium dioxidezirconium dioxide for Core 2, Seed 1; and uranium dioxide-zirconium dioxide-calcium oxide for Core 2, Seed 2. They were 0.8 - or 1.0 -inch high by 0.22 - or 0.261 -Inch wide by 0.036 -Inch thick. II the blanket, the wafers consisted of high-density natural uranium dioxide and were 1.53-inch high by 0.248 -inch wide by 0.10 -inch thick. The full-length plates were welded longitudinally to form the fuel assemblies. All seed and blanket assemblies were supported and positioned by a bottom support plate.

Reactivity control was achieved by means of cruciform-hafnium control rods, with one rod in each seed assembly for a total of 20 rods, and by the inclusion of fixed, self-shielded boron which acted as a burnable poison. Soluble boron was not used for reactivity control during either normal core operation or shutdown. The coolant flow arrangement was single-pass for the seed assemblies, and two-pass for the blanket assemblies.

In addition to achieving good fuel utilization, the principle design objeclives of PWR Core 2 were to obtain high power density (160 kw/liter in the seed; compared with 80 to $105 \mathrm{kw} /$ liter for current commercial PWR cores), long lifetime between refuelings $(10,000 \mathrm{EFPH}$ tor the seeds and 20,000 EFPH for the blanket), and reduction in the number of control rods and fuel assemblics relative to PWR Core 1.

PWR Core 2 was operated for a total of 23,800 EFPH from April 1965 through February 1974. During most of this time the station was operated as a peak load station for the Duquesne Light Company system. However, to verify core capability, the reactor was operated periodically at close to 100-percent power continuously for 1 to 15 days. Seed 1 was operated for 13,650 EFPH and Seed 2 was operated for 10,100 EFPH. In February 1974, core operation was terminated prior to the end of useful life of Seed 2 to permit repair of the Shippingport Plant turbine-generator and to prepare for refueling with the LWBR core. During operation of the core, all design objectives were met. ExamInation of spent seed and blanket assemblies indicated that all fuel performance objectives were also met. 
TABLE C-3. PWR CORE 2 CHARACTERISTICS

\begin{tabular}{|c|c|c|}
\hline Reactor Power, Mw(th) & 505 & \\
\hline Pressure, psia & 2000 & \\
\hline Inlet Temperature, F & 512 & \\
\hline Outlet Temperature, F & 560 & \\
\hline Coolant Flowrate, $10^{6} \mathrm{lb} / \mathrm{hr}$ & 28.0 & \\
\hline Reactor Vessel Pressure Drop, psi & 93 & \\
\hline \multicolumn{3}{|l|}{ Number of Modules } \\
\hline Seed & 20 & \\
\hline Blanket & 77 & \\
\hline Module Pitch, inches & 7.5 & \\
\hline \multirow[t]{2}{*}{ Core Reactivity Lifetime, EFPH, Seeds 1 plus 2} & 26,150 & \\
\hline & Seed & Blanket \\
\hline Lifetime Average Power Fraction, Seed 1 & 0.5 & 0.5 \\
\hline \multicolumn{3}{|l|}{ Loading } \\
\hline Blanket & - & $19,400 \mathrm{~kg} \mathrm{UO}$ \\
\hline Seed 1 & $336 \mathrm{~kg}^{235} \mathrm{U}$ & - \\
\hline Seed 2 & $390 \mathrm{~kg}^{235} \mathrm{U}$ & - \\
\hline \multicolumn{3}{|l|}{ Fuel Composition, w/o } \\
\hline Blanket & - & $100 \%$ UNATO$_{2}$ \\
\hline Seed 1 , Zone 1 & $36.5 \mathrm{w} / \mathrm{o} \mathrm{UE} \mathrm{O}_{2}$ & - \\
\hline Seed 1, Zone 2 & $27.4 \mathrm{w} / \mathrm{o} \mathrm{UEO}_{2}$ & - \\
\hline Seed 1 , Zone 3 & $\begin{array}{l}19.4 \text { w/o UE } \mathrm{U}_{2} \\
6.4 \mathrm{w} / \mathrm{o} \cup^{\mathrm{NAT} \mathrm{O}_{2}}\end{array}$ & - \\
\hline Seed 2, Zone 1 & $54.9 \mathrm{w} / \mathrm{OU}^{\mathrm{E}} \mathrm{O}_{2}$ & - \\
\hline Seed 2, Zone 2 & $40.2 \mathrm{w} / \mathrm{o} \mathrm{U}^{\mathrm{E}} \mathrm{O}_{2}$ & - \\
\hline Seed 2, Zone 3 & $26.5 \mathrm{w} / \mathrm{O} \mathrm{UEO}_{2}$ & - \\
\hline Fuel Plate Thickness, inches & 0.076 & 0.140 \\
\hline Fuel Meat Thickness, inches & 0.036 & 0.100 \\
\hline Fuel Clad Thickness, inches & 0.020 & 0.020 \\
\hline Seed Uranium-235 Depletion, \%, Seeds 1 and 2 & $50 \%$ & - \\
\hline Average Fuel Depletion, fissions/cc & $15 \times 10^{20}$ & $3 \times 10^{20}$ \\
\hline Average Fuel Depletion, MWD/MTU, Blanket Through & - & 14,000 \\
\hline \multicolumn{3}{|l|}{ Secd 2} \\
\hline Maximum Fuel Depletion, fissions/cc & $30 \times 10^{20}$ & $8.5 \times 10^{20}$ \\
\hline Maximum Fuel Depletion, MWD/MTU-Blanket & - & - \\
\hline Metal/Water Ratio & - & - \\
\hline Flow, $10^{6} \mathrm{lb} / \mathrm{hr}$ & 17.2 & 10.8 \\
\hline Mass Velocity, $10^{6} \mathrm{Ib} / \mathrm{hr}^{-\mathrm{ft}^{2}}$ & - & - \\
\hline Coolant Velocity, $\mathrm{ft} / \mathrm{sec}$ & 35.9 & 10 to $14^{(1)}$ \\
\hline Orifice Pressure Drop, psi & - & - \\
\hline Maximum Average Power Density, kw/liter & 160 & - \\
\hline Maximum Average Heat Flux, Btu/hr- $\mathrm{ft}^{2}$ & 197,000 & 53,000 \\
\hline Fuel Utilization, $\mathrm{MWY}(\mathrm{th}) / \mathrm{ST} \mathrm{U}_{3} \mathrm{O}_{8}$ (once-through) & & \\
\hline
\end{tabular}

(1) Range covers pass 1 and pass 2 blanket assemblies 


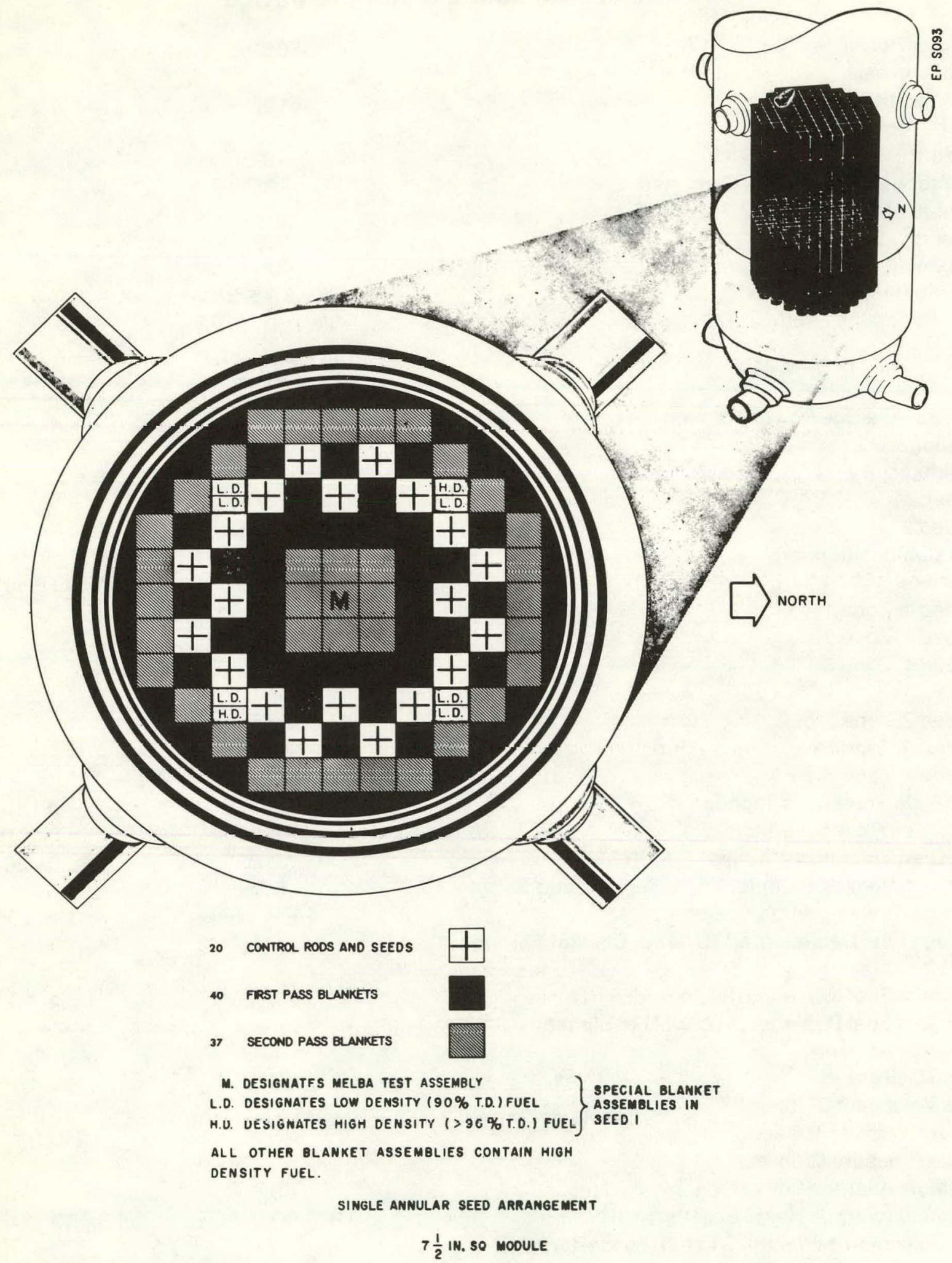

Figure C-5. PWR Core 2 Cross Section 

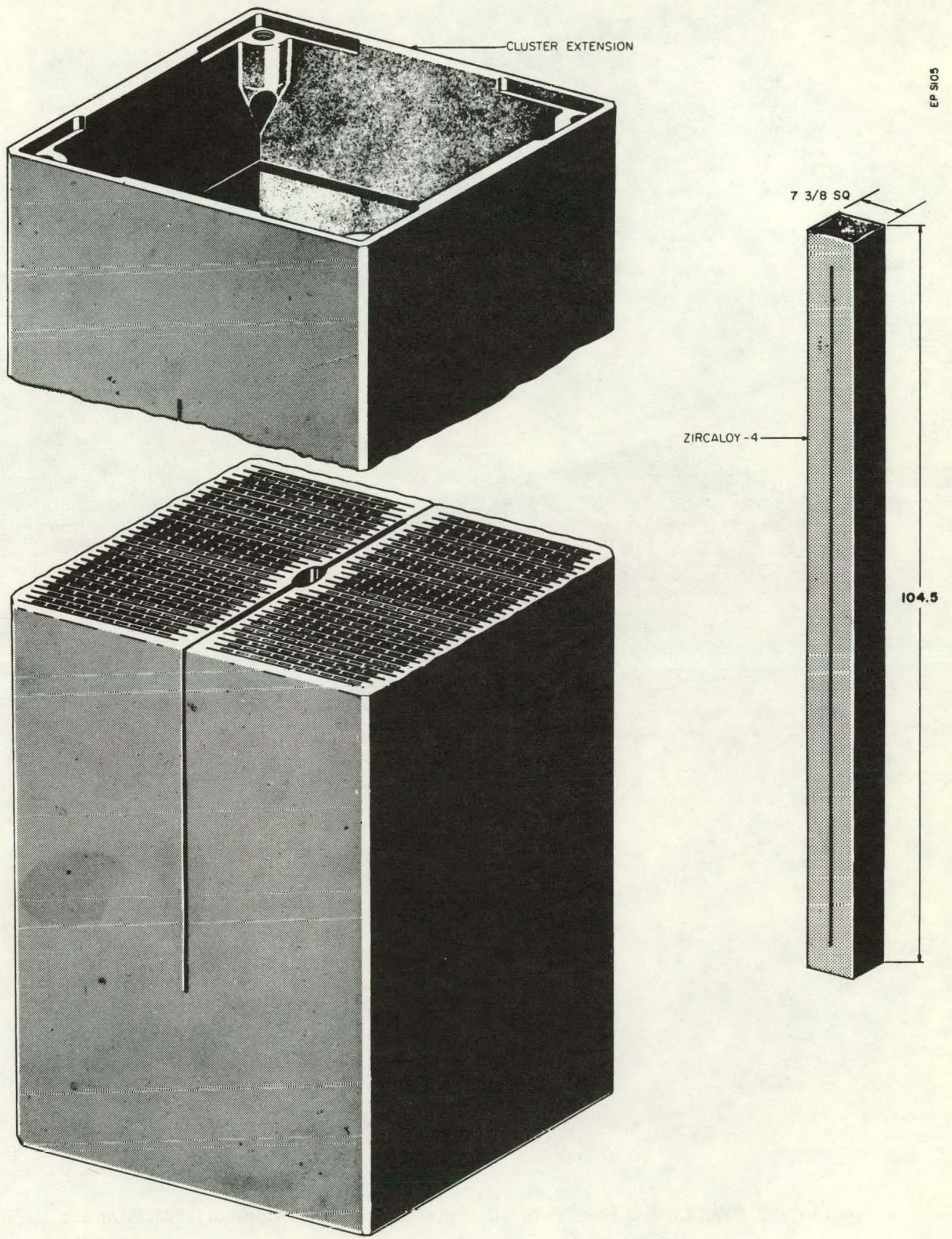

Figure C-6. PWR Core 2 Blanket Fuel Assembly 


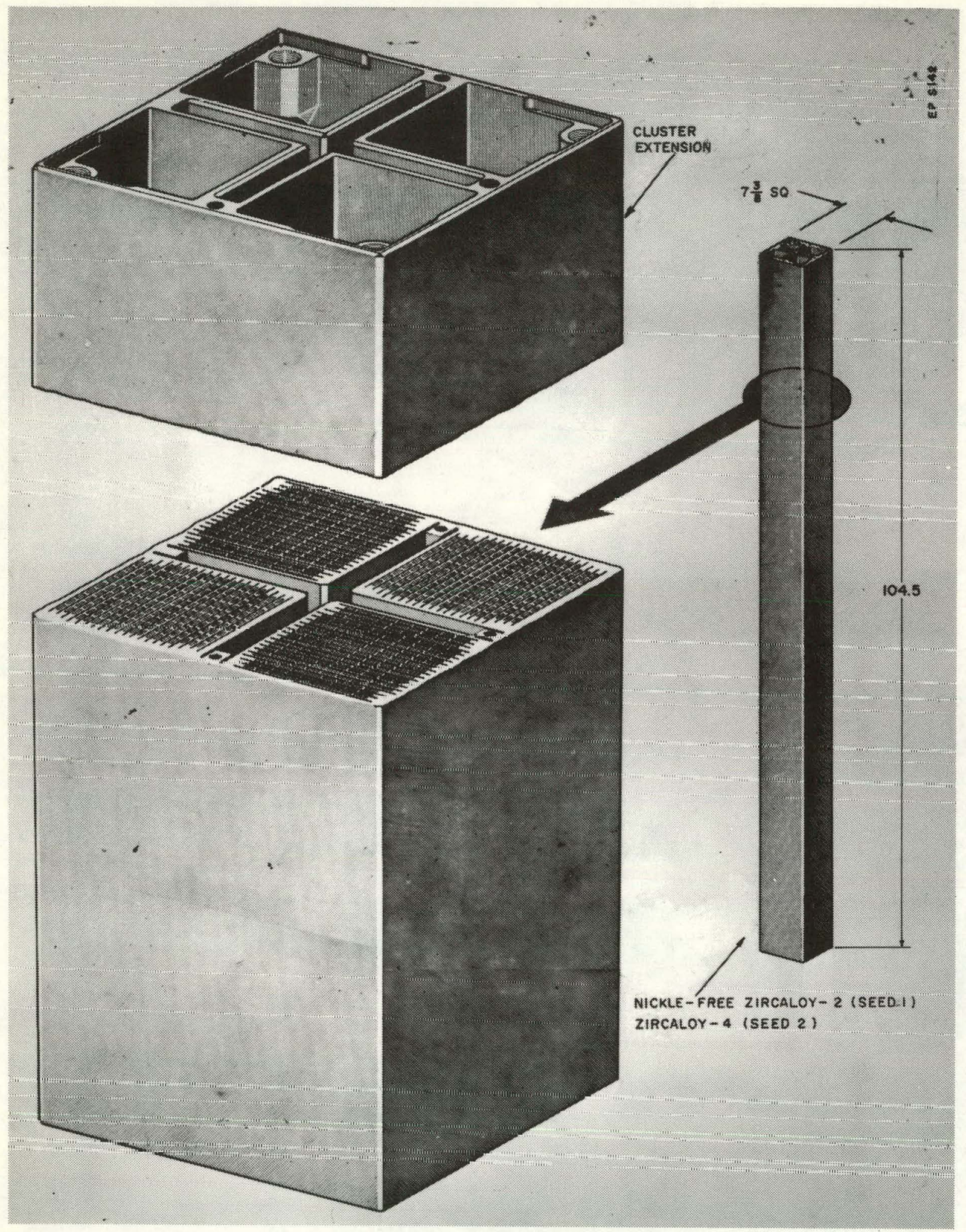

Figure C-7. PWR Core 2 Seed Fuel Cluster with Cruciform Control Rod Channel 

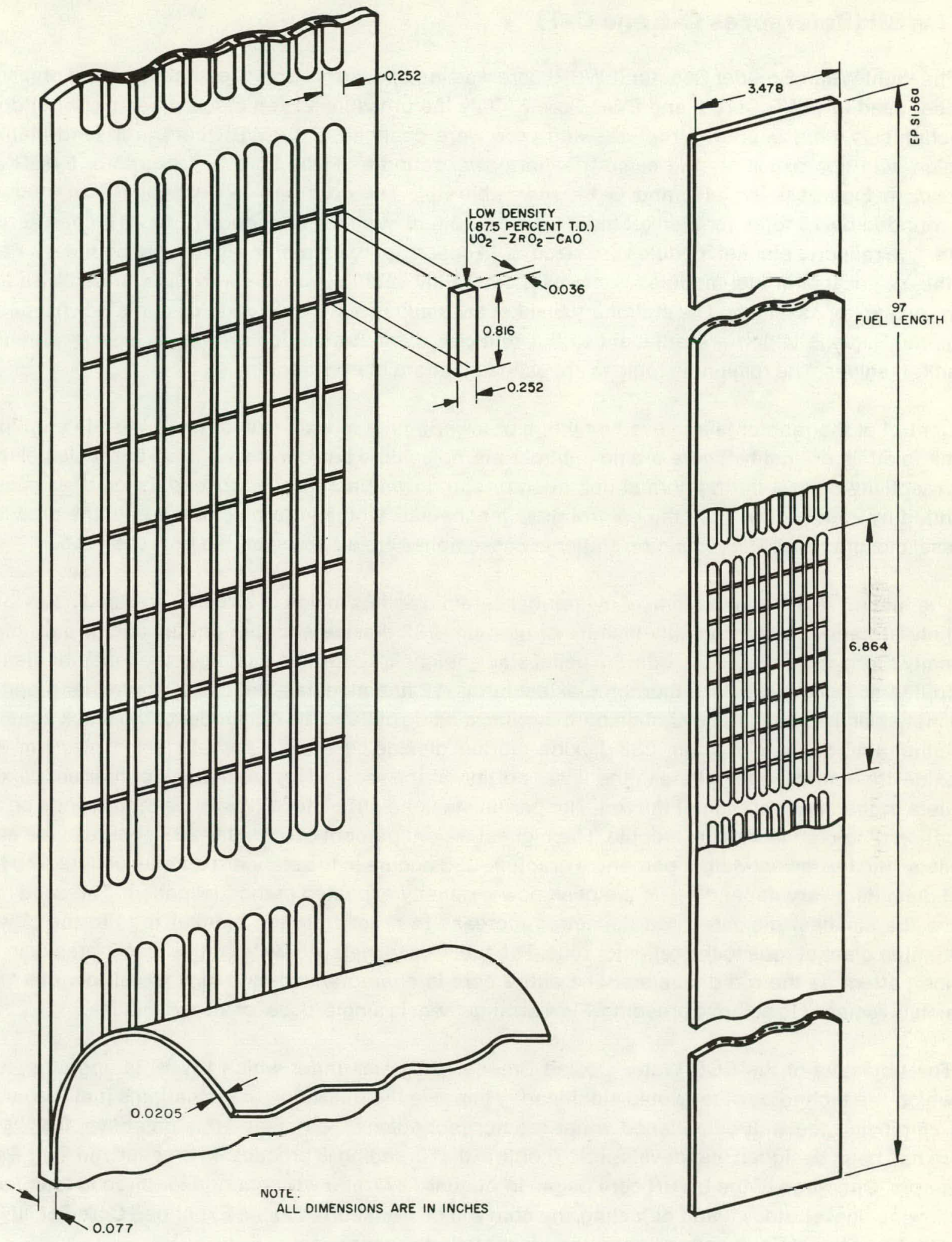

Figure C-8. PWR Core 2 Cross Section Showing Seed 2 Fuel Wafers and Compartments 


\section{LWBR (References C-6 and C-7)}

The Light Water Breeder Reactor (LWBR) core was installed in the same reactor plant and pressure vessel used for PWR Core 1 and PWR Core 2. Only the pressure vessel closure head, control drive mechanisms, core support structures and core were changed. The LWBR core is a seed-blanket design with approximately the same thermal power rating as PWR Core 1. Features of LWBR are shown in Figures C-9, C-10, and C-11 and Table C-4. The core has 12 hexagonal fuel modules surrounded by 15 reflector blanket modules. The 12 fuel modules are about 17 to 20 inches across flats. The reflector blanket modules are sized to fill out an approximately circular core boundary. Each of the 12 hexagonal fuel modules contains a central movable seed assembly surrounded by a stationary blanket assembly. The stationary blanket assemblies of the fuel modules contain two types of regions. Regions which are adjacent to the reflector blanket modules are called power-flattening blanket regions. The remaining regions are called standard blanket regions.

Control of the reactor is achieved by lifting or lowering the movable seed assemblies in a uniform bank to attain criticality. There are no control rods, no soluble poison, and no fixed burnable poisons for reactivity control during normal operation or shutdown. Each of the 12 seed assemblies is suspended by a leadscrew from the control drive mechanism which in turn is attached to the pressure vessel closure head. The remaining stationary assemblies are also suspended from the head.

The fuel in LWBR is in the form of cylindrical ceramic pellets inside of Zircaloy-4 rods. The as-built pellets are either a high-density mixture of uranium-233 dioxide and thorium dioxide or pure highdensity thorium dioxide. In all rods, the pellet stack height is about 104 inches. In the reflector blanket modules all pellets are pure thorium dioxide. In the 12 fuel modules, the top 10 inches and bottom 10 inches of the pellet stack contain pure thorium dioxide pellets; the remainder of the stack consists of either a full stack of uranium-233 dioxide-thorium dioxide pellets or a partial stack of uranium-233 dioxide-thorium dioxide pellets in the lower portion of the rod and a partial stack of thorium dioxide pellets in the upper portion of the rod. The partial stack height of each type of pellet depends on the location of the rod in the fuel module. The highest weight percent of uranium-23'3 occurs in the seed pellets, and the lowest weight percent of uranium-233 occurs in the standard blanket pellets. The fuel rod diameters vary depending on the peak power density expected in the fuel pellets. The seed rods have the smallest diameter; rod diameters increase in order from the blanket rods to the powerflattening blanket rods to the reflector rods. The fuel region metal-to-water ratios also increase in the same pattern as the rod diameters. The entire core is characterized by a high metal-to-water ratio which is required to achieve breeding. Flow arrangement is single-pass for all assemblies.

The objective of the DOE Water-Cooled Breeder program, under which LWBR is operated, is to develop the technology that would significantly improve the utilization of the nation's fuel resources by employing the well-established water reactor technology. To achieve this objective, the LWBR core has been designed and developed to confirm that breeding is practical in pressurized light water reactors. Operation of the LWBR core began in August 1977 and will continue for three to four years. Following final shutdown and defueling, the core will be transported to the Expended Core Facility (at the Idaho National Engineering Laboratory) for detailed examination. 
Reactor Power, MW(th)

237
2000
520
542
31
49
27
17.3
$>15,000$

Pressure, psia

Inlet Temperature, $F$

Outlet Temperature, $\mathrm{F}$

Coolant Flowrate, $10^{6} \mathrm{lb} / \mathrm{hr}$

Blanket

Reactor Vessel Pressure Drop, psi

Maximum Power Fraction

Lifetime Average Power Fraction

Loading

Fuel Composition

Average Fuel Depletion, fissions/cc Average Fuel Depletion, MWD/MTHM(1)

Maximum Fuel Depletion, fissions/cc Maximum Fuel Depletion, MWD/MTHM(1)

Fuel Rod Outside Diameter, inches

Clad Thickness, inches

Fuel Pellet Outside Diameter, inches

Metal/Water Ratio

Distance between Support Spacers, in.

Flow, $10^{6} \mathrm{lb} / \mathrm{hr}$

Mass Velocity, $10^{6} \mathrm{lb} / \mathrm{hr}-\mathrm{ft}^{2}$

Coolant Velocity, ft/sec

Pressure Drop through Region, psi

Orifice Pressure Drop, psi

Average Power Density, kw/liter

Average Heat Flux, Btu/hr- $\mathrm{ft}^{2}$
Seed

\begin{tabular}{c} 
Seed \\
0.39 \\
0.38 \\
-- \\
$233 \mathrm{UO}_{2}(4.3$ to \\
$5.2 \mathrm{w} / 0)+\mathrm{ThO}_{2}$ \\
$2.7 \times 10^{20}$ \\
12,900 \\
$10.1 \times 10^{20}$ \\
47,700 \\
0.306 \\
0.022 \\
0.252 to 0.256 \\
Seed \\
\hline 1.7 \\
12.5 \\
7.7 \\
2.6 \\
15 \\
40 \\
60 \\
60,000
\end{tabular}

Initial Core Loading

\begin{tabular}{cc}
$\frac{\text { Blanket }}{0.62}$ & Reflector \\
\cline { 2 - 2 } 0.61 & 0.03 \\
-- & 0.01 \\
$233 \mathrm{UO}_{2}(1.2$ to & ThO $^{2}$ \\
$2.7 \mathrm{w} / \mathrm{O})+\mathrm{ThO}_{2}$ & \\
1.2 to $1.3 \times 10^{20}$ & $0.03 \times 10^{20}$ \\
5500 to 5900 & 140 \\
5.4 to $5.1 \times 10^{20}$ & $0.8 \times 10^{20}$ \\
20,300 to 22,900 & 3600 \\
0.527 to 0.572 & 0.832 \\
0.026 to 0.028 & 0.042 \\
0.470 to 0.511 & 0.742 \\
Blanket & Reflector \\
\hline 1.8 to 3.0 & 3.5 \\
16 & 18 \\
15.7 & 2.9 \\
2.8 to 3.3 & 0.7 \\
16 to 19 & 4 \\
16 & 2 \\
34 to 40 & - \\
56,000 to 61,000 & 3400
\end{tabular}

Mass (kg)

\begin{tabular}{|c|c|c|}
\hline & Isotope & Mass (kg \\
\hline \multicolumn{3}{|c|}{ Seed } \\
\hline Uranium-233 & & 199 \\
\hline Uranium-235 & & 0.2 \\
\hline Thorium-232 & & 5207 \\
\hline \multicolumn{3}{|c|}{ Blanket } \\
\hline Thorium-232 & & 18,275 \\
\hline Uranium-233 & + Protactinium-233 & 302 \\
\hline \multicolumn{3}{|c|}{ Uranium-235 } \\
\hline & Reflectur & \\
\hline Thorium-232 & & 18,574 \\
\hline Uranium-233 & + Protactinium-233 & 0 \\
\hline
\end{tabular}

(1) MTHM = metric tons heavy metal (uranium + thorium). 


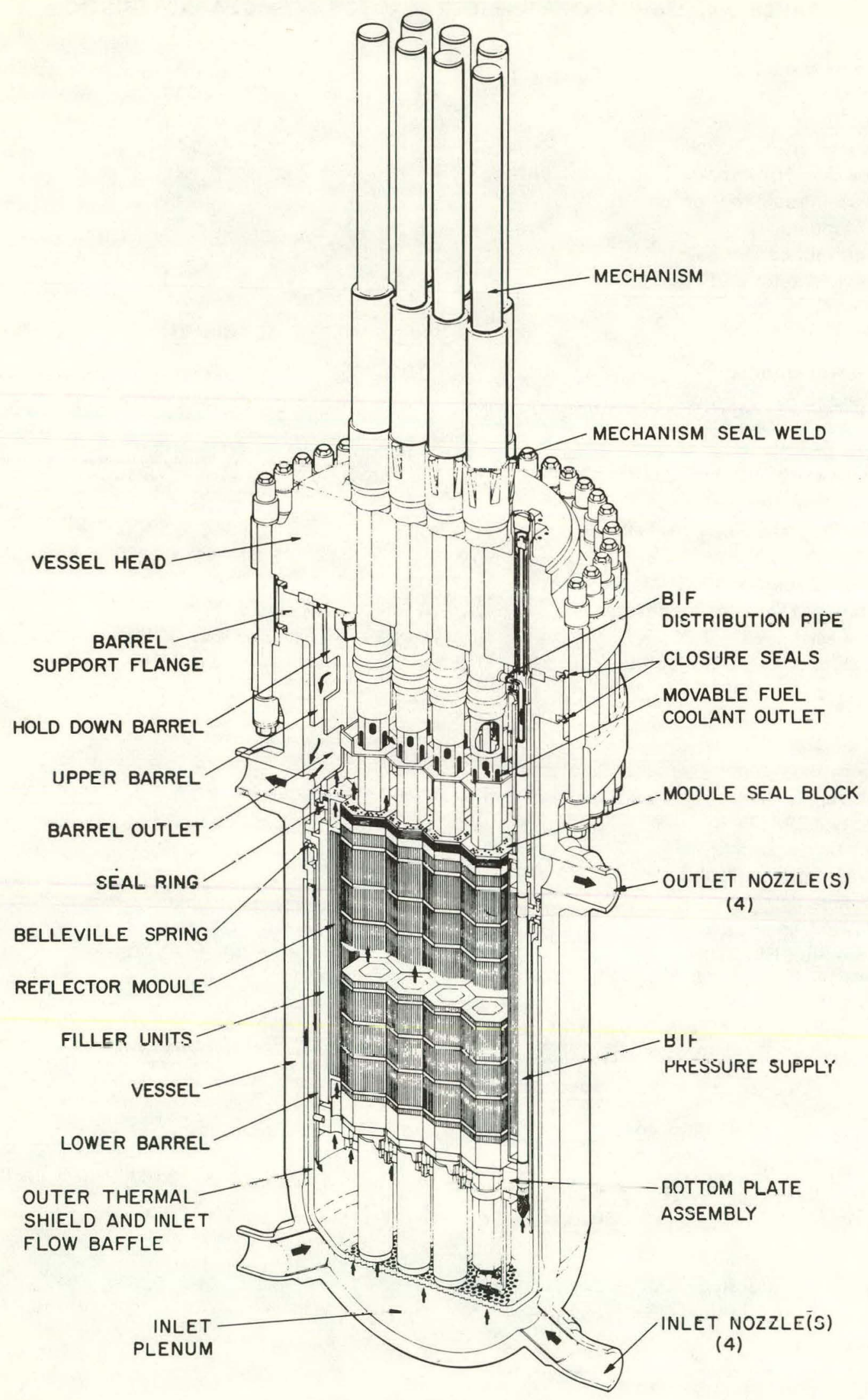

Figure C-9. LWBR Reactor 


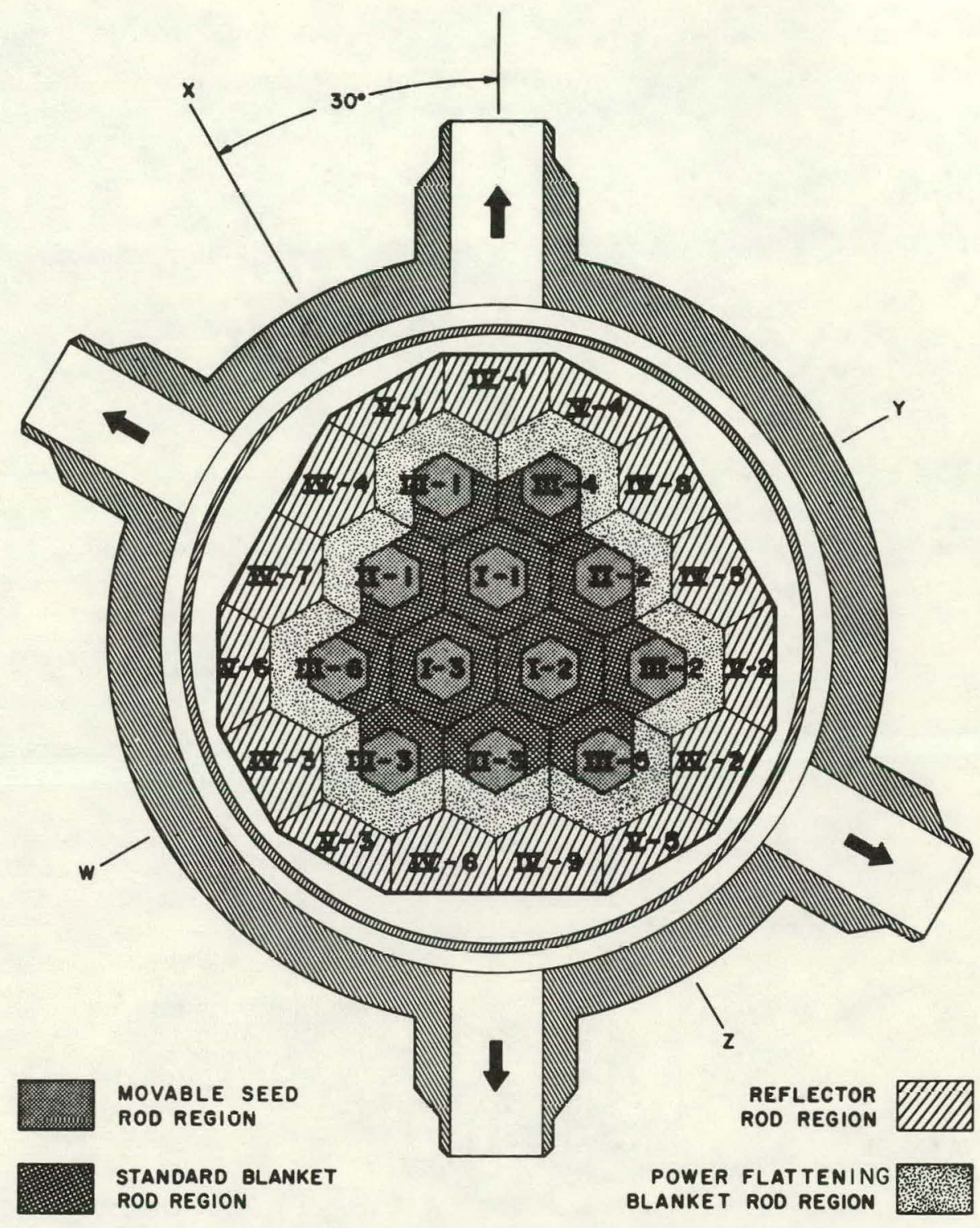

Figure C-10. LWBR Cross Section Module Identification 


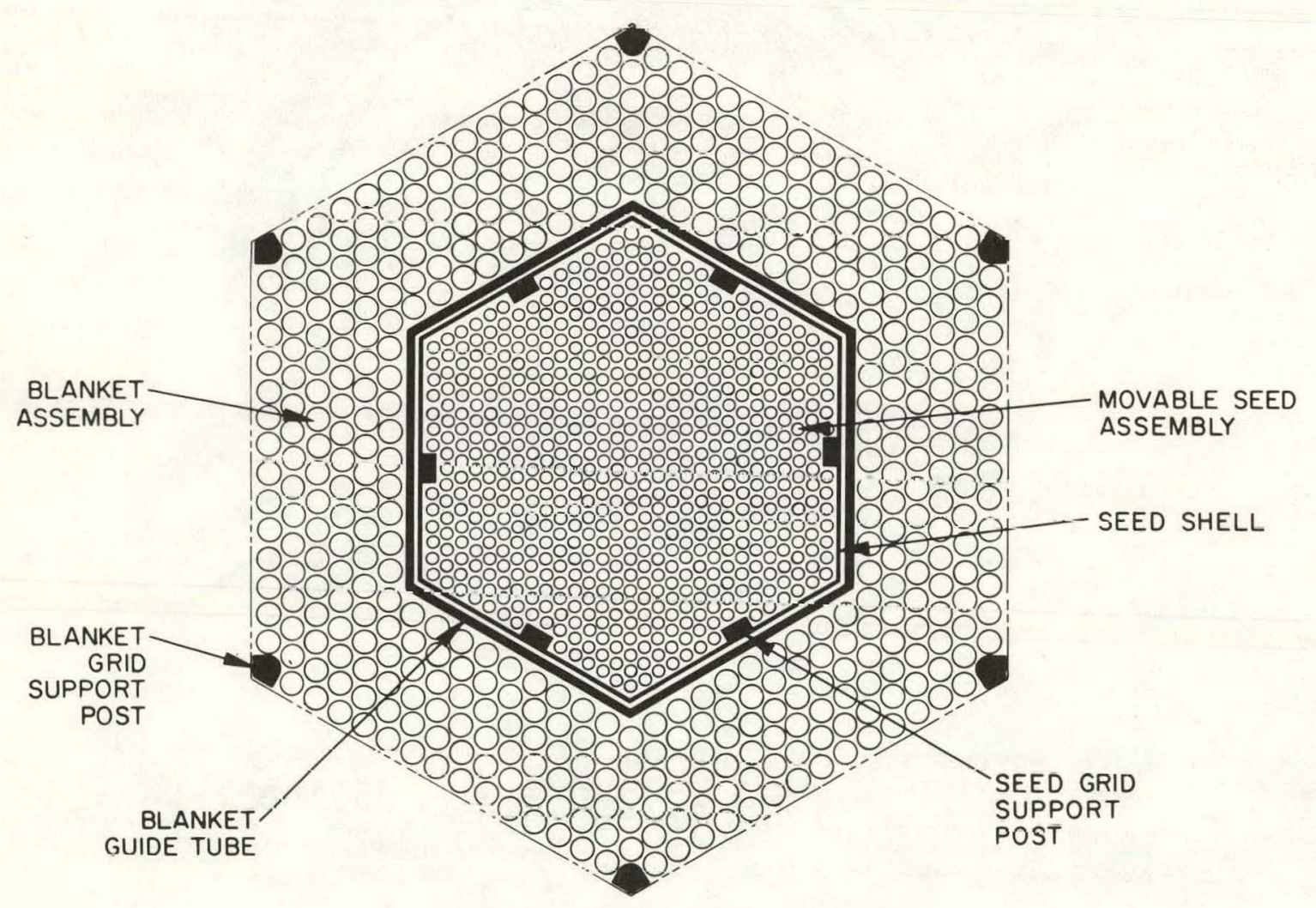

Figure C-11. Typical LWBR Seed-Blanket Module Cross Section 


\section{MOVABLE FUEL CONTROLLED SEED-BLANKET CONVERTER-BURNER STUDIES}

\section{A. Introduction}

A large number of core studies were performed between 1962 and 1965. In all cases the module arrangement consisted of circular movable fuel modules surrounded by chevron-shaped stationary modules. A typical core cross section is shown in Figure C-12. The movable fuel concept was assumed to achieve reactivity control during power operation solely by lifting or lowering the movable fuel without the need for control rods, soluble poison, or fixed burnable poison. In the absence of such poisons, excess neutrons would be absorbed primarily in fertile materials uranium-238 or thorium232, thus, achieving maximum utilization of uranium-235. The particular configuration of circular and chevron-shaped modules was developed to permit through-the-head refueling of both types of modules, with a refueling port located above each movable fuel module. These designs also had shutdown rods which would be completely withdrawn during normal operation. These rods would eliminate the need for soluble boron for normal reactivity shutdown.

Among the variations in core loading arrangements were rod pitches, diameters, and blanket types. The blankets included natural uranium, thorium, and thorium spiked with natural uranium.

In all of these concepts, the fuel would be in the form of cylindrical ceramic pellets inside of Zircaloy tubing. Seed pellets would consist of highly enriched uranium dioxide and zirconium dioxide. The blanket pellets would consist of natural uranium dioxide, thorium dioxide, or thorium dioxide spiked with highly enriched uranium dioxide. In all of these concepts, the movable fuel assemblies would contain both seed and blanket fuel rods, and the stationary fuel assemblies would also contain both seed and blanket fuel rods. The seed rods were assumed to be similar to those of the LWBR core with respect to containing either full-height stacks of seed-pellets, or partial height stacks of seed pellets and partial height stacks of blanket pellets.

The objective of these conceptual studies was to design a core which would operate for a long period of time (as long as 8 years at 100 percent power) with no refueling, or refueling only of seed modules. As these were primarily survey calculations, there was no fuel management of either seed or blanket modules. As a result of these objectives, higit enrichment (93 percent) seed fuel was required and a large amount of reactivity control was required from movable fuel. Furthermore, it was anticipated that spent fuel would be reprocessed to reclaim uranium-233 and uranium-235 so that high burnup of the seed and blanket (which are required for high once-through fuel utilization) was not a primary objective. The core heights were also limited to a range of 7 feet to 8 feet in order to meet constraints which had been specified for the pressure vessel. Despite these objectives and restrictions, some of these conceptual designs were calculated to achieve relatively high fuel utilization on a once-through basis.

For purposes of illustration, two of these concepts are presented in the following section, "Conceptual Design Core Descriptions." The calculated fuel utilization values would range between 12.2 and 13.8 MWYth/ST $\mathrm{U}_{3} \mathrm{O}_{8}$. Although these conceptual designs indicated the feasibility of operating a reactor using movable fuel reactivity control (and these studies eventually culminated in the design and operation of LWBR), for various reasons they would not, without further optimization, be practical 
reactors for once-through fuel irradiation. The most apparent reason is that they would be more complex than current commercial reactors but at best would have only slightly better fuel utilization. In addition, they would require a very high initial inventory of highly enriched uranium which would probably result in relatively poor economics. The fuel element performance of some of the designs would also be questionable. For example, in the WAPD-LPR-256 and the CB6.2 designs, the fission density corresponding to 100 percent depletion of the uranium-235 in the seed rods is $30 \times 10^{20} \mathrm{f} / \mathrm{cc}$ and $20 \times 10^{20} \mathrm{f} / \mathrm{cc}$, respectively. Although 100 percent depletion of uranium-235 would not occur at any point, the maximum fission density which would occur would probably still be too large in the WAPD-LPR-256 and CB6.2 designs.

Some of the performance features of these concepts (for example, maximum heat fluxes during normal operation) were calculated in an approximate fashion, and no analyses were made to determine core performance under LOCA (Loss-of-Coolant Accident) conditions.

\section{B. Conceptual Design Core Descriptions}

\section{WAPD-LPR-256 Thorium Converter-Burner (Reference C-8)}

In this concept, the seed rods contained enriched uranium and the blanket rods contained thorium. Figure $\mathrm{C}-13$ is representative of the general features of the core modules. The two objectives were:

1. To optimize the power obtainable from the blanket by conversion of thorium-232 to uranium233 and burning the uranium-233 in place

2. To achieve a very long lifetime without refueling.

Seed and blanket regions were present in both the fixed and movable fuel modules.

This concept was characterized by a relatively high seed burnup but a low lifetime average power fraction in the blanket (about 50 percent). Since the blanket initially contained no fissile material, the blanket power fraction was initially zero and reached 50 percent only after about 20,000 EFPH. Despite the continuing depletion of the seed, the blanket power fraction remained high because of the good neutronics properties of the uranium-233/thorium system. (Uranium-233 produces more fission neutrons per neutron absorbed than does uranium-235.)

The two thorium converter-burner conceptual designs considered were a batch-loaded core and a fuel-managed core. In the batch-loaded core, all fuel modules were assumed to be left in place for the full core lifetime of $70,000 \mathrm{EFPH}$. In the fuel-managed core, half of the modules (both movable and stationary) were assumed to be replaced approximately every $35,000 \mathrm{EFPH}$. It was found that the overall fuel utilization of the fuel-managed design would be about 10 percent higher than for the batch-loaded design. After the first refueling, the fuel-managed design relative to the batch-loaded design would have had about a 16 percent greater power capability because of a more uniform power distribution. However, this occurred at the expense of about an 8 percent decrease in core lifetime. Thus, the total energy output per module would be larger by about 8 percent. See Table C-5 for additional core characteristics of the batch-loaded concept. 


\section{CB6.2 Converter-Burner}

In this concept the seed rods would contain 93 percent enriched uranium (diluted with zirconium dioxide), while the blanket would contain thorium spiked with a small amount of natural uranium. The natural uranium in the blanket would increase the early-in-life power fraction of the blanket (relative to what would have been the case with only thorium) and thereby would reduce the early-in-life power density of the seed. The features of this module are displayed in Figure C-14. All of the seed rods would be located in the circular part of the fuel module so that the stationary chevron modules contain only blanket-type rods. Relative to the WAPD-LPR-256 design the fabrication and handling of the chevron assemblies would be simplified.

The average burnup of the blanket region would be only about $26,000 \mathrm{MWD} / \mathrm{MT}$. At this low burnup the thorium blanket would be an inefficient user of excess neutrons and, therefore, the fuel utilization was low relative to what could have been obtained by irradiating the blanket for more than one seed life. Table C-6 presents characteristics of this core. 


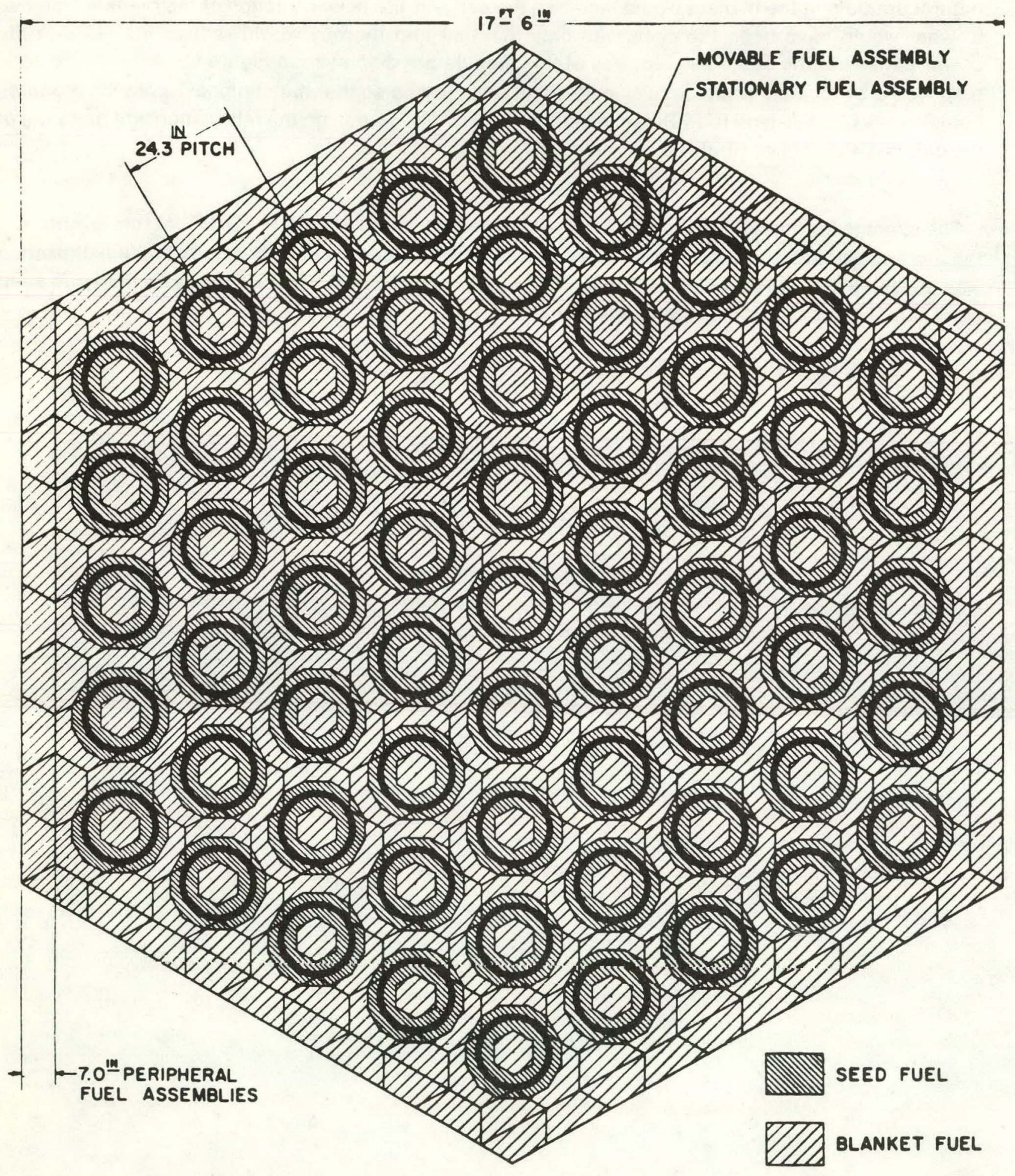

Figure C-12. 1000 MW(e) Seed-Blanket Core, Typical Conceptual Core Cross Section 
TABLE C-5. WAPD-LPR-256 BATCH-LOADED THORIUM CONVERTER-BURNER CORE CHARACTERISTICS

Typical Thorium Converter-Burner Characteristics

Reactor Power, MW(th)

Pressure, psia

Inlet Temperature, $\mathrm{F}$

Outlet Temperature, $\mathrm{F}$

Coolant Flowrate, $10^{6} \mathrm{lb} / \mathrm{hr}$

Reactor Vessel Pressure Drop, psi

Number of Modules

Module Pitch, inches

Core Reactivity Lifetime, EFPH

Maximum Power Fraction

Lifetime Average Power Fraction

Loading

Fuel Composition, w/o

Zone 1

Zone 2

Average Fuel Depletion, fissions/cc Average Fuel Depletion, MWD/MTHM Maximum Fuel Depletion, fissions/cc Maximum Fuel Depletion, MWD/MTHM

Fuel Rod Outside Diameter, inches

Clad Thickness, inches

Fuel Pellet Outside Diameter, inches

Fuel Pellet Inside Diameter, inches-Zone 1

Seed Uranium-235 Burnup, \%

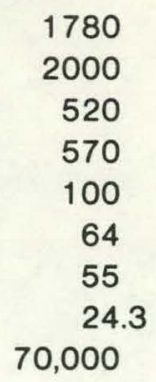

1780

2000

520

570

100

64

55

24.3

70,000

\author{
Seed \\ 1.0 \\ 0.50 \\ $4443 \mathrm{~kg}^{235 \mathrm{U}}$ \\ $33 \mathrm{UEO}_{2}+67 \mathrm{ZrO}_{2}$ \\ $18 \mathrm{UEO}_{2}+6 \mathrm{CaO}+76 \mathrm{ZrO}_{2}$ \\ $21 \times 10^{20}$ \\ $-$ \\ $30 \times 10^{20}$ \\ $-$ \\ 0.280 \\ 0.018 \\ 0.240 \\ 0.102 \\ 75
}

Coolant Pass 1

(Stationary Fuel)

Coolant Pass 2

(Movable Fuel)

Seed-Blanket Blanke

Metal/Water Ratio

Distance between Support Spacers, inches

Flow, $10^{6} \mathrm{lb} / \mathrm{hr}$

Mass Velocity, $10^{6} \mathrm{lb} / \mathrm{hr}^{-\mathrm{ft}^{2}}$

Coolant Velocity, $\mathrm{ft} / \mathrm{sec}$

Pressure Drop through Region, psi

Orifice Pressure Drop, psi

Maximum Average Power Density, kw/liter

Maximum Average Heat Flux, Btu/hr- $\mathrm{ft}^{2}$

Time for Maximum Heat Flux, EFPH

0.91

24

53

2.9

16

17

0

150

163,000

\begin{tabular}{c} 
Blanket \\
\hline 1.20 \\
36 \\
44 \\
1.3 \\
7 \\
2 \\
15 \\
44 \\
88,000 \\
70,000
\end{tabular}

Seed-Blanket

Blanket

0.038

0.590

None

0.57

0.50

$77,400 \mathrm{~kg} \mathrm{Th}$

$6.5 \times 10^{20}$

34,000

$15 \times 10^{20}$

80,000

0.674

\begin{tabular}{|c|c|c|}
\hline Isotopic Masses (kg) & Initial & $\begin{array}{c}\text { End-of-Life } \\
\text { Batch }\end{array}$ \\
\hline Seed & & \\
\hline Uranium-235 & 4,443 & 1,117 \\
\hline Uranium-236 & 9 & 617 \\
\hline Uranium-238 & 318 & 264 \\
\hline Blanket & & \\
\hline Thorium-232 & 77,400 & 73,400 \\
\hline Uranium-233 + Protactinium-233 & 0 & 1,128 \\
\hline Uranium-235 & 0 & . 56 \\
\hline
\end{tabular}

Fuel Utilization, $\mathrm{MWT}$ (th)/ST $\mathrm{U}_{3} \mathrm{O}_{8}$ (once-through) $=12.6$ for batch-loaded design. $=13.8$ for fuel-managed design. 


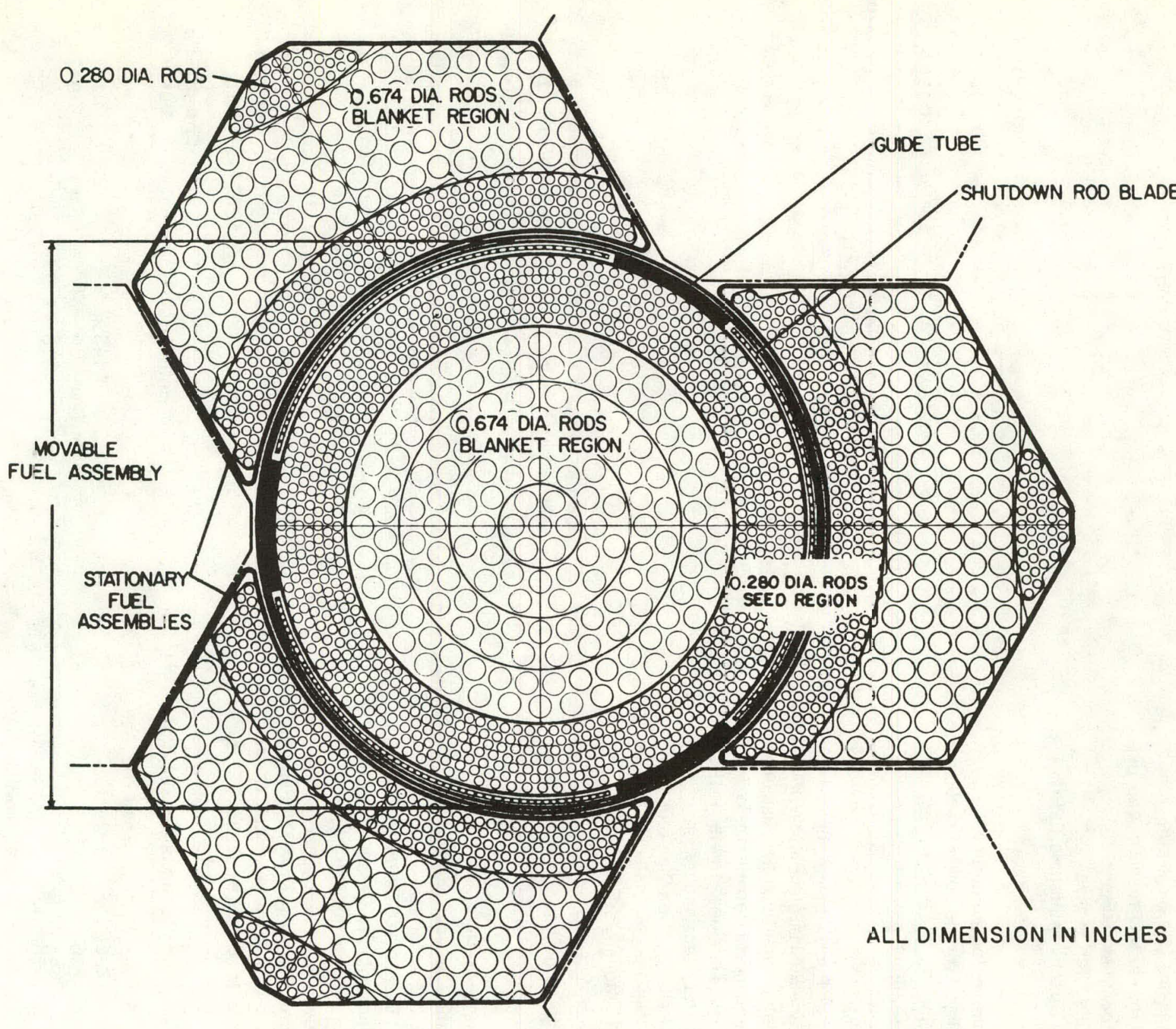

Figure C-13. WAPD-LPR-256 Thorium Converter-Burner Fuel Module Cross Section 
TABLE C-6. CB6.2 CONVERTER-BURNER CORE CHARACTERISTICS

Reactor Power, MW(th)

1790

Pressure, psia

2000

Average coolant temperature $F$ 545

Number of Modules

55

Seed-blanket

Reflector blanket

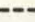

Module Pitch, inches

Core Reactivity L ifetime, EFPH

70,000

Seed

Blanket

Seed

Blanket

Maximum Power Fraction

Lifetime Average Power Fraction

0.67

0.23

Power Fraction-Beginning-of-Life

Power Fraction-End-of-Life

Average Fuel Depletion, fissions/cc

Average Fuel Depletion, MWD/MTHM (1)

Seed Fuel Depletion, Complete U-235 Burnup

$\times 10^{20}$

Metal/Water Ratio

$1.2-1.3$

129,000

0.8

Average Heat Flux, Btu/hr-ft ${ }^{2}$

Initial

End-of-Life

Isotopic Masses (kg)

\section{Seed}

Uranium-235

4620

940

\section{Blanket}

Thorium

64,000

60,000

Natural Uranium

2,900

Fuel Utilization, MWY(th) $/ \mathrm{STU}_{3} \mathrm{O}_{8}$ (once-through)

(1) MTHM-Metric Tons Heavy Metal 


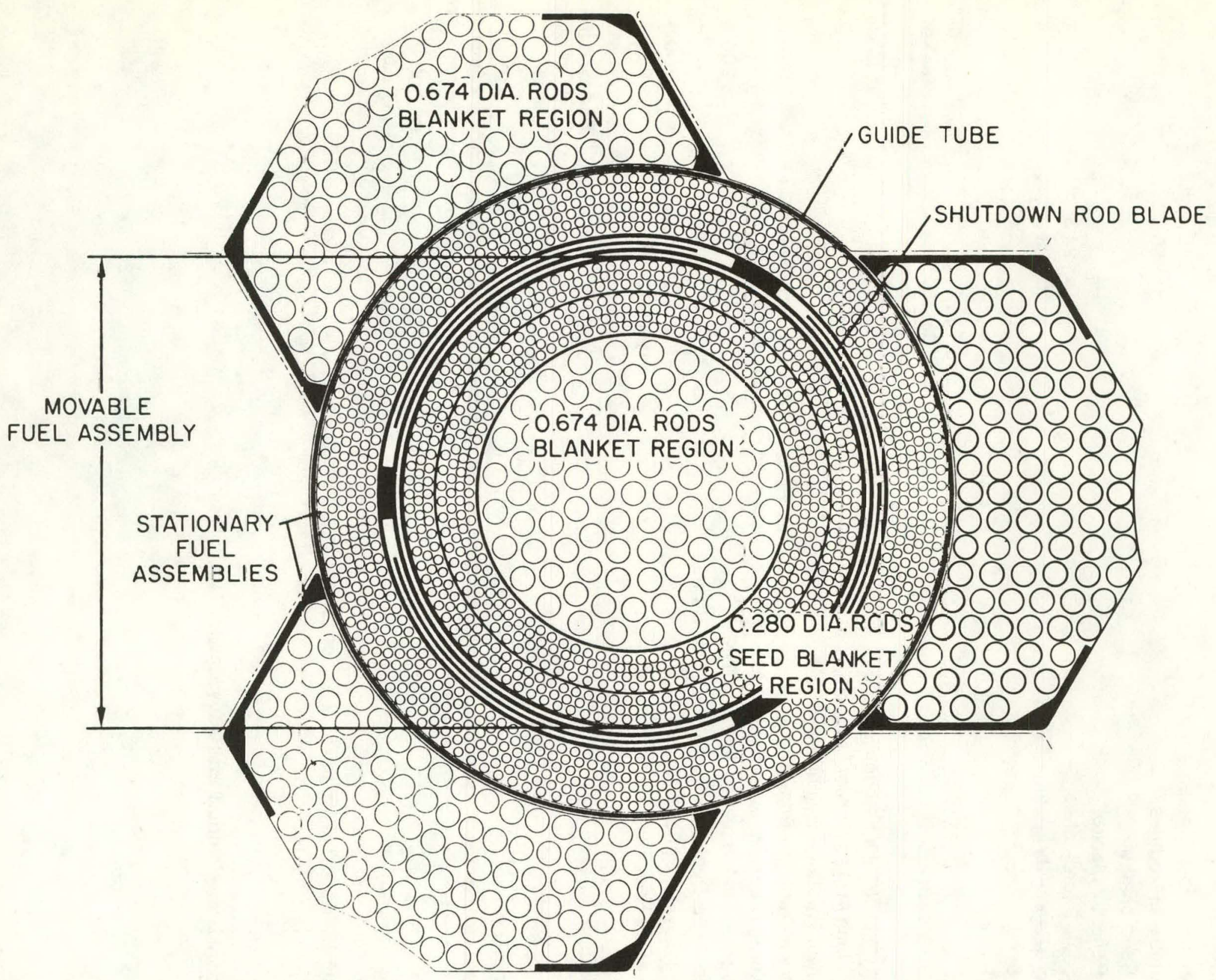

Figure C-14. CB6.2 Converter-Burner Fuel Module Assembly Cross Section 


\section{REFERENCES}

C-1. The Shippingport Pressurized Water Reactor, Addison-Wesley Publishing Co., Inc., September 1958.

C-2. "Directory of Nuclear Reactors," Volume 4, Power Reactors, International Atomic Energy Agency, 1962.

C-3. "Shippingport Operations During PWR Core 1 Depletion," WAPD-294, December 1968.

C-4. "PWR Core 2 Reactor Design Description Report," WAPD-296, March 1969.

C-5. "Shippingport Operation from Initial PWR Core 2 Power Operation to Power Operation After First Refueling," WAPD-332, June 1973.

C-6. "Final Environmental Statement Light Water Breeder Reactor Program," ERDA 1541, June 1976.

C-7. Shippingport Atomic Power Station Safety Analysis Report for the Light Water Breeder Reactor, 1975.

C-8. "Report on Large Power Reactor (LPR) Program (Supplementing WAPD-LPR-181 dated December 1963)," WAPD-LPR-256, September 1964. 